\title{
Aging Effects of the Cathode and Determination of Single Electrode Performance in a Solid Oxide Fuel Cell
}

Xiaoke Chen

West Virginia University

Follow this and additional works at: https://researchrepository.wvu.edu/etd

\section{Recommended Citation}

Chen, Xiaoke, "Aging Effects of the Cathode and Determination of Single Electrode Performance in a Solid Oxide Fuel Cell" (2013). Graduate Theses, Dissertations, and Problem Reports. 429.

https://researchrepository.wvu.edu/etd/429

This Dissertation is protected by copyright and/or related rights. It has been brought to you by the The Research Repository @ WVU with permission from the rights-holder(s). You are free to use this Dissertation in any way that is permitted by the copyright and related rights legislation that applies to your use. For other uses you must obtain permission from the rights-holder(s) directly, unless additional rights are indicated by a Creative Commons license in the record and/ or on the work itself. This Dissertation has been accepted for inclusion in WVU Graduate Theses, Dissertations, and Problem Reports collection by an authorized administrator of The Research Repository @ WVU.

For more information, please contact researchrepository@mail.wvu.edu. 


\title{
Aging Effects of the Cathode and Determination of Single Electrode Performance in a Solid Oxide Fuel Cell
}

\author{
Xiaoke Chen \\ Dissertation submitted to the Eberly College of Arts and Sciences \\ at West Virginia University \\ in partial fulfillment of the requirements for the degree of \\ Doctoral of Philosophy \\ in \\ Chemistry
}

Harry O. Finklea, Ph. D., Chair

Fabien Goulay, Ph. D.

Alan Stolzenberg, Ph. D.

Justin Legleiter, Ph. D.

John Zondlo, Ph. D.

C. Eugene Bennett Department of Chemistry

Morgantown, West Virginia

April, 2013

Keywords: Solid Oxide Fuel Cell, Reference Electrode, Electrochemical,

Deconvolution, Aging effects

Copyright 2013 Xiaoke Chen 


\section{Abstract \\ Aging effects of the cathode and determination of single electrode performance in a Solid Oxide Fuel Cell}

\section{Xiaoke Chen}

Solid oxide fuel cells (SOFCs) are promising electrochemical energy conversion devices due to their advantages of high theoretical efficiency, fuel flexibility (including hydrogen and carbon monoxide), scalability, and low emission. An important problem for commercially using the SOFCs is to improve the long term stability for the SOFCs. To improve the lifetime of SOFCs and develop innovative electrode microstructures; we need to understand the individual process including the degradation processes to the cathode or the anode. To identify the independent anode and cathode contributions to the total impedance, one conventional electrochemical tool for evaluation is the reference electrode. Although reference electrode simulations predict that overpotential/current and impedance data assigned to one electrode will inevitably contain contributions from the other electrode, many current experimental reports persistently use reference electrodes. We have developed several configurations of reference electrodes and cell designs, and have experimentally examined these systems using various gas flows and two temperatures, and have also compared experimental results to simulated predictions. Cyclic Voltammetry (CV) and Electrochemical Impedance Spectroscopy (EIS) were used to collect data. The results for all of our reference electrode designs show agreement with simulation predictions. For the ring reference electrode on the anode-supported cell, the data support that the cathode impedance includes impedance from the anode in the 3-electrode measurement. On the electrolyte-supported cell, using both the ring reference electrode and a micro-reference electrode close to the cathode, the apparent inductance loops in the 3-electrode measurement show up for both reference electrode configurations. The inductive loops are artifacts which indicate the inability to accurately separate impedances for the cathode and anode.

We developed a better protocol to identify the minimum number of processes contributing to the total impedance of a SOFC associate with cathode and anode without the use of reference electrodes. The protocol is based on deconvolution combined with equivalent circuit fitting of impedance data. This protocol uses a spreadsheet program. The impedance / deconvolution technique supplies information of characteristic relaxation time distributions. This information, together with systematic changes in gas composition to the anode or cathode, is used to build the equivalent circuits. We are able to identify the impedance components associated with each electrode. The deconvolution and equivalent circuit analyses are applied successfully to three types of commercially button SOFCs including two anode-supported SOFCs and an electrolytesupported SOFC. The results show the ability to assign the physical processes associated to cathode or anode in real electrode systems. 
In the Strontium-doped lanthanum manganite (LSM) cathode of SOFCs, one special phenomenon of degradation was noticed as a changing polarization resistance over tens of hours in a cell at open circuit voltage (Aging effect). This aging effect was reversible during temperature cycles between $800^{\circ} \mathrm{C}$ and $700^{\circ} \mathrm{C}$. We explored this phenomenon via electrochemical techniques (EIS and $\mathrm{CV}$ ), with the purpose of discovering the true physical source. From the initial investigation, we proposed to relate two processes to the phenomenon we observed: (1) the wetting behavior of the LSM on the Yttria stabilized zirconia (YSZ) surface (2) the segregation of cations. Another approach for separating the processes at different frequencies is deconvolution of impedance spectra combined with complex non-linear regression fitting of the impedance spectra. We performed the extended tests with different cathode and electrolyte compositions under open circuit. This protocol provides the trends in parameters for the equivalent circuit during thermal aging for the impedance data from the extended tests, especially, the frequency ranges associated with aging. Based on results from deconvolution, a hypothesis is proposed to address the aging effect. 
Dedicated to my parents (Yong Chen and Qiuya Zhang), my husband (Qingbiao Huang), and to all who have helped me along the way. 


\section{Acknowledgements}

First and foremost, I would like to personally thanks to my advisor and mentor, Dr. Harry O. Finklea, who brought me to this beautiful electrochemistry world. Without his valuable guidance, mentorship, comments and support throughout my graduate study, I would not be the person I am today.

I would like to thank my committee members: Dr. Fabien Goulay, Dr. Alan Stolzenberg, Dr. Justin Legleiter and Dr. John Zondlo for their valuable time on my graduate study and dissertation. Especially, their very helpful discussions and suggestions are greatly acknowledged.

I wish to thank to Dr. Ismail B. Celik and Dr. Raju Pakalapati for their help on simulation for the SOFC studies. I would also like to thank to Dr. Kirk Gerdes for his academic support.

I'd also like to acknowledge the entire members of the Finklea Group: Many thanks to Dr. Oktay Demircan and Dr. Yun Chen, I gain a lot bench work experience from them and valuable discussions on my research with them. Thanks to Wei Zhang, Kaushalya De Silva and Jony Mahfuz for their friendship and assistance.

Financial supports from the U.S. Department of Energy through Regional University Alliance are highly appreciated. I did most of my research in the National Energy Technology Laboratory. I would like gratefully acknowledge the individual researchers and technicians in SOFC research group in NETL, for their directly or indirectly support this project and very valuable discussions on every aspect of SOFC. 


\section{Table of Contents}

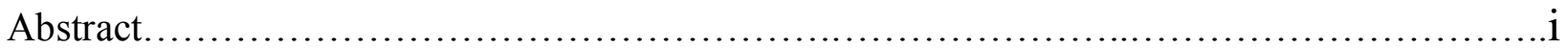

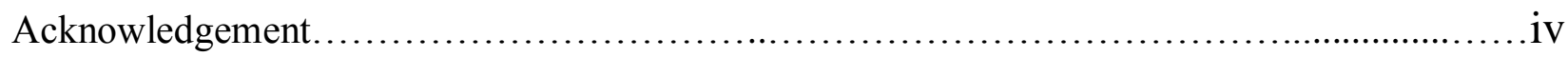

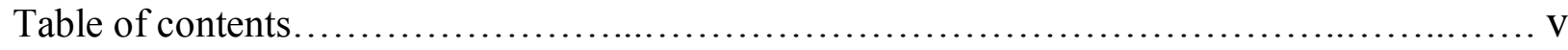

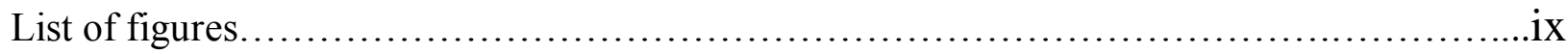

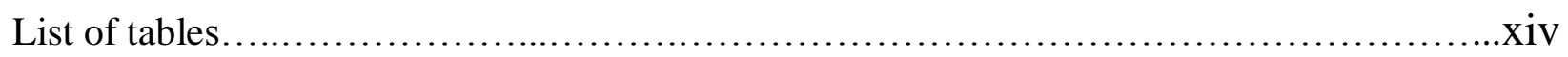

Chapter 1 General introduction .................................................................................................................1

1.1 Solid Oxide Fuel Cells (SOFC) ……………………..................................................

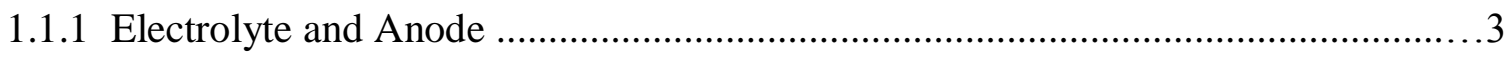

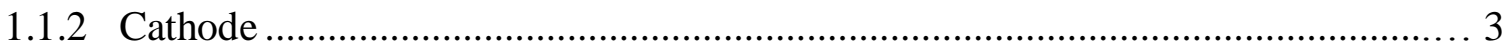

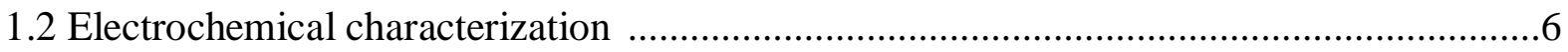

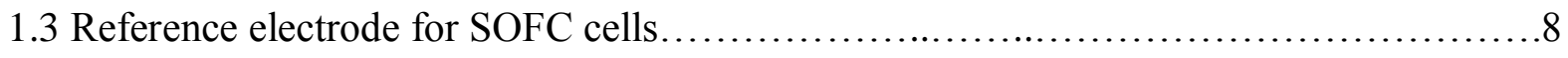

1.4 Simulations of 3-electrode measurements ……………............................................

1.5 Aging effects of cells - lifetime of SOFCs in power generation...................................16

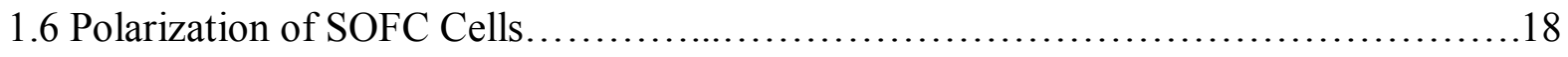

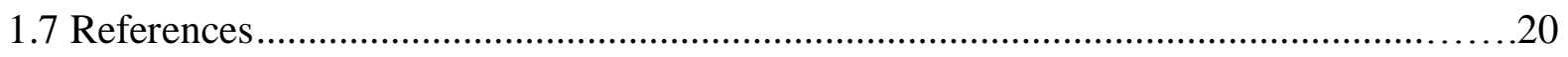

Chapter 2 Deconvolution and complex nonlinear regression fitting of equivalent circuitsgeneral information and equations..................................................24

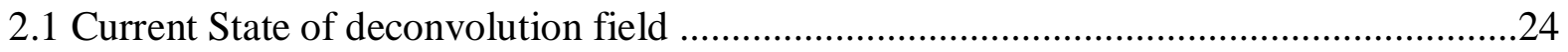

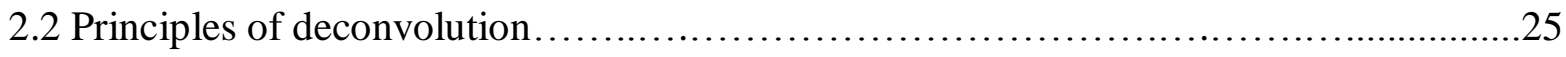

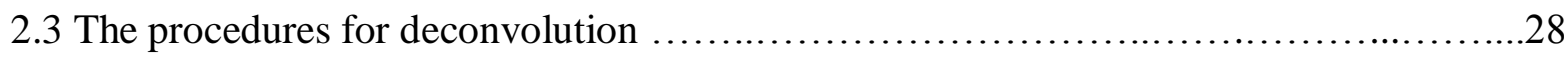

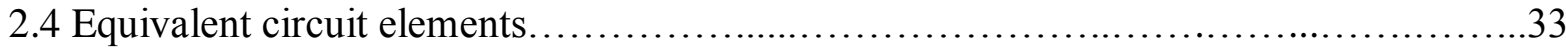


2.5 Strategy

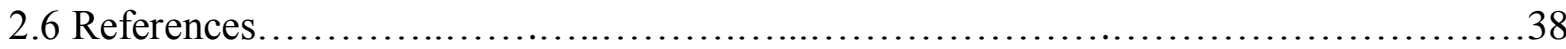

Chapter 3 Analysis of SOFCs using reference electrodes....................................39

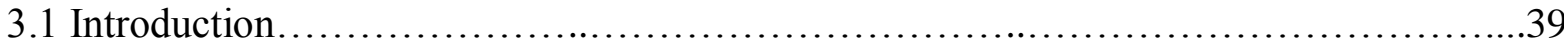

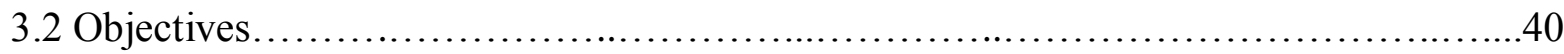

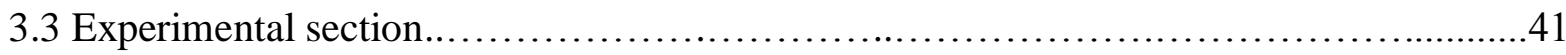

3.3.1. Preparation of LSM/YSZ cathode and LSM/YSZ ring for Ni/YSZ anodesupported cells............................................................. 41

3.3.2 Preparation of the Ag ring for the Electrolyte-supported Cell......................42

3.3.3 Preparation of Ag dot micro reference electrode with glass paste blocking

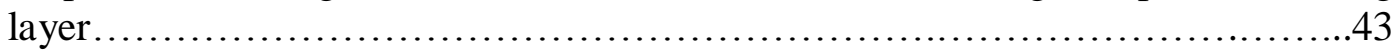

3.3.4. Characterization and SOFC operation conditions.................................43

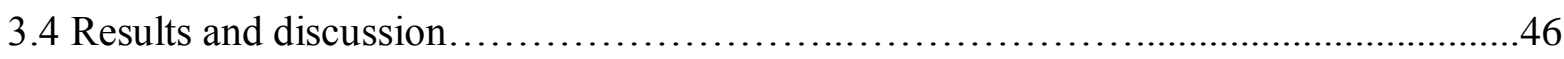

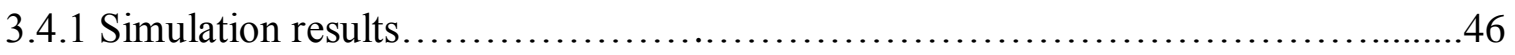

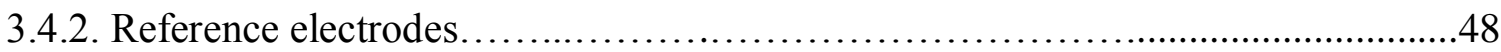

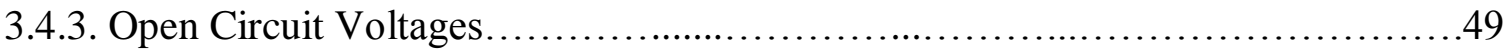

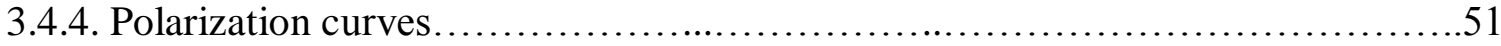

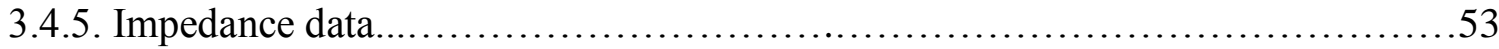

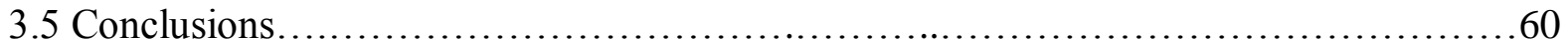

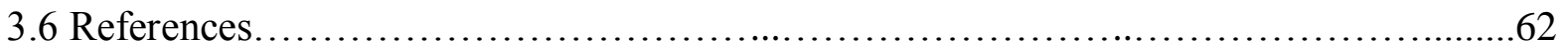

Chapter 4 Analysis of SOFCs with deconvolution methods.................................63

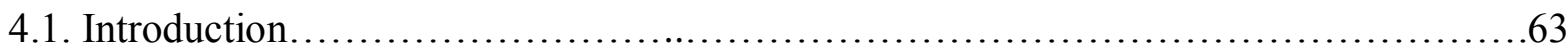

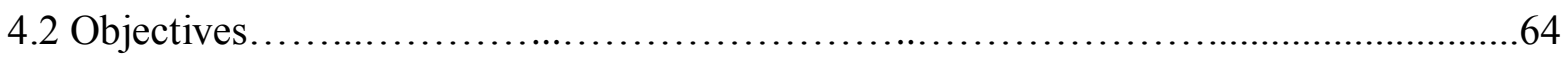

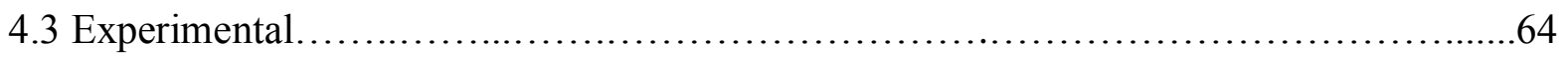


4.4 Results and Discussion .65

4.4.1 Deconvolution and equivalent circuits....................................65

4.4.2 Cell 1: Anode-supported cell with LSM/YSZ cathode.........................66

4.4.3. Cell 2: Electrolyte-supported cell with LSM/YSZ cathode......................75

4.4.4. Cell 3: MSRI Anode-supported Cell with LSM/SDC cathode......................83

4.5 Conclusion................................................................. 91

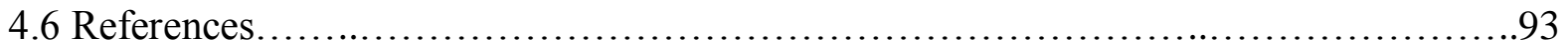

Chapter 5 Aging effect of LSM electrodes...............................................96

5.1 Introduction................................................................... 96

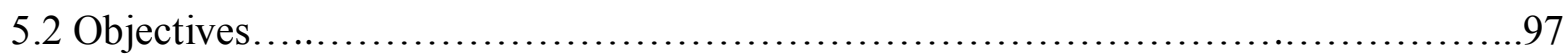

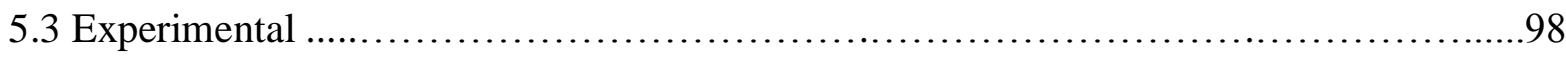

5.3.1 Symmetrical cells with pure LSCF, LSM and LSM/YSZ composite electrodes and YSZ electrolytes aged at 700,800 and $850^{\circ} \mathrm{C}$ in air...........................98

5.3.2 Cycling LSM/YSZ/LSM symmetrical cells between 700 and

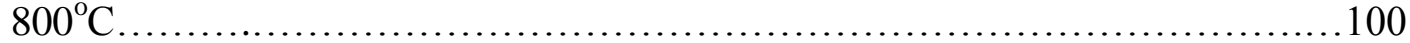

5.3.3 Extended thermal aging of the LSM/YSZ/LSM symmetrical cells at $800^{\circ} \mathrm{C}$ or $700^{\circ} \mathrm{C}$ for 500 hour before cycling the cells between 700 and $800^{\circ} \mathrm{C} \ldots \ldots \ldots \ldots \ldots \ldots \ldots$

5.3.4 Extended thermal aging of the LSM/YSZ/LSM, LSM/GDC/LSM and $\mathrm{LSCF} / \mathrm{GDC} / \mathrm{LSCF}$ symmetrical cells at $800^{\circ} \mathrm{C}$ for 50 hour before cycling the cells between $800^{\circ} \mathrm{C}$ and $700^{\circ} \mathrm{C}$ 101

5.4 Results and Discussion...................................................... 101

5.4.1. Impedance analysis with thermal aging................................. 101

5.4.2 Discussion of possible causing of aging effect............................ 105

5.4.3 Deconvolution analysis of LSM/YSZ/LSM symmetrical cells and (LSM/YSZ)/YSZ/(LSM/YSZ) composite symmetrical cells....................108

5.4.4 Deconvolution analysis of LSM/GDC/LSM symmetrical cells..................124 
5.4.5 Deconvolution analysis of LSCF/GDC/LSCF symmetrical cells.

5.4.6 Discussion for the trends and hypotheses for the deconvolution result..............134

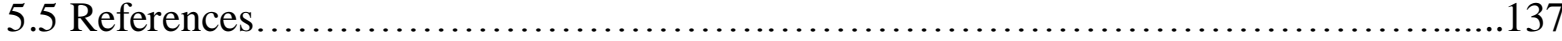

Chapter 6 Conclusions...............................................................................139

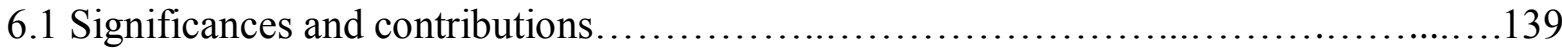

6.2 Future works and recommendations................................................. 


\section{List of figures}

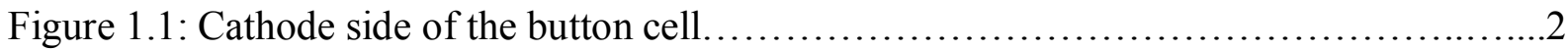

Figure 1.2 Atomic structure of mixed conducting perovskites $\mathrm{ABO}_{3-\delta} \ldots \ldots \ldots \ldots \ldots \ldots \ldots \ldots . \ldots$

Figure 1.3: The graph of the triple phase boundary (TPB) .............................

Figure 1.4: The graph of a mixed ionic and electronic conductor (MIEC) Cathode............5

Figure 1.5: Polarization curve and Power curve for a single cell...........................

Figure 1.6: A typical EIS data graph.............................................. 8

Figure 1.7: The reference electrode is near to the WE on the surface of the electrolyte or on the rim of the electrolyte plane.......................................... 11

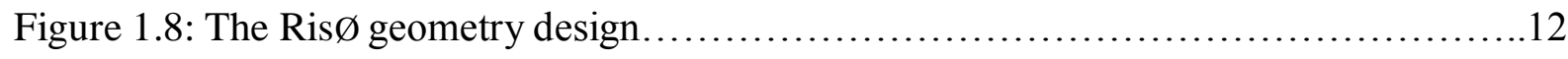

Figure 1.9: Point electrode on thick electrolyte design ..............................12

Figure 1.10: The Inter- digitated WE/RE geometry design............................12

Figure 1.11: Equipotential line (red) probed by the reference electrode at zero (solid line) and infinity (dashed line) frequencies.....................................13

Figure 1.12: The simulation Nyquist plot from Cimenti's paper showing the Nyquist plot for cathode

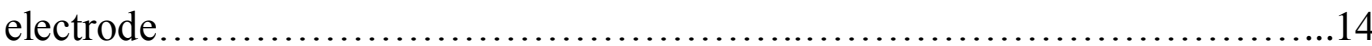

Figure 1.13: The distribution of electric potential near the edge of cathode.................15

Figure 1.14: graph of the voltage drop of SOFC as a function of current density.............18

Figure 2.1: The equivalent circuit consisting and corresponding deconvolution spectrum....26

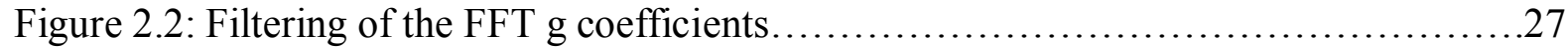

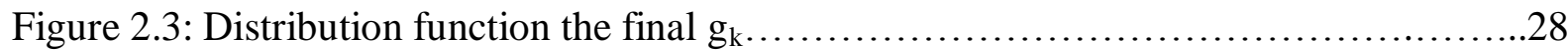

Figure 2.4: The step of processing the out-of-phase impedance $Z$ "'....................29

Figure 2.5: (a) The $\log (\mid \mathrm{Z}$ ”|) vs $\log$ f plot.( b) The $\log (\mid \mathrm{Z}$ ” $\mid)$ vs $\log \mathrm{f}$ plot after fixing the deviant

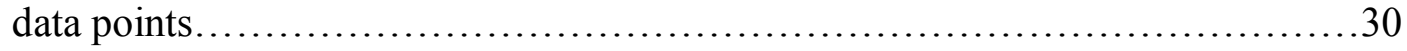

Figure 2.6: (a) plot of processed Z" vs $\log$ f. (b) Plot of processed $\log (\mid \mathrm{Z}$ ”|) vs $\log \mathrm{f} . \ldots \ldots \ldots . . .32$

Figure 2.7: Impedance and deconvolution spectra for $(R Q)$ circuits.....................34 
Figure 2.8: (A)Nyquist (B) deconvolution plots for the generalized Gerischer impedance....35

Figure 2.9: (A)Nyquist and (B) deconvolution spectra of a finite length Warburg element...36

Figure 3.1: The LSM/YSZ ring reference electrode on Ni/YSZ anode-supported cell.......42

Figure 3.3: Micro-reference electrode on an electrolyte-supported cell...................43

Figure 3.4: Schematic drawing of the electrolyte-supported fuel cell mounted in the furnace.

Figure 3.5: (a) Comparison of simulation polarization curve and (b) simulation impedance to the data from the anode-supported cell at $800^{\circ} \mathrm{C}$ and normal flow...............46

Figure 3.6: Bode plots of the simulated impedance Z' (a) and $-Z$ "' (b) $\ldots \ldots \ldots \ldots \ldots \ldots \ldots . \ldots 4$

Figure 3.7: Overlay Bode plots of the simulated cathode impedance Z' (A) and -Z" (B) for normal $(\mathrm{N})$, low air (LA) and low fuel (LF) flow........................48

Figure 3.8: Difference Bode plots of the simulated cell, cathode and anode impedances dZ'(a) and $\mathrm{dZ} "$ (b) going from normal flow to low fuel flow........................48

Figure 3.9: Polarization curves for the anode supported cell with ring reference electrode....52

Figure 3.10: Polarization curves for the electrolyte-supported cell with ring reference electrode.

Figure 3.11: Polarization curves for the electrolyte-supported cell with micro-reference electrode. .52

Figure 3.12: Nyquist plots for the cathode/anode and cathode/ring/anode impedances obtained using the anode-supported cell in normal flow at $800^{\circ} \mathrm{C} \ldots \ldots \ldots \ldots . . . .54$

Figure 3.13: Difference Bode plots for low air vs normal flow ( $\mathrm{a}$ b) and low fuel vs normal

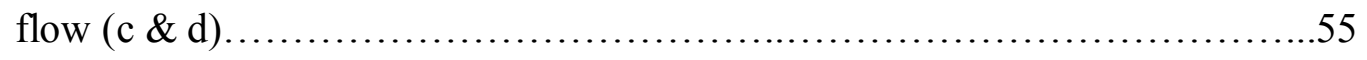

Figure 3.14: Nyquist plot for the 3-electrode anode/ring/cathode impedance for the anodesupported cell at $800^{\circ} \mathrm{C}$ and normal flow. .56

Figure 3.15: Cathode/anode Nyquist plot (a) and -Z" vs log f (b) for an electrolyte-supported cell at $800^{\circ} \mathrm{C}$....

Figure 3.16: Overlay Nyquist plots and plots of $-\mathrm{Z}$ " vs $\log \mathrm{f}$ for cathode/anode, and cathode/reference/anode and anode/reference/cathode at $800^{\circ} \mathrm{C}$ and normal flow with ring refrence electrode. . .58 
Figure 3.17:Overlay Nyquist plots and plots of $-\mathrm{Z}$ " vs $\log \mathrm{f}$ for cathode/anode, and cathode/reference/anode and anode/reference/cathode at $800^{\circ} \mathrm{C}$ and normal flow with micro- refrence electrode.

Figure 4.1: Cell 1: (a) cathode/anode Nyquist plots at $800^{\circ} \mathrm{C}$. (b) cathode/anode deconvolution spectra at $800^{\circ} \mathrm{C}$. (c) cathode/anode Nyquist plots at $700^{\circ} \mathrm{C}$. (d) cathode/anode deconvolution spectra at $700^{\circ} \mathrm{C}$. .68

Figure 4.2: Equivalent circuit fit to Cell 1 at $800^{\circ} \mathrm{C}$ with normal flow 69

Fig. 4.3: Cell 1: (a) Nyquist plots for the cathode/anode and cathode/reference/anode impedances obtained in normal flow at $800^{\circ} \mathrm{C}$. (b) Deconvolution spectra for impedances in (a). (c) Deconvolution spectra for the cathode/anode and cathode/reference/anode impedances in low air flow at $800^{\circ} \mathrm{C}$. (d) Deconvolution spectra for the cathode/anode and cathode/reference/anode impedances in low fuel flow at $800^{\circ} \mathrm{C}$. .74

Figure 4.4: Cell 2: (a) Nyquist plot and (b) deconvolution spectra for the electrolyte-supported cell at $800^{\circ} \mathrm{C}$; (c) Nyquist plot and (d) deconvolution spectra at $700^{\circ} \mathrm{C}$. .76

Figure 4.5: Equivalent circuit fit to Cell 2 at $800^{\circ} \mathrm{C}$ with normal flow .... .77

Figure 4.6: Cell 3 residuals for (a) Z' and (b) Z" impedances for four sequential impedance measurements at $800^{\circ} \mathrm{C}$ and normal flow .84

Figure 4.7: Cell 3 residuals for (a) Z' and (b) Z" impedances for four sequential impedance measurements 84

Figure 4.8: Cell 3 Nyquist plots at $800^{\circ} \mathrm{C}$ for (a) normal, $50 \%$ air, and $20 \%$ air flows, and (b) normal, $50 \%$ hydrogen, and $20 \%$ hydrogen flows.

Figure 4.9: Cell 3 Deconvolution plots at $800^{\circ} \mathrm{C}$ for (a) normal, $50 \%$ air, and $20 \%$ air flows, and (b) normal, $50 \%$ hydrogen, and $20 \%$ hydrogen flows. .85

Figure 4.10: Equivalent circuit fit to Cell 3 at $800^{\circ} \mathrm{C}$ with normal flow.... . .86

Figure 5.1: NexTech Hionic ${ }^{\mathrm{TM}}$ electrolyte-supported cell with LSM/GDC composite cathode

Figure 5.2: The setup of the symmetrical cell .99

Figure 5.3: The LSM/YSZ Cell was characterized at the first $4 \mathrm{~h}$ at $850^{\circ} \mathrm{C}$ by cyclic voltammograms (CVs) and electrochemical impedance spectroscopy (EIS)...100 
Figure 5.4: Initial polarization resistances of a pure LSM/YSZ/LSM symmetrical cell in air at $700^{\circ} \mathrm{C}, 800^{\circ} \mathrm{C}$ and $850^{\circ} \mathrm{C}$ 102

Figure 5.5: Initial polarization resistances of an LSM/YSZ composite symmetrical cell in air at $700^{\circ} \mathrm{C}, 800^{\circ} \mathrm{C}$ and $850^{\circ} \mathrm{C}$ 102

Figure 5.6: Initial polarization resistances of a pure LSCF/YSZ/LSCF symmetrical cell in air at $700^{\circ} \mathrm{C}, 800^{\circ} \mathrm{C}$ and $850^{\circ} \mathrm{C}$ 102

Figure 5.7: Polarization resistances of the LSM/YSZ/LSM cell in Fig 5.4 at (a) $700^{\circ} \mathrm{C}$ and (b) $800^{\circ} \mathrm{C}$ during temperature cycles. 103

Figure 5.8: A plot of $-\mathrm{Z}$ " vs $\log \mathrm{f}$ for a pure LSM electrode soaking at $700{ }^{\circ} \mathrm{C}$ and $800^{\circ} \mathrm{C}$. 103

Figure 5.9: (a) Polarization resistance of an LSM/YSZ/LSM symmetrical cell during a 522 hour soak at $800^{\circ} \mathrm{C}$. (b) Polarization resistances of the cell at $700^{\circ} \mathrm{C}$. (c) Polarization resistances of the cell at $800^{\circ} \mathrm{C}$ .104

Figure 5.10: (a) Polarization resistance of an LSM/YSZ/LSM symmetrical cell during a 516 hour soak at $700^{\circ} \mathrm{C}$. (b) Polarization resistances of the cell at $700^{\circ} \mathrm{C}$ after soaking at $700^{\circ} \mathrm{C}$ for 510 hour. (b) Polarization resistances of the cell at

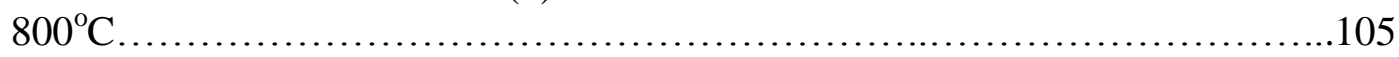

Fig. 5.11: Impedance spectra and deconvolution spectra for cell A and cell B

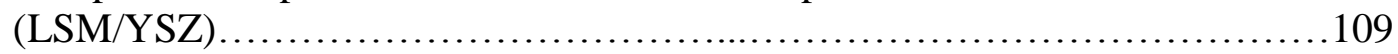

Figure 5.12: Equivalent circuit fit for the first 2.2 hour data collected at $800^{\circ} \mathrm{C}\left(1^{\text {st }}\right.$ cycle for cell A) ......................................................... 110

Figure 5.13: Equivalent circuit fit for the 2.3 hour data collected at $800^{\circ} \mathrm{C}\left(1^{\text {st }}\right.$ time $)$ for cell

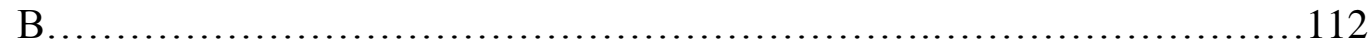

Figure 5.14: Equivalent circuit fit for the 45.7 hour data collected at $800^{\circ} \mathrm{C}\left(1^{\text {st }}\right.$ time) for cell B................................................................ 113

Figure 5.15: The parameters for the equivalent circuit as a function of time for the first data set of cell $\mathrm{A}$ and $\mathrm{B}$ at $800^{\circ} \mathrm{C}$. 115

Figure 5.16: The parameters for the equivalent circuit as a function of time for the second data set of cell $\mathrm{A}$ and $\mathrm{B}$ at $800^{\circ} \mathrm{C}$. 116

Figure 5.17: The parameters for the equivalent circuit as a function of time for the third data set of cell $\mathrm{A}$ at $800^{\circ} \mathrm{C}$. 116

Figure 5.18: The corresponding polarization resistance of cell $\mathrm{A}$ and $\mathrm{B}$ with time at $800^{\circ} \mathrm{C}$ over two or three temperature cycles. .117 
Figure 5.19: Equivalent circuit fit for the 1.0 hour data collected at $800^{\circ} \mathrm{C}\left(1^{\text {st }}\right.$ time $)$ for cell

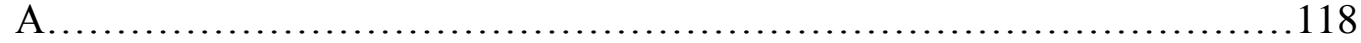

Figure 5.20: Equivalent circuit fit for the 1.1 hour data collected at $800^{\circ} \mathrm{C}\left(1^{\text {st }}\right.$ time $)$ for cell B.

Figure 5.21: The parameters for the equivalent circuit as a function of time for the first data

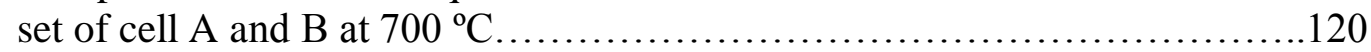

Figure 5.22: The parameters for the equivalent circuit as a function of time for the second data

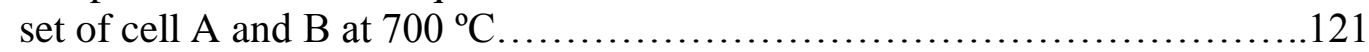

Figure 5.23: The corresponding polarization resistance of cell $\mathrm{A}$ and $\mathrm{B}$ vs. time at $700{ }^{\circ} \mathrm{C}$. (a) Cell A; (b) Cell B.

Figure 5.24: Equivalent circuit fit for the 2.0 hour data collected at $800^{\circ} \mathrm{C}$

Figure 5.25: Equivalent circuit fit for Out-of-phase -Z" data and the contributions from each

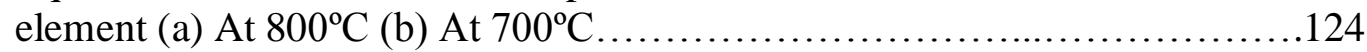

Figure 5.26: The polarization resistances for the equivalent circuit as a function of time (a) At $800^{\circ} \mathrm{C}(\mathrm{b})$ At $700^{\circ} \mathrm{C}$

Figure 5.27: (A) Nyquist plot and (B) Bode plot $-\mathrm{Z}$ " vs $\log \mathrm{f}$ at first $2 \mathrm{~h}$ for cell $\mathrm{A}$ and B at 800

${ }^{\circ} \mathrm{C}$

Figure 5.28: Equivalent circuit fit for the 2.0 hour data collected at $800^{\circ} \mathrm{C}\left(1^{\text {st }}\right.$ time $)$ for cell A. .126

Figure 5.29: The parameters for the equivalent circuit as a function of time for the first data set of cell $\mathrm{A}$ and $\mathrm{B}$ at $800^{\circ} \mathrm{C}$ 128

Figure 5.30: The parameters for the equivalent circuit as a function of time for the second data set of cell $\mathrm{A}$ and $\mathrm{B}$ at $800^{\circ} \mathrm{C}$. 129

Figure 5.31: Comparison of data at the beginning and end of aging for Cell $\mathrm{A}$ at $700^{\circ} \mathrm{C}$ (first cycle).(a) Nyquist plot; (b) Bold plot -Z” vs log f; (c) Deconvolution spectra.130

Fig. 5.32: Equivalent circuit fit for the 2.0 hour data collected at $700^{\circ} \mathrm{C}\left(1^{\text {st }}\right.$ time) for cell A...................................................................

Figure 5.33: The corresponding polarization resistance of cell A vs. time at $700^{\circ} \mathrm{C} \ldots \ldots \ldots . .131$

Figure 5.34: Impedance spectra and deconvolution spectra for cell A (LSCF/GDC)........132

Figure 5.35: The corresponding polarization resistance of cell A vs. time (a) At $800^{\circ} \mathrm{C}$; (b) At $700^{\circ} \mathrm{C}$ 


\section{List of tables}

Table 3.1: Open circuit voltage magnitudes $(\mathrm{mV})$ for electrolyte-supported cells with a ring reference electrode or a micro-reference electrode.

Table 3.2: Open circuit voltage magnitudes $(\mathrm{mV})$ for an anode-supported cell with a ring reference electrode.

Table 4.1: Fitted parameters for the $\mathrm{LR}(\mathrm{Ge})(\mathrm{RQ})_{\mathrm{n}}$ equivalent circuit to impedance data for Cell 1 at $800^{\circ} \mathrm{C}$ 71

Table 4.2: Polarization resistances and the peak frequencies for the 2-electrode impedances of Cell 1 at $800^{\circ} \mathrm{C}$ 72

Table 4.3: Fitting parameters for Cell 2 at $800^{\circ} \mathrm{C}$ as a function of gas flows .78

Table 4.4: Fitting polarization resistance and peak frequencies for Cell 2 at $800^{\circ} \mathrm{C}$ as a function of gas flows................................................79

Table 4.5: Fitting polarization resistance and peak frequencies for Cell 2 at $700^{\circ} \mathrm{C}$ as a function of gas flows.............................................. 81

Table 4.6: Assigned polarization resistances and activation energies for Cell 2 vs Temperature.

Table 4.7 Peak frequencies for Cell 2 vs temperature. 82

Table 4.8: Fitted parameters for Cell 3 at $800^{\circ} \mathrm{C}$ and all five flow conditions .87

Table 4.9: Fitted parameters for Cell 3 at $750^{\circ} \mathrm{C}$ and all four flow conditions .88

Table 4.10: Polarization resistances and frequencies for Cell 3 at $800^{\circ} \mathrm{C}$ and all five flow conditions. 89

Table 4.11: Polarization resistances and frequencies for Cell 3 at $750^{\circ} \mathrm{C}$ and all four flow c conditions. .89

Table 4.12: Effects of temperature on RQ elements for normal flow. .91

Table 5.1: Fitted parameters for the $\mathrm{R}(\mathrm{RQ})_{5}$ equivalent circuit to impedance data for the LSM/YSZ/LSM Cell A at 2.2 hour and 45.6 hour \& Cell B at 2.3 hour and 45.7 hour $800^{\circ} \mathrm{C}\left(1^{\text {st }} \mathrm{Cycle}\right)$.

Table 5.2: Comparison end of $800^{\circ} \mathrm{C}$ collection vs beginning of $700^{\circ} \mathrm{C}$ collection for LSM/GDC/LSM cell A..... .122

Table 5.3: Comparison end of $800^{\circ} \mathrm{C}$ collection vs beginning of $700^{\circ} \mathrm{C}$ collection for $\mathrm{LSM} / \mathrm{GDC} / \mathrm{LSM}$ cell B. 
Table 5.4: Fitted parameters for the $\mathrm{R}(\mathrm{RQ})_{5}$ equivalent circuit to impedance data for the Cell $\mathrm{A}$ at 2.0 hour and Cell $\mathrm{B}$ at 2.1 hour at $800^{\circ} \mathrm{C}\left(1^{\text {st }} \mathrm{Cycle}\right) \ldots \ldots \ldots \ldots \ldots \ldots . .127$

Table 5.5: Fitted parameters for the $\mathrm{LR}(\mathrm{Ge})(\mathrm{RQ})_{2}$ equivalent circuit to impedance data for the LSCF/GDC/LSCF Cell A at 2.2 hour and at 45.7 hour at $800^{\circ} \mathrm{C}\left(1^{\text {st }}\right.$

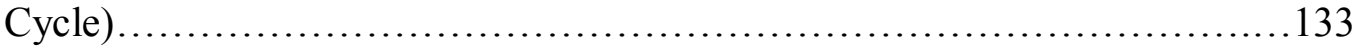




\section{Chapter 1 General introduction}

\subsection{Solid Oxide Fuel Cells (SOFC)}

Despite the facts that the fuel cell was discovered over 160 years ago, and the first SOFC was developed in 1937 by Baur and Preis [1], only now are fuel cells approaching commercial reality. The fuel cells offer high energy conversion efficiencies and significant environmental advantages. As one of the most promising energy conversion devices, the solid oxide fuel cell (SOFC) is a solid-state device which operates at high temperatures, directly and efficiently converting chemical energy to electrical energy with low pollution and fuel flexibility. Since SOFCs can hopefully utilize conventional hydrocarbon fuels, they can be the transition energy conversion device from fossil fuels to hydrogen.

The three components of the SOFC are the cathode, at which $\mathrm{O}_{2}$ is reduced, the anode at which fuel is oxidized, and the electrolyte, which separates the cathode and anode. Although there are different geometric structures of SOFCs, for economic construction and controllable industry development, SOFC research is often performed on a small planar disk with radial dimensions on the order of 1-3 cm (button cells). There are two conventional commercial geometries for the button cell; one is the electrolyte-supported cell, with a thick electrolyte (hundreds of $\mu \mathrm{m}$ ) with symmetrically deposited thin cathode on one side and identical sized thin anode on the other side. The other is the anode-supported button cell, with a thick and large anode (close to $1 \mathrm{~mm}$ ) and a thin and identical sized electrolyte, and a small thin cathode on top of the thin electrolyte layer (Figure 1.1) 


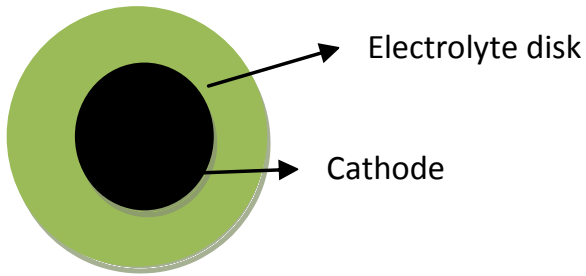

(a)

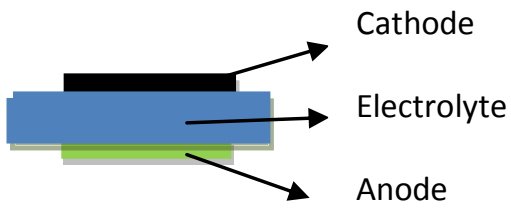

(b)

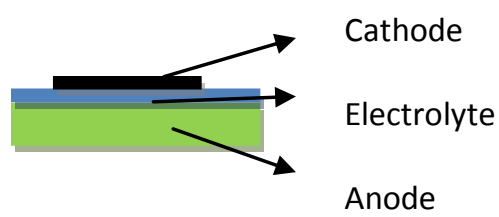

(c)

Fig 1.1: (a) Cathode side of the button cell. Cross section of the (b) Electrolyte-supported cell. (c)Anode-supported cell.

Solid oxide fuel cells use a solid ceramic inorganic oxide as the electrolyte, rather than a liquid electrolyte. The mobile species in the electrolyte is the oxygen ion $\left(\mathrm{O}^{2-}\right)$. The required operating temperature is typically between $750^{\circ} \mathrm{C}--1000^{\circ} \mathrm{C}$ in order to get sufficiently high ionic conductivity in the electrolyte. One major advantage of SOFCs over other types of fuel cells is fuel flexibility. A number of fuels (including coal syngas) can be used, since CO is a fuel, not a poison for the SOFC anode. A summary of the electrode reactions is given below [2]:

Anode:

$$
\begin{aligned}
& \mathrm{H}_{2}(g)+\mathrm{O}^{2-} \rightarrow \mathrm{H}_{2} \mathrm{O}(g)+2 e^{-} \\
& \mathrm{CH}_{4}+4 \mathrm{O}^{2-} \rightarrow \mathrm{CO}_{2}(g)+2 \mathrm{H}_{2} \mathrm{O}(g)+8 \mathrm{e}^{-} \\
& \mathrm{CO}(g)+\mathrm{O}^{2-} \rightarrow \mathrm{CO}_{2}(g)+2 \mathrm{e}^{-}
\end{aligned}
$$

Cathode: $\quad O_{2}(g)+4 \mathrm{e}^{-} \rightarrow 2 O^{2-}$

Overall: $\quad \mathrm{H}_{2}(g)+\mathrm{CO}(g)+\mathrm{CH}_{4}(g)+3 \mathrm{O}_{2}(g) \rightarrow 2 \mathrm{CO}_{2}(g)+3 \mathrm{H}_{2} \mathrm{O}(g)+\Delta \mathrm{E}$

Another advantage is the elevated operating temperature of the SOFC which results in the production of high temperature heat as a by-product in addition to the electrical power.[3] The 
integrated power system which generates electricity from the exhaust heat of the SOFC theoretically has the highest efficiency for converting fuel to electrical power.

\subsubsection{Electrolyte and Anode}

In SOFCs, a solid-state ceramic ionic conductor is employed as the cell electrolyte. The requirement of a good SOFC electrolyte includes a high ionic conductivity (typically $>0.1 \mathrm{~S} / \mathrm{cm}$ ) and negligible electronic conductivity, being chemically unreactive towards the other cell components and being stable in both oxidizing and reducing atmospheres. A typical electrolyte is YSZ - a mixture of zirconia (zirconium oxide, $\mathrm{ZrO}_{2}$ ) doped with about 8 mole \% yttria (yttrium oxide, $\mathrm{Y}_{2} \mathrm{O}_{3}$ ). The YSZ has a thermal expansion coefficient comparable to the favorite cathode material- strontium-doped lanthanum manganite LSM. Sm-doped ceria (SDC) or Gddoped ceria (GDC) are alternative electrolyte materials for intermediate temperature (IT)-SOFCs (operating temperature range $500-800^{\circ} \mathrm{C}$ ). SDC and GDC have higher ionic conductivity and surface oxygen exchange kinetics compared to YSZ, leading to enhanced cell performance in the intermediate temperature (IT) range $\left(500-700^{\circ} \mathrm{C}\right)$. Another advantage of the SOFCs using SDC or GDC as the electrolyte is the prevention of non-conducting zirconate phase which is commonly observed in SOFC using YSZ as electrolyte [4]. However, these ceria-based electrolytes suffer from significant electronic conductivity when exposed to strongly reducing conditions on the fuel cell. The electronic conductivity directly between the cathode and anode causes loss of power in the SOFC.

A common active electrode material for the SOFC anode is nickel. As a gas diffusion electrode, the SOFC anode must have a porous structure. Currently, a porous cermet (ceramic metal mixture) structure such as Ni-YSZ is widely used in SOFCs. The porous cermets can maintain the porosity by preventing sintering of nickel particles during operation, and give maximum contact between the nickel metal and the electrolyte. [5]

\subsubsection{Cathode}

The cathode, like the anode, must be electronically conducting and have a porous structure which must be maintained at the elevated operating temperatures. Also, the cathode must be stable in an oxidizing environment. Many transition-metal oxides have good electrical conductivity, and 
are relatively much lower in cost than Pt. Pt was the precious metal first used as the electrode material for SOFC. One of the first such materials studied: $\mathrm{La}_{1-x} \mathrm{Sr}_{x} \mathrm{CoO}_{3-\delta}(\mathrm{LSC})$ was reported by Button and Archer in 1966. [6] A number of perovskite crystal structures were also reported after that, including strontium-doped lanthanum manganite $\mathrm{La}_{1-x} \mathrm{Sr}_{x} \mathrm{MnO}_{3-\delta}(\mathrm{LSM}, \mathrm{x}=0.2-0.3$ ), which had became the most widely used material for SOFC cathodes. LSM meets the requirements of the cathode and is also inexpensive.

LSM is a perovskite $\mathrm{ABO}_{3-\delta}$ type compound.(Fig. 1.2(a)) For the general perovskite crystal

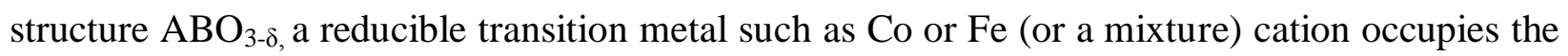
$\mathrm{B}$-site and a mixture of rare and alkaline earths (such as $\mathrm{La}$ and $\mathrm{Sr}$ ) cation fill up the A-site cavity. This composition has high electronic conduction because of a metallic or semiconducting band structure promoted at high temperature. The octahedral symmetry is also quite stable. The structure tolerates missing oxide ions, and consequently oxide ion transport can be supported by a hopping mechanism (Fig. 1.2(b)), which lead to significant bulk ionic oxygen transport.

a)

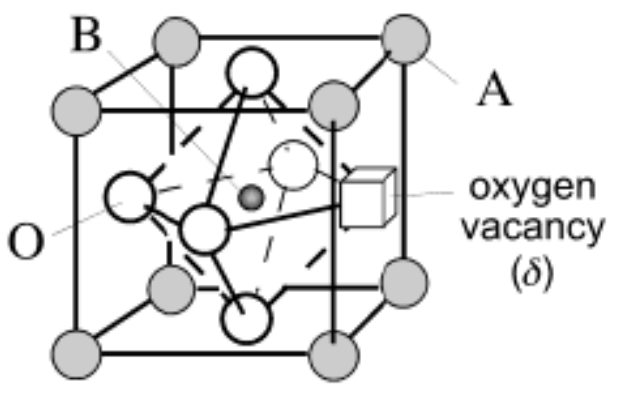

b)

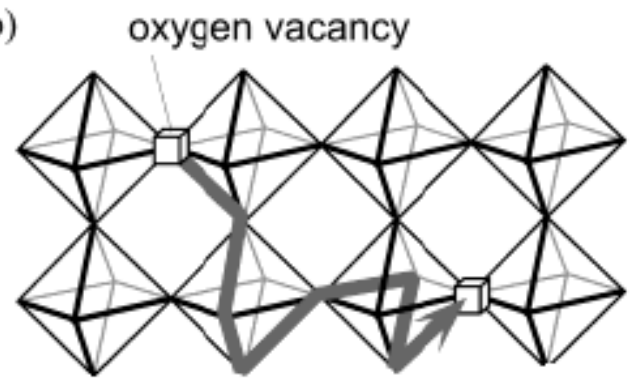

Fig 1.2 (a) Atomic structure of mixed conducting perovskites $\mathrm{ABO}_{3-\delta}$. A corner-sharing $\mathrm{BO}_{6}$ octahedron surrounded by charge-compensating A-site cations. (b) Oxygen transport in mixed conducting perovskites $\mathrm{ABO}_{3-\delta}$ via the random hopping of oxygen ion vacancies on the oxygen sub-lattice. [7] 
The general perovskite crystal structure $\mathrm{ABO}_{3-\delta}$ is often a mixed ionic and electronic conductor (MIEC) [8], so using a MIEC for the cathode has the advantage to extend the electrochemically active sites from only the triple phase boundary (cathode/electrolyte/gas interface TPB) (Fig 1.3) of the original pure electronic conductor cathode to the entire surface of the porous MIEC cathode. The increased electrochemically active sites consequently decrease cathode polarization resistance (Fig 1.4) [9-11]. One problem with LSM is that its ionic conductivity is orders-ofmagnitude lower than its electronic conductivity, so it is considered to be primarily an electronic conductor.

Three Phase Boundary (TPB)

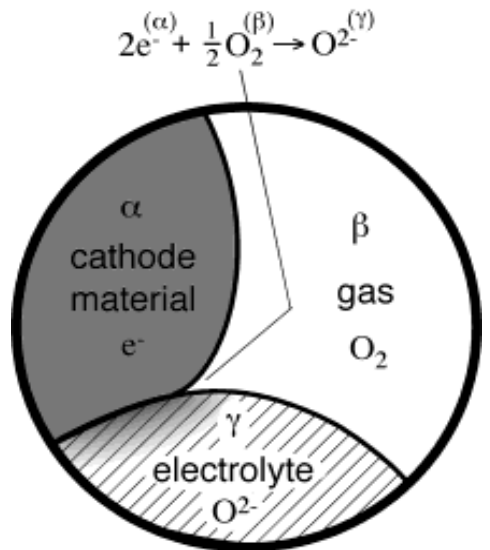

Figure 1.3: The graph of the triple phase boundary (TPB) composed of the electronically conducting (electronic) phase, gas phase, and ionically conducting (ionic) phase in accomplishing oxygen reduction[7].

TPB Cathode (contains both the $\mathrm{e}^{-}$and $\mathrm{O}^{2-}$ )

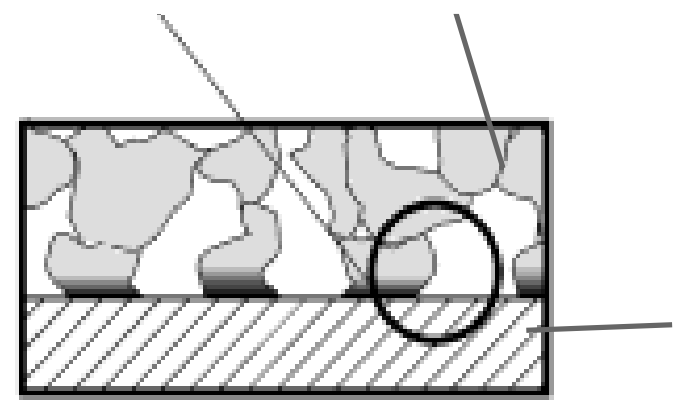

\section{Electrolyte}

Figure 1.4.The graph of a mixed ionic and electronic conductor (MIEC) Cathode. This cathode contains both electrons and oxide ions, so extend the electrochemically active sites from just the triple fhase boundary (TPB) to the entire surface of the porous cathode (dark shaded area) [7] 
Nowadays, it has been well recognized that multiple benefits can be derived by reducing the operating temperature of a SOFC to the intermediate temperature range of $500-800^{\circ} \mathrm{C}$ including reduced fabrication cost, prolonged life time, versatile cell materials, and elegant sealing [12.13]. However, lowering the operation temperature to $500-800^{\circ} \mathrm{C}$ results in the rapid increase in ohmic polarization (also called ohmic loss, due to the internal resistances of the electrolyte and imperfect electrodes) and cathodic polarization (cathodic loss, due to the resistances inside the cathode), which consequently leads to a rapid decrease in the performance of the fuel cells with decreasing temperature. LSM, due to its low ionic conductivity and relatively high activation energy for oxygen dissociation at temperatures below $800^{\circ} \mathrm{C}$, is no longer the ideal cathode material for a lower temperature SOFC [14-16].

Several perovskite compounds with cobalt as the predominant B-site cation are mixed ionic and electronic conductors which have high electronic and ionic conductivity in addition to high catalytic activity for oxygen reduction at the desired low operating temperatures [17-19]. Among the large variety of mixed conducting oxide materials, Lanthanum strontium cobalt ferrite (LSCF) has been the most widely studied cathode material for intermediate temperature SOFC, as it has high oxygen ionic and electronic conductivity in the cubic crystal structure [20, 21].

\subsection{Electrochemical characterization}

Development of solid oxide fuel cells is based on evaluating the cell performance with electrochemical characterization. Typical fuel cell performance indicators including: open circuit voltage, polarization curve (IV curve), power curve, and electrochemical impedance spectroscopy (EIS).

Open-circuit voltage (OCV) is the difference of electrical potential between two terminals of a device when no external electric current flows between the terminals. For the hydrogen fuel cell:

$$
2 \mathrm{H}_{2}(g)+\mathrm{O}_{2}(g) \rightarrow 2 \mathrm{H}_{2} \mathrm{O}(\text { lor } g)
$$

The OCV dependence on respect to temperature is, $\Delta \mathrm{S}$ is the change of entropy: 
$\Delta E(T)=\Delta E^{0}+\frac{\Delta S}{4 F} \times(T-298 K)$

The OCV also depends on gases activities $\left(\alpha_{\mathrm{H} 2} \mathrm{O}, \alpha_{\mathrm{H} 2}\right.$ and $\left.\alpha_{\mathrm{O} 2}\right)$ as calculated from Nernst equation.

$\Delta \mathrm{E}=\Delta \mathrm{E}^{0}-(2.303 * \mathrm{RT} / \mathrm{nF}) \log \left(\alpha_{\mathrm{H} 2 \mathrm{O}}^{2} /\left(\alpha_{\mathrm{H} 2}^{2} \alpha_{\mathrm{O} 2}\right)\right)$

For fuel cell (3\% water vapor in $\mathrm{H}_{2}$ fuel, air for the cathode, total pressure $1 \mathrm{~atm}$ ) at $800^{\circ} \mathrm{C}$, the theoretical OCV $\Delta \mathrm{E}=1.103 \mathrm{~V}[22]$. In practice, the actual $\Delta \mathrm{E}$ is usually lower than theoretical value due to imperfect sealing, especially between the fuel on the anode side and air outside the SOFC.

In a polarization curve (IV curve), the current density $\left(\mathrm{A} / \mathrm{cm}^{2}\right)$ is plotted on the horizontal axis with cell voltage on the vertical axis (Fig 1.5). The cell voltage decreases as the current density increases. In the power curve (IP curve), power (product of current and voltage) is the vertical axis and current density is the horizontal axis (Fig 1.5). The graph shows the peak power. In general, higher power is better. Because various losses decrease with increasing temperature, the power increases dramatically with increasing temperature.

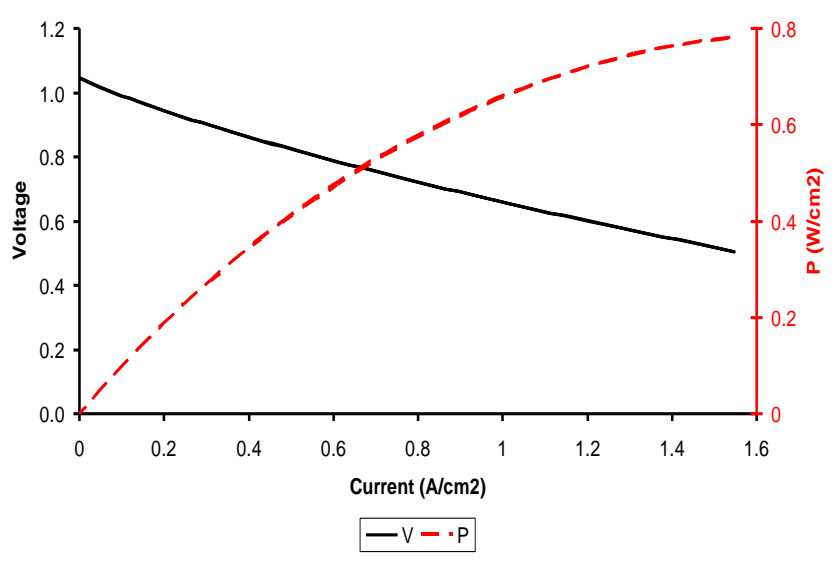

Fig. 1.5.Polarization curve and Power curve for a single cell (Peak power density $0.8 \mathrm{~W} / \mathrm{cm}^{2}$ )

Electrochemical impedance is usually measured by applying an AC potential as an excitation signal to an electrochemical cell and measuring the AC current through the cell. An expression analogous to Ohm's Law is used to calculate the impedance of the system as: 


$$
Z=\frac{E_{t}}{I_{t}}=\frac{E_{0} \sin (\omega t)}{I_{0} \sin (\omega t+\phi)}=Z_{0} \frac{\sin (\omega t)}{\sin (\omega t+\phi)}
$$

The impedance is then represented as a complex number.

$$
\mathrm{Z}(\omega)=\frac{E}{I}=\mathrm{Z}_{0} \exp (\mathrm{j} \phi)=\mathrm{Z}_{0}(\cos \phi+\mathrm{j} \sin \phi)
$$

The expression for $Z(\omega)$ is composed of a real and an imaginary part. Impedance data are usually collected for a wide range of frequencies. In a typical EIS plot (Nyquist plot), the real part is plotted on the $\mathrm{X}$-axis and the negative imaginary part is plotted on the $\mathrm{Y}$-axis for each frequency. The EIS data Plot for a cell is always a set of arcs. The series resistance can found by reading the real axis value at the high frequency intercept. The real axis value at the other (low frequency) intercept is the sum of the polarization resistance and the series resistance. The diameter of the semicircle is therefore equal to the polarization resistance (Fig 1.6). The Series resistance in a SOFC is predominantly the electrolyte resistance. When the potential of an electrode is forced away from its value at open-circuit, the resistance caused by electrochemical reactions occurring at the electrode surface is the polarization resistance. Electrochemical Impedance Spectroscopy (EIS) is generally used to assess the contribution of various mechanisms, such as activation and mass transfer, to the total cell losses with respect to the characteristic frequency.

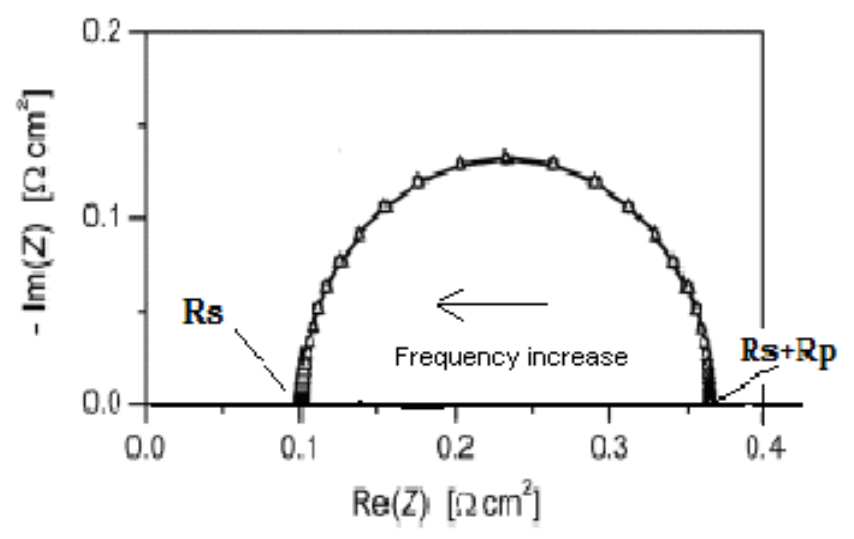

Fig.1.6: A typical EIS data graph [23]. Each point corresponds to a measurement at a single frequency. Frequencies decrease going from left to right along the arc. 


\subsection{Reference electrode for SOFC cells}

The reference electrode is a widely used electrochemistry tool. A reference electrode has a stable and well-known electrode potential. The high stability of the electrode potential is usually reached by employing a redox half-reaction with constant activities of each species of the halfreaction. [24] The most widely use for the reference electrode is as a half cell to build an electrochemical cell. This structure allows the potential of the other half cell to be determined on a thermodynamic scale. The accurate measurement of a single electrode's potential in isolation can be achieved.

In a typical 3-electrode experiment, the reference electrode (RE) is placed between the working electrode and the counter electrode (CE). The potentiostat controls the voltage between the working electrode (WE) and reference electrode (RE) while the current passes between the WE and the counter electrode (CE). Equivalently, a galvanostat controls the current between the WE and $\mathrm{CE}$ and monitors the voltage between the WE and RE. In principle, these configurations can isolate the performance of the WE from the CE and from the total performance of the cell in a typical 2-electrode experiment.

An ideal reference electrode should also have not only a well-defined and stable potential (implying the existence of a single half-reaction at the RE with constant activities of all species in the half-reaction) but also small impedance (implying fast kinetics and high activities of all species in the half reaction).

For some special SOFC configurations, for example, the microelectrodes (micro-patterned thin film electrodes fabricated by lithographic methods) on relatively thick electrolytes, isolation of one electrode's performance can be accomplished without the necessity of a reference electrode [37-40]. Because of the small size of a microelectrode (typically 30-100 $\mu \mathrm{m}$ ), the area ratio of a microelectrode and the normal size counter electrode is $10^{3}-10^{5}$. So, the electrochemical resistance of a micro working electrode is also several orders of magnitude larger than a normal size counter electrode with similar area-specific resistances (ASR) (units of ohms $\mathrm{cm}^{2}$ ). Therefore, the extended counter electrode has negligible influence on the measured polarization and impedance data. Even for the very high-performing microelectrodes with similar absolute 
resistances of the counter electrode, a reference electrode is not needed. The measured performance of the working electrode is still nearly not affected by the counter electrodes. However, this configuration does not permit the testing of SOFC designs intended for power generation.

In SOFC research, as in liquid state electrochemistry, a reference electrode is used to remove any contribution from the counter electrode to the evaluation of the working electrode. However, as the reference electrodes are built on a solid-state electrolyte, the solid state electrolyte has much lower ionic conductivity than the typical liquid solution electrolyte. Because of the lower ionic conductivity, the electrolyte is made as thin as possible between the cathode and anode. This thin layer structure leads to problems with the use of reference electrodes.

\subsection{Simulations of 3-electrode measurements}

Simulations in the literature have shown that for many electrode geometries with the reference electrode, the electrochemical measurement (polarization curve, power curve, and particularly impedance data) of the working electrode with respect to the reference electrode also includes contributions from the counter electrode [25-29]. The contribution from the counter electrode not only leads to an increased apparent resistance in the polarization curve but may also cause an additional arc in the Nyquist plot, which may misleadingly suggest an additional polarization mechanism of the working electrode [31]. More details for the above conclusions will be discussed in the following paragraphs.

In virtually all button cell designs in the literature, the reference electrode is achieved using the same half-reaction as either the cathode (oxygen reduction) or the anode (fuel oxidation). The reference electrodes are usually prepared by depositing Pt, Ag and LSM/YSZ on the electrolyte followed by sintering. The reference electrode is either directly adjacent to the WE on the surface of the electrolyte with the cathode plane (Fig 1.7a) or anode plane (Fig 1.7b), or is located on the rim of the electrolyte plane (Fig 1.7c). 


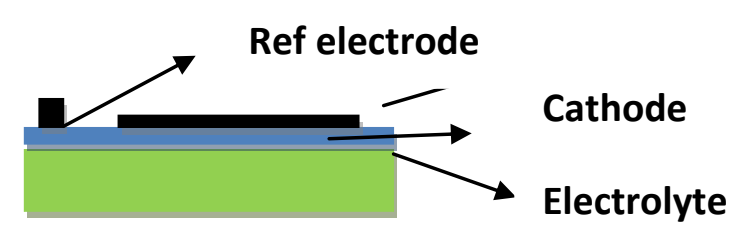

Anode

(a)

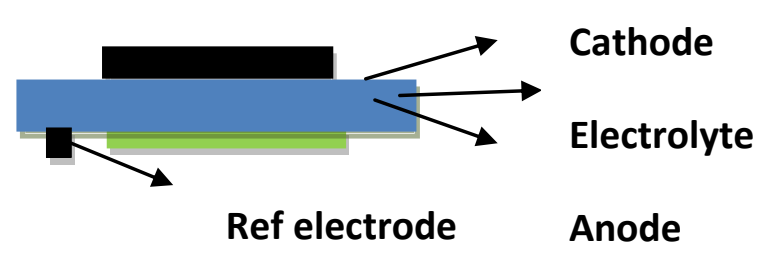

(b)

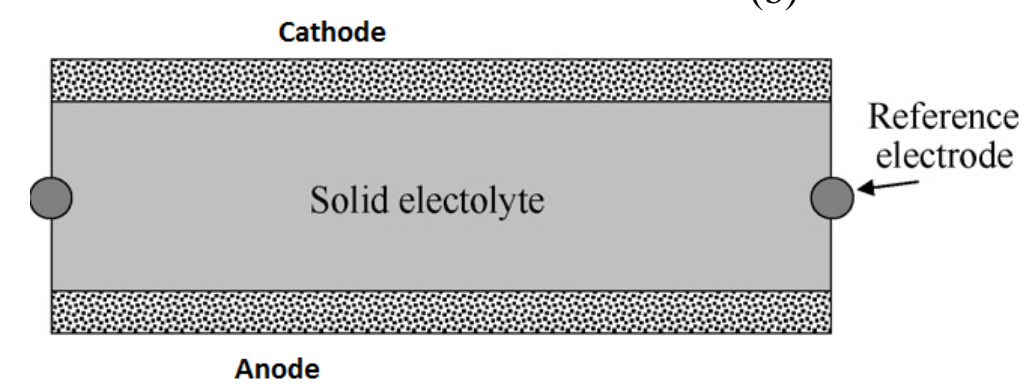

(c)

Fig 1.7: The reference electrode is near to the WE on the surface of the electrolyte with the cathode plane (Fig 1.7a) or anode plane (Fig 1.7b), or is located on the rim of the electrolyte plane (Fig 1.7c) [41]

The critical requirement for proper isolation of the WE performance is that the potential plane sensed by the RE should be located at a fixed position in the electrolyte between the WE and CE. Also, this potential plane should be independent of current density in polarization measurements and of frequency in impedance measurements. This condition is achievable in several specially designed cells. The Ris $\emptyset$ design (Fig 1.8) has pellet geometry with a large thick electrolyte between the Working electrode (WE) and Counter electrode (CE), and the point reference electrode is put very close to the WE through the thick electrolyte [41-46]. Point electrodes on thick electrolytes [47, 48] (Fig 1.9) and interdigitated WE/RE designs (stripes of the WE and RE in alternating order) $[49,50]$ (Fig 1.10) also successfully isolate the performance of the WE from the $\mathrm{CE}$. However, the proper isolation of the WE performance from the $\mathrm{CE}$ is difficult to achieve in commercially relevant SOFC designs with very thin electrolytes between the cathode and anode [51-53]. Impedance data unambiguously assignable to a cathode or anode can be obtained 
from symmetrical half-cells with the same electrode overlapped well on each side, but valid data for symmetrical cells can only be collected at open circuit voltage (OCV) $[54,55]$. Any DC current passing through a symmetrical cell alters the behavior of each electrode differently, since one electrode is functioning as a cathode and the other electrode is functioning as an anode.

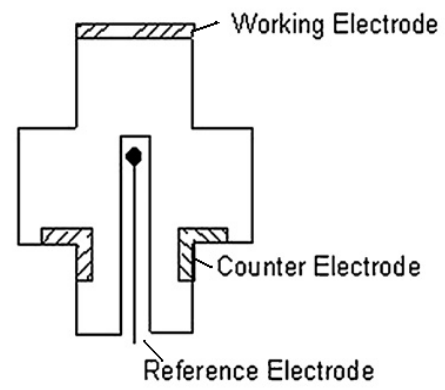

Fig 1.8: The Risø geometry design. [43]

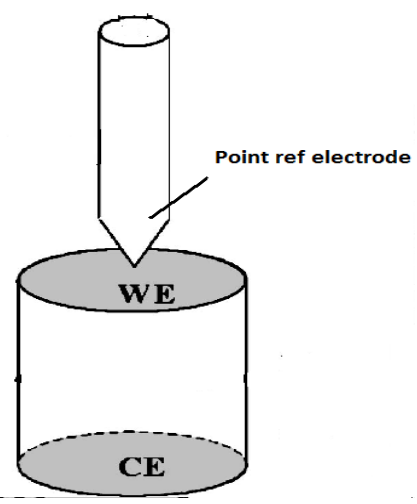

Fig 1.9: Point electrode on thick electrolyte design [47]

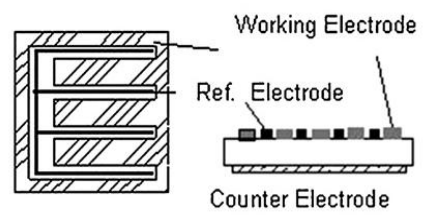

Fig 1.10: The Inter- digitated WE/RE geometry design. [49]

A number of simulations in the literature state the nature of the problem with the reference electrodes using thin electrolytes SOFC.[56-62] In the electrolyte-supported design, the anode and cathode are typically aligned across the electrolyte, and the reference electrode is placed many electrolyte thicknesses away from the edge of the WE electrode on the same side. Several 
papers [57-59, 63] show that the potential distribution in the solid electrolyte changes with varying frequencies, causing distortions in the impedance measured using the 3-electrode method. If one electrode is displaced nearer to the reference electrode by even a fraction of the electrolyte thickness, then the simulations obtained for the primary (infinite frequency) and secondary (zero frequency) potential distributions in a thin planar cell demonstrate that the potential plane sensed by the reference electrode penetrates into the nearer electrode [Fig 1.11]. For example, if the reference electrode is on the same side as the WE and the CE electrode is closer to the RE, then a 3-electrode measurement, either polarization or impedance, contains the performance of both the $\mathrm{WE}$ and the $\mathrm{CE}$, causing significant errors in the measured polarization resistance and impedance of the WE. More subtly, even when the cathode and anode are in perfect alignment, if the time constants (equivalently, the peak frequencies) and/or polarization resistances of the cathode and anode are different, the simulations again show that the 3 -electrode measurement causes the cross-contamination of the electrodes impedance and fails to isolate the performance of the WE from the CE [Fig 1.11]. This situation results in the distortion present in the impedance of the electrodes and apparent inductance loops in the Nyquist plots at either the high frequency or low frequency limits $[59,60,62][$ Fig 1.12].The reason for the artifacts is that the equipotential line sensed by the RE changes with frequency.

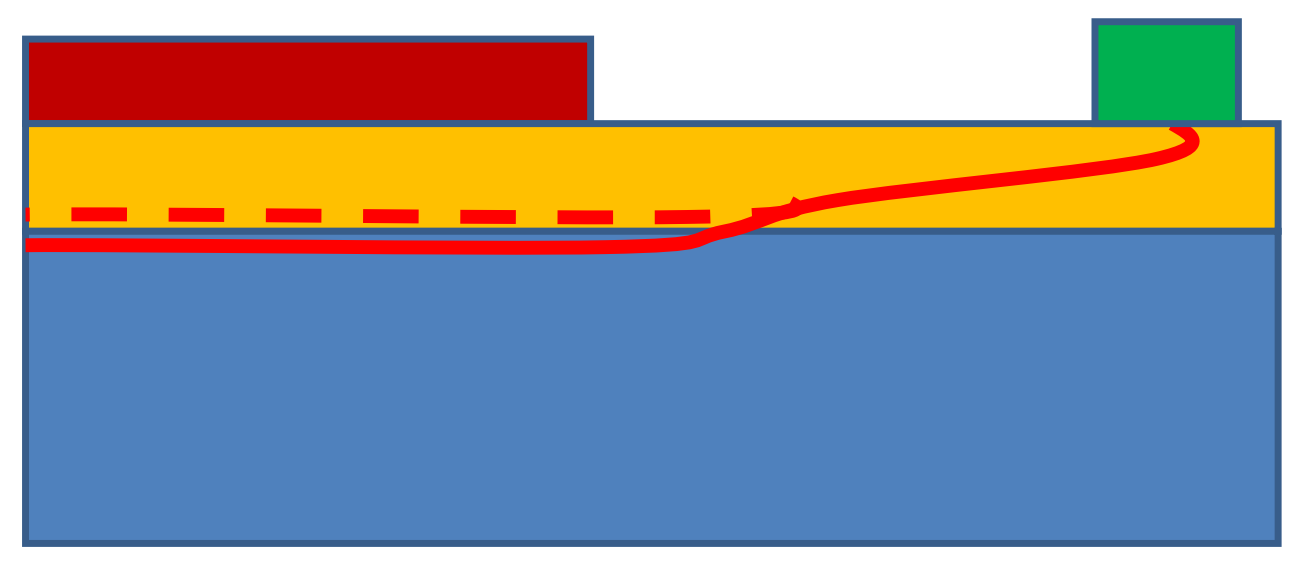

Fig 1.11: Equipotential line (red) probed by the reference electrode at zero (solid line) and infinity (dashed line) frequencies. Blue - anode; gold - electrolyte; red - cathode; green - ring reference electrode. The left border is the center of the cell. 

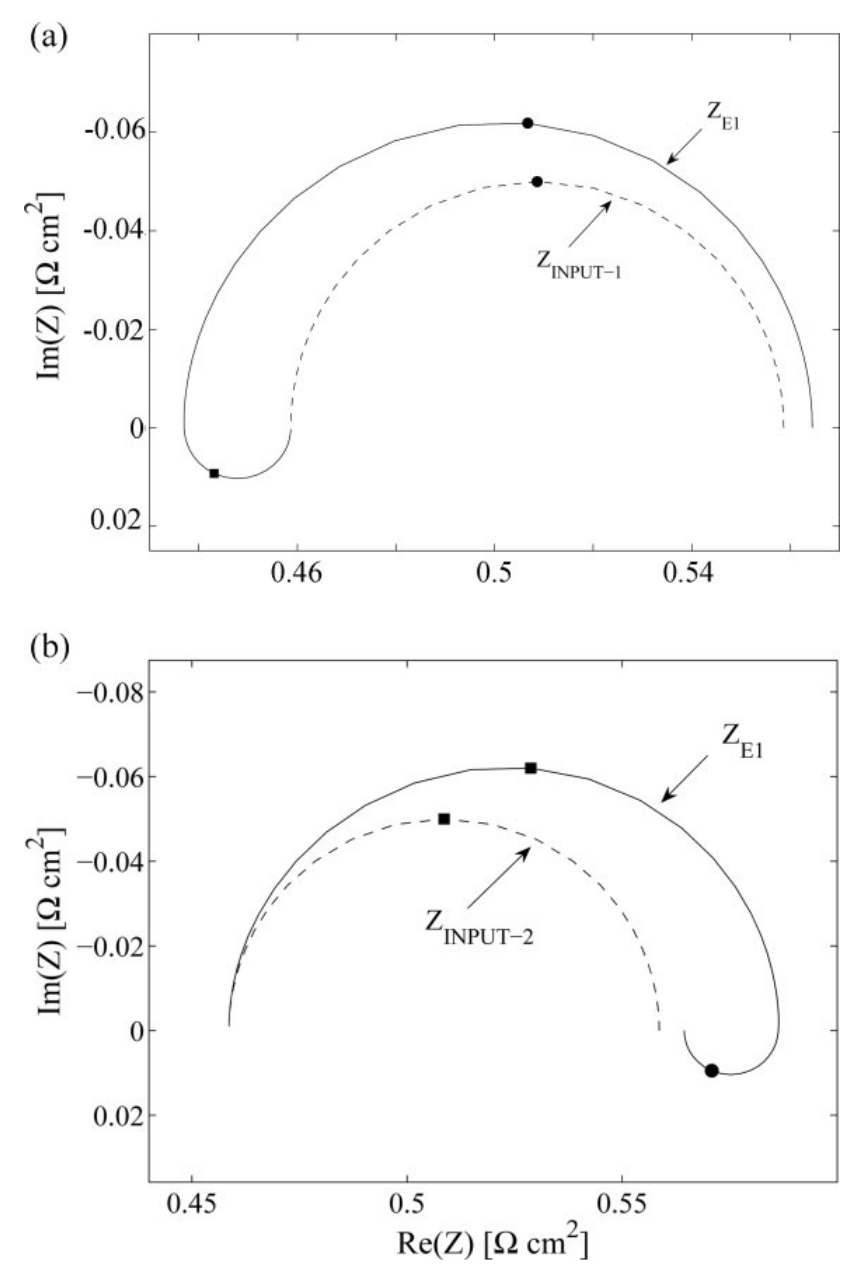

Fig 1.12: The simulation Nyquist plot from Cimenti's paper showing the Nyquist plot for cathode electrode E1 (Input $\mathrm{Rp}=0.1 \mathrm{ohms}$, Peak frequency $10^{2} \mathrm{~Hz}$ ) (a) and anode electrode E2 (Input Rp=0.1 ohms, Peak frequency $10^{5} \mathrm{~Hz}$ ) (b). The markers indicate the peak frequency of $10^{2}$ $\mathrm{Hz}$ for electrode E1 (circle) and peak frequency of $10^{5} \mathrm{~Hz}$ for electrode E2 (square).The high frequencies inductive loop for electrode E1 and at low frequencies inductive loop for E2 are artifacts. (Dashed line shows the actual input area-specific impedance and the solid line shows the apparent area-specific impedance by 3 -electrode measurement). [62]

The anode-supported configuration (See Fig 1.1(c)) requires that the RE to be located opposite the anode. This configuration was simulated by McIntosh and coworkers [60].The simulations demonstrate the inefficacy of the RE when using the 3-electrode configuration to characterize anodes in anode-supported cells. The simulated 3-electrode impedance spectrum (WE = cathode, $\mathrm{CE}=$ anode) closely matches the simulated 2-electrode impedance spectrum (cathode vs anode), and the simulated 3-electrode impedance spectrum with the anode as the WE $(\mathrm{CE}=$ cathode $)$ ) yields an apparent polarization resistance nearly a hundred-fold smaller than the true value. The 
potential line sensed by the RE is non-uniform with respect to the electrolyte volume (Fig 1.13) and at high frequencies extends to the anode/electrolyte interface, so the impedance assigned to the cathode contains contributions from the anode. The simulation is in agreement with experimental impedance data from an anode-supported cell. Simulations by Cui et al. [64] also demonstrate that the measurement of overpotential (polarization losses at the electrodes) for a reference electrode on an anode-supported cell is "essentially meaningless".

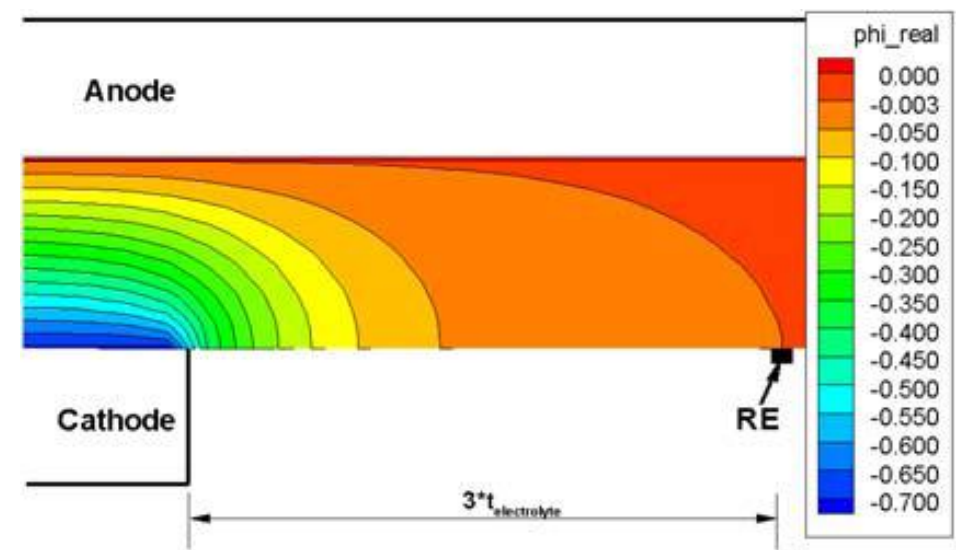

Fig 1.13: The distribution of electric potential near the edge of cathode; the reference electrode is located at bottom right of the electrolyte $\left(x_{R E}=3\right.$ telectrolyte). [65]

More recently, Escobar et al. [65] simulated the impedances of anode-supported cells in which the anode and cathode had different polarization resistances but identical time constants. The simulations indicated that a micro-reference electrode placed very close to the cathode (within a fraction of the electrolyte thickness) would yield relatively accurate polarization resistances for the cathode. However, on an anode-supported cell with very thin electrolyte on the order of 10 microns, such a reference electrode geometry would be impossible, or, at best, extremely difficult to achieve in experiments. However, the authors suggest a correction method by using a reference electrode at a fixed distance (5 electrolyte thicknesses in the simulations), which yields data that could be converted to reasonably accurate polarization resistances through parametric equations derived from the simulations to calculate from apparent resistance. The simulations did not check for the presence of inductive loop artifacts in the impedance spectra as the time constants (peak frequencies) of the cathode and anode are identical. A hidden assumption in the simulation is that the radial width of the reference electrode must be smaller than the electrolyte thickness. However, such micro-reference electrodes will have large impedances, which can lead 
to instrumental artifacts in impedance measurements due to the voltage divider effect when the reference electrode impedance approaches the analyzer input impedance. These artifacts and distortions show up in the Nyquist plot as a capacitive arc and an inductive loop. These distortions can be avoided by using a lower impedance reference electrode or employing an analyzer with higher input impedance. A correction procedure is also available [66-68].

In summary, there are multiple simulations in the literature that reveal the problem with reference electrodes in SOFC cells with thin electrolytes. However, there is little experimental demonstration of the problem, and, judging by recent references [60, 64], many researchers continue to publish data on button cells based on one electrode with respect to a reference electrode.

\subsection{Aging effects of cells - lifetime of SOFCs in power generation}

While the SOFCs are operated at aggressively high operating temperatures, which offer more fuel flexibility and tolerance for fuel contaminants compared to other types of fuel cells, the high temperatures also cause cell material degradation and affect the cell lifetime. Long-term stability is an important requirement for the application of SOFC technology. The US Department of Energy's (DOE) target requirements for SOFCs are 40,000 hours of service for stationary fuel cell applications and greater than 5,000 hours for transportation systems (fuel cell vehicles) at a factory cost of $\$ 400 / \mathrm{kW}$ for a $10 \mathrm{~kW}$ coal-based system without additional requirements. The Solid State Energy Conversion Alliance 2008 target for overall degradation per 1,000 hours is 4.0\%.[69]. Consequently, the lifetime effects including the phase stability, thermal expansion compatibility, element migration and aging effects must be addressed. [70].

For conventional SOFC cells, especially anode-supported SOFCs, the anode layer is the mechanical support for the electrolyte and cathode. Structural integrity of the SOFC anode is needed for successful long-term operation. The anode layer is inherently susceptible to mechanical failure when subjected to moderate stresses [71]. The stress may arise from thermal stress due to the coefficient of thermal expansion mismatch and external mechanical loading $[72,73]$. Also, the dimensional structure and microstructure of the anode could change upon 
redox cycling of the cell (shutting off the cell and exposing the anode to air, then re-reducing the anode in hydrogen), which also generate internal stresses in the anode and other cell components.[74] Another possible cause of the anode degradation is the effect of contaminants (e.g., compounds containing P, S, and As) in the fuel gases. These contaminants are suspected to interact with the SOFC anode material and to induce degradation in electrochemical performance and structural properties during long-term operation $[75,76]$.

The SOFC cathode is the place for reduction of oxygen to an ionic form which is then transported across the gas-impermeable electrolyte membrane. Electrochemical oxygen reduction process is sensitive to the changes in material composition and physical structure of the cathode, so the cathodes are particularly subject to degradation processes. Within the cathode, the fundamental processes of degradation include morphological evolution of LSM, cation migration and secondary phase evolution. [76]. Degradation can occur by the continual formation of lanthanum zirconate and strontium zirconate secondary phases at the cathode perovskite/YSZ electrolyte interface as a function of time or current density. [77,78]. Also, the impurity chromium from the interconnect in SOFC stacks is clearly linked to degradation.[79]

In particular, one phenomenon of degradation was noticed as a temporally changing polarization resistance over tens of hours in an unpolarized cell in response to thermal perturbation. We explored this phenomenon via electrochemical techniques, with the purpose to discover the true physical source associated with it (Chapter 5). The full understanding of this degradation is needed in order to generate a unified picture of cathode degradation that is relevant to SOFC research and the application of SOFCs to large scale energy conversion. Because in practical operation the cells are often held at open circuit or lower overpotentials for long periods of time (off peak hour cycling), this degradation must also be accounted for commercial SOFC systems. 


\subsection{Polarization of the SOFC cells}

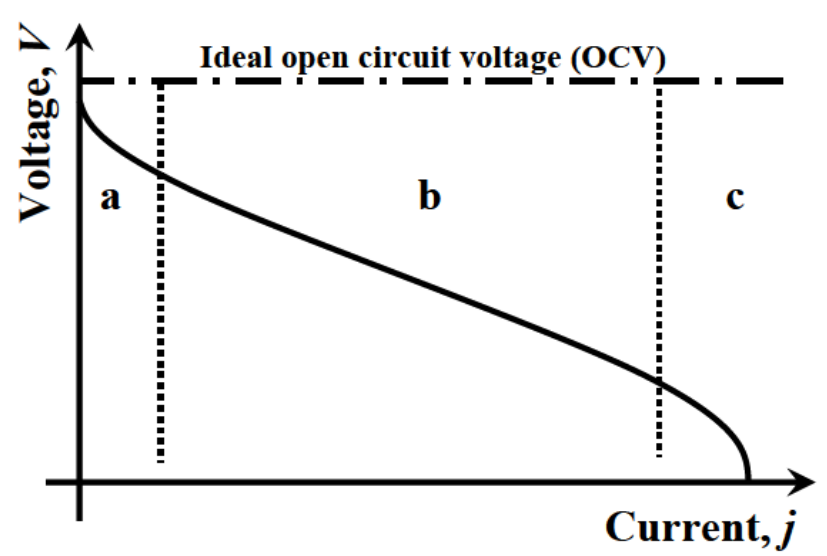

Fig 1.14: graph of the voltage drop of SOFC as a function of current density (a) low current range, (b) medium current range, and (c) high current range.

As shown in Fig 1.14, several sources of voltage loss in SOFCs make the cell voltage deviate away from reversible cell voltage at ideal open air condition. The reversible cell voltage (Nernst potential) is given by $V_{\text {rev }}=-\Delta G / n F$, where $\Delta G$ is the free energy of the global oxidation reaction in SOFC. The internal voltage losses (overpotentials) of SOFCs include ohmic losses and nonohmic losses. The ohmic losses (IR drops) shown in Fig 1.14 (b) range are caused by the series resistances of the electrolyte, anode, and cathode, and the two latter resistances are negligible in real SOFCs. Non-ohmic losses result from all the physical and chemical processes taking place on cathode and anode, and also called overpotential losses, shown in Fig 1.14 (a) (c) ranges. Different chemical and physical processes dominate the loss in different current ranges.

Figure 1.14 shows how the cell polarization changes with the current density. In the low current range (Fig 1.14(a)), the current is affected by all the reactions at the electrodes that limit the electrochemical conversion in the SOFC, including Dissociative adsorption of oxygen and hydrogen, Electrochemical process on the anode surface and at three-phase boundary (TPB) and Charge-transfer at TPB. The Charge-transfer reaction losses at TPB mostly dominate the power losses. These power losses are referred to as activation overpotential and change largely with temperature. In the medium current region (Fig 1.14(b)), the activation overpotential losses decays exponentially and the ohmic drop (IR) begins to dominate the polarization curve. The linear pure ohmic drop is caused by the low ionic conductivity of the electrolyte. In the high current region (Fig 1.14(c)),non-ohmic loss is due to the presence of concentration gradients in 
the porous electrode structures. This area of overpotential is dominated by mass transport processes of reactants and products. Specifically, it includes the surface diffusion of adsorbed fuel species and water on the SOFC anode surface and surface diffusion of adsorbed oxygen species on the SOFC cathode surface, and gas-phase diffusion of hydrogen in the anode and gasphase diffusion of oxygen in the cathode. 


\subsection{References}

[1] Baur, E.; Preis, H. Zeitschrift für Elektrochemie. 1937, 43, 727-732.

[2] Ormerod, R.M. Chem. Soc. Rev. 2003, 32, 17-28.

[3] Bessler, W.G. J. Electrochem. Soc. 2007, 154, 548-559.

[4] Kostogloudis, G.C.; Tsiniarakis, G.; Ftikos, C. Solid State Ionics. 2000, 135, 529-533.

[5] Adler, S.B. Chem. Rev. 2004, 104, 4791- 4843.

[6] Adler, S.B.; Henderson, B.T.; Wilson, M.A.; Taylor, D.M.; Richards. R.E. Solid State Ionics. 2000, 134, 35-39.

[7] Stuart B. Adler Chem. Rev. 2004, 104, 4791-4843.

[8] Hibino, T.; Hashimoto, A.; Inoue, T.; Tokuno, J.; Yoshida, S.; Sano M. Science. 2000, 288, 2031-2037.

[9] Wang, S.Z.; Zou, Y.M. Electrochem Comm. 2006, 8, 927-933.

[10] Adler, S.B.; Lane, J.A.; Steele. B.C.H. J. Electrochem. Soc. 1996, 143, 3554-3559.

[11] Adler, S.B. Solid State Ionics. 1998, 111, 125-129.

[12] Steele, B.C.H.; Heinzel, A. Nature. 2001, 414, 345-348.

[13] Xia, C.; Rauch, W.; Chen, F.; Liu, M. Solid State Ionics 2002, 149, 11-17.

[14] Liliya, A.; Dunyushkina, S.; Adler, B. J. Electrochem. Soc. 2005,152, 2040-2045.

[15] Zha, S.; Rauch, W.; Liu, M. Solid State Ionics. 2004, 166, 241-244.

[16] Jiang, S.P.; Wang, W. Solid State Ionics 2005, 176, 1351-1357.

[17] Shao, Z.P.; Haile, S.M. Nature. 2004, 431, 170-175.

[18] Hibino, T.; Hashimoto, A.; Inoue, T.; Tokuno, J.; Yoshida, S.; Sano. M. Science. 2000, 288, 2031-2034.

[19] Wang, S.Z.; Zou, Y.M. Electrochem.Commun. 2006, 8, 927-932.

[20] Kharton, V.V.; Li, S.B.; Kovalevsky, A.V.; Naumovich, E.N. Solid State Ionics. 1997, 96, 141-146.

[21] Ma, B.; Balachandran, U. Solid State Ionics. 1997, 100, 53-58.

[22] Minh, N.Q; Takahashi, T. Science and Technology of Ceramic Fuel Cell; Elsevier Science B. V.: Amsterdam, 1995. 
[23] Bessler, W.G. J. Electrochem. Soc. 2007, 154, B548-B559.

[24] Bard, A.J.; Faulkner, L.R. Electrochemical Methods: Fundamentals and Applications, 2nd ed. John Wiley and Sons: New York, NY, 2001.

[25] Adler, S.B.; Henderson, B.T.; Wilson, M.A; Taylor, D.M.; Richards, R.E. Solid State Ionics. 2000, 134, 35-39.

[26] Winkler, J.; Hendriksen, P.V.; Bonanos, N.; Mogensen, M. J. Electrochem. Soc. 1998, 145, 1184-1193.

[27] Adler, S.B. J. Electrochem. Soc. 2002, 149, E166-E172.

[28] Pham, A.I.; Glass, R.S. Mat. Res. Soc. Symp. Proc. 1996, 411, 237-242.

[29] Hsieh, G.; Mason, T.O.; Garboczi, E.J.; Pederson, L.R. Solid State Ionics.1997, 96, 153-159.

[30] Adler, S.B. Chem. Rev. 2004, 104, 4791-4843.

[31] Fleig, J. Апnи. Rev. Mater. Res. 2003, 33, 361-382.

[32] Jiang, S.P. J. Mater. Sci. 2004, 39, 4405-4439.

[33] Jiang, S.P. J. Mater. Sci. 2008, 43, 6799-6833.

[34] Atkinson, A.; Barnett, S.; Gorte, R.J.; Irvine, J.T.S.; Mcevoy, A.J.; Mogensen, M.; Singhal, C.; Vohs, J. Nature Mater. 2004, 17, 1-11.

[35] Sun, C.; Hui, R.; Roller. J. J. Solid State Electrochem. 2010, 14, 1125-1144.

[36] Jørgensen, M.J.; Mogensen, M. J. Electrochem. Soc. 2001, 148, A433-A442.

[37] Fleig, J. Solid State Ionics. 2003, 161, 279- 289.

[38] Fleig, J.; Baumann, F.S.; Brichzin, V.; Kim, H.R.; Jamnik, J.; Cristiani, G.; Habermeier, H.U.; Maier, J. Fuel Cells. 2006, 6, 284-292.

[39] Baumann, F.S.; Fleig, J.; Habermeier, H.U.; Maier, J. Solid State Ionics. 2006, 177, 10711081.

[40] Baumann, F.S.; Fleig, J.; Cristiani, G.; Stuhlhofer, B.; Habermeier H.U.; Maier, J. J. Electrochem. Soc. 2007, 154, B931-B941

[41] Ostergard M.J.L.; Mogensen, M. Electrochimica Acta. 1993, 38, 2015-2020.

[42] Ostergard, M.J.L.; Clausen, C.; Bagger, C.; Mogensen, M. Electrochimica Acta. 1995, 40, 1971-1981.

[43] Winkler, J.; Hendriksen, P.V.; Bonanos, N.; Mogensen, M. J. Electrochem. Soc. 1995, 145, 2431-2439. 
[44] Jørgensen, M.J.; Primdahl, S.; Mogensen, M. Electrochimica Acta. 1999, 44, 4195-4201.

[45] Brown, M.; Primdahl, S. Mogensen, M. J. Electrochem. Soc. 2000, 147, 475-485.

[46] Jørgensen M. J.; Mogensen, M. J. Electrochem. Soc. 2001, 148, A433-A442.

[47] Esquirol, A.; Brandon, N.P.; Kilnerand J.A.; Mogensen. M. J. Electrochem. Soc. 2004, 151, A1847-A1855.

[48] Hansen, K.V.; Norrman K.; Mogensen, M. J. Electrochem. Soc. 2004,151, A1436-A1444.

[49] Hashibon, A.; Raz, S.; Riess, I. Solid State Ionics. 2002, 149, 167- 176.

[50] Dunyushkina, L.A.; Lu, Y.; Adler, S.B. J. Electrochem. Soc. 2004, 152, A1668-A1676.

[51] Rutman, J.; Riess, I. Electrochimica Acta. 2007, 52, 6073-6083.

[52] Offer, G.J.; Shearing, P.; Golbert, J.I.; Brett, D.J.L.; Atkinson, A.; Brandon, N.P. Electrochimica Acta. 2008, 53, 7614-7621.

[53] Brett, D.J.L.; Kucernak, A.R.; Aguiar, P.; Atkins, S.C.; Brandon, N.P.; Clague, R.; Cohen, L. F.; Hinds, G.; Kalyvas, C.; Offer, G.J.; Ladewig, B.; Maher, R.; Marquis, A.; Shearing, P.; Vasileiadis, N.; Vesovic, V. Chem Phys. 2010, 11, $2714-2731$.

[54] Jørgensen, M.J.; Primdahl, S.; Mogensen, M. Electrochimica. Acta. 1999, 44, 4195-4201.

[55] Jørgensen, M.J.; Mogensen, M. J. Electrochem. Soc. 2001, 148, A433-A442.

[56] Chan, S.H.; Chen, X.J.; Khor, K.A. J. Appl. Electrochem. 2001, 31, 1163-1170.

[57] Winkler, J.; Hendriksen, P.V.; Bonanos, N.; Mogensen, M. J. Electrochem. Soc. 1998, 145, 1184-1193.

[58] Adler, S.B.; Henderson, B.T.; Wilson, M.A.; Taylor, D.M.; R.E. Solid State Ionics. 2000, $134,35-42$.

[59] Adler, S.B. J. Electrochem. Soc. 2002, 149, E166-E172.

[60] McIntosh, S.; Vohs, J.M.; Gorte. R.J. J. Electrochem. Soc. 2003, 150, A1305-A1312.

[61] Cimenti, M.; Co, A.C.; Birss, V.I.; Hill, J.M. Fuel Cells. 2007, 7, 364-376.

[62] Cimenti, M.; Birss, V.I.; Hill. J.M. Fuel Cells. 2007, 7, 377-391.

[63] Reinhardt, G.; Göpel, W. Ionic and Mixed Conducting Ceramics, 3rd ed.; Paris, 1997; pp. 610.

[64] Cui, D.; Yang, C.; Huang, K.; Chen, F. Int. J. Hydrogen Energy. 2010, 35, 10495-10504.

[65] Escobar, J.A.; Pakalapati, S.R.; Celik, I.B.; Finklea, H. ECS Transactions. 2009, 25, 391400. 
[66] Vanysek, P. ECS Transactions. 2008, 13, 101-113.

[67] Hsieh, G.; Ford, S.J.; Masona, T.O.; Pedersonb, L.R. Solid State Ionics. 1996, 91, 191-201.

[68] Hsieh, G.; Masona, T.O.; Pedersonb, L.R. Solid State Ionics. 1996, 91, 203-212.

[69] SECA-Coal and Power Systems. Http://netl.doe.gov (Accessed Nov 27, 2011).

[70] Stambouli, A.B.; Traversa, E. Renewable and Sustainable Energy Reviews. 2002, 6, 433455.

[71] Li, W.; Hasinska, K.; Seabaugh, M.; Swartz S.; Lannutti, J. J. Power Sources 2004, 138, 145-155.

[72] Laurencin, J.; Morel, B.; Bultel, Y.; Lefebvere-Joud, F. Fuel Cell 2006, 6, 64-70.

[73] Iqbal, G.; Guo, H.; Kang, B. Int. J. Appl. Ceram.Technol. 2011, 8, 13-22.

[74] Laurencin, J.; Morel, B.; Bultel, Y.; Lefebvere-Joud, F. Fuel Cell. 2006, 6, 64-70.

[75] Cayan, F.N.; Zhi, M.; Pakalapati, S.R.; Celik, I.; Wu, N.; Gemmen, R. J. Power Sources. 2008, 185, 595-602.

[76] Murata, K.; Shimotsu, M. Electrochem. 1999, 67, 789-791.

[77] Primdahl, J.; Mogensen, S. J. Appl. Electrochem. 2000, 30, 247-250.

[78] Lee, H.Y.; Oh, S.M. Solid State Ionics 1996, 90, 133-135.

[79] Badwal, D.; Deller, S.; Foger, R.; Ramprakash, K.; Zhang, Y. Solid State Ionics 1997, 99, 297-299. 


\section{Chapter 2: Deconvolution and complex nonlinear regression fitting of equivalent circuits-general information and equations}

As discussed in section 1.2.3 for most widely used commercial button cell designs (anodesupported and electrolyte supported cells), several simulation papers show the inability of reference electrodes to isolate the performance (polarization curve or impedance) of a single electrode in these two types of button SOFCs. The simulations predict that the impedance measurements of the working electrode versus a reference electrode in a 3-electrode configuration are inevitably contaminated with impedance of the counter electrode. In certain cases, inductive loop artifacts appear at the high or low frequency extremes in 3-electrode impedance measurements. For the same reasons, polarization curves of a single electrode (potential or overpotential vs current) are inaccurate. An independent method to obtain the polarization/impedance of single electrode using 2-electrode impedance measurements is needed. In this chapter, the deconvolution method will be introduced, through deconvolution and fitting the impedance to the equivalent circuit, the components at different frequency range in impedance spectra can be assigned to the cathode and the anode.

\subsection{Current State of deconvolution field}

Ivers-Tiffee and co-workers first developed the deconvolution method (also known as the distribution of relaxation times) [1] for identifying key relaxation times (alternately, peak frequencies) in impedance spectra. The information of key frequencies can be used to design relevant equivalent circuit models for the cell impedance. Then, using the complex nonlinear regression, fitting of the equivalent circuit parameters to the impedance data yields polarization resistances associated with the cathode and the anode. This deconvolution approach uses the distribution of relaxation times to increase the frequency resolution of impedance spectra, so it allows the identification and separation of impedance features. This approach has been applied to several types of commercially relevant cells [2-13]. 
Bessler summarizes the concerns about using equivalent circuits to analyze the impedance of SOFCs [14]. It is difficult to unambiguously prove a connection between physical processes and impedance elements because of several reasons: Different physical processes may result in similar impedance features, and a single physical process can transform into multiple impedance elements. Impedance of some physical processes may be masked by impedances overlapping from different processes. Consequently, equivalent circuit models are ambiguous. So it is difficult to prove a clear connection between physical processes and impedance elements. However, the minimum number of arc-forming elements that must exist in the equivalent circuit (representing the number of processes) could be indicated from the deconvolution spectrum. By changing the gas composition to the anode or cathode, certain peak frequencies in the impedance spectra and equivalent circuit elements can be strongly affected, so these processes can be assigned to the cathode or the anode. The analysis also helps to identify which electrode and equivalent circuit elements contribute mainly to the total impedance, and thus provide guidance on how to improve the SOFC. Consequently, this deconvolution method is very promising to obtain the separated polarization / impedance behavior of each electrode.

\subsection{Principles of deconvolution}

Based on Schichlein et al. [15], the methodology of deconvolution is based on the following equations. Equation [2.1] shows a convolution equation that connects the distribution of relaxation times to the observed impedance spectrum, where $\gamma(\tau)$ is the distribution of relaxation times, $\tau$ is the time constant, $\omega$ is the radial frequency $(2 \pi \mathrm{f}), j$ is the square root of $-1, Z(\omega)$ is the impedance data, $R_{0}$ is the ohmic (frequency-independent) impedance, $Z_{\text {pol }}(\omega)$ is the polarization part, and $\mathrm{R}_{\mathrm{pol}}$ is the polarization resistance of the impedance.

$$
Z(\omega)=R_{0}+Z_{\text {pol }}(\omega)=R_{0}+R_{\text {pol }} \int_{0}^{\infty} \frac{\gamma(\tau)}{1+j \omega \tau} d \tau \quad \text { with } \int_{0}^{\infty} \gamma(\tau) d \tau=1
$$

Figure 2.1 shows the interpretation of EIS data in terms of (a) equivalent circuit models and (b) distributions of relaxation times on a $\ln (\tau)$ scale (also known as deconvolution spectra). Any 
fundamental impedance can be transformed into the corresponding equivalent circuit model. Dynamic processes are represented in the distribution by the peaks at the corresponding relaxation time. This observation implies that the area under a peak equals the total polarization resistance of the respective dynamic process.

(a)
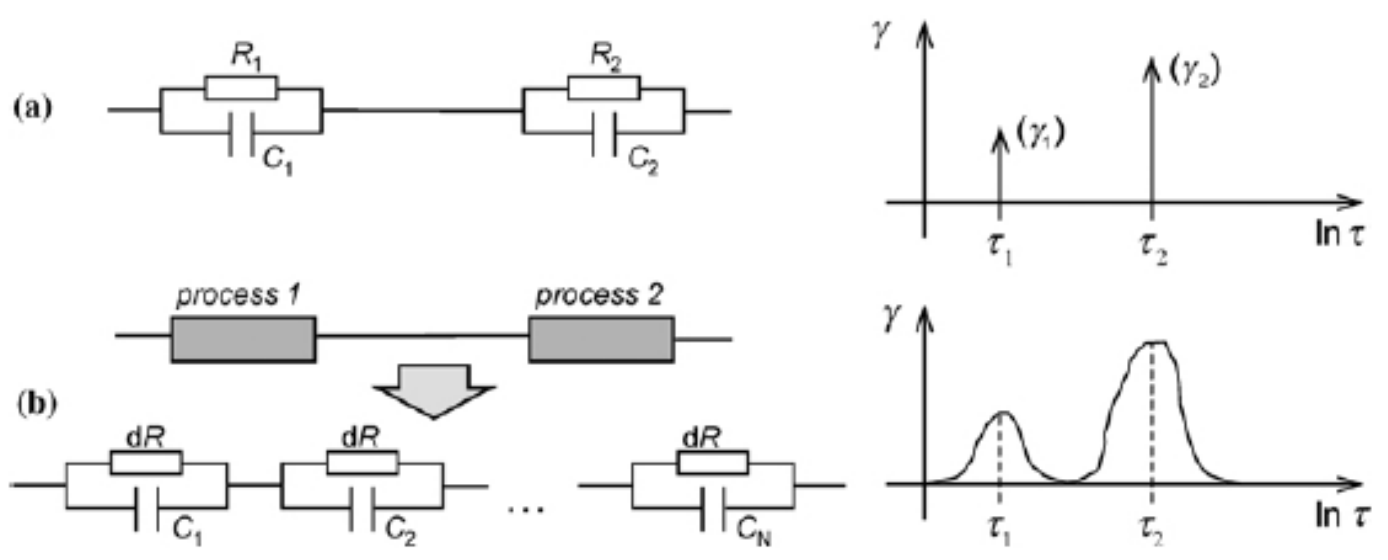

Figure 2.1: (a) On the left, the equivalent circuit consisting of two parallel resistance/ capacitance combinations (RC elements) in series. On the right, the corresponding deconvolution spectrum showing two lines at the time constants of each RC element. (b) On the left, two processes, each with a distribution of RC elements with slightly different time constants. On the right, the corresponding deconvolution spectrum showing peaks with finite widths centered at the average time constants.

To obtain $\gamma(\tau)$ from $\mathrm{Z}_{\mathrm{pol}}(\omega)$ in the form of a convolution product, it is sufficient to consider only the imaginary part of impedance Z" (out-of-phase impedance) because the real and imaginary parts of impedance data are from a linear and time- invariant system and are connected by the Kramers-Kronig transformations. Since the impedance is typically measured at equal intervals of $\log (\mathrm{f})$, the frequency variables could be converted in the integral as follows: $\mathrm{x}=\ln \left(\omega / \omega_{0}\right), \mathrm{y}=$ $\ln (\mid \omega \tau)$.

$$
\begin{gathered}
\operatorname{Im}\left\{Z_{\text {pol }}(\omega)\right\}=Z^{\mathrm{\prime}}(\omega)=-R_{\text {pol }} \int_{0}^{\infty} \frac{\omega \tau}{1+(\omega \tau)^{2}} \gamma(\tau) d \tau \\
Z^{\mathrm{\prime}}(\omega)=-\frac{R_{\text {pol }}}{2} \int_{-\infty}^{\infty} \operatorname{sech}(y) g(y-x) d y
\end{gathered}
$$

With 


$$
\operatorname{sech}(y)=\frac{2}{e^{y}+e^{-y}} ; g(y-x)=\gamma(\tau) \tau
$$

Equation 2.3 has the form of a convolution integral. After discrete Fourier transformation, the convolution integral is converted into an algebraic product in transformed space (Equation. 2.5). The strategy is to use the Fourier transform to convert $Z$ " into its Fourier transform $Z_{n}$ and the $\operatorname{Sech}(y)$ function into its Fourier transform $S_{n},\left(\right.$ Fig 2.2) and then divide each element of $Z_{n}$ by the corresponding $S_{n}$ element to get the Fourier coefficient of $g_{n . .}$ Then the $g_{n}$ coefficients are subjected to the inverse Fourier transform to get the desired relaxation time distribution $\left\{g_{k}\right\}$ (the coefficients at each frequency). Due to numerical error amplification (see Fig. 2.2), $g_{n}$ diverges over a range of frequencies resulting in meaningless results. Therefore, prior to the inverse transform, $\mathrm{g}_{\mathrm{n}}$ must be attenuated at the higher frequencies using a digital filter, with all the data points within a certain range set to zero. After filtering, inverse Fourier transformation gives the desired distribution $\left\{\mathrm{g}_{\mathrm{k}}\right\}$ (Fig 2.3).

$$
Z_{n}=-N T \frac{R_{p o l}}{2} g_{n} \times S_{n}
$$

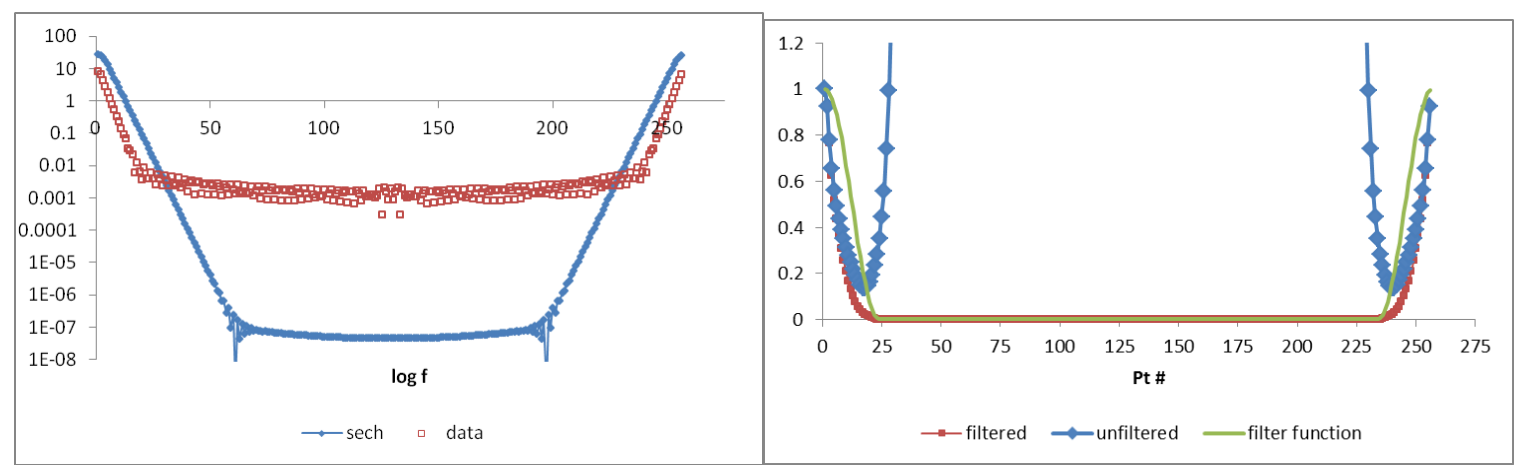

Fig 2.2: Filtering of the FFT g coefficients. On the left, the magnitude of the Fourier transform of Z" data and the sech function with respect to frequency are shown. On the right are shown the unfiltered FFT g coefficients (blue diamonds), the Hahn filter function (green line), and the product of the filter function and $\mathrm{g}$ coefficients. The product is subjected to the inverse FFT operation to generate the deconvolution spectrum. 


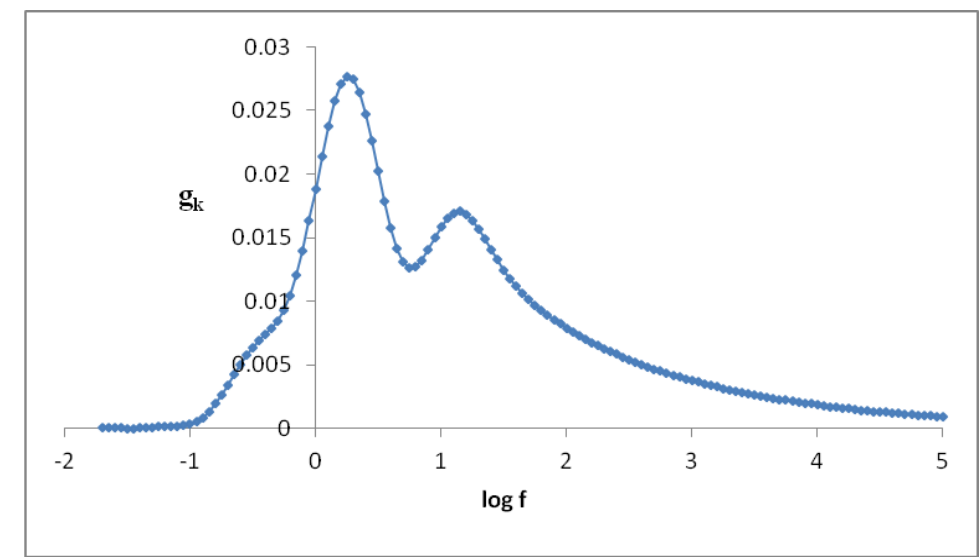

Fig 2.3: Distribution function the final $g_{k}$ after the inverse Fourier transform calculated from experimental impedance data of the anode supported cell.

\subsection{The procedures for deconvolution}

The general deconvolution steps are summarized as following:(a) processing the out-of-phase impedance Z" to remove inductance, (b) applying the Fast Fourier Transform (FFT) to the Z" vs frequency data set, (c) dividing each element of the Z" transform $\left(z_{n}\right)$ by the equivalent FFT element of the hyperbolic secant function $\left(s_{n}\right)$ and obtaining the dividend $\left(g_{n}\right)$, (d) filtering the dividend $\left(\mathrm{g}_{\mathrm{n}}\right)$ to remove high frequency noise, and (e) performing the inverse FFT to produce the deconvolution spectrum $\left\{\mathrm{g}_{\mathrm{k}}\right\}$. All calculations are performed in an Excel spreadsheet after importing the Z" data.

The detailed procedures for applying the deconvolution to our data is as following: The data for deconvolution are collected from $100 \mathrm{kHz}$ to $0.1 \mathrm{~Hz}$ or $0.02 \mathrm{~Hz}$ with 10 even log frequency steps per decade. The data is noise-free or low noise. The out-of-phase impedance Z" should be approaching zero at both the high and the low frequency limits. At the high frequency limit, the data always show the inductance. At the low frequency limit, for some tests, as Z" was not approaching zero at $0.1 \mathrm{~Hz}$, the re-collected impedance data reached a lower limit of $0.02 \mathrm{~Hz}$ to obtain the adequate frequency limit. Another problem is that sometimes an oscillation showed up on the OCV with time periods on the order of a few seconds, which makes the low frequency data noisy. The cause of the oscillations is usually liquid water in the anode or possibly the cathode exhaust line. Although such low frequency noise is small, it may be amplified after 
deconvolution and form false peaks. So processing of the impedance data before deconvolution is needed.

There are three steps for data processing. First, the effects of inductance are removed. Second, the data are extrapolated from $\log \mathrm{f} 5 \mathrm{up}$ to $\log \mathrm{f} 8.4$ and from $\log \mathrm{f}-1.7$ to $\log \mathrm{f}-4.35$. The purpose of extrapolation is to create a data file with 256 points needed for the Fast Fourier Transform (FFT), to ensure that the end points at the high and low frequency limits are close to zero and to ensure that the collected impedance data is in the central range of the frequencies. In the process of extrapolation, the data are also interpolated with extra data points at $0.05 \log \mathrm{f}$ units to improve frequency resolution in the deconvolution spectra. Third, the data is smoothed to avoid large transients in the deconvolution spectrum.

The first step is to correct for the inductance (and parallel resistance) at the high frequency limit. An artifact due to inductive effects from the measurement of the wires always shows up. For the out-of-phase impedance Z" (Fig 2.4), the inductance L is removed according to Equation. 2.6:

$$
Z{ }^{\prime}{ }_{\text {corr }}(f)=Z \text { '(f) }+\omega L
$$

Where $\omega=2 \pi f$. The value for L can be estimated by plotting $-Z$ " vs $\log (\mathrm{f})$. At the high frequency limit, this plot is generally linear (i.e., Z" is decaying exponentially towards zero as $\log \mathrm{f}$ increases). The $\mathrm{L}$ value is adjusted so that Fig. 2.4 shows a smooth decay of the Z" points towards zero without going negative. Later, after fitting the data to the equivalent circuit, the fitted value for $\mathrm{L}$ can be used to obtain the best corrected data.

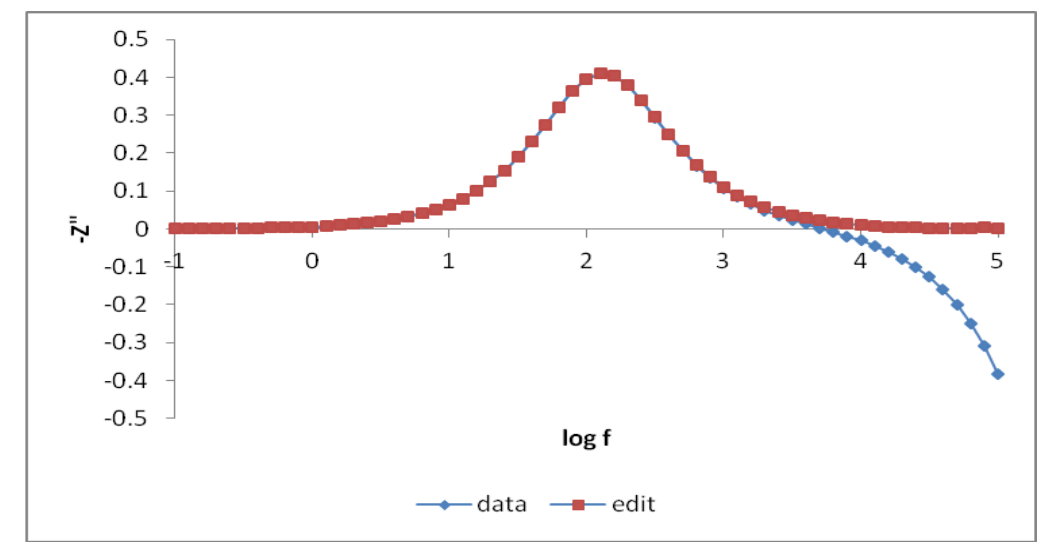

Fig 2.4: The edit data shows the step of processing the out-of-phase impedance Z" to remove the inductance artifact. 
The Fig 2.5(a) is a plot of $\log \left(\left|Z^{\prime}\right|\right)$ vs $\log \mathrm{f}$, which will be used as an example for explaining corrections, smoothing and extrapolations. The extrapolations are based on the observation that an RQ element will exhibit linear decay in this plot at frequencies away from the peak frequency.

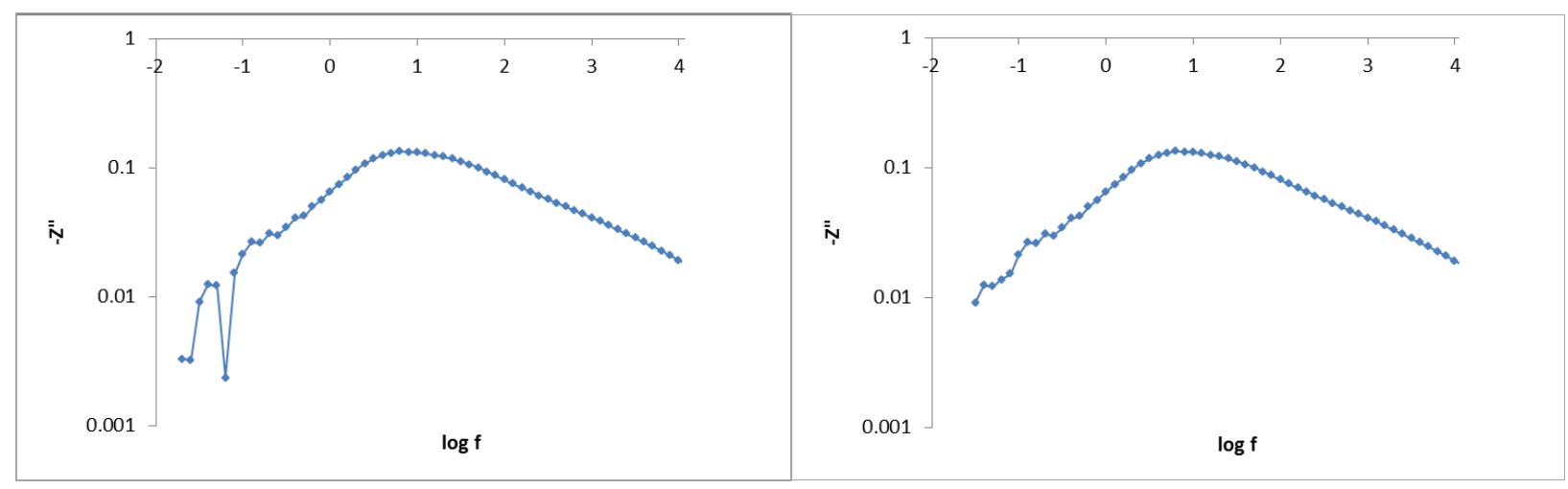

(a)

(b)

Fig 2.5: (a) The $\log \left(\left|Z^{\prime \prime}\right|\right)$ vs $\log$ f plot.( b) The $\log \left(\left|Z^{\prime \prime}\right|\right)$ vs $\log$ f plot after fixing the deviant data points.

In principle, the convolution in Equation 2.1 requires an infinite integration range while the frequency ranges of measurement data is limited by the experimental conditions. Therefore, to reduce numerical errors from the limited frequency range, the Z" data must be extended by extrapolation over a sufficiently wide range of frequencies. The Z" data is extrapolated to a value close to zero at the upper and lower frequency limits, so that the integration error is negligible and FFT works well. As noted above, the plot of $\log \left(Z^{\prime \prime}\right)$ vs $\log (f)$ usually exhibits linear behavior at both the high frequency and low frequency limits. Theoretically, the first 3 or 4 data points at each end are fitted to a linear regression equation to obtain coefficients. The coefficients are used to calculate Z" values beyond the measured frequency limits. The new frequency limits are extended sufficiently for Z" to approach zero.

However, Fig 2.5(a) also shows some problems for extrapolation, which are very common in our data analysis. For example, the change in slope above $\log \mathrm{f}=4$ and the data at the 2 highest frequencies are increasing, instead of decreasing. These deviations are thought to be caused by inaccurate impedance measurements by the Solartron Cell Test system. Similarly, at the low frequency limit (below $\log f=-1$ ), some data points show deviance from the line extrapolated from higher frequencies. 
The deviant Z" data at the high frequency end (above $\log f=4$ ) can be replaced with a reasonable exponential decay. The linear regression slope is then calculated and the linear regression intercept of $\log \left(Z^{\prime \prime}\right)$ vs $\log f$ linear decay from $\log f=3.6$ to 4.0 . These parameters are used to calculate extrapolate values of $Z$ " to $\log f=8.4$.

The deviant Z" data at the low frequency limit presents a greater problem. Any wrong guesses here will result in a false peak in the deconvolution spectrum. One method is to repeat the impedance acquisition, so that the data sets can be averaged to minimize the deviance. Some of the points in Fig 2.5 (a) are clearly way off ( $\log f=-1.2,1.6$, and -1.7$)$. These can be replaced by the average of the data points on either side or deleted. Fig 2.5(b) shows the result after fixing the deviant data points. In Fig. 2.5 (a), peaks in the frequency range $\log f-1.5$ to -0.5 are suspect. Smoothing the data is required. Z" data were smoothed by averaging 3 adjacent points. The $\ln$ (smoothed Z") values from $\log f=-1.5$ to -0.5 were included in a linear regression analysis to obtain the parameter for extrapolating the Z" data to $\log f=-4.35$.

Now, after extrapolation, $\log f$ greater than 4 and $\log f$ less than $-1.5, Z$ " are calculated from the corresponding high and low frequency linear regression slopes and intercepts. Then from $\log \mathrm{f}=$ 8.4 to $\log f=-4.35$, data points $(\log f=x . x 5)$ are interpolated using the average of the two adjacent data points, make the whole data set with a $\log f$ interval of 0.05 . The last step for data processing is smoothing Z", which is done by averaging up to five adjacent points. Fig. 2.6 shows plots of processed Z" both in linear and log format. Checking the validity of the extrapolated Z" data is done by matching the extrapolated slopes in Fig. 2.6(b) with slopes of the data. 


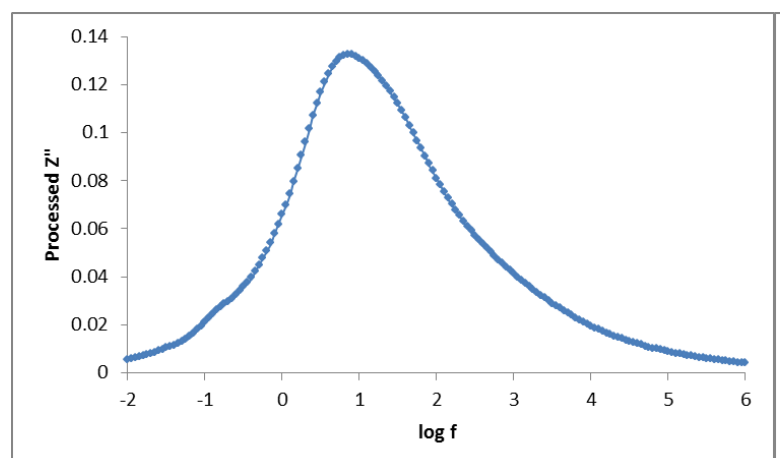

(a)

Fig. 2.6 (a) plot of processed Z" vs log f. (b) Plot of processed $\log (\mid Z$ '|) vs $\log f$.

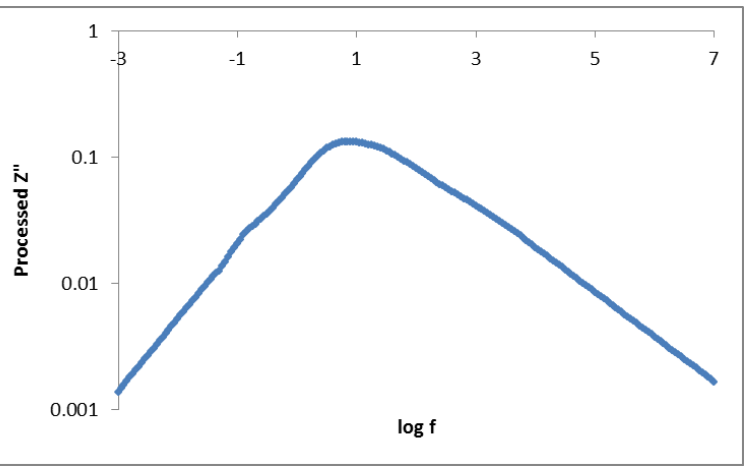

(b)

Now the Fast Fourier Transform (FFT) is applied to the processed Z", dividing each element of the Z" transform $\left(\mathrm{z}_{\mathrm{n}}\right)$ by the equivalent FFT element of the hyperbolic secant function $\left(\mathrm{s}_{\mathrm{n}}\right)$ to obtain the dividend $\left(g_{n}\right)$. Fig 2.2 shows amplitude of the FFT Z"data and sech function. It is evident that points from about 25 to 235 , the values of FFT Z" and sech function have huge differences and cause noise, so these points must be eliminated before performing the inverse FFT. A Hahn filter is applied to control the numerical error amplification from FFT before inverse transfer. The Hahn filter is multiply with $g_{n}$ coefficients to eliminate the noise, where Hahn filter function is $\left(0.5+0.5^{*} \cos \left(\mathrm{pi}^{*} \mathrm{n} / 27\right)\right)$, and $\mathrm{n}$ is the data point. Points 24 through 235 in the Hahn filter are set to zero. The product of the Hahn filter and the $g_{n}$ coefficients is subjected to the inverse FFT operation to generate the deconvolution spectrum. Fig 2.2 shows the plot of "filtered $g_{n}$ function", which provides a check whether excessive noise is still present prior to performing the inverse FFT step. This filtering process removes high frequency noise but at the same time causes unavoidable broadening of the deconvolution spectrum.

After performing the inverse FFT for the filtered FFT $g_{n}$ coefficients, the final $g_{k}$ can be obtained. The final result is a plot of the amplitude $g_{k} v s \log f$. The deconvolution spectrum is normalized for the sum of all $\mathrm{g}_{\mathrm{k}}$ values is 1 (Fig 2.3).

The deconvolution spectrum can provide much useful information to construct an equivalent circuit, such as the peak number, peak frequency, and peak height and peak shape. The peak number suggests how many elements needed for the circuit and the peak shape suggests what kinds of arc-generating element to be used. Then we use ZView ${ }^{\circledR}$ to fit the elements of the 
circuit with the impedance data. A spreadsheet "Impedance simulator" was created to simulate the impedance spectra using the information from deconvolution spectrum. The simulation parameters are adjusted to obtain reasonable values for the various elements. These values were inputted as the starting numbers for ZView ${ }^{\circledR}$ equivalent circuit fit. The impedance simulator can be used as a check for fit, not only for the simulated impedance with the collected data, but also the deconvoluted impedance from equivalent circuit fit with the deconvoluted collected data.

\subsection{Equivalent circuit elements}

Equivalent circuits for SOFCs are usually composed of a series of arc-generating elements. The arc-generating elements usually include the RQ element, the Gerischer impedance and the finite length Warburg impedance. The most common arc-generatoris RQ is a parallel combination of a charge transfer resistance and a constant phase element (CPE). R represents the resistance from charge transfer in the electrode. Q represents electrons transfer to and from the interface of the electrode and electrolyte, and is affected by rough surfaces. The RQ element can be used to model a variety of processes occurring on SOFCs. The admittance Y of the CPE is dependent on two parameters, a magnitude $|\mathrm{Q}|$ and an exponent $n(0<n \leq 1)$. When exponent $n=1$, the CPE becomes the ideal capacitance. And with exponent $n<1$, the impedance of this $R Q$ element becomes a distributed impedance. The admittance of the RQ element is given by:

$$
Y=|Q|(j \omega)^{n}
$$

The peak frequency of the $(R Q)$ element can be matched to peaks in the deconvolution spectrum through Equation 2.8.

$$
F_{p}=\frac{1}{(2 \pi R|Q|)^{\frac{1}{n}}}
$$

The parallel $R Q$ combination generates a "depressed" arc in the Nyquist plot $(n<1)$. The Z" component of the $(R Q)$ impedance vs $\log \mathrm{f}$ is a symmetrical peak with the half-width scaling inversely with respect to the exponent (Fig. 2.7A). Deconvolution of the impedance data for $(R Q)$ yields a symmetrical peak whose half-width also increases as n decreases from 1 (Fig. 
2.7B). Because of the filtering process broadening, deconvolution of the data set for $n=1$ is a narrow peak instead of the expected spike at the peak frequency of the impedances.

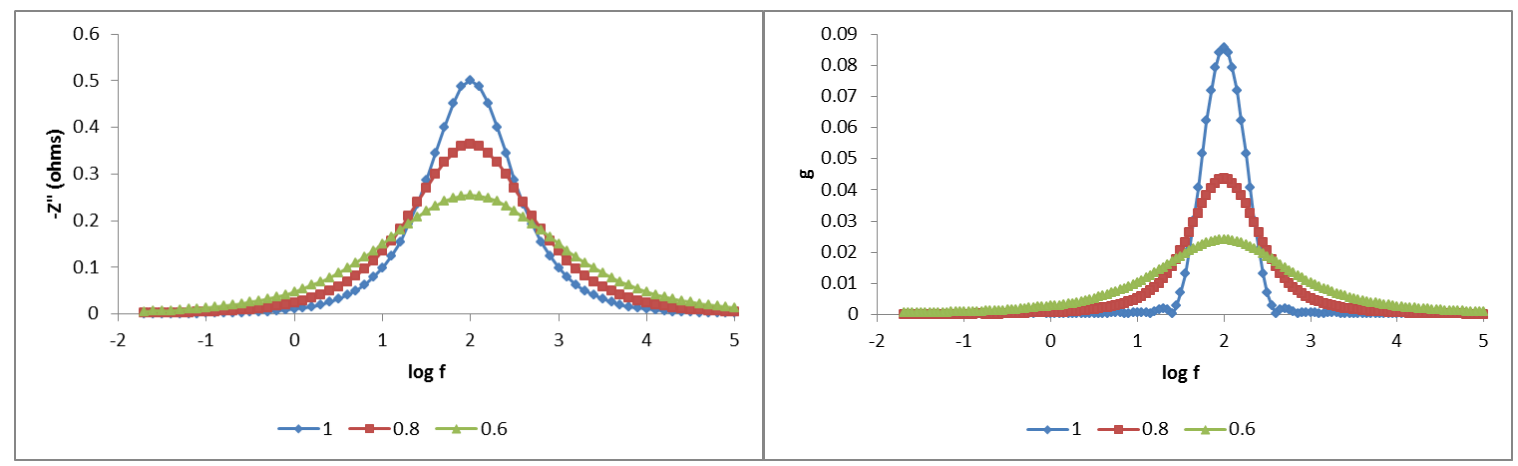

Fig. 2.7: Impedance and deconvolution spectra for $(R Q)$ circuits. The peak frequency is $100 \mathrm{~Hz}$, and the exponents are shown in the legend. (A) -Z" vs $\log \mathrm{f}$; (B) deconvolution spectrum g vs $\log f$.

Other arc-generating elements include the Gerischer impedance and the finite length Warburg impedance. The Adler/Lane/Steele model for porous electrodes prepared using mixed ionic/electronic conductors shows that a Gerischer impedance is anticipated [83]. More generally, Boukamp and Bouwmeester [84] showed that the Gerischer impedance appears when a charge transfer step is coupled to a mass transfer step in an electrode. In a Nyquist plot, the Gerischer impedance exhibits a characteristic different from $(R Q)$ with the shape of a straight line at the high frequency limit (slope close to 1) and an arc at the low frequency limit (Fig. 2.8A). The Gerischer impedance is defined by three parameters, the polarization resistance $R$ which represents the process of oxygen reaction with the LSM surface with a mass transfer step, a parameter $T$ and exponent $n$, shown in Equation 2.9:

$$
Z=\frac{R}{(1+j T \omega)^{n}}
$$

The exponent $n$ is equal to 0.5 in the ideal Gerischer element, yielding the following expression for the peak frequency.

$$
F_{p}=\frac{3^{1 / 2}}{2 \pi T}
$$


A generalized Gerischer impedance (also known as a Cole-Davidson impedance) is the exponent $n$ to deviate from $1 / 2$. The peak frequency is given by Equation 2.11:

$$
F_{p}=\frac{1}{2 \pi T} \times \frac{\sin \left(\frac{\pi}{2(n+1)}\right)}{\sin \left(\frac{\pi n}{2(n+1)}\right)}
$$

Deconvolution of a Gerischer-type arc produces an asymmetrical peak with a smaller peak at approximately 20 times the peak frequency on the high frequency side and an extended tail to higher frequencies (Fig. 2.8B)[16,17]. Because of the filtering process, the secondary peak is barely visible in the deconvolution spectrum. The deconvolution spectrum with an exponent $n$ lower than $1 / 2$ becomes a distributed impedance. Boukamp and Bouwmeester refer to this case as a fractal Gerischer element [16].

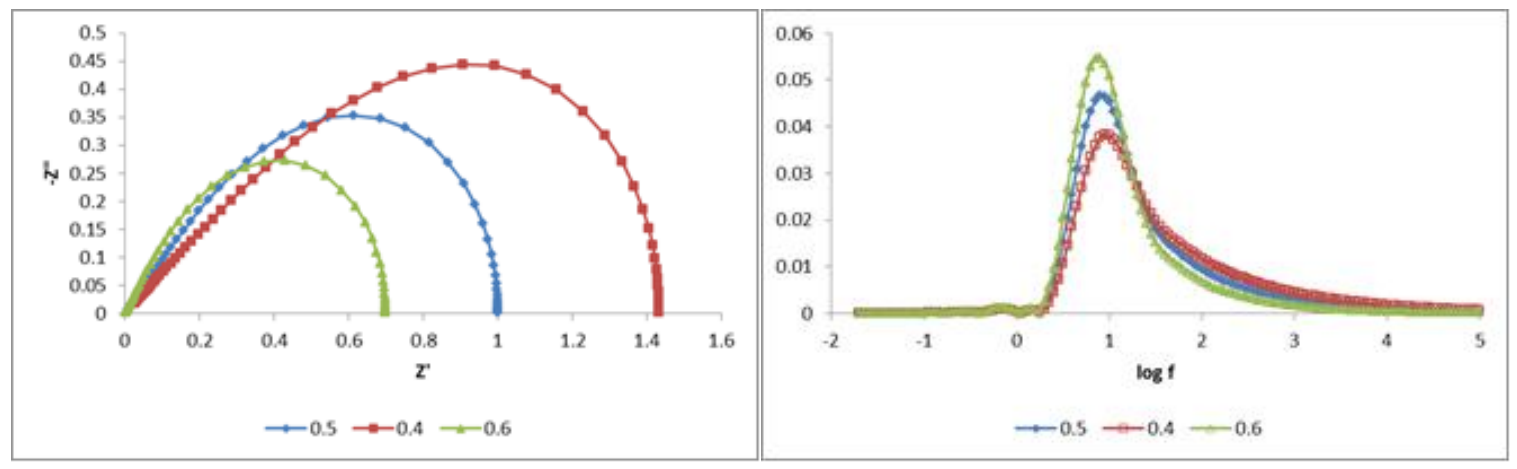

Fig. 2.8: (A)Nyquist (B) deconvolution plots for the generalized Gerischer impedance. Peak frequency $=10 \mathrm{~Hz}$. The exponents are shown in the legend.

The finite length Warburg impedance is used to model mass transfer control of the reactant over a finite thickness (e.g. current limited by diffusion of the reactant gas across the thickness of the porous SOFC electrode). The finite length Warburg impedance is also defined by three parameters, the diffusion resistance $R$ which represents the reactant gases mass transfer through the porous SOFC electrode, a parameter $T$ which is affected by the diffusion coefficient and the finite distance over which diffusion occurs, and exponent $n$ :

$$
Z=R \times \frac{\tanh (u)}{u}
$$




$$
u=(j \omega T)^{n}
$$

The exponent $n$ is equal $1 / 2$ for the ideal element, but a generalized finite length Warburg (FLW) allows the exponent to deviate from $1 / 2$. The $T$ parameter equals $1^{2} \mathrm{D}$, where 1 the finite diffusion length and $\mathrm{D}$ is is the diffusion coefficient of the reactant. The peak frequency is given by Equation (2.14) for $n=0.5$ :

$$
F_{p}=\frac{2.541}{2 \pi T}
$$

Similar to the Gerischer impedance, the Nyquist plot exhibits a straight line of slope 1 at the high frequency limit and an arc at the low frequency limit (Fig. 2.9A). Deconvolution of the FLW impedance yields an asymmetrical peak with a distinct secondary small peak at approximately a 10-fold higher frequency, which is more visible compared to Gerischer deconvolution spectrum (Fig. 2.9 B).

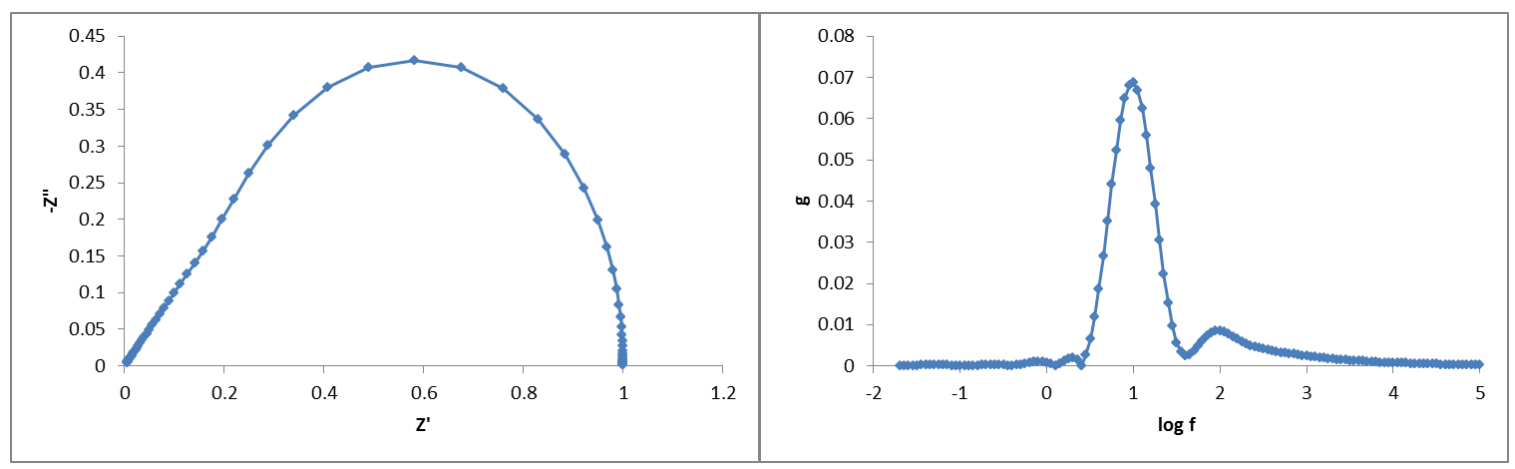

Fig. 2.9: Nyquist (A) and deconvolution spectra (B) of a finite length Warburg element (exponent $n=1 / 2)$ with a peak frequency of $10 \mathrm{~Hz}(T=0.04044)$.

The deconvolution spectra in Figures 2.7-2.9 demonstrate how the contribution of each arcforming element to the total impedance extends over four or more orders-of-magnitude changes in frequency. Consequently, a complex nonlinear regression fitting procedure is applied to find the best values for the parameters in the equivalent circuit. The commercial software ZView ${ }^{\circledR}$ (Scribner) provides all of the preceding elements in the design of an equivalent circuit, and yields least squares fits and uncertainties of all parameters. The fitting function that is minimized is given in equation 2.15 . 
Error $=\sum\left\{\left[Z^{\prime}(\text { data })-Z^{\prime}(\text { sim })\right]^{2}+\left[Z^{\prime \prime}(\text { data })-Z^{\prime \prime}(\text { sim })\right]^{2}\right\}$

Where the sum is carried out over all frequencies. The error function is weighted by the amplitude of the simulated impedance.

As a check on the choice of equivalent circuit elements, the calculated impedance of the equivalent circuit is compared to the original impedance. In addition, the calculated impedance of the equivalent circuit is subjected to deconvolution and the simulated deconvolution spectrum of the circuit is compared to the deconvolution spectrum of the original data. This check approach ensures the correct choice of a valid equivalent circuit [1].

The ZView program sometimes yields unrealistic parameters (e.g., the exponent $\mathrm{n}$ being greater than 1 for an RQ element) and sometimes the details of the deconvolution spectrum are not captured by the parameter values returned by ZView. In such cases, certain parameters are fixed and $\mathrm{ZView}$ is used to find best fit values for the remaining parameters.

\subsection{Strategy}

In the following chapters, the deconvolution is applied for analyzing the impedance data of anode-supported cells, electrolyte-supported cells and symmetrical cells, so that the main frequencies of processes in the impedance spectrum could be identified, Construction of an equivalent circuit by using the information from deconvolution is followed by using ZView ${ }^{\circledR}$ to fit the elements of the circuit. Through identifying the changes in the fitted parameters of the equivalent circuit at changed operation conditions (Temperature, gas flow, DC voltage), equivalent circuit elements could be assigned with the cathode and anode. 


\subsection{References}

[1] Schichlein, H.; Muller, A.C.; Voigts, M.; Krugel, A.; Ivers-Tiffée, E. J. Appl. Electrochem. 2002, 32, 875-882.

[2] Leonide, A.; Sonn, V.; Weber, A.; Ivers-Tiffée, E. J. Electrochem. Soc. 2008, 155, B36-B41.

[3] Peters, C.; Weber, A.; Ivers-Tiffée, E. J. Electrochem. Soc. 2008, 155, B730-B737.

[4] Leonide, B.; Rüger, A.; Weber, W.; Meulenberg, A.; Ivers-Tiffée, E. J. Electrochem. Soc. 2010, 157, B234-B239.

[5] Endler, C.; Leonide, A.; Weber, A.; Tietz, F.; Ivers-Tiffée, E. J. Electrochem. Soc. 2010, 157, B292-B298.

[6] Kromp, A.; Leonide, A.; Weber, A.; Ivers-Tiffée, E. J. Electrochem. Soc. 2011, 158, B980B986.

[7] Ivers-Tiffée, E.; Hayd, J.; Klotz, D.; Leonide, A.; Han, F.; Weber, A. ECS Transactions. 2011, 35, 1965-1973.

[8] Hayd, J.; Guntow, U.; Ivers-Tiffée, E. ECS Transactions. 2011, 35, 2261-2273.

[9] Leonide, A.; Weber, A.; Ivers-Tiffée, E. ECS Transactions. 2011, 35, 2961-2968.

[10] Klotz, D.; Schmidt, J.P.; Kromp, A.; Weber, A.; Ivers-Tiffée, E. ECS Transactions. 2012, 41, 25-33.

[11] Kromp, A.; Dierickx, S.; Leonide, A.; Weber, A.; Ivers-Tiffée, E. ECS Transactions. 2012, 41,161-169.

[12] Kromp, A.; Dierickx, S.; Leonide, A.; Weberand, A.; Ivers-Tiffée, E. J. Electrochem. Soc. 2012, 159, B597-B601.

[13] Klotz, D.; Szasz, J.; Weberand, A.; Ivers-Tiffée, E. ECS Transactions. 2012, 45, 241-249.

[14] Gewies, S.; Bessler, W.G. J. Electrochem. Soc. 2008, 155, B937-B952.

[15] Adler, S.B. J. Electrochem. Soc. 1996, 143, 3554-3564.

[16] Boukamp, B.A.; Bouwmeester, H.J.M. Solid State Ionics. 2003, 157, 29-33.

[17] Endler, C.; Leonide, A.; Weber, A.; Tietz, F.; Ivers-Tiffée, E. J. Electrochem. Soc. 2010, 157, B292-B298. 


\section{Chapter 3: Analysis of SOFCs using reference electrodes}

\subsection{Introduction}

As discussed in section 1.2.4, in a three-electrode system (Working Electrode - WE, Reference Electrode - RE and Counter Electrode - CE), a reference electrode is a widely used tool to remove any contribution of the electrochemical behavior of the counter electrode from the electrochemical behavior of the Working electrode. In SOFC research, finding a reliable method to separate the cathode performance from the anode for commercial SOFC cells is required since SOFC development depends on the ability to identify limitations of performance of the whole cell in terms of the cathode and anode contributions. Reference electrodes have been frequently used to isolate the performance of one electrode in SOFCs. However, it is difficult to achieve accurate separation of the WE performance from the cell performance in commercially relevant SOFC designs with very thin electrolytes between the cathode and anode. A number of simulations in the literature state the nature of the problem with the reference electrodes used on thin-electrolyte SOFC. For the SOFC Cells, either the cathode or the anode can be the WE. In the following chapters, the cathode is the WE unless otherwise stated. The dissertation adopts a 3-electrode notation as WE/RE/CE (cathode/reference/anode) and 2-electrode notation as WE/CE (cathode/anode).

Despite the fact that difficulties for using the reference electrode predicted in simulation and experienced in practice have been reported, numerous papers still use reference electrode on 3electrode polarization curves or impedance data [1-9]. The interpretation of 3-electrode polarization or impedance data yields misleading results for one electrode, which may contain the performance of the other electrode. Some mitigation methods for the known problems have also been reported. Van den Bossche et al. [10] describe a test for checking the isolation of anode overpotential. The cathode overpotential-current plot is examined as a function of the fuel composition to the anode. Since the cathode plot exhibited little change, the authors concluded that the anode and cathode overpotential-current plots were effectively separated. This method is essentially the one that is discussed in this chapter. Offer et al. [11] describe a method for correcting the working electrode polarization curves in 3-electrode system using the high 
frequency intercept of the 3-electrode impedance plots only for experimentally simple cell geometries. However, many current papers report single electrode polarization curves and impedance data without mitigation methods or comment on the problems discussed above.

\subsection{Objectives}

In this chapter, the polarization plots and impedance data are examined for an anode-supported cell with a ring reference electrode, an electrolyte-supported cell with a ring reference electrode, and an electrolyte-supported cell with a micro-reference electrode close to the cathode. Analysis of the impedance data for multiple configurations (cathode/anode, cathode/reference/anode, anode/cathode, anode/reference/cathode), three gas flow conditions (normal, low air, low fuel) and two temperatures $\left(800^{\circ} \mathrm{C}, 700^{\circ} \mathrm{C}\right)$ are described. The assumption of using the changed gas flows to separate the cathode/anode spectra is that changing the reactant concentration to one electrode has a minimal effect on the impedance behavior of the other electrode. This assumption is supported by simulations performed by Dr. Ismail Celik and Dr. Raju Pakalapati in the Mechanical \& Aerospace Department at WVU [private communication]. Through changing of gas flows and examining changes in the impedance associated with gas composition changes to the cathode or the anode, it is possible to identify the main ranges of frequencies in the impedance data associated with the cathode and/or the anode.

Also, the method described by Van den Bossche is applied to impedance data. The 3-electrode impedance (cathode/reference/anode) is measured using different fuel compositions. If the 3electrode impedance is truly isolating the cathode impedance from the anode impedance, then changes in fuel composition should not affect the 3 -electrode impedance measurement. If, however, the 3-electrode impedance is affected, then the anode impedance is mixed in with the cathode impedance. The analyses support the conclusion that proper placement of a reference electrode is technically nearly impossible and that 3 -electrode measurements generated using a reference electrode could not provide true impedance data or polarization curves for the electrodes. A more promising approach for analysis of single electrode performance is the deconvolution protocol including the deconvolution and equivalent circuit fitting applied to the three above button cells, which will be discussed in detail in the next chapter. 


\subsection{Experimental section}

Three geometries with reference electrodes were successfully build up for investigation, including an anode-supported cell with a ring reference electrode, an electrolyte-supported cell with a ring reference electrode, and an electrolyte-supported cell with a micro-reference electrode.

Dr. Yun Chen started to create micro-reference electrodes on anode-supported cells using lithography method. He used an electron-beam evaporator to create an $\mathrm{Al}_{2} \mathrm{O}_{3}$ blocking pad on the electrolyte side of the anode-supported cells, and then he created an Ag sputtered microreference electrode on the $\mathrm{Al}_{2} \mathrm{O}_{3}$ blocking pad. The sputtered $\mathrm{Ag}$ electrode was about ten micron from the cathode edge. However, this geometry had a problem. The current connector to the $\mathrm{Ag}$ electrode always failed after sintering in high temperature $\left(800^{\circ} \mathrm{C}\right)$ and the evaporated $\mathrm{Al}_{2} \mathrm{O}_{3}$ blocking pad was suspected of not truly insulating the Ag electrode from the electrolyte. So, the second best approach was used. An Ag paste micro-reference electrode on an electrolytesupported cell was manufactured. The reason for using this geometry is that, compared to the anode-supported cell (order of 10 microns thick electrolyte), the electrolyte-supported cell has a thicker electrolyte (hundreds of microns). Based on Escobar et al.'s simulation the microreference electrode can be located within tens of microns of the cathode for the electrolytesupported cell instead of 10 microns away from cathode of the anode-supported cell [12]. The former geometrical requirement for the micro-reference electrode is much easier to achieve.

\subsubsection{Preparation of LSM/YSZ cathode and LSM/YSZ ring for Ni/YSZ anode-supported cells}

Anode-supported cells were constructed from half-cells (diameter $27 \mathrm{~mm}$ ) purchased from Fuel Cell Materials. The half cell had a Ni/YSZ anode thickness of $0.9 \mathrm{~mm}$ and an YSZ electrolyte thickness of 10 microns. A disk cathode electrode with a diameter of 0.5 inches (area $1.27 \mathrm{~cm}^{2}$ ) was screen-printed on the electrolyte using six layers of LSM/YSZ paste (1:1 by weight). Four layers of pure LSM paste were screen-printed on top of the LSM/YSZ layers as the current 
collector layer. A ring electrode with an inner diameter of 0.625 inches and outer diameter of 0.75 inches (area $0.87 \mathrm{~cm}^{2}$ ) was screen-printed with five layers of LSM/YSZ and three layers of pure LSM paste (Fig 3.1). The cathode and ring electrodes were sintered at $1100^{\circ} \mathrm{C}$ for 3 hours. Currents, power and impedances were normalized with respect to the area of the cathode.

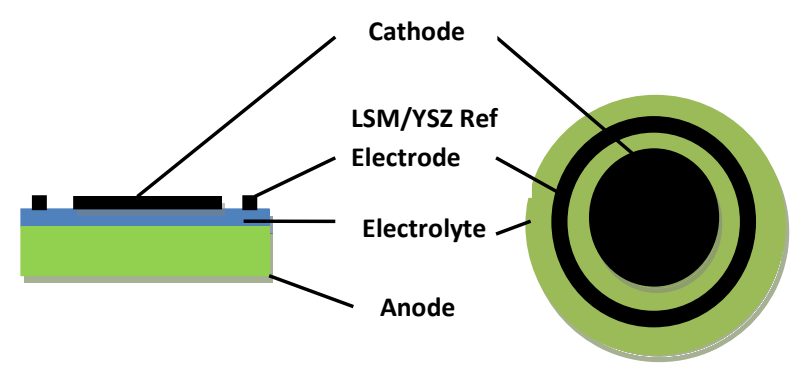

Fig 3.1: The LSM/YSZ ring reference electrode on Ni/YSZ anode-supported cell.

\subsubsection{Preparation of the Ag ring for the electrolyte-supported cell}

Electrolyte-supported cells were purchased from Fuel Cell Materials. The cells consist of a $\mathrm{Ni} / Y S Z$ anode $\left(0.5\right.$ inch diameter, area $1.27 \mathrm{~cm}^{2}$ ), a proprietary (Hionic $®$ ) electrolyte (thickness $0.15 \mathrm{~mm}$, diameter $28 \mathrm{~mm}$ ), and a LSM/YSZ cathode (diameter and position matching the anode). Silver paste was painted in a ring around the cathode; inner and outer diameters were 15 $\mathrm{mm}$ and $19 \mathrm{~mm}$, respectively (area $1.0 \mathrm{~cm}^{2}$ ) (Fig 3.2). The silver ring was sintered at $800^{\circ} \mathrm{C}$ for 1 hour before testing.

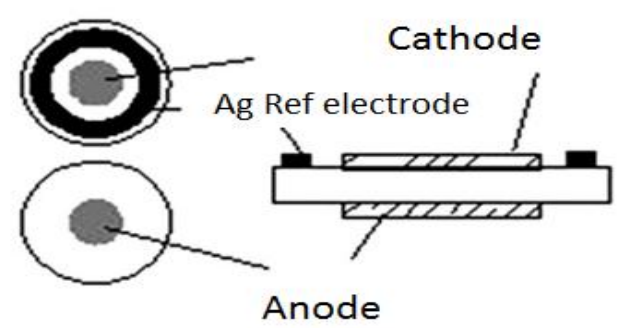

Fig 3.2: The silver ring reference electrode on the electrolyte-supported cell 


\subsubsection{Preparation of Ag dot micro reference electrode with glass paste blocking layer}

For the micro-reference electrode, glass paste was painted on the electrolyte layer near the cathode edge to form an insulating pad. To ensure the insulating ability of the glass paste, symmetrical cells with a silver electrode of one side on glass paste and the opposite side silver electrode directly on the electrolyte were tested using impedance measurements. The very high series resistances and polarization resistance (>10 kiloohms) showed that glass paste has good insulating ability. After firing the glass paste at $850^{\circ} \mathrm{C}$, silver paste was painted on the glass layer with a thin silver line connecting to a small pad of silver on the electrolyte near the cathode edge, which was again sintered to $800^{\circ} \mathrm{C}$ for 1 hour. Fig. 3.3 shows the micro-reference electrode. The critical dimensions are 145 microns width, 110 microns radial thickness, with an area of approximately $2 \times 10^{-4} \mathrm{~cm}^{2}$, and separation from the cathode edge 18 microns.

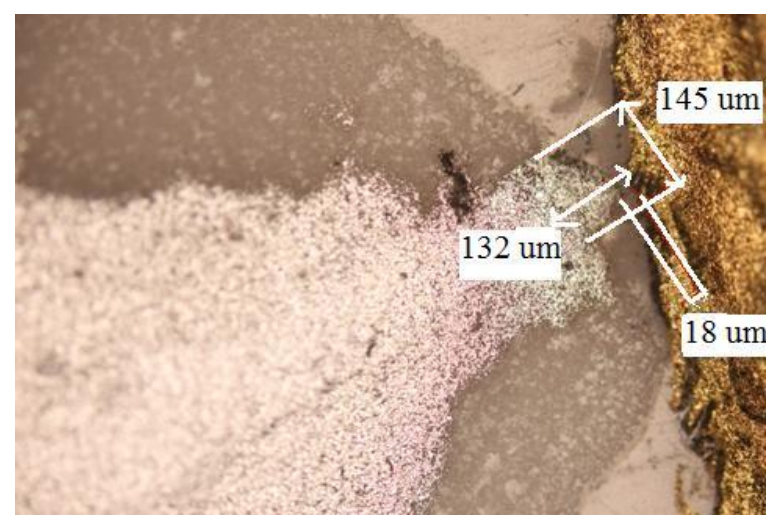

Fig. 3.3: Micro-reference electrode on an electrolyte-supported cell. The gold-coated cathode is on the right side. The grey area is the glass paste layer, and the bright area is the silver reference electrode and contact pad. Lengths and spacing of the micro-reference electrode are shown.

\subsubsection{Characterization and SOFC operation conditions}

The cell assembly is as follows. The anode was connected to a gold or platinum mesh using nickel paste, and the cathode and ring electrode were connected to gold wires using gold paste. 
The micro-reference electrode was connected to a silver wire using silver paste. Gold paste covered the entire cathode and the entire ring. The cell was mounted in a test stand as show in Fig 3.4. The temperature-controlled humidifiers are connected to the anode and cathode gas inlet pipeline. Through increasing the temperature of the humidifier, more water vapor can be added in the gas flows to the anode and cathode. To mitigate the problems of accumulation of condensed water in the anode gas outlet pipeline and the possible cathode degradation by the effect of cathode gas humidification [13], we set temperatures of both humidifiers for the anode and cathode to room temperature $\left(25^{\circ} \mathrm{C}\right)$. The gas flow allowed control of gas composition to both the anode and the cathode. The cell was sealed to the anode flange using glass paste and several high temperature mica washers were put between the cathode side electrolyte and flange and inside the flange and $\mathrm{Al}_{2} \mathrm{O}_{3}$ tube to ensure the sealing. Two leads (current and voltage sense) were connected to short wires leading to the anode and cathode, respectively. A single lead was connected to the ring electrode or micro-reference electrode. The cell was slowly heated to $850^{\circ} \mathrm{C}$ to soften the glass paste with air to the cathode and reference electrodes and nitrogen to the anode, and then cooled to $800^{\circ} \mathrm{C}$. The anode was reduced using first $20 \%$ hydrogen in nitrogen overnight, and then $100 \%$ hydrogen.

Electrochemical measurements were performed using a Solartron Cell Test system. Measurements were performed in both a two-electrode configuration and a three-electrode configuration as noted previously. Impedances of the reference electrodes were checked with a two-electrode configuration (reference/anode). One channel of the Cell Test passed current between the WE and CE electrodes with the reference lead either connected to the CE (2electrode measurement) or to the RE (3-electrode measurement). A second channel monitored the voltage between the RE and WE at the same time.

At each flow condition and temperature, a series of measurements were performed: (a) open circuit voltages (OCVs) of all two electrode combinations (cathode/anode, cathode/reference, anode/reference), 1000 data points per second measuring for a second, and 10 data points per second measuring for 30 second; (b) polarization curves for cell voltages scanning from the OCV to $0.5 \mathrm{~V}$ or $0.3 \mathrm{~V}$, data collected at $10 \mathrm{pts} / \mathrm{s}$, scan from OCV to the terminal voltage for $30 \mathrm{~s}$, and scan back to OCV for $30 \mathrm{~s}$; (c) two-electrode and three-electrode impedance measurements at OCV with the voltage controlled at the OCV $\left(10^{5} \mathrm{~Hz}\right.$ to 0.1 or $0.02 \mathrm{~Hz}, 10$ log linear steps per 
decade), and (d) slow scan cyclic voltammograms over a potential range of OCV +/- $25 \mathrm{mV}$ over $100 \mathrm{~s}$ (effective frequency of $0.01 \mathrm{~Hz}$ ). The slow scan CVs provided a confirming measurement of the total resistance obtained from the low frequency intercept of the Nyquist plot.

Gas flows to the cathode and anode were used: (1) 250 standard cubic centimeters per minute $(\mathrm{sccm})$ hydrogen to anode, $400 \mathrm{sccm}$ air to cathode, labeled as normal (N), (2) $250 \mathrm{sccm}$ hydrogen to anode, $50 \mathrm{sccm}$ air $+350 \mathrm{sccm}$ nitrogen mixture gas to cathode, labeled as low air (LA) condition, (3) $50 \mathrm{sccm}$ hydrogen $+200 \mathrm{sccm}$ nitrogen to anode, $400 \mathrm{sccm}$ air to cathode, labeled as low fuel (LF) condition. Both gas streams were saturated with respect to water vapor at $20^{\circ} \mathrm{C}$. The reference electrodes were exposed to the same gas condition as the cathode.

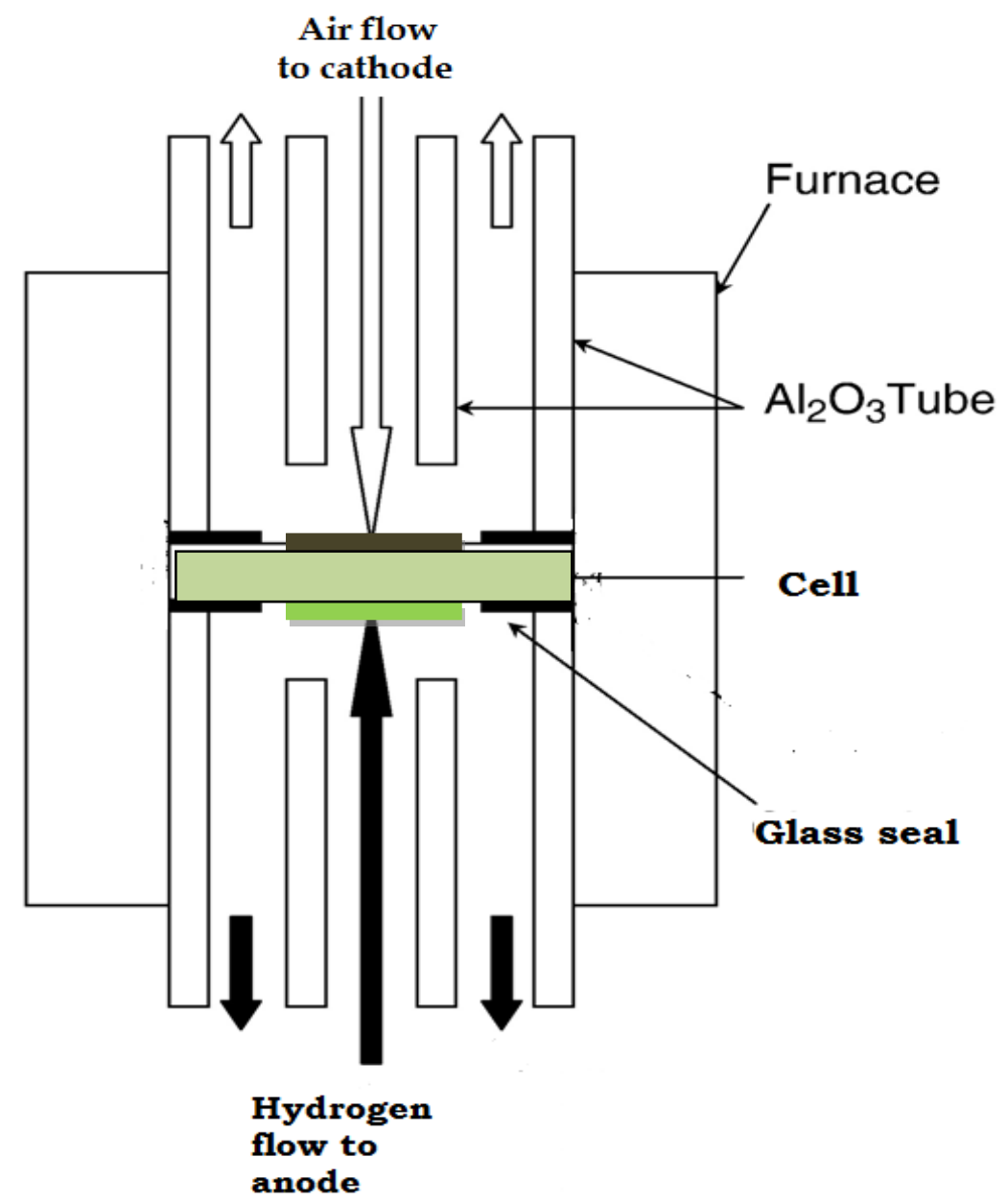

Fig 3.4: Schematic drawing of the electrolyte-supported fuel cell mounted in the furnace 


\subsection{Results and discussion}

\subsubsection{Simulation results}

To use the protocol of analyzing the 3-electrode impedance data, the assumption that changing the gas composition to one electrode does not affect the impedance of the other electrode should be replicated by computational simulation. A computational simulation was developed by Dr. Raju Pakalapati and Dr. Ismail Celik (private communication), which was performed on the anode-supported cell. The simulation did support this assumption. The simulation incorporated the following three physical processes during cell operation: (a) the current generated throughout the electrode which depends on overpotential at both the cathode and anode following ButlerVolmer equations; (b) gas diffusion through the porous electrode; and (c) oxide ion transfer through the electrolyte and into the electrolyte network in the porous electrodes. The parameters in the simulation were modified to make sure that both the experimental polarization curve and the impedance data of the anode-supported cell at normal flow condition at $800^{\circ} \mathrm{C}$ approximately matched (Fig. 3.5). The impedances of the cathode and anode were calculated by 3 electrode measurement using a virtual reference electrode which is located at the midpoint of the electrolyte.

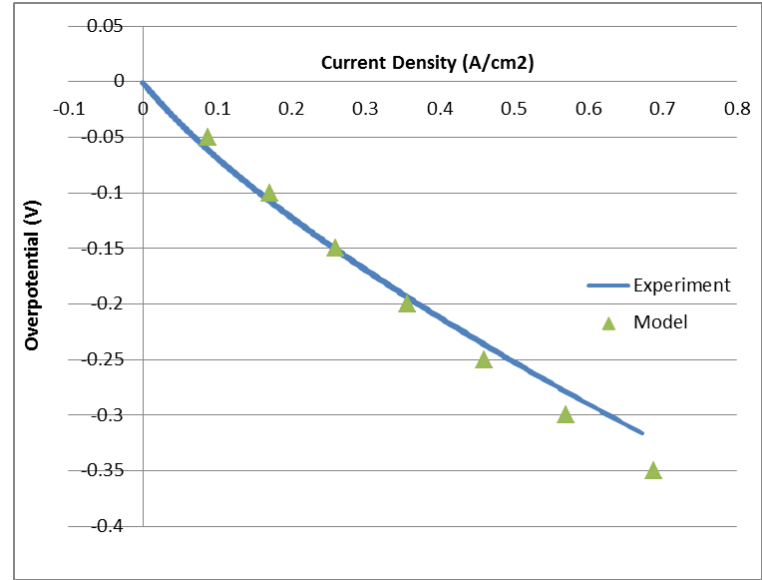

(a)

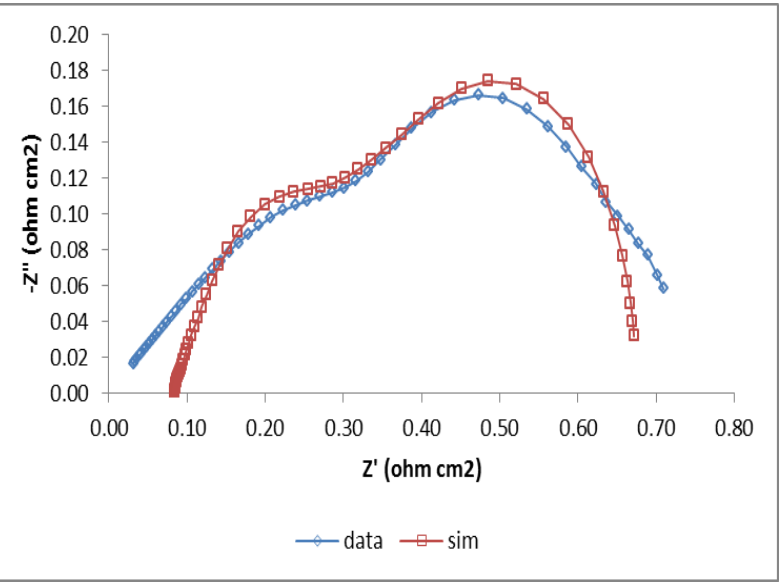

(b)

Figure 3.5: (a) Comparison of simulation polarization curve and (b) simulation impedance to the data from the anode-supported cell at $800^{\circ} \mathrm{C}$ and normal flow. The effects of inductance and series resistance have been removed from the cell impedance. In (a), experimental polarization curve solid blue line, simulation results green triangles. In (b), corrected impedance data blue diamonds, simulation impedance red squares. 
The simulation was applied for each normal, low air and low fuel flow conditions. Bode plots (Fig. 3.6) show that in the normal flow condition, the higher frequency arc corresponds to the cathode and the lower frequency arc is related to the anode. The height of the anode $Z$ ' change is about three times the cathode Z' change, which means that the total polarization resistance contains more contributions from the anode (about 75\%). Fig. 3.7 compares the cathode Bode impedances for normal, low air and low fuel flow conditions. Compared to normal flow, at low air flow, the cathode polarization resistance increases and the peak frequency in the $-Z$ " plot shifts to a lower frequency (from 40 to $32 \mathrm{~Hz}$ ). The impedance for low fuel flow totally overlaps with the impedance for normal flow. Consequently, low fuel flow for the anode has no effect on the cathode impedance. The different Bode plots going from normal flow to low fuel flow are shown in Fig. 3.8. For cathode, anode and whole cell, the difference Bode plots (dZ) are calculated by subtraction of the Z' and $-Z$ " values for normal flow from the corresponding values for low fuel flow. The cathode $\mathrm{dZ}$ values are essentially zero, and the anode and cell $\mathrm{dZ}$ values are identical. Changing flow from normal to low fuel condition, the change of the whole cell impedance is all from the change of the anode impedance. The cathode impedance has no change. Similarly, dZ plots for low air flow vs normal flow demonstrate that low air flow only changes the cathode impedance. This simulation supports the possibility of separating the anode and cathode impedances by examining the impedance change for the cathode or anode electrode with gas composition changes. Consequently, a real 3-electrode measurement (cathode/reference/anode) should not exhibit any changes when the fuel flow to the anode (the counter electrode) is altered. The method of checking whether the 3-electrode measurements successfully isolate the impedance of one electrode is based on such result.

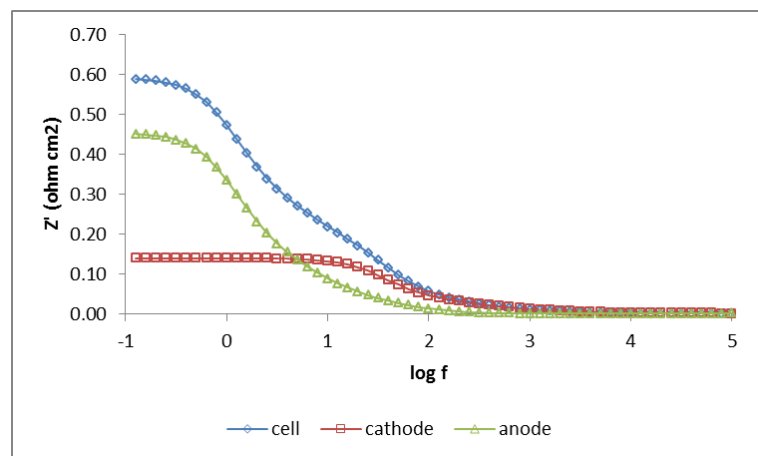

(a)

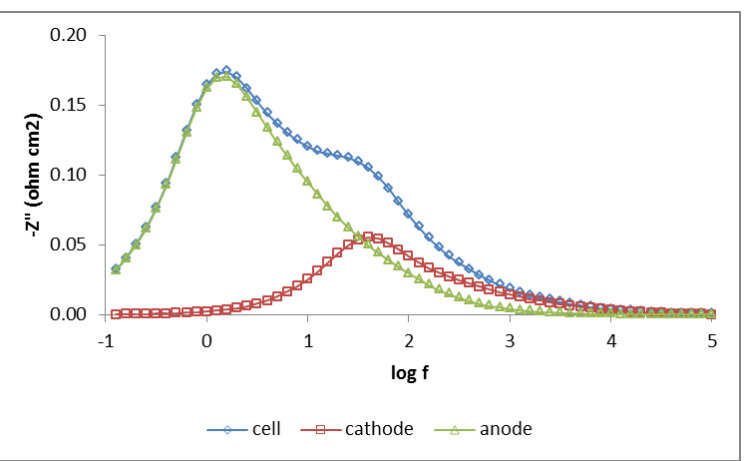

(b)

Figure 3.6: Bode plots of the simulated impedance Z' (a) and -Z' (b). The Z' data are corrected for the ohmic resistance. The blue diamonds are cell data, red squares are the cathode data and green triangles are the anode data. 


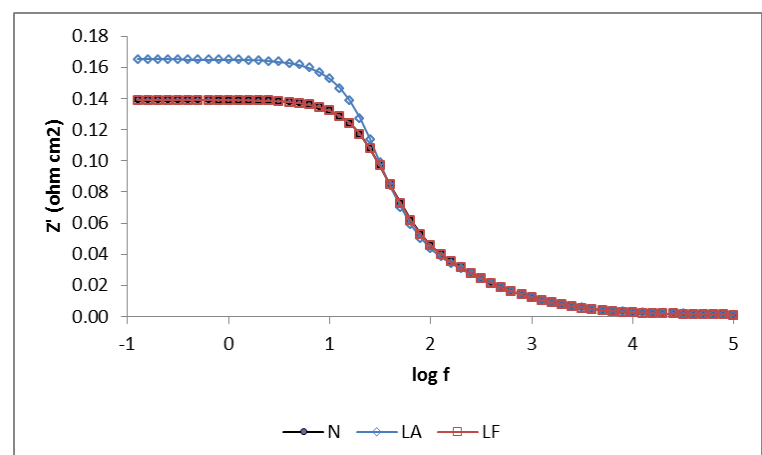

(a)

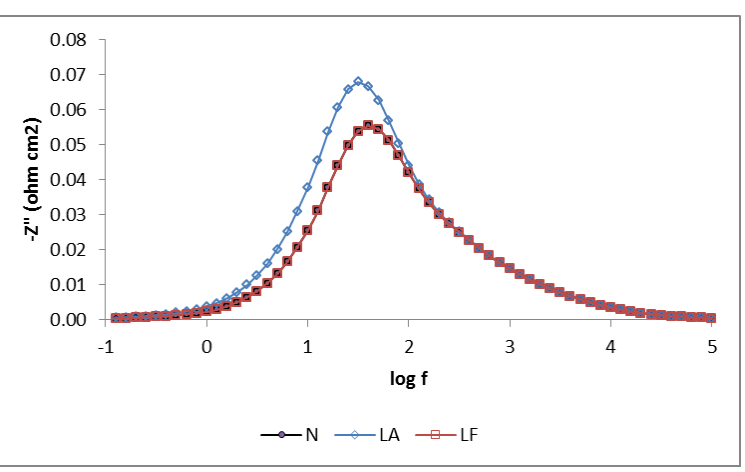

(b)

Figure 3.7: Overlay Bode plots of the simulated cathode impedance Z' (A) and -Z" (B) for normal (N), low air (LA) and low fuel (LF) flow. Normal condition solid black diamonds, low air condition blue diamonds and low fuel red squares.

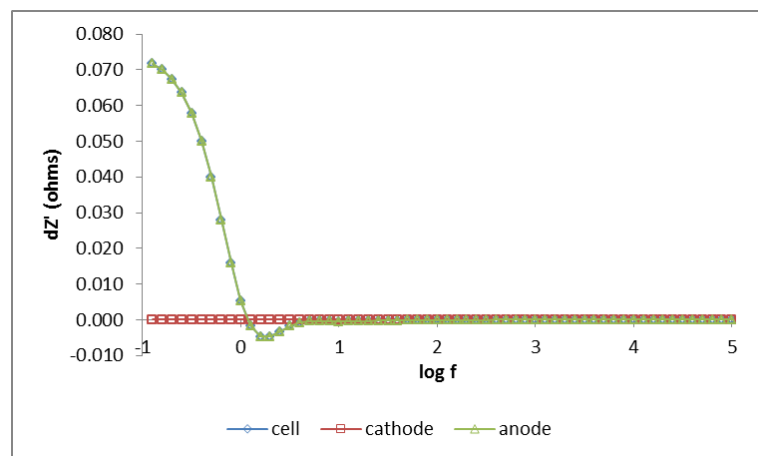

(a)

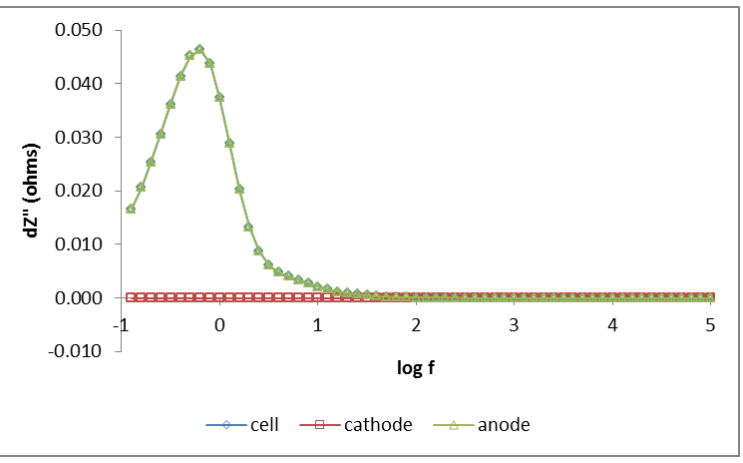

(b)

Figure 3.8: Difference Bode plots of the simulated cell, cathode and anode impedances dZ' (a) and dZ" (b) going from normal flow to low fuel flow. The blue diamond is cell data, red square is cathode and green triangle is the anode.

\subsubsection{Reference electrodes}

In the anode-supported cell, various materials were tried for the formation of useful reference electrodes. Platinum paste and gold paste electrodes exhibit high polarization resistances and tend to delaminate from the electrolyte over the test time of an operation cycle (several days). Silver paste electrodes yield lower polarization resistances but also have delamination problems. Often, a silver paste reference electrodes are observed exhibiting a short-circuit connection to the anode, which is suspected to arise from penetration of silver paste into the pinholes in the thin electrolyte. Compared to the metal electrodes, the LSM/YSZ composite electrodes have the advantages of providing a stable potential with good adhesion to the electrolyte and a much lower polarization resistances. Two-electrode measurements with the reference electrode as the 
working electrode indicate that the LSM/YSZ reference electrodes have a low polarization resistance no larger than $1 \mathrm{ohm} \mathrm{cm}^{2}$ at $800^{\circ} \mathrm{C}$ (normal air flow).

On the electrolyte-supported cells, silver paste and LSM/YSZ composite electrodes work equally well. For the micro-reference electrode, silver paste is the only option when glass paste is used to insulate the contact pad from the electrolyte, because at the sintering temperature of LSM/YSZ composite $\left(>1000{ }^{\circ} \mathrm{C}\right)$, the glass paste becomes a liquid. The Nyquist impedance plot for the micro-reference electrode and the anode (reference/anode) shows a single arc with a peak frequency of $1 \mathrm{kHz}$, a series resistance of $1 \mathrm{kiloohm}\left(0.2 \mathrm{ohms} \mathrm{cm}{ }^{2}\right)$ and a polarization resistance of 3.5 kiloohm $\left(0.2 \mathrm{ohms} \mathrm{cm}^{2}\right)$. Open circuit voltage measurements using the micro-reference electrode exhibit $60 \mathrm{~Hz}$ bursts with an amplitude of a few $\mathrm{mV}$. The $60 \mathrm{~Hz}$ bursts are probably related to electromagnetic noise picked up from the heating coils of the furnace.

\subsubsection{Open Circuit Voltages}

Open circuit performance is a key indicator of reference electrode quality. A reference electrode set on the cathode side should respond to the same half-reaction as the cathode:

$$
\mathrm{O}_{2}+2 \mathrm{~V}_{\mathrm{O}} \ddot{*}+4 \mathrm{e}^{-}<->2 \mathrm{O}_{\mathrm{O}}^{\mathrm{x}}
$$

Equation 3.1 shows the oxygen reduction in the cathode with Kroger-Vink notation. $\mathrm{V}_{\mathrm{O}}{ }^{*}$ is the oxide ion vacancy in the electrolyte lattice, and the $\mathrm{O}_{\mathrm{O}}{ }^{\mathrm{x}}$ is the oxide ion occupying the oxide ion lattice site. The dots represent a positive charge of +2 relative to the charge of the ion normally occupying the lattice site. The $\mathrm{x}$ represents a zero charge relative to the charge of the ion normally occupying the lattice site. Based on the configuration, theoretically, the potential between the cathode and reference electrode at open circuit should be on the order of $+/-1 \mathrm{mV}$, since the activities of $\mathrm{O}_{2}, \mathrm{~V}_{\mathrm{O}}{ }^{\ddot{ }}$, and $\mathrm{O}_{\mathrm{O}}{ }^{\mathrm{x}}$ are expected to be very similar at the two electrodes as the two electrodes are in the same gas composition. In the electrolyte-supported cell, the OCVs of the cathode with respect to both the ring reference electrode and the micro-reference electrode are, as expected, close to zero (Table 3.1). In general, the observed cathode/anode OCVs of electrolyte-supported cells follow the voltage predicted by the Nernst equation, but are typically $10-20 \mathrm{mV}$ below the Nernst voltage (Table 3.1, 3.2). Equation 3.2 shows the Nernst equation for a SOFC: 
$\Delta E_{\text {cell }}=\Delta E_{\text {cell }}^{0}-(2.303 * \mathrm{RT} / \mathrm{nF}) \log \left(\alpha_{\mathrm{H} 20}^{2} /\left(\alpha_{\mathrm{H} 2}^{2} * \alpha_{\mathrm{O} 2}\right)\right)$

Where $\mathrm{E}_{\text {cell }}^{0}=$ cell potential under standard conditions. $\mathrm{R}=$ gas constant, which is 8.31 (voltcoulomb $) /($ mol-K), $\mathrm{T}=$ operation temperature, $\mathrm{n}=$ number of moles of electrons exchanged in the electrochemical reaction, $\mathrm{F}=$ Faraday's constant $(96500 \mathrm{coul} / \mathrm{mol})$, and $\alpha$ is the chemical activity for the relevant species. At $800^{\circ} \mathrm{C}$ standard condition (the pressures of the gases $\mathrm{H}_{2}, \mathrm{O}_{2}$ and $\mathrm{H}_{2} \mathrm{O}$ are $1 \mathrm{~atm}), \Delta \mathrm{E}_{\text {cell }}^{0}=1096 \mathrm{mV}$ for $\mathrm{SOFC}$ at $800^{\circ} \mathrm{C}$.

Table 3.1: Open circuit voltage magnitudes $(\mathrm{mV})$ for electrolyte-supported cells with a ring reference electrode or a micro-reference electrode

\begin{tabular}{|l|l|r|r|r|r|r|}
\hline Temperature/Flow & Ref & Cat/an & Cat/ref & An/ref & Nernst & delta \\
\hline $\mathbf{8 0 0 N}$ & Ring & 1086 & 0 & 1085 & 1096 & -10 \\
\hline 800LA & Ring & 1034 & 1 & 1035 & 1049 & -15 \\
\hline 800LF & Ring & 1003 & 0 & 1002 & 1022 & -19 \\
\hline $\mathbf{7 0 0 N}$ & Ring & 1096 & 0 & 1096 & 1113 & -17 \\
\hline $\mathbf{7 0 0 L A}$ & Ring & 1057 & 0 & 1054 & 1070 & -13 \\
\hline $\mathbf{7 0 0 L F}$ & Ring & 1033 & 1 & 1032 & 1046 & -14 \\
\hline $\mathbf{8 0 0 N}$ & Micro & 1085 & 0 & 1085 & 1096 & -9 \\
\hline $\mathbf{8 0 0 L A}$ & Micro & 1037 & 2 & 1037 & 1049 & -12 \\
\hline $\mathbf{8 0 0 L F}$ & Micro & 1015 & 1 & 1015 & 1022 & -7 \\
\hline $\mathbf{7 0 0 N}$ & Micro & 1102 & 0 & 1102 & 1113 & -11 \\
\hline $\mathbf{7 0 0 L A}$ & Micro & 1078 & 0 & 1079 & 1070 & -8 \\
\hline $\mathbf{7 0 0 L F}$ & Micro & 1026 & 0 & 1028 & 1046 & -20 \\
\hline
\end{tabular}

Delta is the cathode/anode voltage $\mathrm{E}_{\text {actual }}$ minus the Nernst voltage $\mathrm{E}_{\mathrm{N}}$.

On the anode-supported cell, the cathode/ ring voltage was in the range of 10 to $20 \mathrm{mV}$ with the cathode positive with respect to the ring electrode (Table 3.2). The possible causes of this deviation from $+/-1 \mathrm{mV}$ are discussed elsewhere [Pakalapati et al., submitted to ECS Trans.], but are generally assumed to arise from leakage of fuel across the electrolyte and possibly the seal around the anode so that the pressure of oxygen is different at the ring than at the cathode. In the anode- supported cell, cathode/anode voltages are also $25-35 \mathrm{mV}$ below the predicted Nernst voltage (Table 3.2). The possible reasons are pinhole leaks in the thin electrolyte as well as leaks in the seal around the anode so that the pressure of water is raised on the anode side (the water is produced when leaking oxygen reacts with hydrogen). 
Table 3.2: Open circuit voltage magnitudes $(\mathrm{mV})$ for an anode-supported cell with a ring reference electrode

\begin{tabular}{|l|r|r|r|r|r|}
\hline Temperature/Flow & \multicolumn{1}{|c|}{ cat/an } & \multicolumn{1}{c|}{ cat/ref } & an/ref & Nernst & delta \\
\hline 800N & 1070 & 12 & 1058 & 1096 & -26 \\
\hline 800LA & 1015 & 12 & 1003 & 1049 & -34 \\
\hline 800LF & 995 & 19 & 976 & 1022 & -27 \\
\hline 700N & 1089 & 13 & 1075 & 1113 & -24 \\
\hline 700LA & 1039 & 17 & 1022 & 1070 & -31 \\
\hline 700LF & 1015 & 16 & 999 & 1046 & -31 \\
\hline
\end{tabular}

Delta is the cathode/an voltage minus the Nernst voltage.

\subsubsection{Polarization curves}

Polarization curves of the two-electrode measurements of WE vs RE are widely seen in the literature as an important indicator for the electrode performance with the implication that the polarization curve is assignable to one electrode. Polarization curves for both the cathode and the anode with respect to the reference electrode and the cell polarization curve are less commonly seen. However, it is more instructive for seeing how the reference electrode affects the measuring the polarization loss of one electrode. Figures 3.9 shows Polarization curves (voltage vs. current and overvoltage vs. current) for the anode-supported cell and the electrolytesupported cell with ring reference electrodes are shown 3.10 at $800^{\circ} \mathrm{C}$ and gas at normal flow condition. All the polarization curves are without correction for iR drop. The reason is based on simulation. It is difficult to obtain the correct ohmic resistance in a 3-electrode configuration from impedance measurements. The two figures show both the forward scan from OCV to $0.5 \mathrm{~V}$ or $0.3 \mathrm{~V}$ and the return scan back to OCV. The exact overlap between the forward and reverse scans (absence of hysteresis) indicates that the currents are near their steady-state values. In the anode-supported cell, the anode/reference voltage shows ohmic behavior with very little change in overvoltage with respect to a large change of current. Correspondingly, the cathode/reference voltage exhibits considerable change over same range of current and the cathode/reference overvoltage change is very close to the overvoltage change of the cathode/anode (the whole cell overvoltage) (Fig. 3.9b). In contrast, in the electrolyte-supported cell, the anode/reference voltage changes dramatically with respect to current change (Fig 3.10a) and anode/reference overvoltage exhibits similar curvature to the cathode/reference overvoltage (Fig 3.10b). A 
similar polarization curve is also obtained using the micro-reference electrode on the electrolytesupported cell (Fig 3.11).
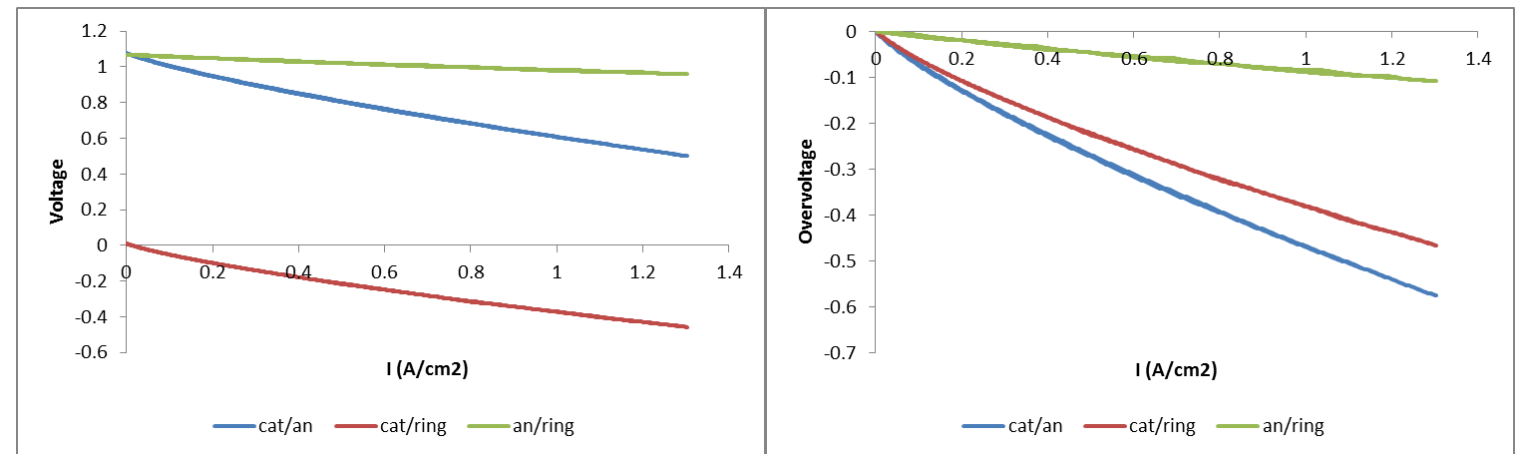

(a)

(b)

Figure 3.9: Polarization curves for the anode supported cell with ring reference electrode. Currents are normalized with respect to the cathode area. Voltages are not corrected for iR drop. $800 \mathrm{~N}$ conditions. (a) voltage (b) overvoltage. Cathode/anode polarization curve blue line, cathode/ring polarization curve red line and anode/ring/cathode polarization curve green line.

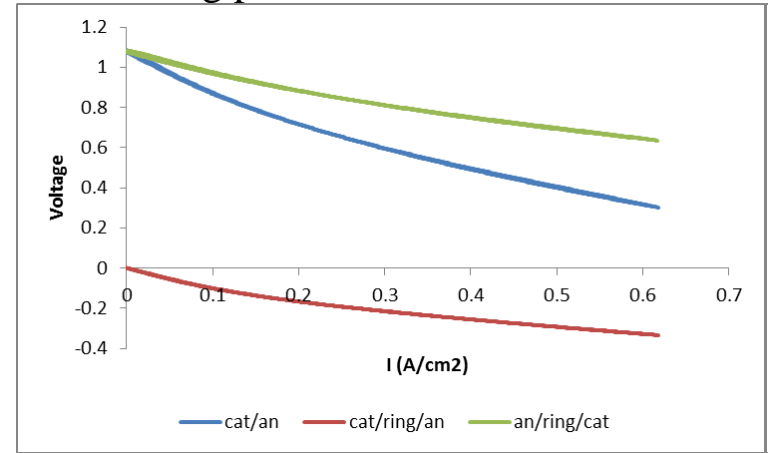

(a)

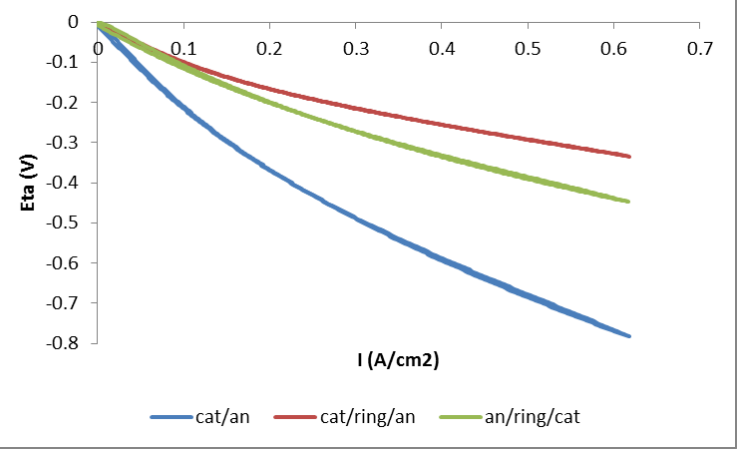

(b)

Figure 3.10: Polarization curves for the electrolyte-supported cell with ring reference electrode. Voltages are not corrected for iR drop. $800 \mathrm{~N}$ conditions. (a) voltage, (b) overvoltage. Cathode/anode polarization curve blue line, cathode/ring/anode polarization curve red line and anode/ring/cathode polarization curve green line.

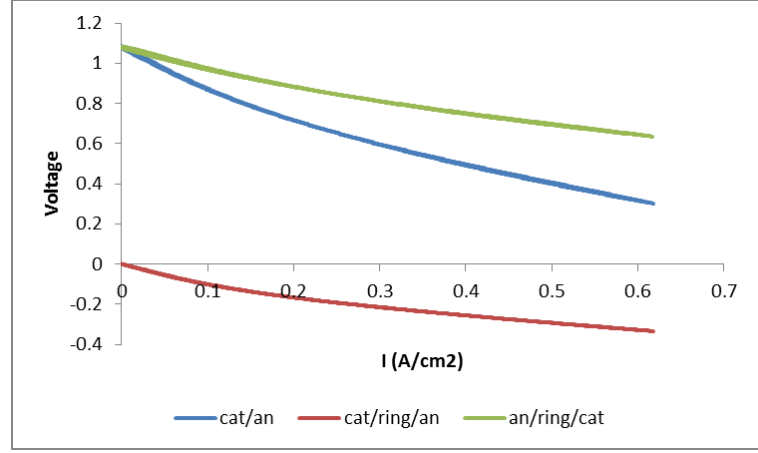

(a)

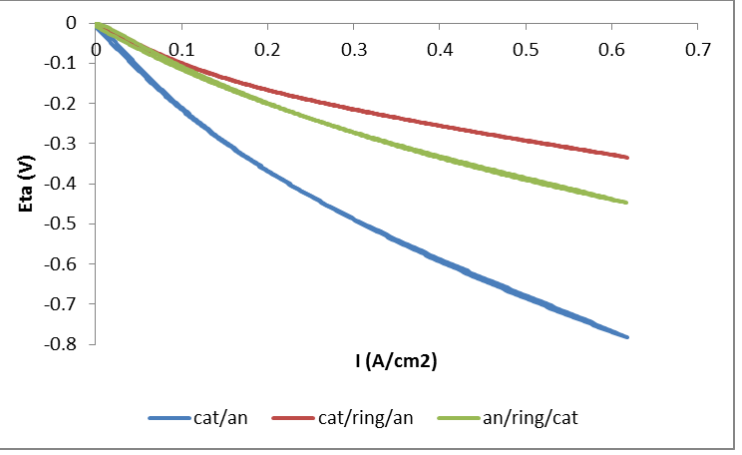

(b)

Figure 3.11: Polarization curves for the electrolyte-supported cell with micro-reference electrode. Voltages are not corrected for iR drop. $800 \mathrm{~N}$ conditions. (a) voltage, (b) overvoltage. Cathode/anode polarization curve blue line, cathode/ring/anode polarization curve red line and anode/ring/cathode polarization curve green line. 
Based on the polarization curves, in the anode-supported cell, the cathode contributes mainly to total overvoltage change of the cell, while for the electrolyte-supported cell, the cathode and anode almost equally contribute to the total overvoltage change of the cell. However, as discussed in the introduction, these assignments are likely to be faulty. Simulations predict that the potential plane sensed by the ring reference electrode will be close to the interface between the opposite overlapping electrode (bigger size) and the electrolyte, or even within the overlapping electrode (anode). Consequently, in an anode-supported cell, polarization losses measured by ring reference with the cathode/reference connection include polarization losses of both the anode and the cathode. The presence of distortion in the polarization overvoltages in the electrolyte-supported cells is less visible since the cathode and anode overvoltages are almost equally divided, but impedance data demonstrate that distortion is still probably present.

\subsubsection{Impedance data}

The impedance data of this section will demonstrate that a reference electrode does not isolate the performance of one electrode. The approach for explaining the impedance data of anodesupported cells is based on the observed difference for the impedance plots, which were obtained with changing gas compositions to the cathode or anode.

\section{Anode-supported button cell}

This analysis method is applied to the anode-supported button cell with LSM/YSZ ring reference electrode. All data were collected at OCV. Nyquist plots for the 2-electrode (cathode/anode) and 3-electrode (cathode/reference/anode) measurements are shown in Fig. 3.12(a) for $800^{\circ} \mathrm{C}$ and normal flow. It is obvious that the 3-electrode measurement has a smaller ohmic resistance and a smaller inductance than the 2-electrode measurement. These differences are consistent with the simulation results. The simulation indicates that a ring electrode senses an electrostatic plane near the anode/electrolyte interface. So compared to 2-electrode measurement, the 3-electrode measurement does not include the contact resistance for the anode and the inductance of the anode. In next chapter, the alternative deconvolution approach will be applied by fitting the impedance of an appropriate equivalent circuit to the original impedance data. This fitting procedure provides accurate values for the series resistances and inductances. Because series 
resistances and inductances for 2-electrode and 3-electrode measurements are different, removing these two elements is necessary for comparisons. Fig. 3.12(b) shows the overlay plots after removing ohmic resistance and the total inductance by calculation. This plot shows that the 3-electrode measurement is clearly missing a low frequency component, which is visible in 2electrode measurement. Except for that component, the two Nyquist plots all match at higher frequencies. So any physical process associated with this low frequency component is the only physical process separated by the reference electrode.

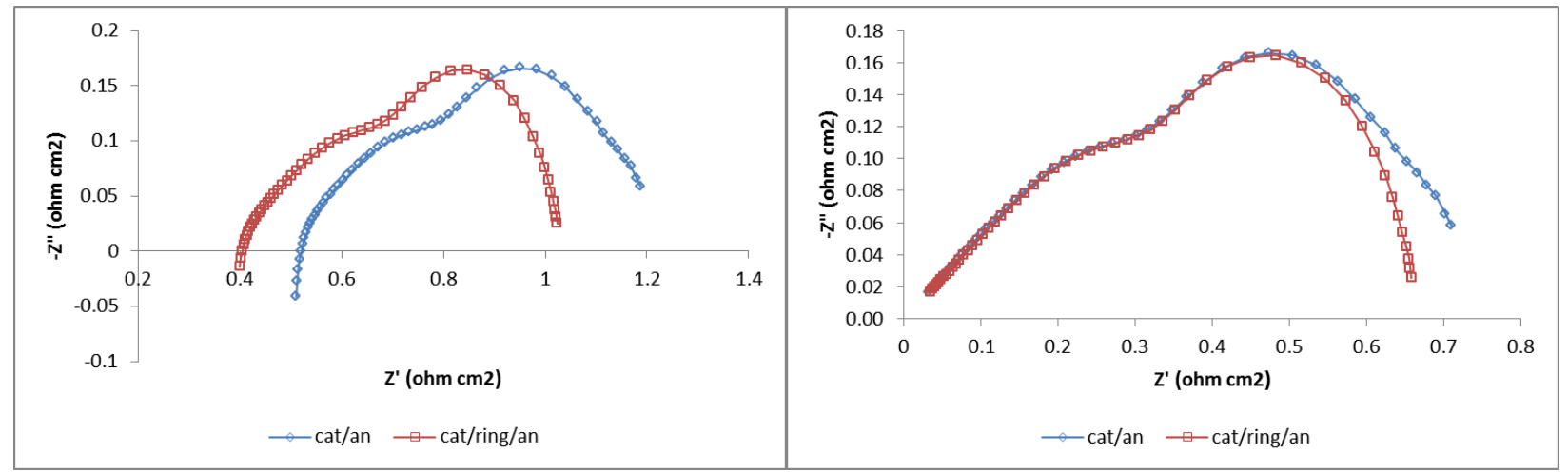

(a)

(b)

Figure 3.12: Nyquist plots for the cathode/anode and cathode/ring/anode impedances obtained using the anode-supported cell in normal flow at $800^{\circ} \mathrm{C}$. Frequency range $20 \mathrm{kHz}$ to $0.1 \mathrm{~Hz}$. (a) Original data; (b) corrected for ohmic resistances and inductances. Cathode/anode two electrode measurement blue diamonds and cathode/ring/anode measurement red squares.

The inability of the reference electrode for separating cathode and anode impedances in an anode-supported cell is more obvious by comparing the difference Bode plots ( $\mathrm{dZ}$ ' and dZ') in different flow conditions. Figure 3.13 shows difference Bode plots for both low air vs normal flow and low fuel vs normal flow. When reducing the oxygen pressure (low air) from normal for the 2-electrode (cathode/anode) measurement, dZ' shows changes below $100 \mathrm{~Hz}$ and dZ" shows a peak frequency at $6 \mathrm{~Hz}$ (Fig. 3.13(a,b)). The dZ' and dZ" plots for the 3-electrode (cathode/ring/anode) measurements show similar changes but are not identical to the twoelectrode changes. Theoretically, the dZ' and dZ" changes for the two-electrode measurements are all from the cathode going to low air flow. So, if the 3-electrode measurement only includes the cathode behavior, the changes of 3 -electrode measurement should totally overlap with the changes of the 2-electrode measurement. The difference between the 2-electrode and 3-electrode 
$\mathrm{dZ}$ ' and dZ" plots means that the reference electrode cannot isolate the cathode impedance from the anode impedance. The $\mathrm{dZ}$ plots for low fuel vs normal flow more clearly show this conclusion (Fig. 3.13(c, d)). For low fuel flow condition, the 2-electrode impedances as expected dramatically increase in the frequency range below $10 \mathrm{~Hz}$; the peak dZ" frequency appears at $0.5 \mathrm{~Hz}$. For the 3-electrode impedance, as proved in the simulation section (Fig. 3.8), changing the anode fuel composition should not affect the real 3-electrode impedance with the cathode as the working electrode. The $\mathrm{dZ}$ plots should be zero over the entire frequency range. However, the experimental $\mathrm{dZ}(\mathrm{dZ}$ ' and $\mathrm{dZ}$ ') values for the 3-electrode measurement are not zero (Fig. 3.13(c, d)). This result clearly demonstrates that the 3-electrode impedance contains the changes in the anode impedance. The conclusion agrees with that of the simulations in the literature. The reference electrode on the anode-supported cell fails to isolate the impedance of the cathode from the cell impedance.

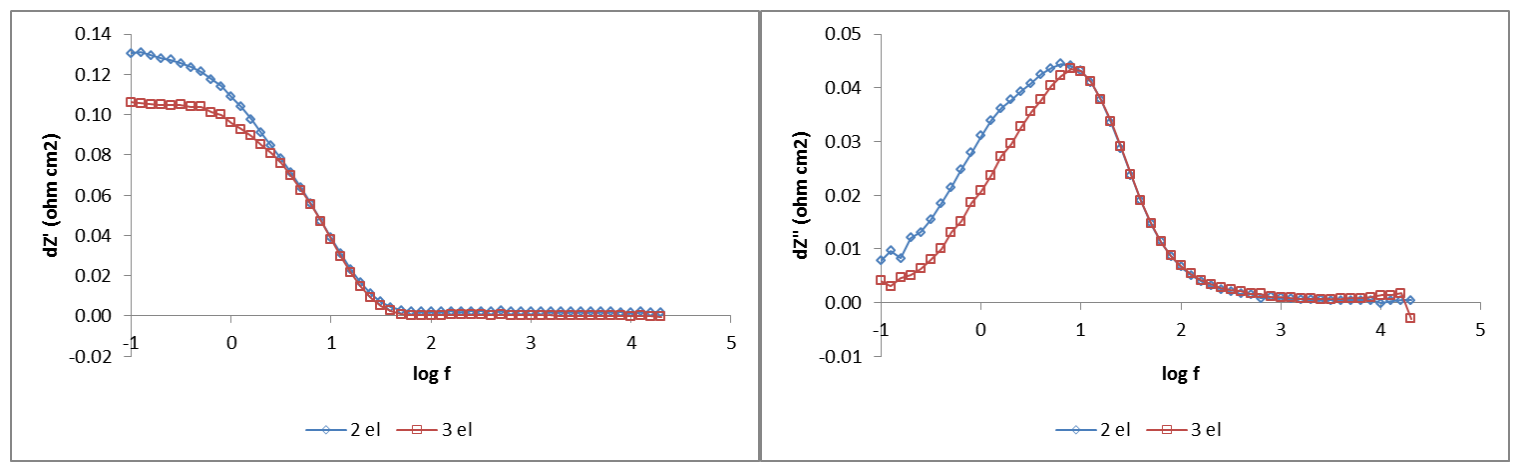

(a)

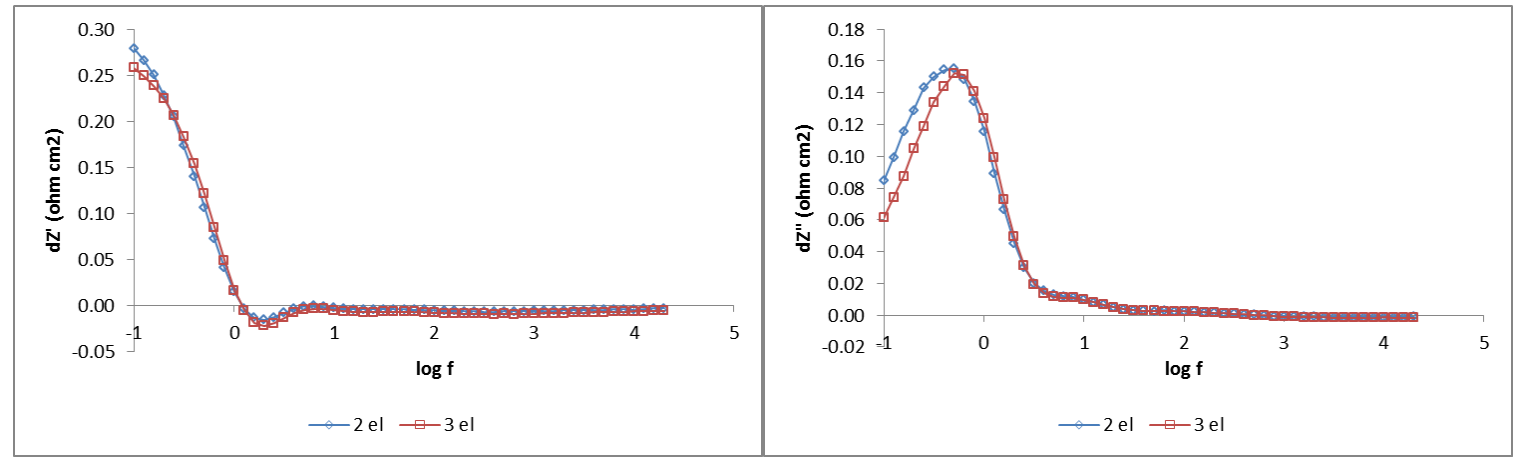

(c)

(d)

Figure 3.13: Difference Bode plots for low air vs normal flow (a \& b) and low fuel vs normal flow (c \& d). Anode-supported cell at $800^{\circ} \mathrm{C}$ with 2-electrode (cathode/anode) and 3-electrode (cathode/ring/anode) measurements. All data are corrected for series resistance and inductance. Cathode/anode two electrode measurement blue diamond and cathode/ring/anode measurement red square. 
However, by examining the complementary 3 -electrode anode/reference/cathode data (connect the anode as the working electrode), a more subtle distortion is found. The corresponding Nyquist plot for the normal flow conditions before and after correcting for the inductance and ohmic resistance shows the distortion (Fig 3.14). Contrary to simulations, this distortion as a significant impedance arc is visible at the lowest frequencies. The existence of this arc agrees with the difference in the 2-electrode and 3-electrode Nyquist plots in Fig. 3.12b. This arc can be assigned to a gas diffusion process between the anode current collector and the equipotential plane sensed by the reference electrode. As simulations suggest, the equipotential plane line sensed by the reference electrode is inside the anode near the anode/electrolyte interface. The corrected "arc" exhibits negative values for some part of Z'. This behavior is likely an artifact instead of real polarization resistance, the origin of which is related to the change in position of the equipotential line sensed by the reference electrode as a function of frequency. So the anode/reference/cathode measurement data cannot be used for obtaining an accurate measurement of the gas diffusion impedance.

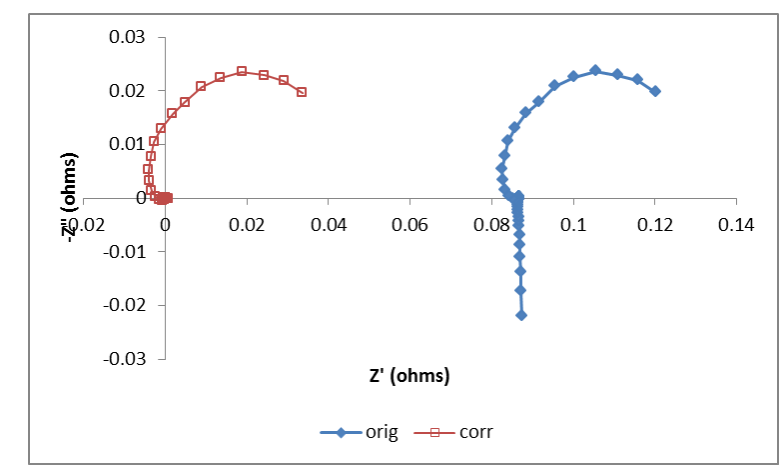

Fig. 3.14: Nyquist plot for the 3-electrode anode/ring/cathode impedance for the anodesupported cell at $800^{\circ} \mathrm{C}$ and normal flow. The corrected data is obtained from the original data by subtraction of the inductance and series resistance. The blue diamonds show the original data and the red squares show the corrected data.

\section{Electrolyte-supported Cell}

As discussed in section 1.2.4, for the 3-electrode impedance measurements, simulations predict that the inductance loops either at the high frequency end or the low frequency end of the Nyquist plot are artifacts. These artifacts are obvious when the time constants for the anode and cathode differ by orders-of-magnitude. So if we observe such inductance loop artifacts for our 
experimental impedance data for the electrolyte-supported cell, we can say that the impedance measurements for the 3-electrode configuration are distorted and are not accurate.

For the electrolyte-supported cell with the ring reference electrode, Fig. 3.15 shows the 2electrode impedance data for all gas flows. All 2-electrode Nyquist plots exhibit two welldefined arcs at very different frequencies (Fig. 3.15(a)). Through changing the flow from normal to low air flow, the corresponding high frequency arc increases and low frequency arc has no change (Fig. 3.15(b)). When changing from normal to low fuel flow, the low frequency arc increases and the high frequency arc has no change. So the high frequency arc is associated to cathode impedance and low frequency arc is assigned to the anode. This interpretation of the data corresponds to the simulations reported by Cimenti et al. [17, 18], in which the cathode and anode also have very different time constants.

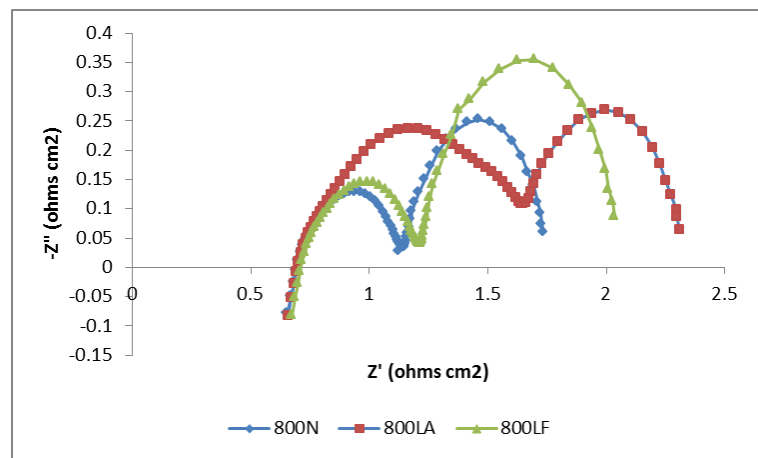

(a)

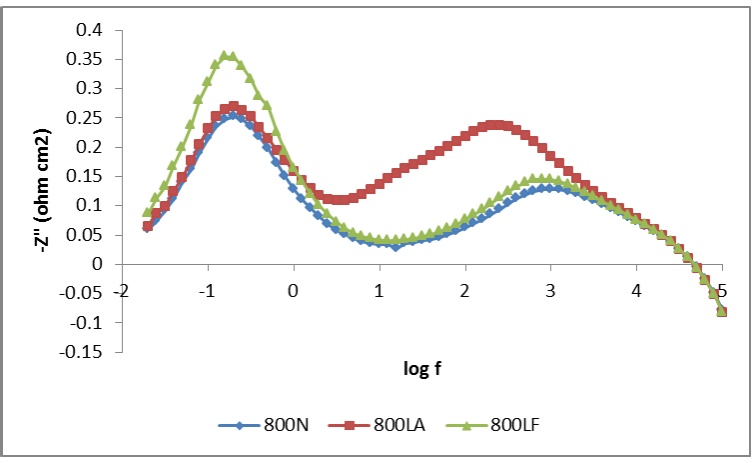

(b)

Fig. 3.15: Cathode/anode Nyquist plot (a) and -Z" vs log f(b) for an electrolyte-supported cell at $800^{\circ} \mathrm{C}$ and at normal (blue line with blue diamonds), low air (blue line with red squares) and low fuel gas flows (green line with green triangles).

Fig. 3.16(a) contains the 2-electrode and the complementary 3-electrode impedance measurements for $800^{\circ} \mathrm{C}$ and normal flow. In order to better illustrate peak frequencies, Fig. 3.16(b) shows the corresponding plots of -Z" vs log f. The 2-electrode impedance contains two arcs with peak frequencies near $500 \mathrm{~Hz}(\log \mathrm{f}=1.9)$ and $0.25 \mathrm{~Hz}(\log \mathrm{f}=-0.6)$. The 3-electrode cathode/reference/anode measurement has a peak frequency of $250 \mathrm{~Hz}(\log \mathrm{f}=2.4)$, close to the high frequency arc in the 2-electrode measurement. In the Nyquist plot (Fig. 3.16(a)), this cathode/reference/anode impedance plot exhibits a loop structure at the low frequency end 
(larger Z' values). The shape of the loop is characteristic of an inductance parallel to a resistance. Hence, this shape is often called an inductive loop in the literature. As noted in section 1.2.4, this loop is an artifact. The anode/reference/cathode measurement yields an arc at $0.25 \mathrm{~Hz}$ which identically matches in frequency the low frequency arc in the 2-electrode impedance measurement. A large inductive loop appears at the high frequency end. This pattern is repeated for the three gas flow conditions and the two temperatures. Since the high frequency arc is assigned to the cathode, the cathode/reference/anode measurement shows that generally the reference electrode can isolate the cathode impedance in the tested electrolyte-supported cell when the anode and cathode have largely different time constants. However, the inductive loops at the low frequency end show that this isolation is not perfect. The inductive loop masks any possible low frequency component in the cathode impedance. The anode/reference/cathode impedance likewise matches the low frequency arc in the 2-electrode impedance, but the high frequency inductive loop suggests that the anode/reference/cathode impedance measurement includes cathode impedance. In both 3-electrode measurements, the series resistance at low frequencies is not the same as series resistance obtained at high frequencies because of the inductive loops. This is the reason that the polarization curves cannot be accurately corrected with true iR drop based on 3-electrode measurements.

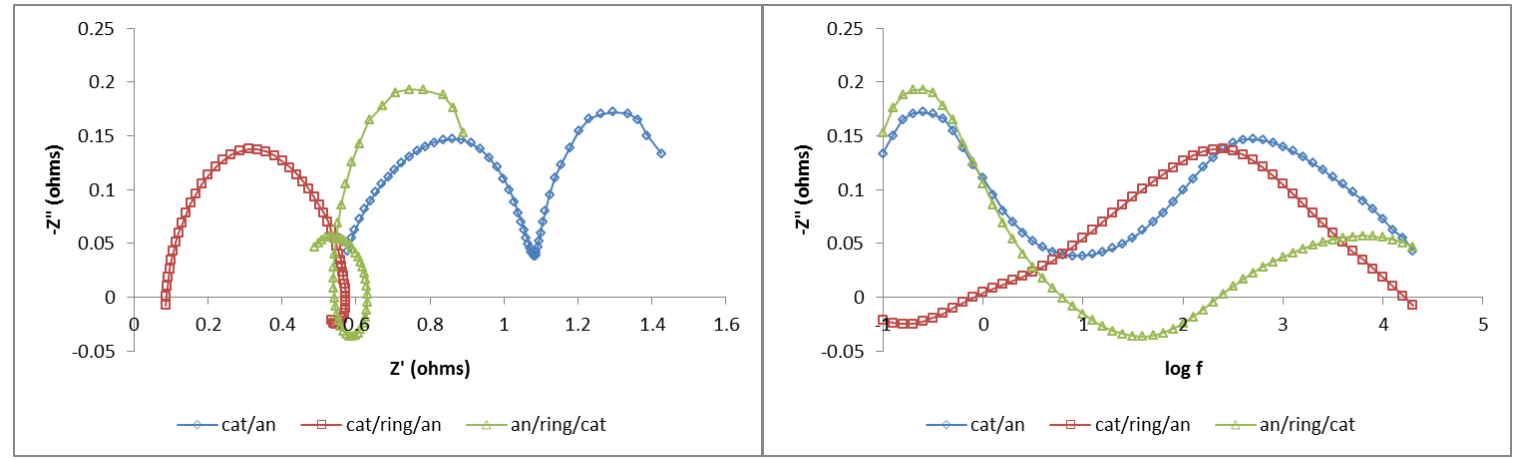

(a)

(b)

Fig. 3.16: (a) Overlay Nyquist plots for cathode/anode (blue line with blue diamonds), and cathode/reference/anode (red line with red squares) and anode/reference/cathode at $800^{\circ} \mathrm{C}$ and normal flow (green line with green triangles). The ring electrode is on the cathode side. (b) Overlay plots of $-Z$ " vs $\log f$. 
The above behavior observed in the electrolyte-supported cell with the ring reference electrode is very similar to the behavior predicted by simulations [18-20]. On an electrolyte-supported cell, simulations predict that if one electrode is displaced nearer to the reference electrode by even a fraction of the electrolyte thickness, the equipotential plane sensed by a reference electrode will be biased toward the electrode closer to the reference electrode [17-18]. When the cathode and anode have impedances with different peak frequencies (correspondingly time constants), the position of the equipotential plane sensed by the reference electrode changes with frequency. In one simulation by Cimenti et al., at the highest frequencies where both electrodes show nearly ohmic behavior, the plane is closer to the working electrode. As the frequency decreases, the equipotential plane moves towards the counter electrode, and even penetrates into the counter electrode, therefore including the performance of the counter electrode. If the cathode and anode have different polarization resistances or time constants, the 3-electrode impedance exhibits artifacts that appear like inductance loops either at the high frequency end or the low frequency end of the Nyquist plot. Even in a cell with the cathode and anode arcs with overlapping frequencies, the inductive loops might not be apparent, but the counter electrode impedance would still affect the 3-electrode measurement. So, the presence of inductive loops clearly shows that impedance measurement for the working electrode is inaccurate and that the counter electrode impedance is present in the 3-electrode measurements.

As noted in the previous chapter (section 1.2.4), simulations suggested that a micro-reference electrode located near the working electrode might provide better isolation of the working electrode performance from the counter electrode performance. The micro-electrode must be within one electrolyte thickness of the working electrode and have a radial dimension less than one electrolyte thickness. This requirement was achieved on the relatively thick electrolyte supported cell. For the electrolyte-supported cell with the silver micro-reference electrode (Fig. 3.17), the peak frequencies of the major arcs for the 3-electrode cathode/reference/anode and anode/reference/cathode measurements again identically match the high and low peak frequencies of the 2-electrode impedance (Fig. 3.17b). Also, similar inductive loops still show up in impedance spectra (Fig. 3.17a). A visible inductive loop shows up at the low frequency end with cathode/reference/anode measurement and the anode/reference/cathode impedance shows a small inductive loop at high frequencies. In both cases, the frequency of the minima in $-Z$ " in 3 - 
electrode measurements coincides with the frequency of the peak in the 2-electrode Z" plot (Fig. 3.17(b)). Consequently, use of a micro-electrode with dimensions equal or smaller than the electrolyte thickness fails to isolate the impedance of one electrode.

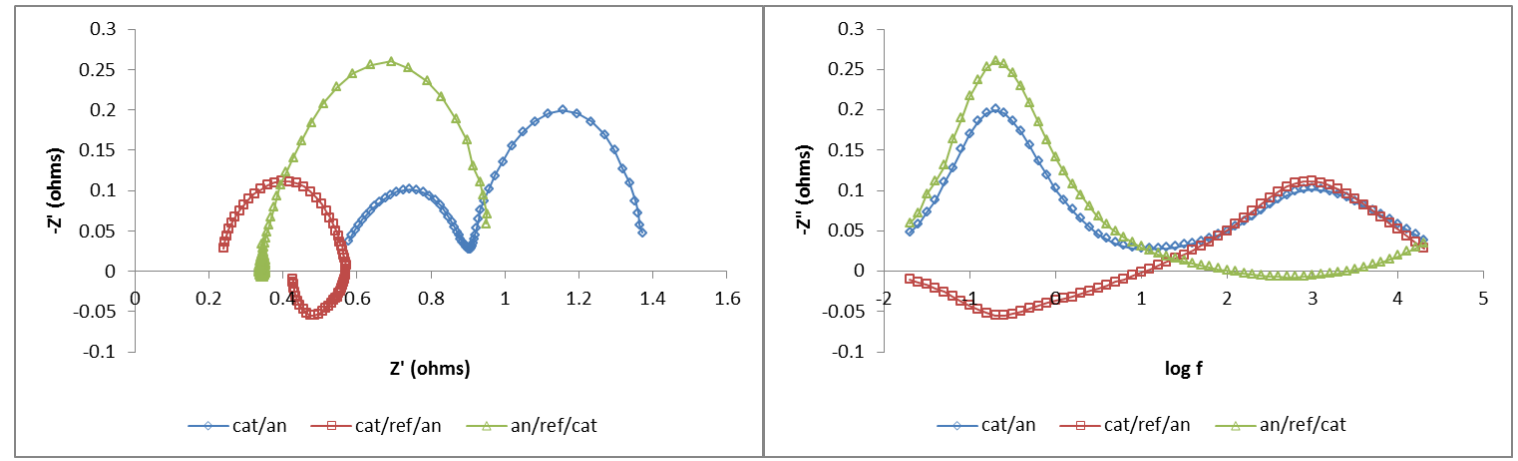

(a)

(b)

Fig. 3.17: (a) Overlay Nyquist plots for cathode/anode (blue line with blue diamonds) and cathode/reference/anode (red line with red squares) and anode/reference/cathode (green line with green triangles) at $800^{\circ} \mathrm{C}$ and normal flow. The microreference electrode is next to the cathode. (b) Overlay plots of $-Z$ " vs $\log f$.

\subsection{Conclusions}

In either of the common button cell configurations, anode-supported or electrolyte-supported, the inability of the reference electrode to isolate the performance (polarization curves and impedance) of one electrode was proved by both simulation and experiment. In the anode-supported cell, the cathode/reference/anode measurement only separates the gas diffusion impedance on the anode side from all other impedances in the anode and cathode. The anode/reference/cathode measurement contains a distortion which is probably an inductive loop artifact. The inductive loop leads to an incorrect value for the series resistance at lower frequencies. In the electrolytesupported cell, the cathode and anode have widely separated peak frequencies in the impedance spectra. This property leads to the presence of inductive loops in the 3 -electrode measurements. The change in the equipotential plane sensed by the reference electrode with changing frequency causes inductive loops. Neither a polarization resistance nor a series resistance for one electrode is readily obtained from the 3 -electrode impedance measurement because of the distortion present as the inductive loops. 
In general, for the common button SOFC with a thin electrolyte, a simple protocol is suggested when using a reference electrode to prove whether the working electrode impedance is truly accurate. The protocol is changing the gas composition to the counter electrode. The observed absence of change in the 3-electrode measurement validates the ability to use the reference electrode to isolate the working electrode impedance. For evaluating the impedance and polarization resistance associated with one electrode, a better strategy is developed and will be described in next chapter, which is the deconvolution analysis and equivalent circuit fitting as a function of gas flow. 


\subsection{References}

[1] Anne, C.; Co, S.; Xia, J. ; Birss, V.I. J. Electrochem. Soc. 2005, 152, A570-A576.

[2] Barbucci, A.; Carpanese, P.; Cerisola, G.; Viviani, M. Solid State Ionics. 2005, 176, $1753-$ 1758.

[3] Matsui, T.; Mikami, Y.; Muroyama, H.; Eguchi, K. J. Electrochem. Soc. 2010, 157, B1790B1794.

[4] Xiao, H.; Reitz, T.L.; Rottmayer, M.A. J. Power Sources 2008, 183, 49-54.

[5] Xiao, H.; Rottmayer, M.A.; Seibert, T.; Reitz, T.L. ECS Transactions 2009, 16, 189-201.

[6] Tao, Y.; Nishino, H.; Ashidate, S.; Kokubo, H.; Watanabe, M.; Uchida, H. Electrochim. Acta 2009, 54, 3309-3315.

[7] Liu, B.; Jiang, Z.; Ding, B.; Chen, F.; Xia. C. J. Power Sources 2011, 196, 999-1005.

[8] Jiang, Z.; Zhang, L.; Feng, K.; Xia, C. J. Power Sources 2008, 185, 40-48,

[9] Wang, W.; Jiang, S.P. Solid State Ionics 2006, 177, 1361-1369.

[10] Bossche, M.V.; Matthews, R.; Lichtenberger, A.; McIntosh, S. J. Electrochem. Soc. 2010, 157, B392-B399.

[11] Offer, G.J.; Shearing, P.; Golbert, J.I.; Brett, D.J.L.; Atkinson, A.; Brandon, N.P. Electrochim. Acta 2008, 53, 7614-7621.

[12] Escobar J. A.; Pakalapati, S. R.; Celik, I. B.; Finklea, H. ECS Transactions 2009, 25(2), 391-400.

[13] Nielsen, J.; Hagen, A.; Liu, Y.; Solid State Ionics. 2010, 181, 517-524

[14] Schichlein, H.; Muller, A.C.; Voigts, M.; Krugel, A.; Ivers-Tiffée, E. J. Appl. Electrochem. 2002, 32, 875-882.

[15] Winkler, J.; Hendriksen, P.V.; Bonanos, N.; Mogensen, M. J. Electrochem. Soc. 1998, 145, 2431-2439.

[16] Jørgensen, M.J.; Primdahl, S.; Mogensen, M. Electrochim. Acta 1999, 44, 4195-4201.

[17] Cimenti, M.; Co, A.C.; Birss, V.I., Hill, J.M. Fuel Cells 2007, 7, 364-376.

[18] Cimenti, M.; Birss, V.I.; Hill, J.M. Fuel Cells 2007, 7, 377-391.

[19] Adler, S.B. J. Electrochem. Soc. 2002, 149, E166-E172.

[20] McIntosh, S.; Vohs, J.M.; Gorte, R.J. J. Electrochem. Soc. 2003, 150, A1305-A1312. 


\section{Chapter 4 Analysis of SOFCs with deconvolution methods}

\subsection{Introduction}

In chapter 3, the experimental data have supported the simulation results that a reference electrode does not accurately isolate the performance (polarization curve or impedance) of a single electrode in two types of commercially important button SOFCs, an anode-supported design and an electrolyte supported design. The results were obtained through analysis of both 2-electrode (e.g. cathode vs anode, or cathode/anode) and 3-electrode (e.g. cathode as the working electrode, anode as the counter electrode, and a reference electrode, or cathode/reference/anode) impedances as a function of fuel and air compositions and at two temperatures. The results are in agreement with several simulations in the literature for button cell designs [1-7]. The simulations predict that impedance measurements of the working electrode with a reference electrode in a 3-electrode configuration cannot totally separate the impedance of working electrode from the counter electrode. Certain cases, when the cathode and anode each has widely separated peak frequencies for impedances, lead to inductive loop artifacts present at the high or low frequency extremes in 3-electrode impedance measurements. The polarization curves of a single electrode (overvoltage vs current) are also inaccurate because of the cross contamination of the cathode polarization by the anode polarization. Only specialized cell designs are capable of accurately measuring the impedance of a cathode or anode. [8-17]

Deconvolution analysis and equivalent circuit fitting as a function of gas flow is a better strategy for obtaining the separated cathode or anode performance. This analysis method will be described in this chapter. As discussed in chapter 2, the deconvolution method was first developed by Ivers-Tiffee and co-workers [18]. The deconvolution plot is a plot of distribution of relaxation times. It is used to identify key relaxation times (peak frequencies) in impedance spectra. As will be shown, the deconvolution plot brings out peak frequencies not readily visible

in the original impedance spectrum. The major peak information is used to design relevant equivalent circuit models for the cell impedance. Then the fit of the equivalent circuit parameters 
to the impedance data using a nonlinear regression method (ZView ${ }^{\circledR}$ software) is examined as a function of gas flows. Based on the assumption that gas flow changes to the cathode do not affect the anode impedance, the separate cathode and the anode polarization resistances can be identified. Ivers-Tiffee and co-workers have already applied the deconvolution method to several types of commercially relevant cells (LSCF cathode, Ni anode) and to symmetrical cells [19-30]. Mogensen used another approach based on the derivative of the in-phase impedance with respect to the log frequency as a function of changing gas flows, which also provides the information of peak frequencies associated with the anode or cathode [31].

\subsection{Objectives}

In this chapter, an approach for generating deconvolution spectra combined with the appropriate equivalent circuit fitting is discussed. All the deconvolution analysis can be completed on an Excel® spreadsheet and without any extra mathematics software. Two button cells (one anodesupported SOFC and the other electrolyte-supported SOFC) discussed in last chapter and another anode-supported design are analyzed with this method. All three designs use LSM as the cathode material and nickel as the anode material. The results provide insight on the number of processes contributing to the total impedance of a SOFC. Through systematic changes in gas composition to the anode or cathode, the approximate contributions of the cathode and anode to the total polarization resistance of the SOFC are identified. A comparison is made between the apparent polarization resistances obtained using a reference electrode on an anode-supported design and the polarization resistances obtained from this method.

\subsection{Experimental}

The detailed experimental approach for preparing two kinds of button cells (one anode-supported SOFC and the other electrolyte-supported SOFC) is provided in section 3.2. Briefly, an anodesupported half-cell (Ni/YSZ as anode and YSZ as electrolyte) from MSRI was prepared by screen printing a homemade cathode composed of LSM/YSZ and a layer of pure LSM on top as current collector (Cell 1). This cell was discussed in section 3.3 and had the LSM/YSZ ring reference electrode. An electrolyte-supported cell was purchased from Fuel Cell Materials, and was composed of a proprietary electrolyte, a Ni/YSZ anode and an LSM/YSZ cathode (Cell 2). This cell was also discussed in section 3.3 and had the silver micro-reference electrode. In both 
cells, the effective electrode area was the cathode area $\left(1.27 \mathrm{~cm}^{2}\right)$. Impedance data here shown on the graphs are without correction for the area. A new kind of anode supported cell from MSRI was composed with a anode of $0.8 \mathrm{~mm}$ thick Ni/YSZ support and a 12 micron Ni anode active layer, a 10 micron YSZ electrolyte with a 5-15 micron SDC barrier layer between the cathode and the electrolyte and a cathode of 15 micron SDC/LSM active layer and a 50 micron LSM current collector layer (area $2.27 \mathrm{~cm}^{2}$ ) on top (Cell 3). A pair of leads from the potentiostat to the cell works as current and voltage sense, one pair to the cathode and the other to the anode of the mounted cells.

All the electrochemical measurements were obtained at OCV using a Solartron Cell Test system with the frequency range between $100 \mathrm{kHz}$ and 0.1 or $0.02 \mathrm{~Hz}$ using $10 \mathrm{log}$ linear steps in frequency per decade. Significant inductance effects $\left(\sim 10^{-7} \mathrm{H}\right)$ appear above $10 \mathrm{kHz}$ because of the length of the leads, so the data for analyses were cut off to frequencies below $20 \mathrm{kHz}$. Multiple flow conditions were used for cell testing: (1) Normal flow (100\% wet $\mathrm{H}_{2}, 100 \%$ humid air), (2) Low Air (100\% wet $\mathrm{H}_{2}$ to anode, $50 \%, 20 \%$ or $12.5 \%$ air with the balance nitrogen to cathode), and (3) Low Fuel (50\% or $20 \%$ wet $\mathrm{H}_{2}$ with the balance nitrogen to anode, $100 \%$ humid air to cathode) and the testing temperatures were set at $800^{\circ} \mathrm{C}, 750^{\circ} \mathrm{C}$ or $700^{\circ} \mathrm{C}$. For Cell 3, four impedance scans were completed in sequence at each gas flow condition for error analysis and improving the signal-to-noise. Polarization curves were also obtained.

\subsection{Results and Discussion}

\subsubsection{Deconvolution and equivalent circuits}

The detailed process for deconvolution steps and building of equivalent circuits is discussed in chapter 2. The deconvolution spectrum indicates the minimum number of arc-forming elements required in the equivalent circuit. The equivalent circuit is composed of multiple elements in series and each element contributes to one of the arcs in the deconvolution spectrum. By changing the gas composition to the anode or cathode, certain peak frequencies in the deconvolution plot will change and equivalent circuit elements strongly associated with that peak frequencies can be assigned to the cathode or the anode. Through this analysis, the electrode and equivalent circuit element that dominates the total impedance can be identified, and thus these results provide guidance on how to improve the SOFC. 
The arc-generating elements composed of equivalent circuits for SOFCs include the most common arc-generator (RQ), a parallel combination of a charge transfer resistance and a constant phase element (CPE), the Gerischer impedance and the finite length Warburg impedance.

To find the best values for the parameters in the equivalent circuit requires a complex nonlinear regression fitting procedure. The commercial software ZView ${ }^{\circledR}$ can provide least squares fits of all parameters, and yields all of the parameters for elements in the design of an equivalent circuit. Fitting the data by ZView has two restrictions. Initial guesses for the parameters need to be reasonably close to the correct values, or else the software fails to converge to a solution. A spreadsheet is first used to calculate the impedances of the equivalent circuit and the parameters are adjusted to get an approximate fit to both the impedances and the peak frequencies obtained from the deconvolution spectrum. These parameters are then put to ZView as the initial guess. With this procedure, ZView rapidly converges to an optimum fit. However, in some cases, the parameters (particularly if the exponents of some of the RQ elements greater than 1) are fixed to avoid unrealistic results returned by the ZView fit. As an added requirement, the calculated impedances of the best fit equivalent circuit are subjected to deconvolution analysis and the resulting deconvolution spectrum is compared to the deconvolution spectrum of the data. This second requirement helps to identify the need for additional elements and sometimes causes some of the equivalent circuit parameters be fixed.

\subsubsection{Cell 1: Anode-supported cell with LSM/YSZ cathode}

Fig. 4.1 shows the Nyquist plots and deconvolution spectra for Cell 1 at two temperatures and three flow conditions. In this experiment, the lowest frequency reaches $0.1 \mathrm{~Hz}$. Each data set is the average of impedance collected with the cathode as the working electrode and one collected with the anode as the working electrode. The two data sets agree very well, and to reduce stochastic noise, the Z' and Z" data are merged in ZView (see section 4.4.4 for a discussion of sources of noise). In Fig 4.1, at least 2 arcs are visible in the Nyquist plots, and the deconvolution spectra indicate the presence of three or more arcs. 
The obvious feature for all of the deconvolution spectra of this cell is a long tail extending to the high frequency limit, which is particularly evident in the $700^{\circ} \mathrm{C}$ deconvolution spectra (Fig. 4.1(d)). From the discussion in chapter 2, the single fractal Gerischer impedance is possible to fit the tail, so it is suggested to be used as an appropriate element in equivalent circuit. An equivalent circuit without a Gerischer impedance (RQ elements only) requires at least one RQ element with a very low exponent $(\mathrm{n}<0.3)$, and leads to the parameters for all elements having large uncertainties in the ZView output. Consequently, any discussion of trends in the equivalent circuit parameters with respect to gas flow or temperature is compromised. Fitting the tail with the finite Warburg element also fails because the characteristic sharp small peak at higher frequencies from the main peak (Fig. 2.9(b)) is not present in the deconvolution spectra of the data. The tail in the data deconvolution spectrum also decays more slowly than in the FLW deconvolution spectra.

The Adler/Lane/Steele model predicts an ideal Gerischer impedance (exponent $n=0.5$ ) for a mixed ionic/electronic conductor [32]. The key assumptions in that model include the following: (1) the electrode is treated as dilute solid solution with one independent parameter, the oxide ion vacancy concentration; (2) the porous electrode is treated as a superposition of two continuous phases, solid and gas; (3) the active or utilization layer thickness is larger than the particle sizes; (4) the total electrode thickness is much larger than the active layer thickness; and (5) the only contributions to polarization resistance are diffusion of oxygen species in the solid and exchange of $\mathrm{O}_{2}$ at the solid/gas interface. This model is applied to mixed ionic-electronic conductor like LSC, so it does not apply to an electrode composed of only LSM because of the very small ionic conductivity of this material. However, we argue that a composite LSM/YSZ electrode can resemble a pure mixed ionic-electronic conductor as the LSM contributes average electronic properties and YSZ contributes average ionic properties. Consequently, the behavior of a LSM/YSZ cathode can be reasonably described by a Gerischer-type equivalent circuit element. As discussed in section 5.4.3, symmetrical cells with pure LSM electrodes do not exhibit the Gerischer impedance, since the pure LSM is not a mixed ionic-electronic conductor, which also support the conclusion here. Deviations from these assumptions for the original model (e.g., utilization layer lengths approaching the size of the particles at higher frequencies) may account for non-ideal $(\mathrm{n}<0.5)$ exponents in the Gerischer impedance. [32, 33] 


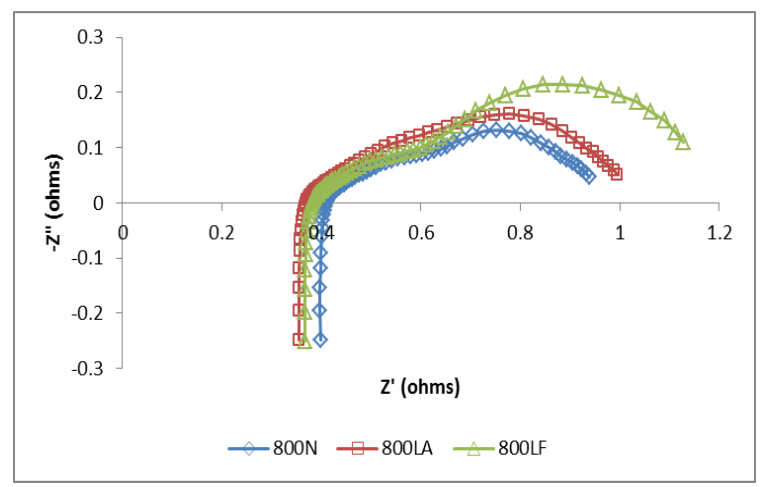

(a)

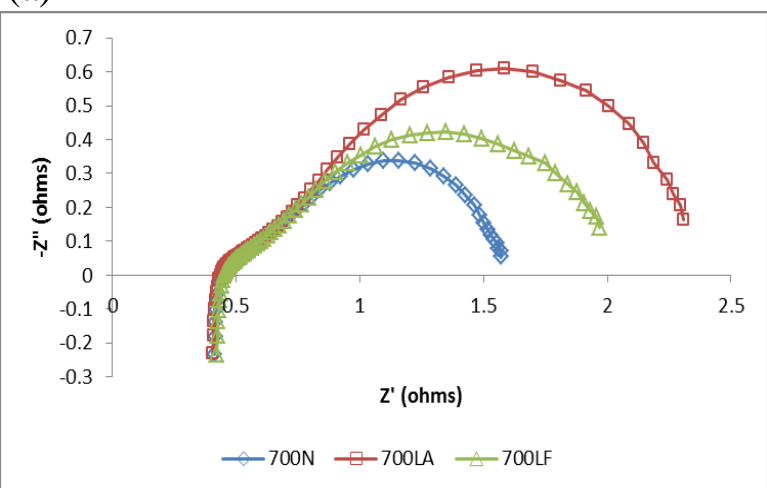

(c)

Fig. 4.1: Cell 1: (a) cathode/anode Nyquist plots at $800^{\circ} \mathrm{C}$. (b) cathode/anode deconvolution spectra at $800^{\circ} \mathrm{C}$. (c) cathode/anode Nyquist plots at $700^{\circ} \mathrm{C}$. (d) cathode/anode deconvolution spectra at $700^{\circ} \mathrm{C}$. Blue diamonds show normal flow, green triangles show low air flow and red squares show low fuel flow.

Based on the preceding discussion, the equivalent circuit used to fit the impedance data is composed of a series inductance, a "single fractal" Gerischer element, and one or more RQ elements $\left(\mathrm{LR}(\mathrm{Ge})(\mathrm{RQ})_{\mathrm{n}}\right)$. At $800^{\circ} \mathrm{C}$, a "single fractal" Gerischer element is found to be sufficient to fit the impedance and deconvolution spectra for all three gas flow conditions; a "double fractal" Gerischer element did not provide a significantly improved fit to the data (see chapter 2 for an explanation of "single fractal" and "double fractal").

Figure 4.2 illustrates the quality of the fit to the equivalent circuit for the data collected at $800^{\circ} \mathrm{C}$ and normal flow. All the data has been corrected for the inductance and series resistance obtained from the ZView fit. The three peaks in the deconvolution spectrum correspond to the three elements (Ge, RQ2, RQ3). Not only do the Nyquist plots of the data and the simulated impedances from the equivalent circuit overlay very well, but also the plots of deconvolution spectra for the data and for the simulated impedances of the equivalent circuit overlay very well. Fig (4.2(d)) shows the residuals do not exceed 0.01 ohms. 


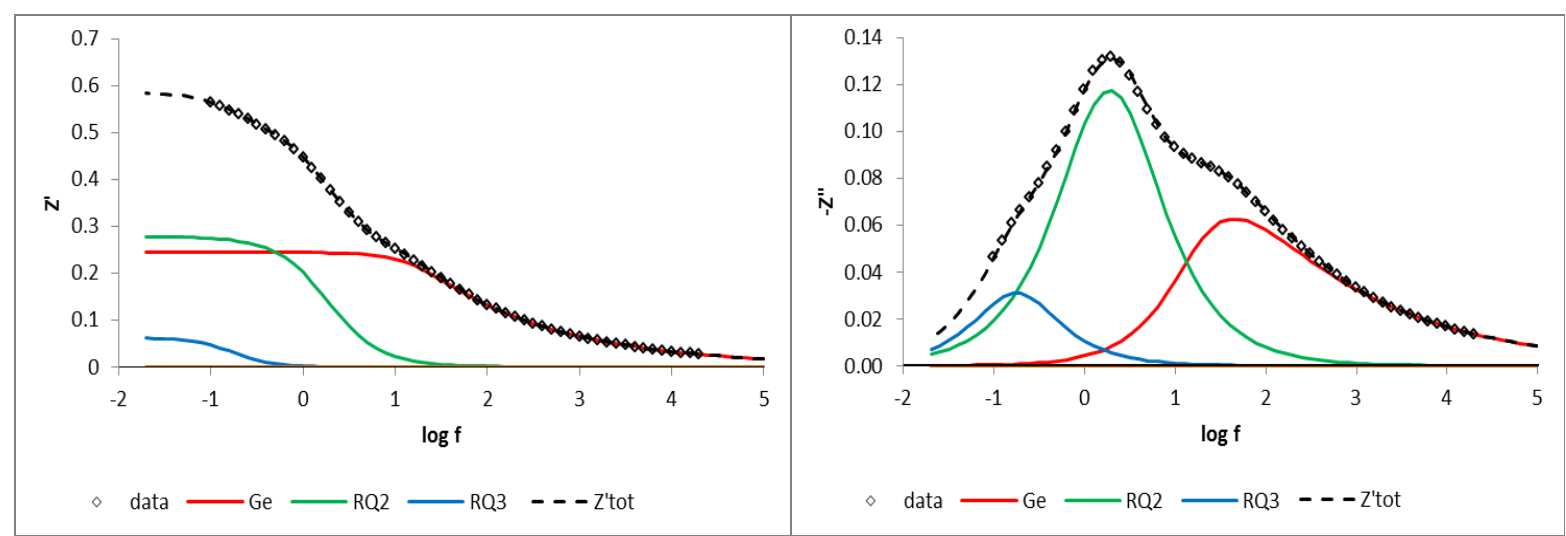

(a)

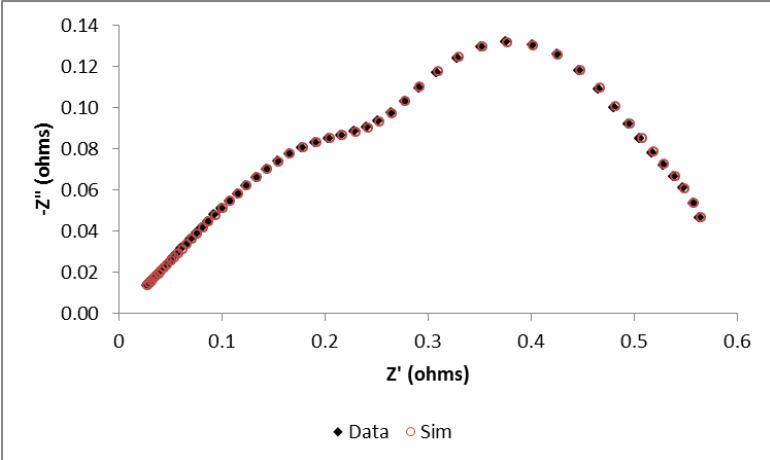

(c)

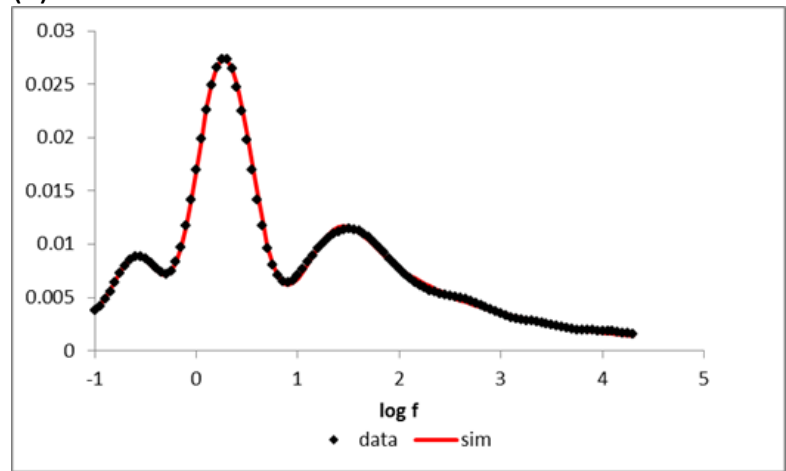

(b)

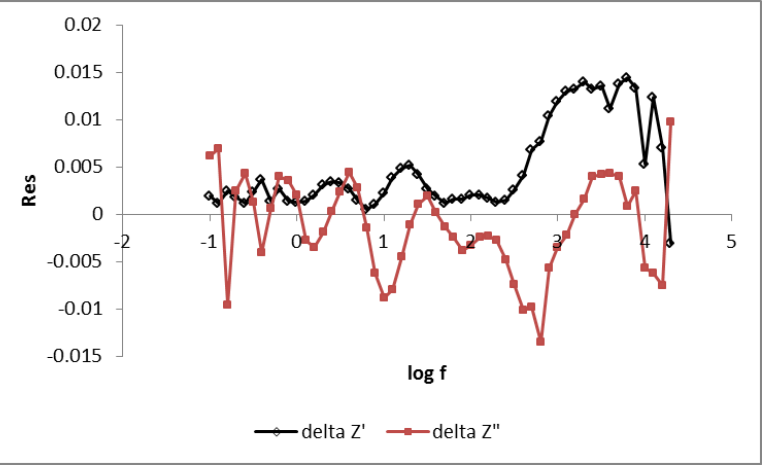

(d)

(e)

Fig 4.2. Equivalent circuit fit to Cell 1 at $800^{\circ} \mathrm{C}$ with normal flow. (a) In-phase $Z$ ' data and the contributions from each element in the equivalent circuit; (b) Out-of-phase $-Z$ " data and the contributions from each element; (c) Nyquist plot overlaying the data and the simulated impedances from the equivalent circuit; (d) Residuals (Z'(sim) - Z'(data)) and (Z'(sim) Z"(data)); (e) Overlay plot of the deconvolution spectra for the data and for the simulated impedances of the equivalent circuit. In these plots, the series resistance and inductance have been removed by calculation.

Table 4.1 contains the fitted parameters for three flow conditions at $800^{\circ} \mathrm{C}$ and for 2 -electrode and 3-electrode measurements. In the cathode/anode 2-electrode measurements, for low fuel, as shown in Fig. 4.1(b), the additional peak in the deconvolution spectrum appears near $10 \mathrm{~Hz}$, so a third RQ element (RQ1) was added. After aligning elements by maximum frequency from high 
to low, this new element is labeled RQ1, and the other two lower frequency elements RQ2 and RQ3. Table 4.2 shows just the polarization resistances and peak frequencies for 2-electrode measurements for three flow conditions at $800^{\circ} \mathrm{C}$. For the Gerischer element, the polarization resistance significantly increases and the frequency significantly decreases going from normal flow to low air. From normal flow to low fuel, the opposite trend is observed. These observations confirm that the Gerischer element is mainly associated with the cathode. For RQ3, the polarization resistance significantly increases going from normal flow to low fuel. From normal flow to low air, the polarization resistance exhibits no change, which suggests the assignment of RQ3 to the anode. For normal flow, RQ3 could also be omitted to obtain a good fit to the Nyquist plot and deconvolution spectrum, but keeping this element and fixing the resistance to $0.003 \mathrm{ohms}$ and the frequency maximum to $0.2 \mathrm{~Hz}$ improves the fit to the deconvolution spectrum. RQ1 only appears in low fuel flow and therefore is assigned to the anode. Based on changes in the polarization resistance and the frequency, RQ2 appears to have contributions from both the cathode and anode. However, a larger increase in polarization resistance $(0.28 \mathrm{ohms}$ for normal flow to $0.32 \mathrm{ohms}$ for low air, compared to $0.43 \mathrm{ohms}$ for low fuel) and a larger decrease in frequency in low fuel flow $(1.9 \mathrm{~Hz}$ for normal flow to $1.8 \mathrm{~Hz}$ for low air, compared to $0.8 \mathrm{~Hz}$ for low fuel) show the contributions arise mainly from the anode (see Table 4.2). 
Table 4.1: Fitted parameters for the $\mathrm{LR}(\mathrm{Ge})(\mathrm{RQ})_{\mathrm{n}}$ equivalent circuit to impedance data for Cell 1 at $800^{\circ} \mathrm{C}$.

\begin{tabular}{|c|c|c|c|c|c|c|c|}
\hline \multirow{2}{*}{$\begin{array}{l}\text { Flow } \\
\text { Parameter }\end{array}$} & \multicolumn{2}{|c|}{ Normal } & \multicolumn{2}{|c|}{ Low air } & \multicolumn{2}{|c|}{ Low fuel } & \multirow[b]{2}{*}{ Units } \\
\hline & 2-el & 3el & 2-el & 3el & 2-el & 3el & \\
\hline $\mathbf{L}$ & 3.7 & 1.9 & 3.7 & 1.9 & 3.7 & 2.0 & $\mathbf{x 1 0 ^ { - 7 } H}$ \\
\hline Rs & 0.38 & 0.29 & 0.33 & 0.25 & 0.35 & 0.26 & ohms \\
\hline Ge R & 0.24 & 0.25 & 0.30 & 0.30 & 0.22 & 0.21 & ohms \\
\hline Ge T & 9.4 & 9.3 & 16.9 & 17.0 & 6.3 & 5.9 & $\mathbf{x 1 0 ^ { - 3 }} \mathrm{s}$ \\
\hline Ge P & 0.30 & 0.30 & 0.30 & 0.30 & 0.32 & 0.32 & \\
\hline Ge $f_{\max }$ & 45 & 45 & 25 & 25 & 63 & 68 & $\mathrm{~Hz}$ \\
\hline $\mathbf{R 1}$ & & & & & 0.06 & 0.06 & ohms \\
\hline Q1 & & & & & 0.29 & 0.25 & \\
\hline N1* & & & & & 1 & 1 & \\
\hline RQ1 $\mathbf{f}_{\max }$ & & & & & 9 & 10 & $\mathrm{~Hz}$ \\
\hline $\mathbf{R 2}$ & 0.28 & 0.28 & 0.32 & 0.31 & 0.43 & 0.47 & ohms \\
\hline Q2 & 0.40 & 0.37 & 0.35 & 0.33 & 0.58 & 0.51 & \\
\hline N2 & 0.89 & 0.91 & 0.90 & 0.91 & 0.88 & 0.90 & \\
\hline $\mathbf{R Q 2} \mathbf{f}_{\max }$ & 1.9 & 2.0 & 1.8 & & 0.8 & 0.8 & $\mathbf{H z}$ \\
\hline $\mathbf{R 3}$ & 0.06 & 0.003 & 0.07 & & 0.12 & & ohms \\
\hline Q3 & 15 & 26 & 14 & & 7 & & \\
\hline $\mathrm{N3}^{*}$ & 1 & 1 & 1 & & 1 & & \\
\hline $\mathbf{R Q 3} \mathbf{f}_{\max }$ & 0.18 & 0.2 & 0.18 & & 0.2 & & $\mathbf{H z}$ \\
\hline $\mathbf{R p}$ (total) & 0.58 & 0.53 & 0.69 & 0.61 & 0.83 & 0.74 & ohms \\
\hline
\end{tabular}

*Certain parameter values were fixed when using ZView to improve the fit to the deconvolution spectrum and to prevent unrealistic exponents $(n>1)$. The units of $T$ and $Q$ depend on the exponents and are not shown here. 


\begin{tabular}{|c|c|c|c|c|}
\hline Flow & Normal & Low air & Low fuel & Units \\
\hline Ge R & 0.24 & 0.30 & 0.22 & ohms \\
\hline R1 & & & 0.06 & ohms \\
\hline $\mathbf{R 2}$ & 0.28 & 0.32 & 0.43 & ohms \\
\hline $\mathbf{R 3}$ & 0.06 & 0.07 & 0.12 & ohms \\
\hline $\mathbf{G e} \mathbf{f}_{\max }$ & 45 & 25 & 63 & $\mathbf{H z}$ \\
\hline RQ1 f $\mathbf{f}_{\max }$ & & & 9 & $\mathrm{~Hz}$ \\
\hline RQ2 $\mathbf{f}_{\text {max }}$ & 1.9 & 1.8 & 0.8 & $\mathrm{~Hz}$ \\
\hline $\mathbf{R Q 3} \mathbf{f}_{\max }$ & 0.18 & 0.18 & 0.2 & $\mathrm{~Hz}$ \\
\hline
\end{tabular}

These assignments are in general agreement with assignments in the literature [34, 35]. The Gerischer element at $25-60 \mathrm{~Hz}$ is associated with the dissociative oxygen adsorption and transport to the triple phase boundaries in the cathode. RQ1 has a similar assignment to dissociative adsorption of hydrogen and transport to the TPB in the anode. RQ3 is assigned to the anode since the polarization resistance rises and the maximum frequency decreases going from normal to low fuel, and because the absence of change in these parameters going from normal to low air flow. Evidence below demonstrates that this low frequency impedance is also present at $700^{\circ} \mathrm{C}$ at roughly the same frequency. The most likely assignment for an impedance element that is nearly independent of temperature is one based on gas diffusion. RQ2 might be assigned to gas diffusion inside each electrode. However, there is no confirmation of this assignment from the temperature dependence of RQ2 (see discussion of the other two cells).

Because RQ2 element contains anode and cathode elements with overlapping maximum frequency, an unambiguous determination of the cathode and anode polarization resistances is not possible. The addition of extra assumptions is needed to provide a means of estimating individual polarization resistances. If the polarization resistance of the RQ2 element is divided equally between the cathode and anode, then the cathode polarization resistance is $0.38 \mathrm{ohms}$ and the anode polarization resistance is $0.20 \mathrm{ohms}$. It seems more likely that the anode contribution to RQ2 is greater than $50 \%$. If, for example, $80 \%$ of RQ2 polarization resistance is assigned to the anode, then the anode and cathode polarization resistances at $800^{\circ} \mathrm{C}$ and normal flow are nearly equal ( 0.28 and $0.30 \mathrm{ohms}$, respectively). These values are very different from the results of the 3-electrode measurements in chapter 3. In those measurements, the impedance data 
suggested that nearly all of the cell polarization resistance was due to the cathode. The deconvolution and equivalent circuit fitting confirm the inability of the reference electrode to isolate the polarization resistance of the cathode and anode in the anode-supported cell.

To avoid the need for extra assumptions, a wider range of gas flow conditions are recommended. By varying the $\mathrm{H}_{2} / \mathrm{H}_{2} \mathrm{O}$ ratio or replacing $\mathrm{H}_{2} / \mathrm{H}_{2} \mathrm{O}$ with $\mathrm{CO} / \mathrm{CO}_{2}$ or $\mathrm{D}_{2} / \mathrm{D}_{2} \mathrm{O}$, the peak frequency for the anode element can separated from the cathode element peak frequencies, and anode processes can be more readily identified. [31]

Analysis of the data at $700^{\circ} \mathrm{C}$ is a difficult challenge. As shown in Fig. 4.1(b) and (d), the peak of the Gerischer element at $700^{\circ} \mathrm{C}$ shifts to the lower frequency and now overlaps severely with the lower frequency RQ elements. Using the ZView fitting leads to multiple sets of values of the equivalent circuit; all sets of values can fit both the impedances and the deconvolution spectra equally well. Consequently, without well-defined temperature effects on the parameters changes associated with each element, further analysis is not possible. Smaller temperature steps are proposed for future work to track each element's changes for this type of cell.

Since the deconvolution method successfully separates the cathode and anode impedance with 2electrode measurements, we can also apply the deconvolution method to cathode/reference/anode 3-electrode measurements as a check for the simulation results. After removing these two elements (ohmic resistance and the total inductance by calculation), Fig 4.3(a) shows the overlay Nyquist plots for the cathode/anode and cathode/reference/anode impedances obtained at normal flow and $800^{\circ} \mathrm{C}$. This plot shows that the 3-electrode measurement is clearly missing a low frequency component. This low frequency component is more clearly visible in the deconvolution spectra. (Fig4.3 (b)) A peak is present at $0.2 \mathrm{~Hz}$ for the 2-electrode measurement while, at the same frequency, the peak is almost absent in the 3 electrode measurement. This arc is likely associated with an anode process. Table 4.1 includes the equivalent circuit parameters for the 3-electrode impedances. In the 3-electrode measurements, RQ3 is not needed to fit the impedance data under low air or low fuel flows. RQ3 is the source of the $0.2 \mathrm{~Hz}$ peak. Fig4.3 (c) and (d) shows deconvolution spectra for the cathode/anode and cathode/reference/anode impedances in low air and low fuel. It illustrates the change in the deconvolution spectra caused by the presence of $0.2 \mathrm{~Hz}$ peak in the 2-electrode 
impedance data and its absence in the 3-electrode impedance data at low air and at low fuel flows. So RQ3 is the element that can be separated by the 3-electrode measurement.

Based on the preceding analysis, the 3-electrode cathode/reference/anode measurement only separates the gas diffusion impedance (RQ3) from the total impedance on the anode-supported cell. In low fuel condition, except RQ3, other elements remain almost the same in the 3-electrode measurements as 2-electrode measurements (Table 4.1). In Table 4.1, going from normal flow to low fuel flow, the cathode/anode and the cathode/reference/anode total polarization resistances both increase. Since the cathode polarization resistance should not be significantly affected by changes in fuel concentration, the 3-electrode cathode/reference/anode measurement must contain contributions from the anode impedance. This observation is evidence that the 3electrode cathode/reference/anode measurement contains contributions from the anode impedance. These results are consistent with the simulation predictions for the anode supported cell.

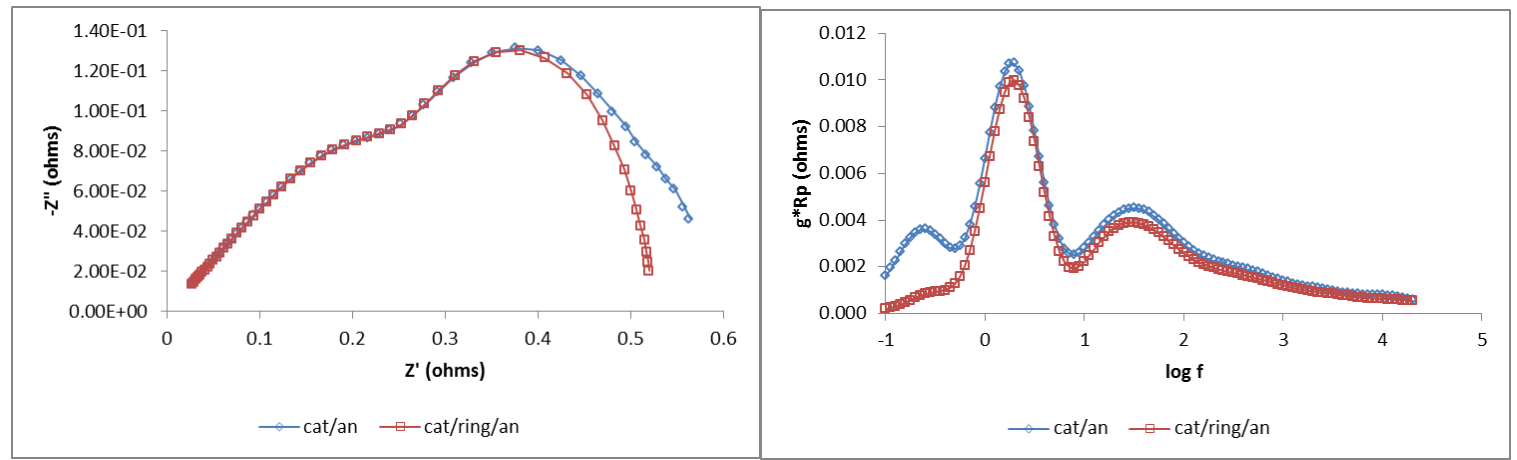

(a)

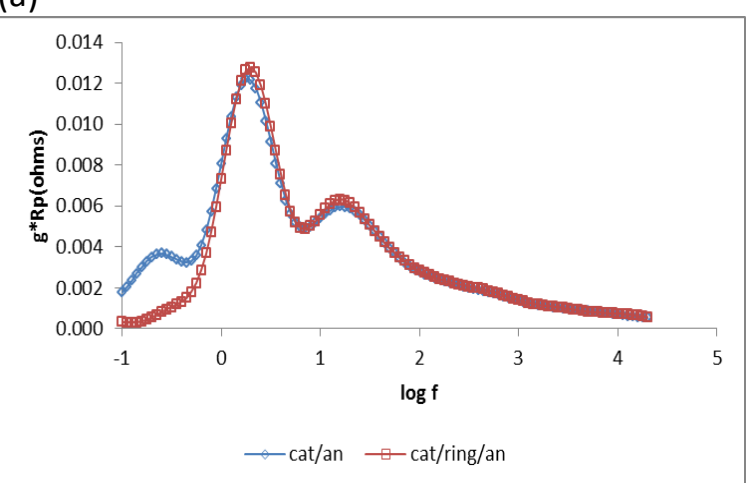

(b)

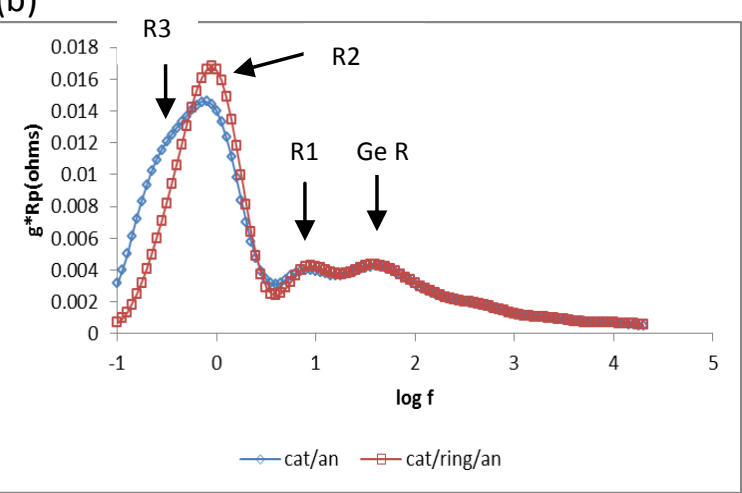

(c)

(d)

Fig. 4.3: Cell 1: (a) Nyquist plots for the cathode/anode and cathode/reference/anode impedances obtained in normal flow at $800^{\circ} \mathrm{C}$. Frequency range $20 \mathrm{kHz}$ to $0.1 \mathrm{~Hz}$. corrected for ohmic resistance and inductance (b) Deconvolution spectra for the cathode/anode and cathode/reference/anode impedances in (a). (c) Deconvolution spectra for the cathode/anode and cathode/reference/anode impedances in low air flow at $800^{\circ} \mathrm{C}$. (d) Deconvolution spectra for the 
cathode/anode and cathode/reference/anode impedances in low fuel flow at $800^{\circ} \mathrm{C}$. The deconvolution $\mathrm{g}$ values are multiplied by the total polarization resistance of each measurement.

\subsubsection{Cell 2: Electrolyte-supported cell with LSM/YSZ cathode}

The impedance and deconvolution spectra for the LSM/YSZ electrolyte supported cell are shown in Fig. 4.4. The lowest frequency of Impedance data extends to $0.02 \mathrm{~Hz}$. Two well-separated arcs appear in the Nyquist plot. It is clear that the higher frequency arc changes with low air flow and the lower frequency arc changes with low fuel flow. The deconvolution spectra show at least 4 arcs. Particularly in the low air condition, the 4 arcs are more obvious. At $800^{\circ} \mathrm{C}$, the low frequency peak has a definite shoulder on the high frequency side. To fit the highest frequency arc with a tail to higher frequencies, a fractal Gerischer impedance is appropriate for this element. However, attempts to fit the low frequency peak with a fractal Gerischer element or a finite Warburg element did not yielded good matches in the deconvolution spectra. So the other peaks can be fitted using three RQ elements. The data for all conditions are fitted to the $\mathrm{LR}(\mathrm{Ge})(\mathrm{RQ})_{3}$ equivalent circuit. 


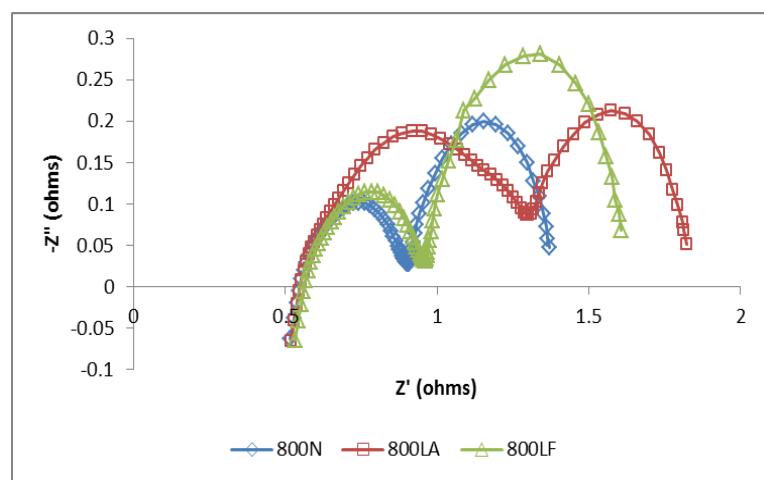

(a)

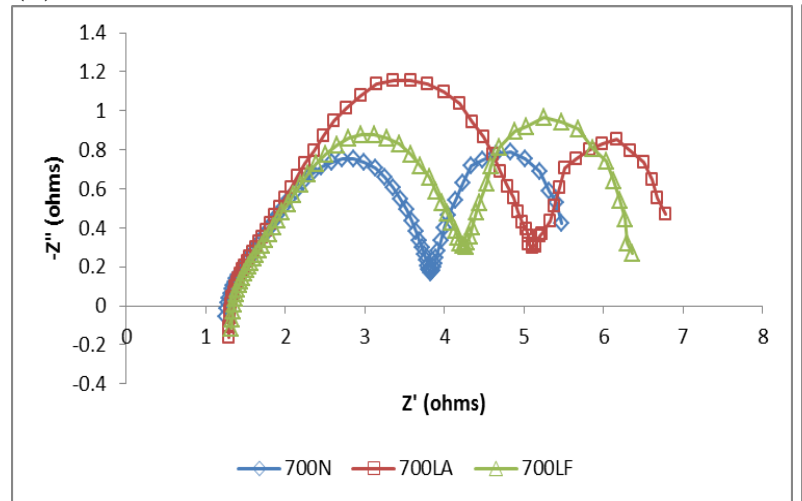

(c)

Fig. 4.4: Cell 2: (a) Nyquist plot and (b) deconvolution spectra for the electrolyte-supported cell at $800^{\circ} \mathrm{C}$; (c) Nyquist plot and (d) deconvolution spectra at $700^{\circ} \mathrm{C}$. Blue diamonds (A) show normal flow, red squares (B) show low air flow and green triangles (C) show low fuel flow.

The equivalent circuit fit to the data collected at $800^{\circ} \mathrm{C}$ and normal flow is shown in Figure 4.5. The fit quality is not as good as the fit to the anode-supported cell. Fig 4.5(d) shows the larger residuals present for out-of-phase impedance (Z") particularly at lower frequencies (smaller than $0.05 \mathrm{ohms}$ ), and the deconvolution spectra for the data and the simulated impedances fit well except a discrepancy between 1 and $10 \mathrm{~Hz}$ (Fig 4.5(e)). However, the overall fit is judged to be satisfactory. The fit to the low frequency arc requires the presence of two RQ elements below 1 $\mathrm{Hz}$ with close frequencies, which leads to larger uncertainties associated with the parameters for the two elements. However, two RQ elements are needed as a single RQ element does not fit the low frequency arc well. 

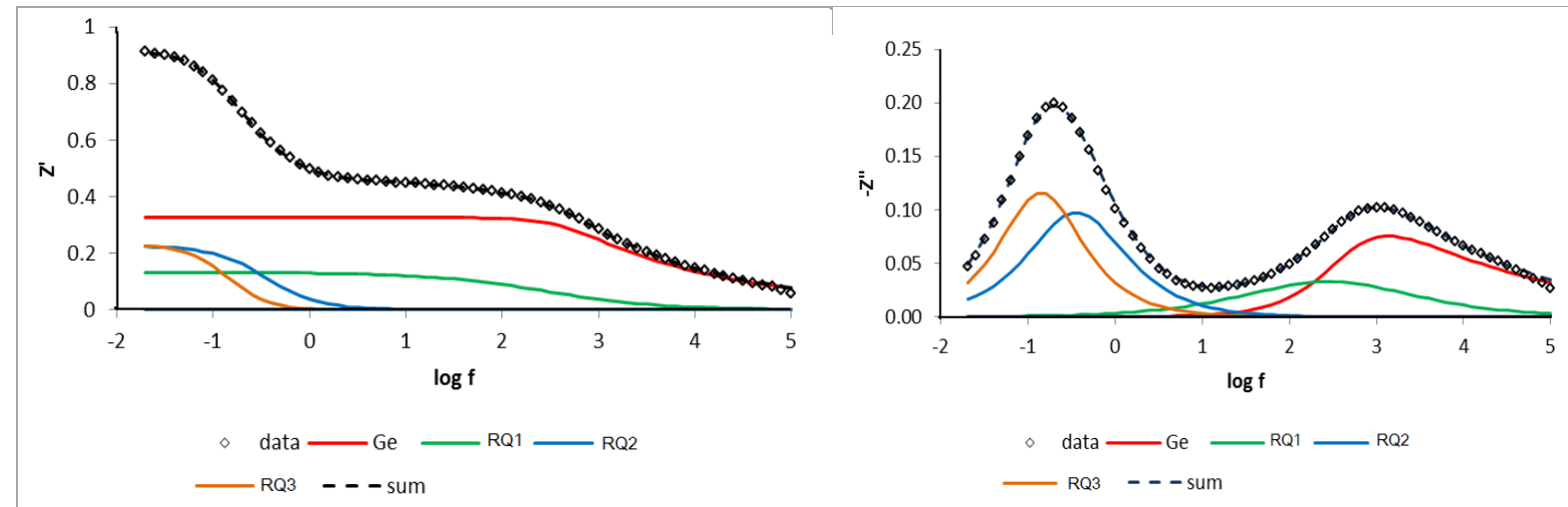

(a)

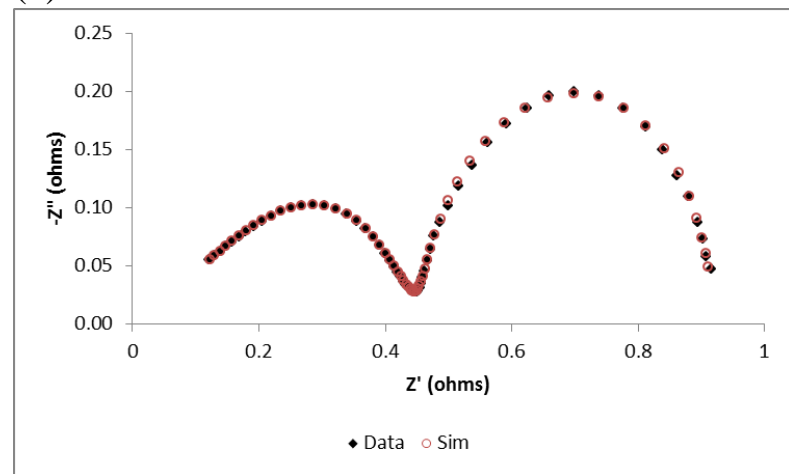

(c)

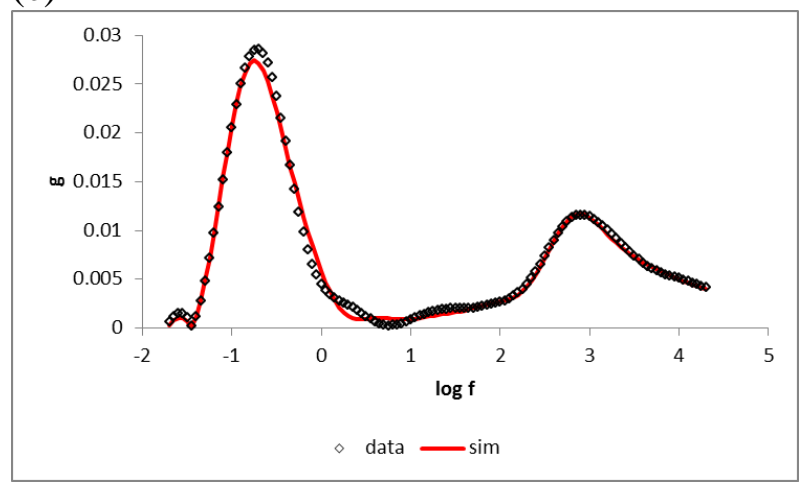

(b)

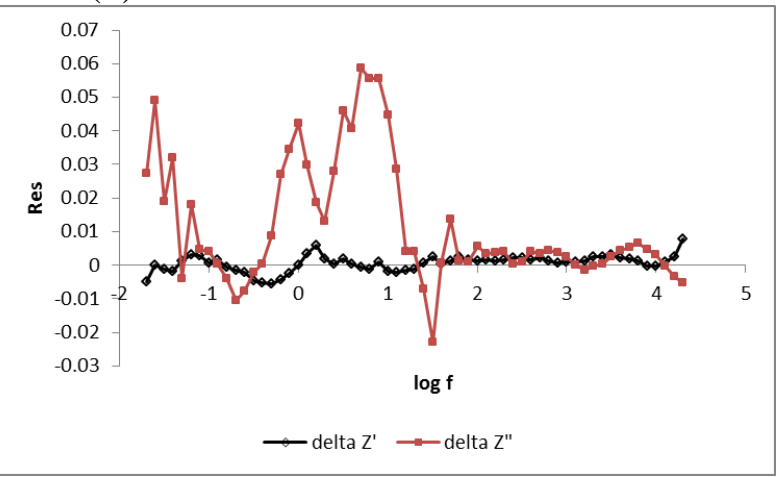

(d)

(e)

Fig. 4.5.Equivalent circuit fit to Cell 2 at $800^{\circ} \mathrm{C}$ with normal flow. (a): In-phase $Z$ ' data and the contributions from each element in the equivalent circuit; (b) Out-of-phase $-Z$ " data and the contributions from each element; (c) Nyquist plot overlaying the data and the simulated impedances from the equivalent circuit; (d) Residuals for Z' and Z"; (e) Overlay plot of the deconvolution spectra for the data and for the simulated impedances of the equivalent circuit. 
Table 4.3: Fitting parameters for Cell 2 at $800^{\circ} \mathrm{C}$ as a function of gas flows.

\begin{tabular}{|l|l|l|l|l|l|}
\hline Flow & & normal & $\begin{array}{l}\text { low } \\
\text { air }\end{array}$ & $\begin{array}{l}\text { low } \\
\text { fuel }\end{array}$ & units \\
\hline Element & Parameter & & & & \\
\hline L & & 1.4 & 1.4 & 1.4 & $\mathrm{x} 10^{-7} \mathrm{H}$ \\
\hline Rs & & 0.47 & 0.48 & 0.48 & ohms \\
\hline Ge & R & 0.33 & 0.55 & 0.38 & ohms \\
\hline Ge & T & 3.6 & 11.2 & 4.1 & x10-4 $\mathrm{s}$ \\
\hline Ge & P & 0.25 & 0.33 & 0.28 & \\
\hline Ge & f & 1340 & 350 & 1070 & $\mathrm{~Hz}$ \\
\hline RQ1 & R & 0.13 & 0.29 & 0.116 & ohms \\
\hline RQ1 & Q & 0.094 & 0.070 & 0.086 & \\
\hline RQ1 & n & 0.59 & 0.77 & 0.67 & \\
\hline RQ1 & f & 280 & 25 & 150 & $\mathrm{~Hz}$ \\
\hline RQ2 & R & 0.23 & 0.20 & 0.19 & ohms \\
\hline RQ2 & Q & 2.1 & 2.1 & 2.2 & \\
\hline RQ2 & n & 0.90 & 0.96 & 0.90 & \\
\hline RQ2 & f & 0.36 & 0.39 & 0.42 & $\mathrm{~Hz}$ \\
\hline RQ3 & R & 0.23 & 0.29 & 0.45 & ohms \\
\hline RQ3 & Q & 4.9 & 4.0 & 2.3 & \\
\hline RQ3 & n* & 1 & 1 & 1 & \\
\hline RQ3 & f & 0.14 & 0.14 & 0.15 & $\mathrm{~Hz}$ \\
\hline & R & 0.92 & 1.33 & 1.13 & ohms \\
\hline
\end{tabular}

*Certain parameter values were fixed when using ZView to improve the fit to the deconvolution spectrum and to prevent unrealistic exponents $(n>1)$. Units for $\mathrm{Q}$ depend on the exponent. 
Table 4.4: Fitting polarization resistance and peak frequencies for Cell 2 at $800^{\circ} \mathrm{C}$ as a function of gas flows.

\begin{tabular}{|l|l|l|l|l|l|}
\hline Flow & & normal & $\begin{array}{l}\text { low } \\
\text { air }\end{array}$ & $\begin{array}{l}\text { low } \\
\text { fuel }\end{array}$ & units \\
\hline Element & Parameter & & & & \\
\hline Ge & R & 0.33 & 0.55 & 0.38 & ohms \\
\hline RQ1 & R & 0.13 & 0.29 & 0.116 & ohms \\
\hline RQ2 & R & 0.23 & 0.20 & 0.19 & ohms \\
\hline RQ3 & R & 0.23 & 0.29 & 0.45 & ohms \\
\hline Rp(total) & $\mathrm{R}_{\mathrm{p}}$ & 0.92 & 1.33 & 1.13 & ohms \\
\hline Ge & f & 1340 & 350 & 1070 & $\mathrm{~Hz}$ \\
\hline RQ1 & f & 280 & 25 & 150 & $\mathrm{~Hz}$ \\
\hline RQ2 & f & 0.36 & 0.39 & 0.42 & $\mathrm{~Hz}$ \\
\hline RQ3 & f & 0.14 & 0.14 & 0.15 & $\mathrm{~Hz}$ \\
\hline
\end{tabular}

Table 4.3 contains the fitting parameters of equivalent circuit for the three gas flows at $800^{\circ} \mathrm{C}$. And Table 4.4 only includes the polarization resistances and peak frequencies for each element. The changes of the two parameters with gas flow change indicate the assignment of each element to the anode or the cathode. In Table 4.4, the polarization resistances increase and peak frequencies for the Gerischer element and RQ1 decrease dramatically in low air. In the low fuel condition, similar trends also show up but are much smaller than in the low air condition. It is evident that the Gerischer element and RQ1 are strongly affected by low air, so they are associated with the cathode, with only minor possible contributions from the anode to both elements. RQ3 shows increased polarization resistance in both low air and low fuel flows. Polarization resistances of RQ2 appear to actually decrease with no change in frequency in low air and low fuel flow. Since the uncertainties of the parameters for RQ2 and RQ3 are large because they have close peak frequencies, the two elements are treated together, and the sum of the polarization resistances of RQ2 and RQ3 increase much more dramatically from normal (0.46 ohms) to low fuel $(0.64 \mathrm{ohms})$ than to low air condition $(0.49 \mathrm{ohms})$, So the two low frequency elements (RQ2 and RQ3) are assigned to the anode, even though there is slight overlap with the cathode. 
Application of the deconvolution protocol to 3-electrode impedance data of the electrolytesupported cell has a problem. All the Nyquist plots for the 3-electrode measurements have visible inductive loop artifacts in either the high frequency end or the low frequency end. These artifacts mean that the impedance data cannot be processed for deconvolution. Consequently, it is also hard to get the accurate total resistance or series resistance from the 3-electrode impedances. So it is not possible to assign cathode and anode polarization resistances by comparing the 2-electrode and 3-electrode measurements because of the inductive loop artifacts in the impedance spectra.

For the data collected at $700^{\circ} \mathrm{C}$, the Nyquist plots show the two defined arcs, similar to the plots at $800^{\circ} \mathrm{C}$, and deconvolution spectra exhibit three or four peaks (Fig. 4.4(c) and (d)). The data are fitted to an equivalent circuit is composed of a high frequency Gerischer element and either two (for low air, low fuel) or three (for normal flow) series RQ elements. The fitting parameters are shown in Table 4.5, and the polarization resistances and frequencies are shown in Table 4.6 and Table 4.7. Trends in the parameters from normal to low air and from normal to low fuel at $700{ }^{\circ} \mathrm{C}$ are similar to those seen at $800^{\circ} \mathrm{C}$. For the two high frequency elements (the Gerischer element and the RQ1 element), the polarization resistances increase and peak frequencies decrease strongly with respect to low air flow and weakly with respect to low fuel flow. The two high frequency elements are again assigned to the cathode. For the two low frequency elements (RQ2 and RQ3), the polarization resistances increase and peak frequencies decrease strongly with respect to low fuel flow and weakly with respect to low air flow. The two low frequency elements are still assigned to the anode.

The deconvolution spectra and Table 4.6 and Table 4.7 show the trends with respect to temperature in the polarization resistances and peak frequencies. From $800^{\circ} \mathrm{C}$ to $700^{\circ} \mathrm{C}$, the anode polarization resistance (the sum of Gerischer and the RQ1) and cathode polarization resistance (the sum of RQ2 and RQ3) increase dramatically. The peak frequencies of each element shift to lower frequencies with lower temperature. For example, the peak frequency of the Gerischer element is $1300 \mathrm{~Hz}$ under normal flow at $800^{\circ} \mathrm{C}$ compared to $200 \mathrm{~Hz}$ at $700^{\circ} \mathrm{C}$. 
Table 4.5: Fitting polarization resistance and peak frequencies for Cell 2 at $700^{\circ} \mathrm{C}$ as a function of gas flows.

\begin{tabular}{|l|r|r|r|l|}
\hline Flow & 700N & 700LA & 700LF & units \\
\hline $\mathrm{L}$ & 2.8 & 4.4 & 4.2 & $\mathrm{x} 10^{-7} \mathrm{H}$ \\
\hline $\mathrm{R}_{\mathrm{s}}$ & 0.95 & 1.1 & 0.96 & ohms \\
\hline Ge R & 1.5 & 3.2 & 1.6 & ohms \\
\hline Ge T & 2.8 & 11 & 3.4 & $\mathrm{x} 10^{-3} \mathrm{~s}$ \\
\hline Ge P & 0.21 & 0.32 & 0.20 & \\
\hline Ge U & 1 & 1 & 1 & \\
\hline fr & 201 & 37 & 180 & $\mathrm{~Hz}$ \\
\hline $\mathrm{R} 1$ & 1.4 & 0.57 & 1.7 & ohms \\
\hline $\mathrm{Q} 1$ & 7.3 & 4.8 & 6.6 & $\mathrm{x} 10^{-3}$ \\
\hline $\mathrm{n} 1$ & 0.77 & 1 & 0.78 & \\
\hline $\mathrm{f} 1$ & 60 & 58 & 49 & $\mathrm{~Hz}$ \\
\hline $\mathrm{R} 2$ & 0.19 & & & ohms \\
\hline $\mathrm{Q} 2$ & 3.5 & & & \\
\hline $\mathrm{n} 2$ & 0.92 & & & \\
\hline $\mathrm{f} 2$ & 0.25 & & & $\mathrm{~Hz}$ \\
\hline $\mathrm{R} 3$ & 1.5 & 1.8 & 2.1 & $\mathrm{ohms}$ \\
\hline $\mathrm{Q} 3$ & 1.6 & 1.13 & 0.51 & \\
\hline $\mathrm{n} 3$ & 1 & 0.93 & 0.95 & \\
\hline $\mathrm{f} 3$ & 0.067 & 0.073 & 0.15 & $\mathrm{~Hz}$ \\
\hline $\mathrm{R}$ p & 4.6 & 5.9 & 5.4 & $\mathrm{ohms}$ \\
total & & & & \\
\hline
\end{tabular}

Table 4.6: Assigned polarization resistances and activation energies for Cell 2 vs

Temperature:

\begin{tabular}{|l|r|r|r|r|r|}
\hline & T $\left({ }^{\circ} \mathrm{C}\right)$ & \multicolumn{1}{l|}{$\mathrm{N}$} & \multicolumn{1}{l|}{ LA } & \multicolumn{1}{l|}{ LF } & \multicolumn{1}{l|}{ Units } \\
\hline cathode & 800 & 0.46 & 0.79 & 0.50 & ohms \\
\hline cathode & 700 & 2.91 & 3.73 & 3.25 & ohms \\
\hline $\begin{array}{l}\mathrm{E}_{\mathrm{a}} \\
\text { cathode }\end{array}$ & & 1.7 & 1.5 & 1.7 & $\mathrm{eV}$ \\
\hline anode & 800 & 0.46 & 0.49 & 0.45 & ohms \\
\hline anode & 700 & 1.70 & 1.83 & 2.13 & ohms \\
\hline $\mathrm{E}_{\mathrm{a}}$ anode & & 1.2 & 1.2 & 1.1 & $\mathrm{eV}$ \\
\hline
\end{tabular}

$\mathrm{N}=$ normal flow; $\mathrm{LA}=$ low air; $\mathrm{LF}=$ low fuel. The sum of polarization resistances of $(\mathrm{Ge} R+\mathrm{R} 1)$ is associated with the cathode. The sum of polarization resistances of $(R 2+R 3)$ is associated with the anode. 


\begin{tabular}{|c|c|c|c|}
\hline \multicolumn{4}{|c|}{$\begin{array}{l}\text { Table 4.7 Peak frequencies for Cell } 2 \text { vs } \\
\text { temperature: }\end{array}$} \\
\hline Temperature & $f(G e R) f(R 1)$ & $f(R 2)$ & $\mathrm{f}(\mathrm{R} 3)$ \\
\hline Units & $\mathrm{Hz} \quad \mathrm{Hz}$ & $\mathrm{Hz}$ & $\mathrm{Hz}$ \\
\hline \multicolumn{4}{|l|}{ Normal flow } \\
\hline $800^{\circ} \mathrm{C}$ & $1340 \quad 280$ & 0.36 & 0.14 \\
\hline $700^{\circ} \mathrm{C}$ & $201 \quad 60$ & 0.25 & 0.067 \\
\hline \multicolumn{4}{|l|}{ Low air } \\
\hline $800^{\circ} \mathrm{C}$ & $350 \quad 25$ & 0.39 & 0.14 \\
\hline $700^{\circ} \mathrm{C}$ & 37 & & 0.073 \\
\hline \multicolumn{4}{|l|}{ Low fuel } \\
\hline $800^{\circ} \mathrm{C}$ & $1070 \quad 150$ & 0.42 & 0.15 \\
\hline $700^{\circ} \mathrm{C}$ & $\begin{array}{ll}180 & 49\end{array}$ & & 0.15 \\
\hline
\end{tabular}

Table 4.6 shows the relative contributions of the cathode and anode to the total resistance at the two temperatures and the three gas flows. For normal flow condition, at $800{ }^{\circ} \mathrm{C}$, the cathode and anode contribute equally at normal flow. With temperature decreasing to $700{ }^{\circ} \mathrm{C}$, the cathode resistance contributes larger than the anode. For low air condition, the cathode is larger component for both temperatures. For low fuel condition, at $800{ }^{\circ} \mathrm{C}$, anode resistance is larger than cathode, at the lower temperature $\left(700^{\circ} \mathrm{C}\right)$, cathode still contributes more than the anode.

By analysis of polarization resistances change with different temperature $\left(800^{\circ} \mathrm{C}\right.$ and $\left.700^{\circ} \mathrm{C}\right)$, for the three gas flows, the cathode polarization resistances are 0.46 to $0.79 \mathrm{ohms}$ at $800^{\circ} \mathrm{C}$ and 2.91 to $3.73 \mathrm{ohms}$ at $700^{\circ} \mathrm{C}$. The approximate activation energy of 1.5 to $1.7 \mathrm{eV}$ is obtained for the cathode. This value is consistent with some literature reports on LSM/YSZ electrodes of 1.5-1.6 $\mathrm{eV}[36]$ and not with others $(1.3 \mathrm{eV})[37]$.

The two low frequency RQ elements at $800^{\circ} \mathrm{C}$ merge to one RQ element at $700^{\circ} \mathrm{C}$ and these elements are assigned to the anode. For all three gas flows, the anode polarization resistances at $800^{\circ} \mathrm{C}$ are 0.5 to $0.6 \mathrm{ohms}$ and increase to 1.7 to $2.1 \mathrm{ohms}$ at $700^{\circ} \mathrm{C}$. From these values, 
activation energies of 1.1 to $1.2 \mathrm{eV}$ are obtained, in good agreement with a literature value of 1.1 $\mathrm{eV}$ [38]. The large values of the activation energies indicate that the processes associated with low frequency element is not gas diffusion, since gas diffusion is not affected much by temperature and has a negligible activation energy. In the literature, the presence of a strongly temperature-dependent process at these low frequencies has not been reported for either the $\mathrm{Ni} / \mathrm{YSZ}$ anode or the LSM/YSZ cathode. Prior reports of anode processes state that the anode peak frequencies are above $1 \mathrm{kHz}$.[39] Finally, the fact that the activation energies of the cathode and anode are essentially constant for three gas flows supports the assignment of the Gerischer element and RQ1 to the cathode and RQ2 +RQ3 to the anode.

\subsubsection{Cell 3: MSRI Anode-supported Cell with LSM/SDC cathode}

Four sequential impedance measurements are applied for this cell at each temperature and flow conditions immediately after recording a polarization curve at $800^{\circ} \mathrm{C}$. To investigate the effect of the flow change more systematically, more flow conditions were included: normal flow, 50\% air, $20 \%$ air, $50 \%$ fuel and $20 \%$ fuel. A complete data set was not obtained at $750^{\circ} \mathrm{C}$ because of a forced shutdown of the test stand.

Through analysis of the residuals from the sequential impedance measurements, the assessment of sources of noise in the impedance data can be provided [40]. The four impedance sets are merged and simultaneously fit to the equivalent circuit to get the simulated values (see later for the equivalent circuit), then the residuals are calculated for each of the four data sets. The plots (Fig.4.6) show all four residuals for data at $800^{\circ} \mathrm{C}$ and normal flow. Two sources of noise are shown in the figures. Fig 4.6a shows visible drift at all frequencies, particularly from 1 to 100 Hz. The drift possibly arises from the effects of polarization measurement (from OCV to $0.3 \mathrm{~V}$ ), which was taken right before the impedance measurements. The drift is attributed to the known activation and recovery of the LSM/YSZ cathode [41, 42]. The second source, stochastic noise, appears below $1 \mathrm{~Hz}$ and is more visible for the Z" impedance (Fig. 4.6(b)). To assess the stochastic noise, the residuals for each of the four data sets are calculated by using the best fit equivalent circuit for each set of corresponding data instead of fitting the merged data (Fig. 4.7). Below $1 \mathrm{~Hz}$, the noise reaches the order of $10 \%$ for Z", while above $1 \mathrm{~Hz}$, stochastic noise is less than $1 \%$ for $Z$ ' and Z'. This low frequency noise is probably from fluctuations in the gas flow velocity, back pressure or humidity in either the fuel or air streams. Because the stochastic noise 
is mainly in the lower frequency range, the parameters for the equivalent circuit elements are obtained from the merged data set to reduce the stochastic noise. For comparison, average values and standard deviations for each parameter are also calculated from the parameters obtained by fitting each data set individually to the equivalent circuit. In general, the average value of each parameter is close to the value obtained by fitting the merged data set (see the very small standard deviations in Table 4.8).

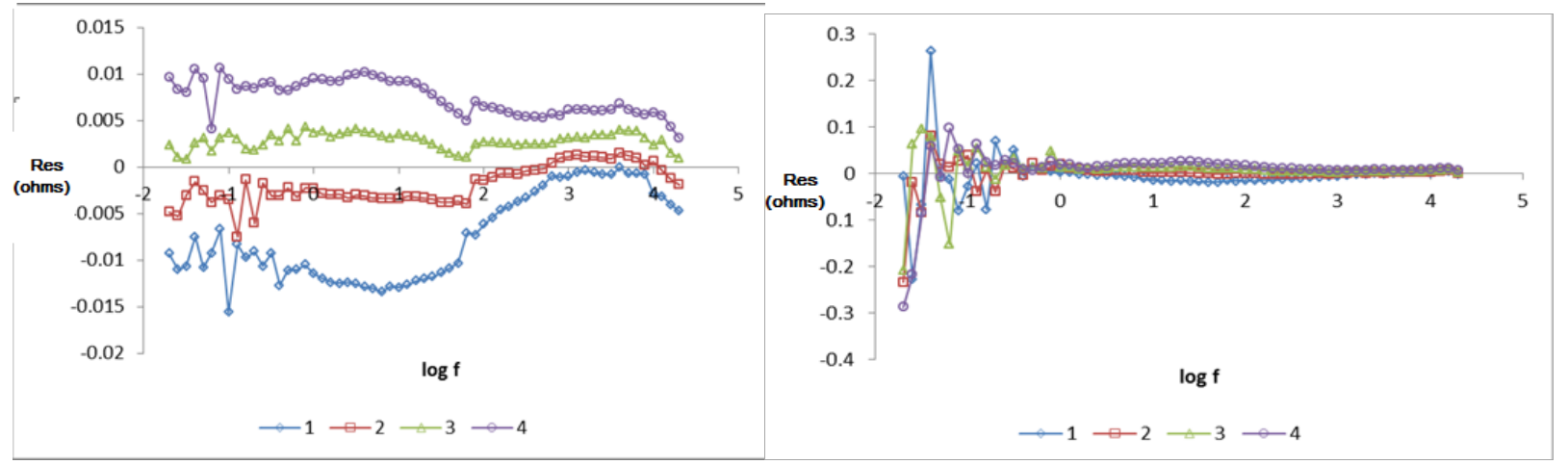

(a)

(b)

Fig. 4.6: Cell 3 residuals for (a) Z' and (b) Z" impedances for four sequential impedance measurements at $800^{\circ} \mathrm{C}$ and normal flow. The residuals are calculated using the simulated impedance of the equivalent circuit fit to the merged data set for all four data sets.

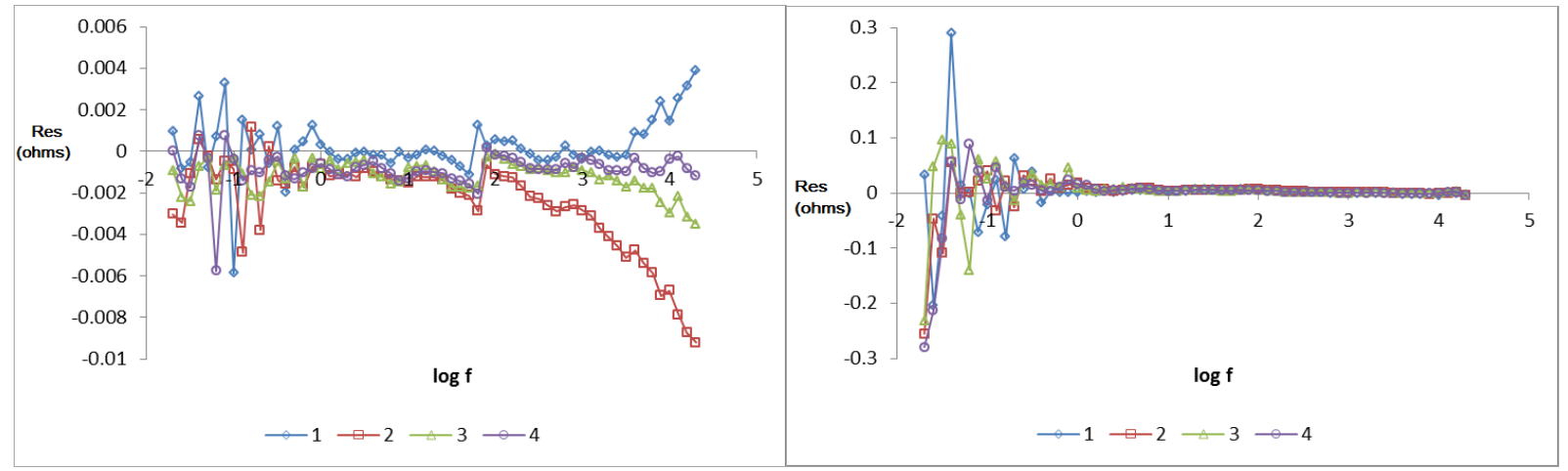

(a)

(b)

Fig. 4.7: Cell 3 residuals for (a) Z' and (b) Z" impedances for four sequential impedance measurements. The residuals are calculated using the simulated impedance of the equivalent circuit fit to the corresponding data set.

Fig. 4.8 shows the Nyquist plots for the five flow conditions at $800^{\circ} \mathrm{C}$. Decreasing air concentration affects on the total polarization resistance stronger than decreasing hydrogen concentration. There is significant structure in the Nyquist plots. In the corresponding deconvolution plots, up to five peaks are visible (Fig. 4.9). None of the peaks match the shape of 
a Gerischer or finite Warburg element, so five series RQ elements were used in the equivalent circuit, in series with the inductance and series resistance (notation: $\left.L R(R Q)_{5}\right)$.

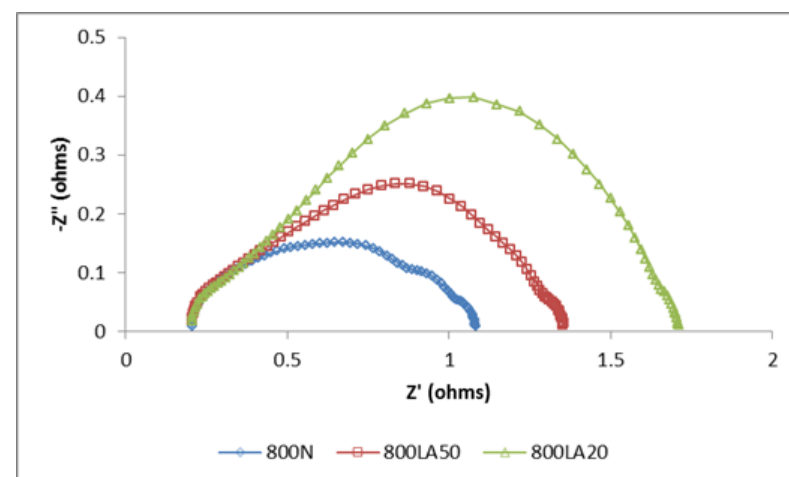

(a)

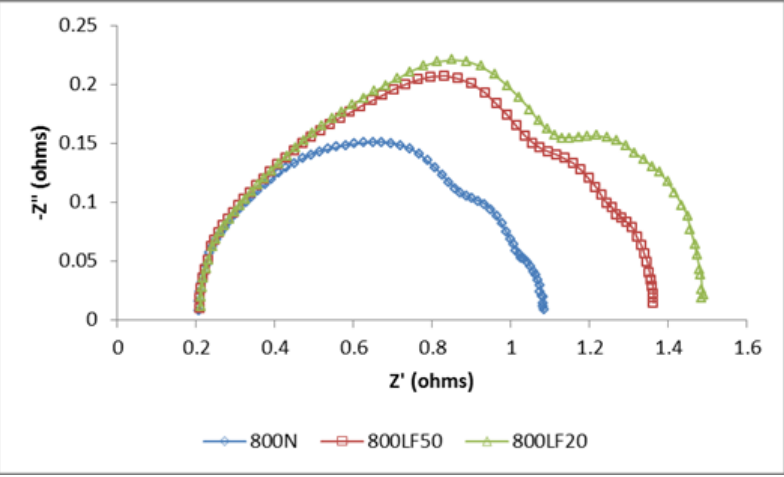

(b)

Fig. 4.8: Cell 3 Nyquist plots at $800^{\circ} \mathrm{C}$ for (a) normal (blue diamonds), $50 \%$ air (red squares), and $20 \%$ air flows (green triangles), and (b) normal (blue diamonds), 50\% hydrogen (red squares), and $20 \%$ hydrogen flows (green triangles). The plots have been corrected for the inductances $\left(\sim 4 \times 10^{-7} \mathrm{H}\right)$.

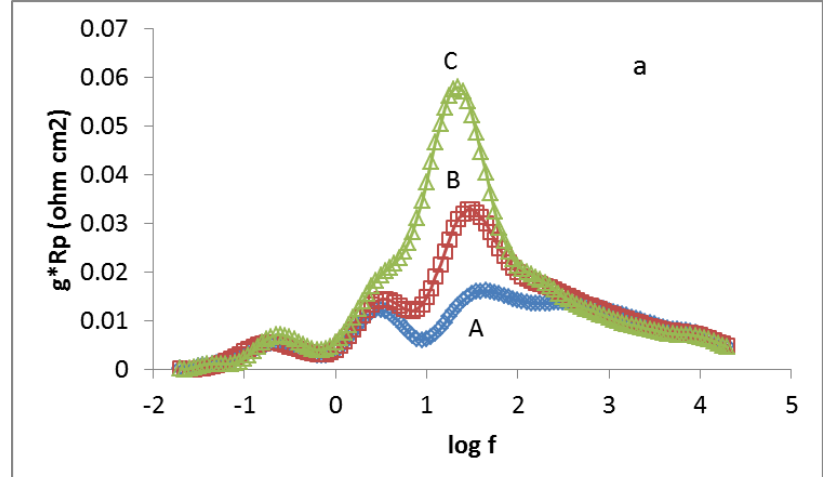

(a) squares), and 20\% air flows (C: green triangles), and (b) normal (A: blue diamonds), 50\% hydrogen (B: red squares), and $20 \%$ hydrogen flows (C: green triangles).

For $800^{\circ} \mathrm{C}$ and normal flow, Fig. 4.10(a) and (b) show the contributions of each element to the impedance. Fig 4.10(c) and (d) show the excellent overlays of both the data and simulated impedances in a Nyquist plot and the deconvolution spectra. In Table 4.8, fitted parameters are based onto the merged data and the standard deviations are based on separate fitting to each of the four data sets. Each element has a frequency roughly a decade apart, which means the elements are well separated. 


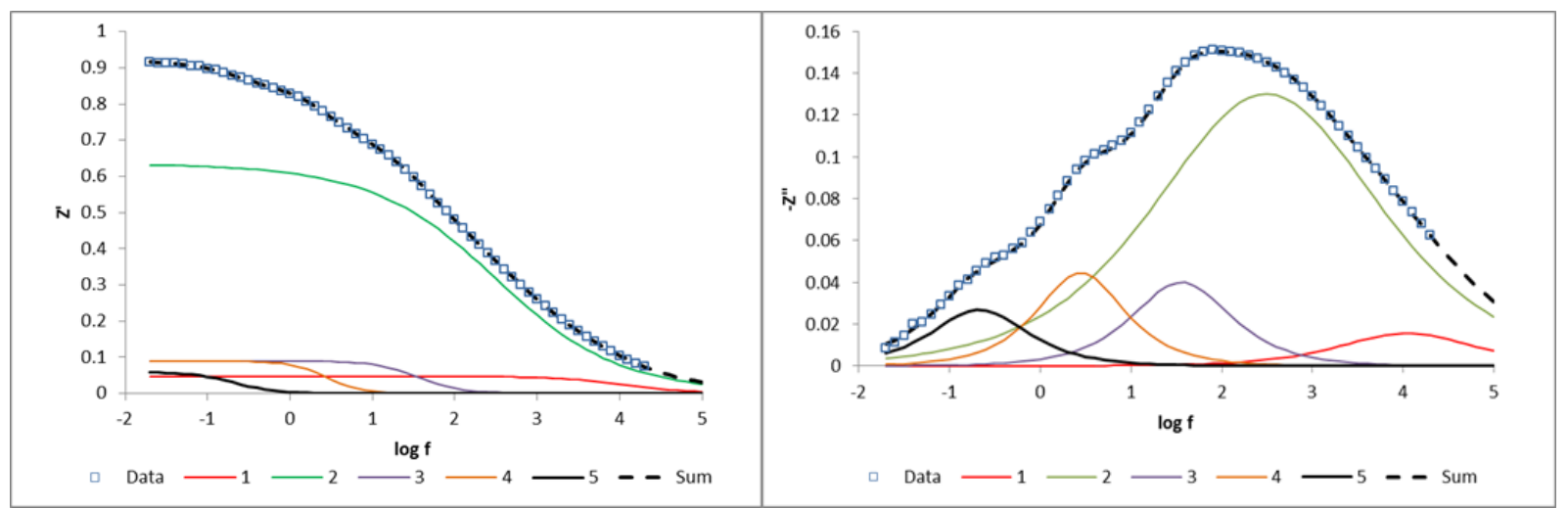

(a)

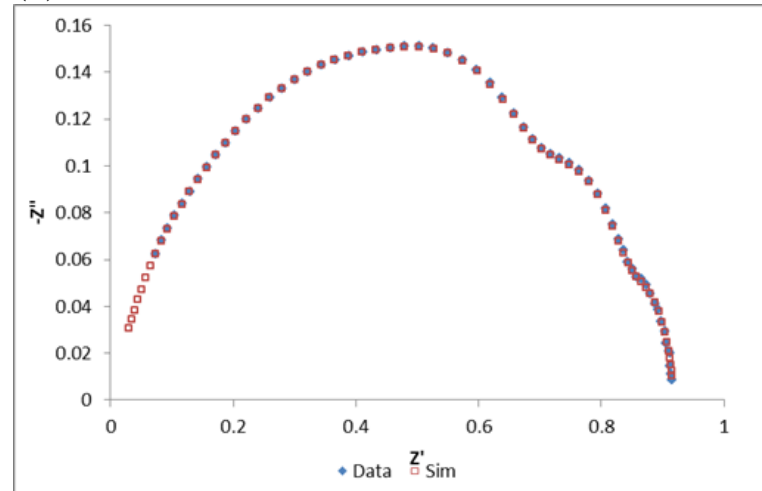

(b)

(c)

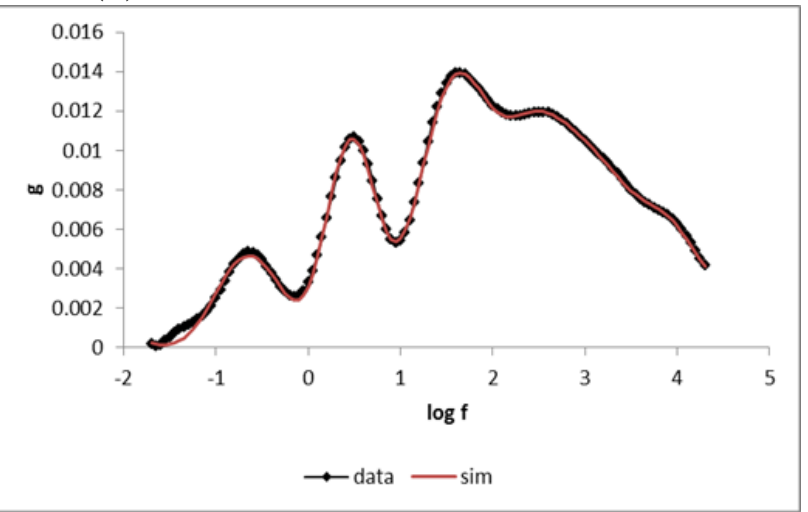

(d)

Fig. 4.10: Equivalent circuit fit to Cell 3 at $800^{\circ} \mathrm{C}$ with normal flow. (a): In-phase Z' data and the contributions from each element in the equivalent circuit; (b) Out-of-phase -Z" data and the contributions from each element; (c) Nyquist plot overlaying the data and the simulated impedances from the equivalent circuit; (d) overlay plot of the deconvolution spectra for the data and for the simulated impedances of the equivalent circuit.

At $800^{\circ} \mathrm{C}$, the effects of low air flows on each of the five RQ elements are shown in Table. 4.8 and Table 4.10. In Table 4.10, RQ1, RQ2 and RQ3 significantly increases in the polarization resistance values going from normal air to $50 \%$ air to $20 \%$ air. The peak frequencies of RQ1 and RQ2 also shift to lower values going from normal air flow to $20 \%$ air. However, the peak frequency for Z" of RQ3 is relatively constant. All three elements appear to be associated with the cathode. Based on literature assignments, RQ1 is attributed to oxygen species transport near the electrode/electrolyte interface, and RQ2 is attributed to dissociative adsorption/desorption of $\mathrm{O}_{2}$ and transport of species across the TPB. For lower frequency RQ4 and RQ5 elements, both polarization resistances and peak frequencies change slightly and without systematic increases in polarization resistances with decreasing air concentration, so these latter two elements are likely associated with the anode. 
Table 4.8: Fitted parameters for Cell 3 at $800^{\circ} \mathrm{C}$ and all five flow conditions.

\begin{tabular}{|c|c|c|c|c|c|c|c|c|c|c|}
\hline$P$ & $800 N$ & $\begin{array}{l}\text { St. } \\
\text { Dev. }\end{array}$ & $800 A 50$ & $\begin{array}{l}\text { St. } \\
\text { Dev. }\end{array}$ & $800 A 20$ & $\begin{array}{l}\text { St. } \\
\text { Dev. }\end{array}$ & 800 LF50 & $\begin{array}{l}\text { St. } \\
\text { Dev. }\end{array}$ & 800 LF20 & $\begin{array}{l}\text { St. } \\
\text { Dev. }\end{array}$ \\
\hline $\mathrm{L}$ & 3.59 & 0.02 & 3.71 & 0.07 & 3.94 & 0.02 & 3.73 & 0.05 & 3.72 & 0.04 \\
\hline Rs & 0.169 & 0.004 & 0.152 & 0.006 & 0.132 & 0.003 & 0.161 & 0.002 & 0.169 & 0.005 \\
\hline R1 & 0.048 & 0.018 & 0.20 & 0.05 & 0.34 & 0.009 & 0.045 & 0.007 & 0.18 & 0.09 \\
\hline Q1 & 0.0051 & 0.0011 & 0.024 & 0.0070 & 0.060 & 0.0051 & 0.0042 & 0.0010 & 0.0091 & 0.0031 \\
\hline $\mathrm{n} 1$ & 0.75 & 0.06 & 0.51 & 0.04 & 0.40 & 0.01 & 0.78 & 0.03 & 0.60 & 0.12 \\
\hline $\mathrm{R} 2$ & 0.63 & 0.07 & 0.74 & 0.05 & 0.78 & 0.03 & 0.82 & 0.009 & 0.48 & 0.22 \\
\hline Q2 & 0.037 & 0.006 & 0.050 & 0.0008 & 0.050 & 0.002 & 0.047 & 0.0008 & 0.024 & 0.013 \\
\hline $\mathrm{n} 2$ & 0.50 & 0.03 & 0.54 & 0.02 & 0.60 & 0.008 & 0.46 & 0.003 & 0.60 & 0.09 \\
\hline R3 & 0.09 & 0.02 & 0.16 & 0.004 & 0.33 & 0.01 & 0.15 & 0.009 & 0.32 & 0.08 \\
\hline Q3 & 0.074 & 0.001 & 0.036 & 0.0009 & 0.024 & 0.0006 & 0.048 & 0.002 & 0.038 & 0.004 \\
\hline n3 & 0.93 & 0.05 & $1 *$ & & $1 *$ & & 0.95 & 0.007 & 0.86 & 0.05 \\
\hline R4 & 0.089 & 0.008 & 0.072 & 0.005 & 0.10 & 0.01 & 0.11 & 0.001 & 0.22 & 0.07 \\
\hline Q4 & 0.64 & 0.070 & 0.72 & 0.050 & 0.41 & 0.040 & 0.73 & 0.013 & 0.65 & 0.11 \\
\hline $\mathrm{n} 4$ & $1^{*}$ & & $1 *$ & & $1^{*}$ & & $1 *$ & & 0.91 & 0.08 \\
\hline R5 & 0.060 & 0.01 & 0.042 & 0.003 & 0.039 & 0.007 & 0.084 & 0.001 & 0.13 & 0.03 \\
\hline $\mathrm{Q} 5$ & 13 & 3 & 21 & 4 & 18 & 4 & 8.8 & 0.2 & 6 & 3 \\
\hline n5 & 0.95 & 0.05 & $1 *$ & & $1^{*}$ & & $1 *$ & & 0.98 & 0.08 \\
\hline f1 & 10670 & 80 & 5500 & 1400 & 2600 & 100 & 10000 & 200 & 8000 & 2000 \\
\hline$f 2$ & 310 & 40 & 72 & 4 & 35.0 & 3 & 190 & 8 & 280 & 60 \\
\hline f3 & 36.0 & 1 & 27.8 & 0.3 & 20.3 & 0.1 & 29.2 & 0.1 & 27.7 & 0.6 \\
\hline f4 & 2.78 & 0.04 & 3.10 & 0.03 & 3.83 & 0.08 & 1.93 & 0.02 & 1.33 & 0.16 \\
\hline f5 & 0.21 & 0.01 & 0.18 & 0.02 & 0.23 & 0.01 & 0.22 & 0.003 & 0.22 & 0.05 \\
\hline
\end{tabular}

P-Parameters. L values $\times 10^{-7} \mathrm{H}$.*Fixed parameter. All resistances are in ohms. Unit for frequency is $\mathrm{Hz}$. Units for Q depend on the exponent. $800 \mathrm{~N}$ is normal flow. $800 \mathrm{~A} 20$ is $20 \%$ air flow. 800 A50 is $50 \%$ air flow. 800 LF50 is $50 \%$ hydrogen flow. 800LF20 is $20 \%$ hydrogen flow. 
Table 4.9: Fitted parameters for Cell 3 at $750^{\circ} \mathrm{C}$ and all four flow conditions.

\begin{tabular}{|l|r|r|r|r|r|r|r|r|}
\hline Parameter & 750N & St. Dev. & 750LA50 & St. Dev. & 750 LA20 & St. Dev. & 750 L50 & St. Dev. \\
\hline L & 3.84 & 0.02 & 3.81 & 0.02 & 3.95 & 0.04 & 3.79 & 0.03 \\
Rs & 0.172 & 0.001 & 0.168 & 0.003 & 0.158 & 0.002 & 0.180 & 0.002 \\
\hline R1 & 0.51 & 0.002 & 0.54 & 0.03 & 0.62 & 0.03 & 0.46 & 0.03 \\
Q1 & 0.0057 & 0.000081 & 0.0067 & 0.00061 & 0.0092 & 0.00051 & 0.0048 & 0.00030 \\
n1 & 0.59 & 0.002 & 0.57 & 0.01 & 0.54 & 0.006 & 0.61 & 0.008 \\
\hline R2 & 0.74 & 0.009 & 0.77 & 0.03 & 0.75 & 0.01 & 0.88 & 0.09 \\
Q2 & 0.012 & 0.00011 & 0.015 & 0.00070 & 0.019 & 0.00040 & 0.012 & 0.0010 \\
n2 & 0.67 & 0.003 & 0.65 & 0.008 & 0.66 & 0.006 & 0.64 & 0.02 \\
\hline R3 & 1.42 & 0.006 & 1.69 & 0.02 & 2.03 & 0.03 & 1.60 & 0.08 \\
Q3 & 0.026 & 0.00030 & 0.021 & 0.00021 & 0.017 & 0.00031 & 0.024 & 0.00021 \\
n3 & 0.79 & 0.003 & 0.82 & 0.005 & 0.85 & 0.004 & 0.80 & 0.02 \\
\hline R4* & 0.04 & & 0.03 & & 0.03 & & 0.12 & \\
Q4* & 35 & & 16 & & 5 & & 3.00 & \\
n4* & 0.95 & & $1 *$ & & $1 *$ & & $1 *$ & \\
\hline R5* & & & 0.03 & & 0.05 & & & \\
Q5* & & & 100 & & 31 & & & \\
n5* & & & $18 *$ & & $1 *$ & & & \\
\hline f1 & 3160 & 50 & 2940 & 200 & 2370 & 180 & 3770 & 170 \\
f2 & 10.3 & 0.1 & 9.2 & 0.1 & 8.2 & 0.07 & 9.4 & 0.2 \\
f3 & 0.11 & & 0.33 & & 1.1 & & 0.44 & \\
f4 & & & 0.053 & & 0.11 & & & \\
f5 & & & 144 & 9 & 103 & 6 & 190 & \\
\hline
\end{tabular}

L values $\times 10^{-7} \mathrm{H}$. *Fixed parameter. All resistances are in ohms. Units for frequency are Hz. Units for Q depend on the exponent. $750 \mathrm{~N}$ is normal flow. 750A20 is $20 \%$ air flow. 750A50 is $50 \%$ air flow. 750LF50 is 50\% hydrogen flow. The test stand had to be shut down before collecting the data at $20 \%$ hydrogen flow. 
Table 4.10: Polarization resistances and frequencies for Cell 3 at $800^{\circ} \mathrm{C}$ and all five flow Conditions

\begin{tabular}{|c|c|c|c|c|c|c|c|c|c|c|}
\hline$P$ & $\mathrm{~N}$ & $\begin{array}{l}\text { St. } \\
\text { Dev. }\end{array}$ & A50 & $\begin{array}{l}\text { St. } \\
\text { Dev. }\end{array}$ & A20 & $\begin{array}{l}\text { St. } \\
\text { Dev. }\end{array}$ & LF50 & $\begin{array}{l}\text { St. } \\
\text { Dev. }\end{array}$ & LF20 & $\begin{array}{l}\text { St. } \\
\text { Dev. }\end{array}$ \\
\hline R1 & 0.048 & 0.018 & 0.20 & 0.05 & 0.34 & 0.009 & 0.045 & 0.007 & 0.18 & 0.09 \\
\hline $\mathrm{R} 2$ & 0.63 & 0.07 & 0.74 & 0.05 & 0.78 & 0.03 & 0.82 & 0.009 & 0.48 & 0.22 \\
\hline R3 & 0.09 & 0.02 & 0.157 & 0.004 & 0.33 & 0.01 & 0.15 & 0.009 & 0.32 & 0.08 \\
\hline R4 & 0.089 & 0.008 & 0.072 & 0.005 & 0.10 & 0.012 & 0.11 & 0.001 & 0.22 & 0.07 \\
\hline R5 & 0.06 & 0.01 & 0.042 & 0.003 & 0.039 & 0.007 & 0.084 & 0.001 & 0.13 & 0.03 \\
\hline$R_{p(\text { total })}$ & 0.92 & & 1.2 & & 1.6 & & 1.2 & & 1.3 & \\
\hline f1 & 10670 & 80 & 5500 & 1400 & 2600 & 100 & 10000 & 200 & 8000 & 2000 \\
\hline f2 & 310 & 40 & 72 & 4 & 35.0 & 3 & 190 & 8 & 280 & 60 \\
\hline f3 & 35.5 & 1.1 & 27.8 & 0.3 & 20.3 & 0.1 & 29.2 & 0.1 & 27.7 & 0.6 \\
\hline f4 & 2.78 & 0.04 & 3.10 & 0.03 & 3.83 & 0.08 & 1.93 & 0.02 & 1.33 & 0.16 \\
\hline f5 & 0.21 & 0.010 & 0.18 & 0.018 & 0.23 & 0.013 & 0.22 & 0.003 & 0.22 & 0.050 \\
\hline
\end{tabular}

P-Parameters. All resistances are in ohms. Units for frequencies are Hz. $\mathrm{N}$ is normal flow. A20 is $20 \%$ air flow. A50 is 50\% air flow. LF50 is 50\% hydrogen flow. LF20 is 20\% hydrogen flow.

Table 4.11: Polarization resistances and frequencies for Cell 3 at $750^{\circ} \mathrm{C}$ and all four flow conditions

\begin{tabular}{|l|r|r|r|r|r|r|r|r|}
\hline Parameter & N & St. Dev. & \multicolumn{1}{|l}{ LA50 } & St. Dev. & LA20 & St. Dev. & LF50 & St. Dev. \\
\hline R1 & 0.51 & 0.002 & 0.54 & 0.03 & 0.62 & 0.03 & 0.46 & 0.03 \\
\hline R2 & 0.74 & 0.009 & 0.77 & 0.03 & 0.75 & 0.01 & 0.88 & 0.09 \\
\hline R3 & 1.42 & 0.006 & 1.69 & 0.02 & 2.03 & 0.03 & 1.60 & 0.08 \\
\hline R4 & 0.04 & & 0.03 & & 0.03 & & 0.12 & \\
\hline R5 & & & 0.03 & & 0.05 & & & \\
\hline$R_{\text {p(total) }}$ & 1.8 & & 2.2 & & 2.6 & & 2.1 & \\
\hline f1 & 3160 & 50 & 2940 & 200 & 2370 & 180 & 3770 & 170 \\
\hline f2 & 185 & $1 *$ & 144 & 9 & 103 & 6 & 190 & 16 \\
\hline f3 & 10.3 & 0.1 & 9.2 & 0.1 & 8.2 & 0.07 & 9.4 & 0.2 \\
\hline f4 & 0.11 & & 0.33 & & 1.1 & & 0.44 & \\
\hline f5 & & & 0.053 & & 0.11 & & & \\
\hline
\end{tabular}

All resistances are in ohms. Units for frequencies are Hz. $\mathrm{N}$ is normal flow. A20 is $20 \%$ air flow. A50 is 50\% air flow. LF50 is $50 \%$ hydrogen flow.

Table 4.10 shows the corresponding low fuel flows effects at $800{ }^{\circ} \mathrm{C}$. RQ1 and RQ2 do not systematically increase going from normal to low fuel. These two elements are definitively assigned to the cathode, which agrees with the results from low air flow. Polarization resistances 
of RQ3 through RQ5 all consistently increase but peak frequencies change little for low fuel. These results confirm the assignments of RQ4 and RQ5 to the anode. Since the RQ3 changes both in low air and low fuel, the mid-frequency element RQ3 is associated with both anode and cathode processes.

Table 4.9 includes all the fitted parameters for Cell 3 at $750^{\circ} \mathrm{C}$ and all four flow conditions. And the corresponding polarization resistances and frequencies are shown in Table 4.11. At $750{ }^{\circ} \mathrm{C}$, for RQ1 and RQ2, the polarization resistances increase and peak frequencies decrease going from normal air to $50 \%$ air to $20 \%$ air. So RQ1 and RQ2 are again assigned to cathode. Table 4.11 shows that at $750^{\circ} \mathrm{C}, \mathrm{RQ} 4$ and RQ5 become a single RQ element in the data, and the polarization resistance is only $0.04 \mathrm{ohms}$, which increases in low fuel condition, so the RQ4 and RQ5 are assigned to anode. The parameters for RQ4 and RQ5 were fixed in order to fit the deconvolution spectra; ZView did not provide a good fit to these small peaks. In agreement with $800{ }^{\circ} \mathrm{C}$, the RQ3 changes both in low air and low fuel, which implies that this element is associated with both anode and cathode processes.

Table 4.12 summarizes effects of temperature on RQ elements for normal flow. The activation energy for the cathode (sum of the polarization resistances R1 and R2) is $1.2 \mathrm{eV}$. The activation energy for the anode (sum of the polarization resistances R4 and R5) does not increase strongly with temperature decrease, which confirms that RQ4 and RQ5 are associated with gas diffusion at the anode. The RQ3 data in Table 4.12 shows this element is strongly dependent on temperature, so large activation energies are associated with processes contributing to this element. According to Mogensen, the process at this frequency is gas diffusion at either the cathode or anode. However, the gas diffusion is not dependent with temperature, so the assignment of RQ3 contradicts their assignment. Because the assignment of RQ3 is ambiguous, the separation of the anode and cathode polarization resistances for RQ3 is not possible by using the current data unless extra assumptions are made. If this element is divided equally between the cathode and anode at $800^{\circ} \mathrm{C}$ and normal flow, then the total cathode polarization resistance is $0.77 \mathrm{ohms}$, nearly $80 \%$ of the total polarization resistance of $0.92 \mathrm{ohms}$. The cathode dominates the total polarization resistance in this cell. 
Table 4.12: Effects of temperature on RQ elements for normal flow

\begin{tabular}{|c|c|c|c|c|c|}
\hline Element & Temp. & f peak & $\mathrm{R}$ (ohms) & $\mathbf{n}$ & Process \\
\hline \multirow[t]{2}{*}{ RQ1 } & 800 & $10.6 \mathrm{kHz}$ & 0.05 & 0.75 & $\begin{array}{l}\text { Cathode. Transport of O species between } \\
\text { LSM \& YSZ near TPB? }\end{array}$ \\
\hline & 750 & $3.2 \mathrm{kHz}$ & 0.51 & 0.59 & \\
\hline \multirow[t]{2}{*}{ RQ2 } & 800 & $310 \mathrm{~Hz}$ & 0.63 & 0.50 & $\begin{array}{l}\text { Cathode. Dissociative adsorption of } \mathrm{O}_{2} \\
\text { transport to TPB. }\end{array}$ \\
\hline & 750 & $185 \mathrm{~Hz}$ & 0.74 & 0.67 & \\
\hline \multirow[t]{2}{*}{ RQ3 } & 800 & $36 \mathrm{~Hz}$ & 0.09 & 0.93 & $\begin{array}{l}\text { Cathode } \& \text { anode. Not just diffusion because } \\
\text { of temperature dependence. }\end{array}$ \\
\hline & 750 & $10 \mathrm{~Hz}$ & 1.42 & 0.79 & \\
\hline RQ4 & 800 & $3 \mathrm{~Hz}$ & 0.09 & 1 & Anode. Gas diffusion impedance. \\
\hline \multirow[t]{2}{*}{ RQ5 } & 800 & $0.2 \mathrm{~Hz}$ & 0.06 & 0.95 & Anode. Gas diffusion impedance. \\
\hline & 750 & $0.1 \mathrm{~Hz}$ & 0.04 & 0.95 & \\
\hline
\end{tabular}

\subsection{Conclusion}

It is possible to separate most of the impedance data with respect to the contributions from the cathode and anode with the availability of high quality impedance data for a series of different gas compositions to the anode and cathode. The process includes deconvolution spectra based on the impedance data to identify the number and type of elements needed in an equivalent circuit. The parameters for the individual elements are obtained from complex nonlinear regression fitting, and the quality of simulated parameters for the equivalent circuit is checked by comparing the deconvolution spectrum of simulated data to the deconvolution spectrum of the data. The response of each element (polarization resistance and frequency) to gas flows can provide clearly identification of the electrode associate to that element. In some cases, a single element appears to be affected by both the cathode and the anode, indicating two or more processes at the electrodes have an overlapping frequency range. The future work for further separation of the element would require a greater variety of gas flow conditions or temperature conditions. 
The common material for all three button cells examined is LSM as the cathode electrode. A common feature for all three button cells is one or more processes occurring at the high frequency range of the impedance spectra, which is general above $10 \mathrm{~Hz}$. These processes are consistent with literature reports, and are assigned to oxygen dissociative adsorption and transport of species to the TPB. The gas diffusion processes at the anode are associated with very low frequency processes. For the intermediate frequency element, it appears to be hard to separate the cathode and the anode contributions. This element also exhibits large apparent activation energy, and consequently cannot be assigned to gas diffusion. Despite the ambiguity, approximate contributions of the cathode and anode to the total polarization resistance can be estimated. Thus, this analysis protocol is a valuable addition to the methods for analyzing real SOFCs under realistic operating conditions. 


\subsection{References}

[1] Chan, S.H.; Chen, X.J.; Khor, K.A. J. Appl. Electrochem. 2001, 31, 1163-1170.

[2] Winkler, J.; Hendriksen, P.V.; Bonanos, N.; Mogensen, M. J. Electrochem. Soc. 1998, 145, 1184-1193.

[3] Adler, S.B.; Henderson, B.T.; Wilson, M.A.; Taylor, R.E. Solid State Ionics 2000, 134, 35-42.

[4] Adler, S.B. J. Electrochem. Soc. 2002, 149, E166-E172.

[5] McIntosh, S.; Vohs, J.M.; Gorte, R.J. J. Electrochem. Soc. 2003,150, A1305-A1312.

[6] Cimenti, M.; Co, A.C.; Birss, V.I.; Hill, J.M. Fuel Cells 2007, 7, 364-376.

[7] Cimenti, M.; Birss, V.I.; Hill, J.M. Fuel Cells 2007, 7, 377-391.

[8] Ostergards, M.J.L.; Mogensen, M. Electrochim. Acta 1993, 38, 2015-2020.

[9] Ostergards, M.J.L.; Clausen, C.; Bagger, C.; Mogensen, M. Electrochim. Acta 1995, 40, 1971-1981.

[10] Aaberg, R.J.; Tunold, R.; Mogensen, M.; Berg, R.W.; Jødegárd, R. J. Electrochem. Soc. 1998, 145, 2244-2253.

[11] Jørgensen, M.J.; Primdahl, S.; Mogensen, M. Electrochim. Acta, 1999, 44, 4195-4201.

[12] Brown, M.; Primdahl, S.; Mogensen, M. J. Electrochem. Soc. 2000, 147, 475-485.

[13] Jørgensen, M.J.; Mogensen, M. J. Electrochem. Soc. 2001, 148, A433-A442.

[14] Esquirol, A.; Brandon, N.P.; Kilner, J.A.; Mogensen, M. J. Electrochem. Soc. 2004, 151, A1847-A1855.

[15] Hansen, K.V.; Norrman, K.; Mogensen, M. J. Electrochem. Soc. 2004, 151, A1436-A1444.

[16] Hashibon, A.; Raz, S.; Riess, I. Solid State Ionics 2002, 149, 167-176.

[17] Dunyushkina, L.A.; Lu, Y.; Adler, S.B. J. Electrochem. Soc. 2005, 152, A1668-A1676.

[18] Schichlein, H.; Muller, A.C.; Voigts, M.; Krugel, A.; Ivers-Tiffée, E. J. Appl. Electrochem. 2002, 32, 875-882.

[19] Leonide, A.; Sonn, V.; Weber, A.; Ivers-Tiffée, E. J. Appl. Electrochem. 2008, 155, B36B41.

[20] Peters, C.; Weber, A.; Ivers-Tiffée, E. J. Electrochem. Soc. 2008, 155, B730-B737.

[21] Leonide, A., Rüger, B.; Weber, A.; Meulenberg, W. A.; Ivers-Tiffée, E. J. Electrochem. Soc. 2010, 157, B234-B239. 
[22] Endler, C.; Leonide, A.; Weber, A.; Tietz, F.; Ivers-Tiffée, E. J. Electrochem. Soc. 2010, 157, B292-B298.

[23] Kromp, A.; Leonide, A.; Weber, A.; Ivers-Tiffée, E. J. Electrochem. Soc. 2011, 158, B980B986.

[24] Ivers-Tiffée, E.; Hayd, J.; Klotz, D.; Leonide, A.; Han, F.; Weber, A. ECS Transactions 2011, 35, 1965-1973.

[25] Hayd, J.; Guntow, U.; Ivers-Tiffée, E. ECS Transactions 2011, 35, 2261-2273.

[26] Leonide, A.; Weber, A.; Ivers-Tiffée, E. ECS Transactions 2011, 35, 2961-2968.

[27] Klotz, D.; Schmidt, J.P.; Kromp, A.; Weber, A.; Ivers-Tiffée, E. ECS Transactions 2012, 41, 25-33.

[28] Kromp, A.; Dierickx, S.; Leonide, A.; Weber, A.; Ivers-Tiffée, E. ECS Transactions 2012, 41, 161-169.

[29] Kromp, A.; Dierickx, S.; Leonide, A.; Weberand, A.; Ivers-Tiffée, E. J. Electrochem. Soc. 2012, 159, B597-B601.

[30] Klotz, D.; Szasz, J.; Weberand, A.; Ivers-Tiffée, E. ECS Transactions 2012, 45, 241-249.

[31] Jensen, S.H.; Hauch, A.; Hendriksen, P.V.; Mogensen, M.; Bonanos, N.; Jacobsen, T. J. Electrochem. Soc. 2007, 154, B1325-B1330.

[32] Lu, Y.; Kreller, C.; Adler, S.B. J. Electrochem. Soc. 2009, 156, B513-B525.

[33] Kreller, C.R.; Drake, M.E.; Adler, S.B. ECS Transactions 2010, 28, 105-121.

[34] Schichlein, H.; Muller, A.C.; Voigts, M.; Krugel, A.; Ivers-Tiffée, E. J. Electrochem. Soc. 2002, 32, 875-882.

[35] Barfod, R.; Hagen, A.; Ramousse, S.; Hendriksen, P.V.; Mogensen, M. Fuel Cells 2006, 6, $141-145$.

[36] Jørgensen, M.J.; Mogensen, M. J. Electrochem. Soc. 2001,148, A433-A442.

[37] Barfod, R.; Mogensen, M.; Klemensø, T.; Hagen, A.; Liu, Y.; Hendriksen, P. J. Electrochem. Soc. 2007, 154, B371-B378

[38] Utz, A.; Joos, J.; Weber, A.; Ivers-Tiffée, E. ECS Transactions 2011, 35, 1669-1682.

[39] Kromp, A.; Leonide, A.; Weber, A.; Ivers-Tiffee, E. J. Electrochem. Soc. 2011, 158, B980B986. 
[40] Agarwal, P.; Crisalle, O.D.; Orazem, M.E.; Garcia-Rubio L.H. J. Electrochem. Soc. 1995, $142,4149-4158$.

[41] Koch, S.; Mogensen, M.; Hendriksen, P.V.; Dekker, N.; Rietveld, B. Fuel Cells 2006, 6, $117-122$.

[42] Vohs, J.M.; Gorte, R.J. Adv. Mater. 2009, 21, 943-956. 


\section{Chapter 5: Aging effect of LSM electrodes}

\subsection{Introduction}

Lanthanum strontium manganite (LSM) and yttria-stabilized zirconia (YSZ) remain the most popular materials for composite cathodes in solid oxide fuel cells (SOFCs) [1]. In practice, two cathode layers are often employed, with the active layer containing a blend of YSZ and the cathode material analogous to the $\mathrm{NiO} / \mathrm{YSZ}$ cermet used as the anode. This blend improves the thermal match of the cathode with the zirconia electrolyte, and results in improved porosity and resistance to sintering, while still showing the required electronic conductivity. The second cathode layer is the current collector layer, which contains pure LSM [2].

In the literature, there is discussion concerning the sharp decrease in polarization resistance of LSM cathodes during the initial application of current (the burn-in effect). One widely observed phenomenon is the activation of LSM/YSZ composite cathodes and pure LSM electrodes by cathodic current flow.[3-16]. The activation process can be caused by even a brief pulse of cathodic current, and this significant reduction in the polarization resistance of both LSM electrodes and LSM/YSZ composite cathodes is relatively quick. Following the electrochemical activation process, the polarization resistance slowly increases under open circuit. However, the relaxation process evolves very slowly (i.e., $\sim 100 \mathrm{~h}$ or more) [9]. The proposed mechanisms on the origins of the electrochemical activation include redox reactions of the catalyst transition metal-manganese (changes in the bulk defect chemistry under polarization). Bulk defects are voids in regions where there are a large number of atoms missing from the lattice. Voids can occur when impurity atoms cluster together to form small regions of a different phase. Other mechanisms include changes in cathode morphology and resulting improved interfacial contact between LSM and YSZ, or redistribution of impurities under current flow, or changes in perovskite surface chemistry [3]. In short, this phenomenon is the subject of much speculation.

As discussed in section 1.3, the cathodes are particularly subject to degradation processes as the electrochemical oxygen reduction process is sensitive to the changes in material composition and physical structure developing in the cathode. So, a full understanding of the cathode degradation mechanism, particularly one phenomenon of degradation, is very helpful for improving the cell long term stability. This phenomenon is a temporally changing polarization resistance over tens 
of hours in a SOFC cell at open circuit with respect to thermal perturbation (reversible aging effect).

\subsection{Objectives}

The reversible aging behavior was first noticed by Dr. Harry Abernathy (NETL) while operating a commercial electrolyte-supported button cell (NexTech Hionic ${ }^{\mathrm{TM}}$ ) at open circuit with no prior current activation. The cathode was a $50 \mu \mathrm{m}$ LSM/LSM-GDC multi-layer. The anode was a 50 $\mu \mathrm{m}$ Ni-GDC/Ni-YSZ multi-layer and the electrolyte was a $150 \mu \mathrm{m}$ zirconia-based layer. The cell was aged at $750^{\circ} \mathrm{C}$ and then $850^{\circ} \mathrm{C}$ for $72 \mathrm{~h}$ at open circuit with the anode exposed to wet hydrogen and the cathode to air. Over the 72 hours operation at $750^{\circ} \mathrm{C}$ and $850^{\circ} \mathrm{C}$, the polarization resistance almost doubled at $750^{\circ} \mathrm{C}$, and it decreased by more than half with respect to the same time at $850^{\circ} \mathrm{C}$. (Fig 5.1) A similar sample which was heated directly to $850^{\circ} \mathrm{C}$ showed a similar decrease in polarization resistance with time, while subsequent aging at $750^{\circ} \mathrm{C}$ led to an increase in polarization resistance. When cycling the sample between the two temperatures, no matter which initial temperature was used, a growing resistance at $750^{\circ} \mathrm{C}$ and a shrinking resistance at $850^{\circ} \mathrm{C}$ were always observed.

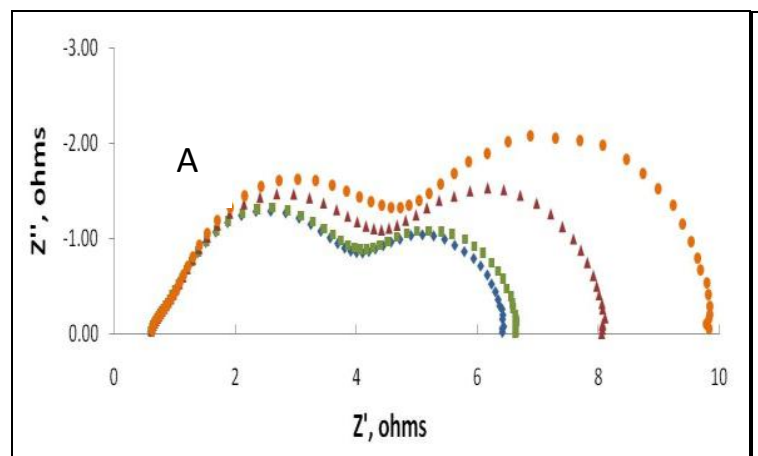

(a)

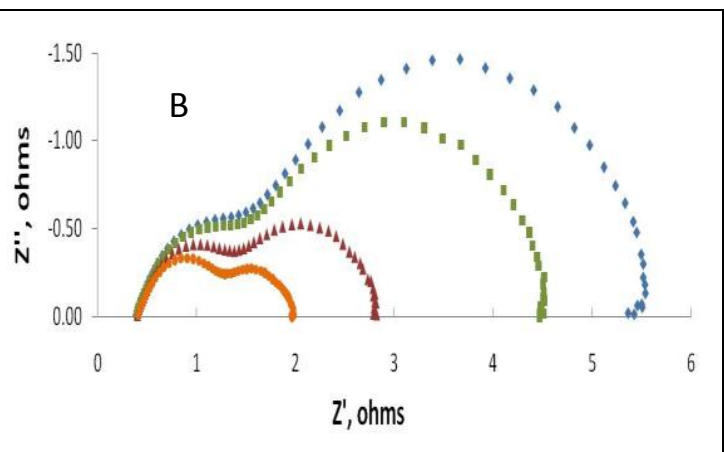

(b)

Fig. 5.1:NexTech Hionic ${ }^{\mathrm{TM}}$ electrolyte-supported cell with LSM/GDC composite cathode.

(a) Impedance plots during aging at $750^{\circ} \mathrm{C}$ for $1 \mathrm{~h}$ (blue diamonds), $5 \mathrm{~h}$ (green squares), $26 \mathrm{~h}$ (red triangles), and $53 \mathrm{~h}$ (orange circles). (b) Impedance plots during aging at $850^{\circ} \mathrm{C}$ for $1 \mathrm{~h}$ (blue diamonds), $5 \mathrm{~h}$ (green squares), $26 \mathrm{~h}$ (red triangles), and $76 \mathrm{~h}$ (orange circles)

We used symmetrical cells (electrodes were prepared with the cathode material) cycling between $700^{\circ} \mathrm{C}$ and $800^{\circ} \mathrm{C}$ at open circuit to investigate systematically the above phenomenon. The symmetrical cells with cathode material electrodes were used instead of conventional SOFCs. The purpose is to separate the contribution from the anode and confirm that the aging effect is 
from cathode. The symmetrical cells can yield unambiguous impedance data at open circuit (DC current is zero). In this chapter, measurements of polarization resistances are reported at various temperatures. We chose to cycle the cells between $700^{\circ} \mathrm{C}$ and $800^{\circ} \mathrm{C}$ because we found that in the symmetrical cells, the polarization resistance increases at $700^{\circ} \mathrm{C}$ and decreases at $800^{\circ} \mathrm{C}$.

The objective of this research is first to verify the reversible aging phenomenon in various cathode compositions at OCV on symmetrical cells by analyzing only the cathode performance. Then we aim to find an explanation for this aging phenomenon by linking the microstructure evolution of cathode material with aging phenomenon, and finally to develop reasonable mechanisms causing this aging behavior of LSM electrodes. We hope that ultimately this study will be helpful for improving the LSM electrode long term stability.

\subsection{Experimental}

As our focus is mainly on the LSM electrodes, we used symmetrical cells (porous LSM electrodes supported on dense YSZ electrolyte pellets in a symmetric configuration on both sides). Because LSCF cathodes are popular in many SOFCs designed to operate at lower temperatures than ones with LSM cathodes, LSCF electrodes were analyzed for comparison. The role of the electrolyte is explored by testing LSM and LSCF symmetrical cells also with GDC (gadolinium-doped ceria) electrolytes. GDC is another popular electrolyte in modern SOFCs.

\subsubsection{Symmetrical cells with pure LSCF, LSM and LSM/YSZ composite electrodes and $Y S Z$ electrolytes aged at 700,800 and $850^{\circ} \mathrm{C}$ in air}

This initial work was performed to verify the presence of the reversible aging phenomenon in various cathode compositions. Three types of freshly-made symmetrical cells were tested in the tube furnace in open air. The types of electrodes included pure LSCF and pure LSM electrodes with electrode diameter of 0.5 inch, and LSM/YSZ composite electrodes with electrode diameter of 0.5 inch, all on YSZ electrolytes. Pure LSCF and pure LSM cells were purchased from Fuel Cell Materials. The LSM/YSZ composite cell was hand- printed with LSM/YSZ composite ink. 
The electrode ink was prepared by mixing LSM with YSZ at 1:1 weight ratio. The cell was sintered at $1200^{\circ} \mathrm{C}$ for 4 hours.

Both electrodes of the three kinds of cells were coated with gold paste as current collectors, and then they were mounted in a furnace (as shown in Figure 5.2). The cell was exposed to laboratory atmosphere. Two wires (current and voltage sense) led from the potentiostat to a point next to each electrode, and a single wire led from that point to the gold paste current collector. One electrode was connected to the working electrode and voltage sense leads, and the other electrode was connected to the counter electrode and voltage sense leads. Cells were characterized by cyclic voltammograms (CVs) and electrochemical impedance spectroscopy (EIS) using the Cell Test system. Both CVs and EIS measured at 4 hour intervals at temperatures of 700,800 , or $850^{\circ} \mathrm{C}$ in air, holding at each temperature for 48 hours. The CV (scan from 0 to 0.1 to -0.1 to $0 \mathrm{~V}$ ) yielded the total resistance $(\Delta \mathrm{E} / \Delta \mathrm{I})$ (Fig 5.3(a)). This $100 \mathrm{~s}$ slow scan CV yielded a more accurate value of total resistance instead of using the low frequency intercept of the EIS data. EIS data sometimes was inaccurate because of the noise that appeared in the low frequency area of the EIS plot. The high frequency intercept of the EIS data yielded the series resistance. The polarization resistance is the total resistance minus the series resistance (Fig 5.3(b)). In most figures, the area-normalized polarization resistance (units ohm $\mathrm{cm}^{2}$ ) are reported. The normalization used the geometric area of the electrode based on its radius.

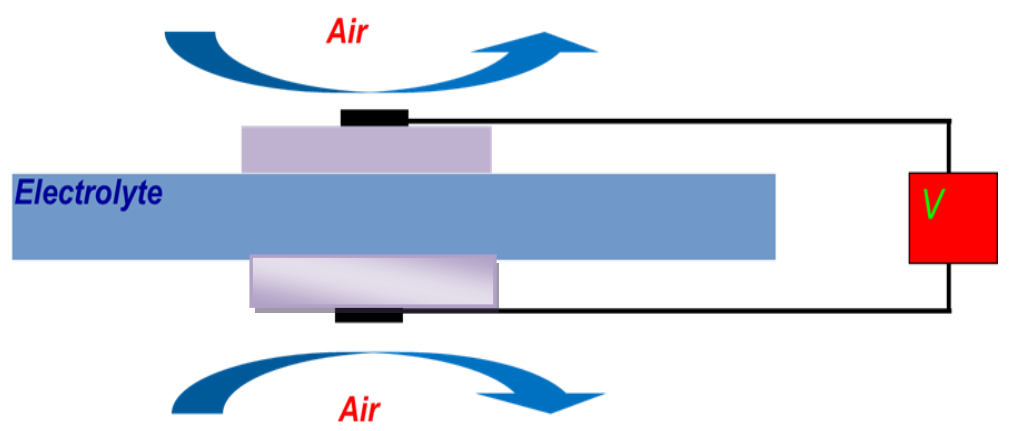

Fig 5.2: The setup of the symmetrical cell 


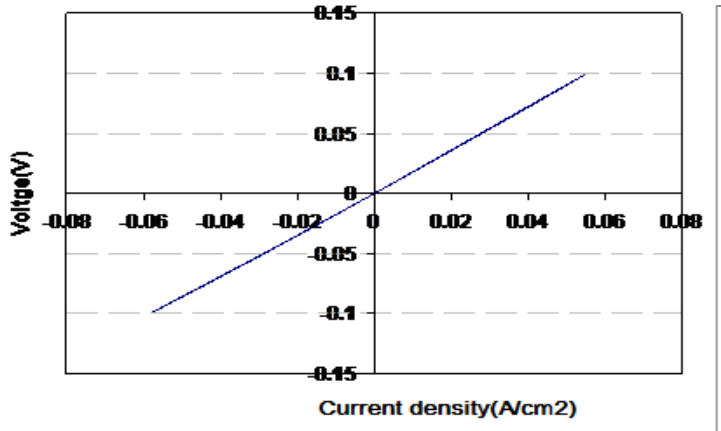

(a)

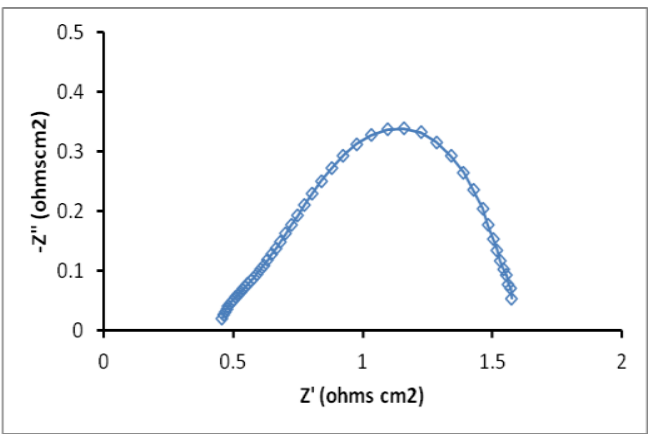

(b)

Fig 5.3: The LSM/YSZ Cell was characterized at the first $4 \mathrm{~h}$ at $850^{\circ} \mathrm{C}$ by cyclic voltammograms (CVs) and electrochemical impedance spectroscopy (EIS). (a) CV scan from - 0.1 to 0.1 yielded

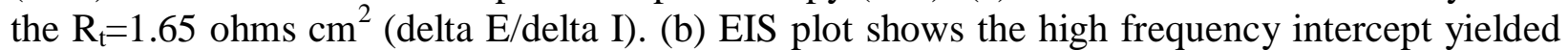
the $R_{s}=0.48$ ohms cm ${ }^{2}$, the low frequency intercept yielded $R_{t}=1.60 \mathrm{ohms} \mathrm{cm}^{2}$. The $R_{p}$ is $R_{t}$ (from $\mathrm{CV}$ ) minus $\mathrm{R}_{\mathrm{s}}$ equal to $1.17 \mathrm{ohms} \mathrm{cm}^{2}$.

\subsubsection{Cycling LSM/YSZ/LSM symmetrical cells between 700 and $800^{\circ} \mathrm{C}$}

To find out how the trend of polarization resistance changes with cycling temperature, a set of LSM/YSZ/ LSM symmetrical cells was cycled between 700 and $800^{\circ} \mathrm{C}$ for five times with soaking at both temperatures for 48 hours.

\subsubsection{Extended thermal aging of the LSM/YSZ/LSM symmetrical cells at $800^{\circ} \mathrm{C}$ or $700^{\circ} \mathrm{C}$ for 500 hour before cycling the cells between 700 and $800^{\circ} \mathrm{C}$}

In order to show the effect of thermal history, four freshly-made LSM/YSZ commercial symmetrical cells (Fuel Cell Materials) were used for comparison. One cell was first aged for 500 hours at $700^{\circ} \mathrm{C}$, and then cycled between $700^{\circ} \mathrm{C}$ and $800^{\circ} \mathrm{C}$ five times with soaking at both temperatures for 2 days. Another cell was aged 500 hours at $700^{\circ} \mathrm{C}$ at open circuit without cycling, and saved for surface analysis. A third cell was aged for 500 hours at $800^{\circ} \mathrm{C}$ at open circuit, and then cycled between $700^{\circ} \mathrm{C}$ and $800^{\circ} \mathrm{C}$ similar to the protocol for the first one. A fourth cell was aged for 500 hours at $800^{\circ} \mathrm{C}$ and saved for surface analysis. During the 500 hours thermal aging, the cells were monitored by $\mathrm{CVs}$ and electrochemical impedance spectroscopy with measurements at six hour intervals, and during the thermal cycling, the cells were characterized as before. 


\subsubsection{Extended thermal aging of the LSM/YSZ/LSM, LSM/GDC/LSM and LSCF/GDC/LSCF symmetrical cells at $800^{\circ} \mathrm{C}$ for 50 hour before cycling the cells between 800 and $700^{\circ} \mathrm{C}$.}

A series of aging experiments are conducted to analyze the aging effects using three kinds of freshly-made commercial symmetrical cells (Fuel Cell Materials) (LSM/YSZ/LSM, LSM/GDC/LSM and LSCF/GDC/LSCF). The electrode diameters were 0.5 inch (cathode area $1.27 \mathrm{~cm}^{2}$ ). For each kind of cell, two cells (cell A and cell B) are tested. Both cell A and cell B were first aged at $800^{\circ} \mathrm{C}$ for $50 \mathrm{~h}$ in air, and then cell $\mathrm{A}$ was cycled starting at $800^{\circ} \mathrm{C}$, then to $700^{\circ} \mathrm{C}$, then to $800^{\circ} \mathrm{C}$, then to $700^{\circ} \mathrm{C}$, and then ending at $800^{\circ} \mathrm{C}$ before cooling (three cycles). The cells were kept at each temperature for two days. Cell B was also cycled between $800^{\circ} \mathrm{C}$ and $700^{\circ} \mathrm{C}$, starting at $800^{\circ} \mathrm{C}$, and, after subjecting to two cycles, ending at $700^{\circ} \mathrm{C}$ before cooling. Again, the cells were kept at each temperature for two days. During the cycling, the electrochemical impedance was collected every one hour for the first 8 hours at each temperature, and then every 6 six hours for the remaining time. The same protocol was applied to each kind of cells. The impedance data for these cells were analyzed using deconvolution and equivalent circuit fitting as described in chapter 2 .

\subsection{Results and Discussion}

\subsubsection{Impedance analysis with thermal aging}

For the symmetrical cells with pure LSM and LSM/YSZ composite electrodes holding at $700^{\circ} \mathrm{C}$, $800^{\circ} \mathrm{C}$ and $850^{\circ} \mathrm{C}$ in air (described in 5.3.1), the aging behavior is readily observable with both types of cells. The aging phenomenon is more apparent with pure LSM cathodes. Fig. 5.4 illustrates the initial changes when a virgin pure LSM electrode symmetrical cell (Fuel Cell Materials) is set inside a tube furnace set to $700^{\circ} \mathrm{C}$, then $800^{\circ} \mathrm{C}$, and finally $850^{\circ} \mathrm{C}$ in air. The polarization resistance rises relatively rapidly in the first few hours and then decays slowly at $700^{\circ} \mathrm{C}$. The decay continues at the higher temperatures and appears to be more rapid at $800^{\circ} \mathrm{C}$ than at $850^{\circ} \mathrm{C}$. Fig 5.5 illustrates the same trend of polarization resistance change for LSM/YSZ composite electrodes as the pure LSM electrodes. The sensitivity of the polarization resistance to thermal history has been observed previously [16]. In comparison, the LSCF/YSZ/LSCF cell was not observed to exhibit similar aging behavior as LSM cells. Fig 5.6 shows the initial 
changes of LSCF electrode symmetrical cell (Fuel Cell Materials) at $700^{\circ} \mathrm{C}$, then $800^{\circ} \mathrm{C}$, and finally $850^{\circ} \mathrm{C}$ in air. The polarization resistance decreases in the first few hours and then increases at $700^{\circ} \mathrm{C}$. This irreversible increase in the polarization resistance continues at the higher temperature of $800^{\circ} \mathrm{C}$ and appears to exhibit no recovery at $850^{\circ} \mathrm{C}$.

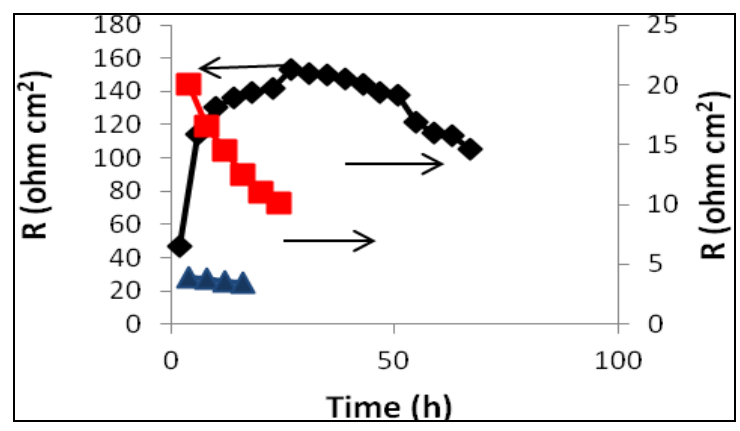

Fig 5.4: Initial polarization resistances of a pure LSM/YSZ/LSM symmetrical cell in air at $700^{\circ} \mathrm{C}$ (black diamonds -left axis), $800^{\circ} \mathrm{C}$ (red squares - right axis), and $850^{\circ} \mathrm{C}$ (blue triangles - right axis).

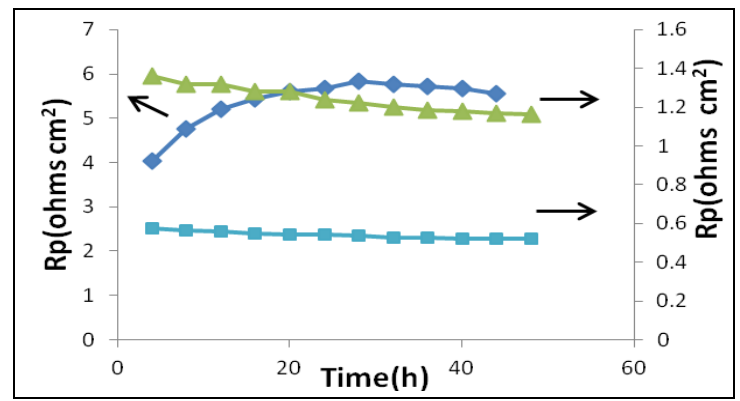

Fig 5.5: Initial polarization resistances of an LSM/YSZ composite symmetrical cell in air at $700^{\circ} \mathrm{C}$ (dark blue diamonds -left axis), $800^{\circ} \mathrm{C}$ (green triangles - right axis), and $850^{\circ} \mathrm{C}$ (light blue squares - right axis).

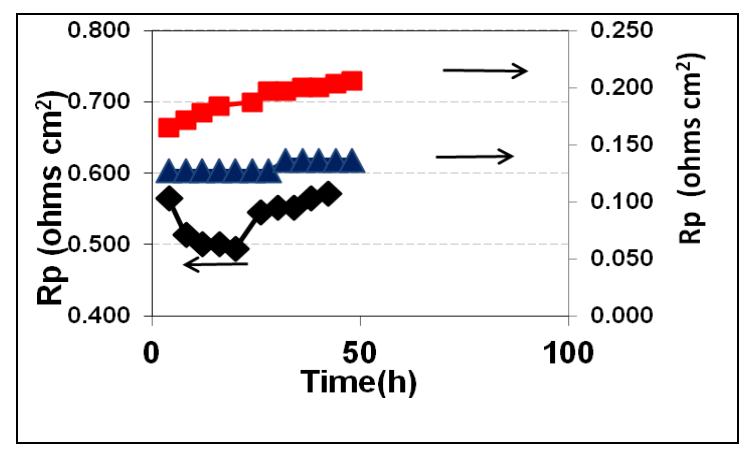

Fig 5.6: Initial polarization resistances of a pure LSCF/YSZ/LSCF symmetrical cell in air at $700^{\circ} \mathrm{C}$ (black diamonds -left axis), $800^{\circ} \mathrm{C}$ (red squares - right axis), and $850^{\circ} \mathrm{C}$ (blue triangles - right axis).

After break-in, the polarization resistance of LSM/YSZ/LSM cell exhibits reversible changes at $800^{\circ} \mathrm{C}$ or $700^{\circ} \mathrm{C}$ (Fig.5.7). The polarization resistance consistently rises with respect to time at 
$700^{\circ} \mathrm{C}$ and decays at $800^{\circ} \mathrm{C}$. A Bode plot of $-\mathrm{Z}$ " vs. $\log (\mathrm{f})$ for the beginning and end of a single temperature $\left(700^{\circ} \mathrm{C}\right)$ shows that the aging effects occur at the lowest frequencies (Fig 5.8). The symmetrical cells constructed in-house show the similar behavior. The steady inter-cycle decrease in the polarization resistance shown in Fig.5.7 indicates a continuing irreversible change occurring in the cell.

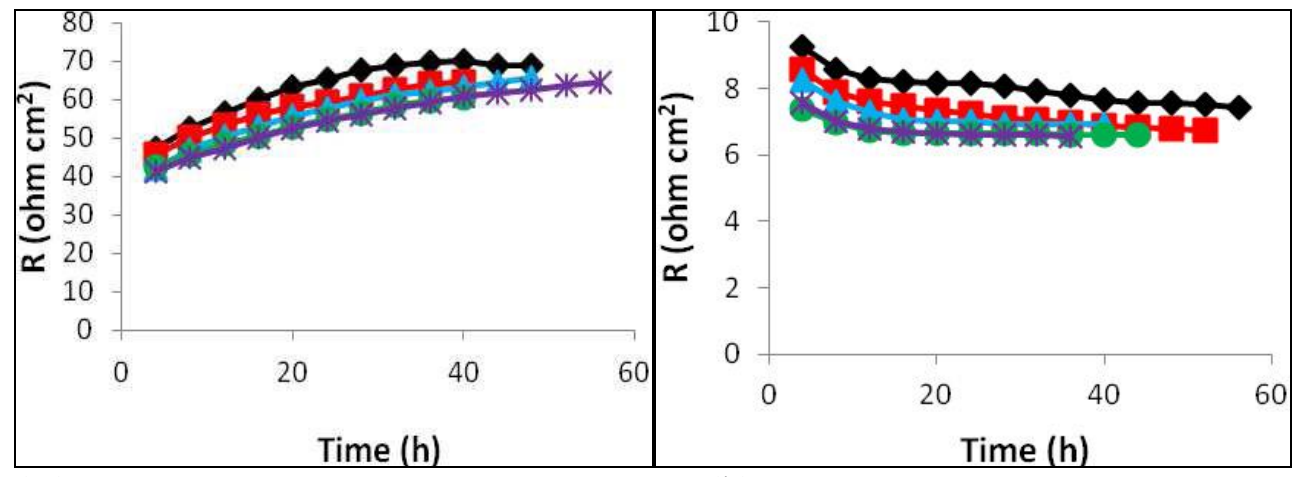

(a)

(b)

Fig 5.7: Polarization resistances of the LSM/YSZ/LSM cell in Fig 5.4 at (a) $700^{\circ} \mathrm{C}$ and (b) $800^{\circ} \mathrm{C}$ during temperature cycles 1 (diamonds), 2 (squares), 3 (triangles), 4 (circles) and 5 (asterisks).

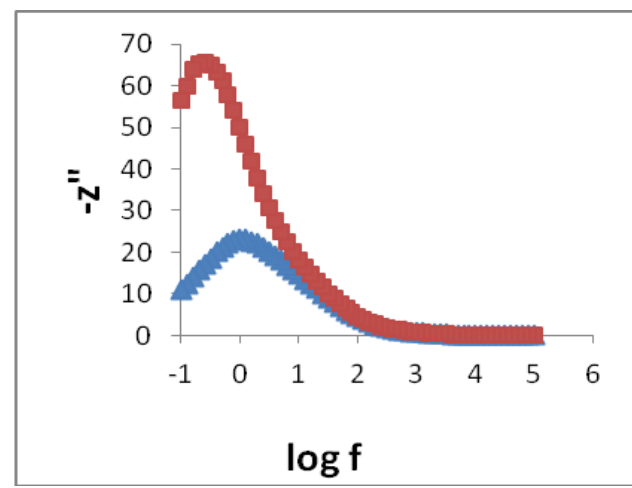

(a)

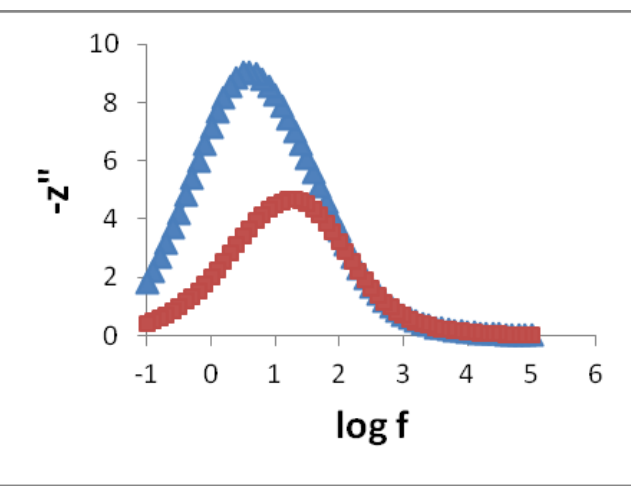

(b)

Fig 5.8 : A plot of $-Z$ " vs $\log \mathrm{f}$ for a pure LSM electrode soaking at $700{ }^{\circ} \mathrm{C}$ and $800^{\circ} \mathrm{C}$ (a): $-Z$ " vs $\log \mathrm{f}$ plot at the beginning and end $\left(48\right.$ hours) of soaking at $700^{\circ} \mathrm{C}$. (b) $-Z^{\prime \prime}$ vs $\log \mathrm{f}$ plot at the beginning and end ( 48 hours) of soaking at $800^{\circ} \mathrm{C}$. It is obvious that the changes of Z" occurs at lower frequencies. Data is collected at the beginning of soaking (blue triangles) and end of soaking (red squares).

The extended thermal aging of four LSM/YSZ/LSM symmetrical cells at $800^{\circ} \mathrm{C}$ or $700^{\circ} \mathrm{C}$ for 500 hours before cycling the cells between $700^{\circ} \mathrm{C}$ and $800^{\circ} \mathrm{C}$ (cells described in in 5.3.3) indicates that the cell thermal history decides the repeatability of the reversible change, as illustrate in Fig 5.9 and Fig 5.10. One freshly-made LSM-YSZ commercial symmetrical cell (Fuel Cell Materials) was aged for more than 500 hours at $800^{\circ} \mathrm{C}$ before being cycled between $700^{\circ} \mathrm{C}$ and 
$800^{\circ} \mathrm{C}$ (Fig. 5.9). The results show that thermal aging at $800^{\circ} \mathrm{C}$ removes the inter-cycle decrease in the polarization resistance and the reversible change becomes very repeatable. Since reproducible polarization resistances can be obtained over five temperature cycles, the results suggest that stable thermodynamic states are obtained after 48 hours at $700^{\circ} \mathrm{C}$ and at $800^{\circ} \mathrm{C}$. For the freshly-made LSM-YSZ commercial symmetrical cell (Fuel Cell Materials) aged for 500 hours at $700^{\circ} \mathrm{C}$ before cycling between $700^{\circ} \mathrm{C}$ and $800^{\circ} \mathrm{C}$ (Fig. 5.10), in contrast, the thermal aging at $700^{\circ} \mathrm{C}$ did not remove the inter-cycle transient effects, and the reversible change pattern of $\mathrm{R}_{\mathrm{p}}$ at $700^{\circ} \mathrm{C}$ and $800^{\circ} \mathrm{C}$ for the cell aged $500 \mathrm{~h}$ at $700^{\circ} \mathrm{C}$ is less reproducible similar to the virgin cell without thermal aging (Fig 5.7).

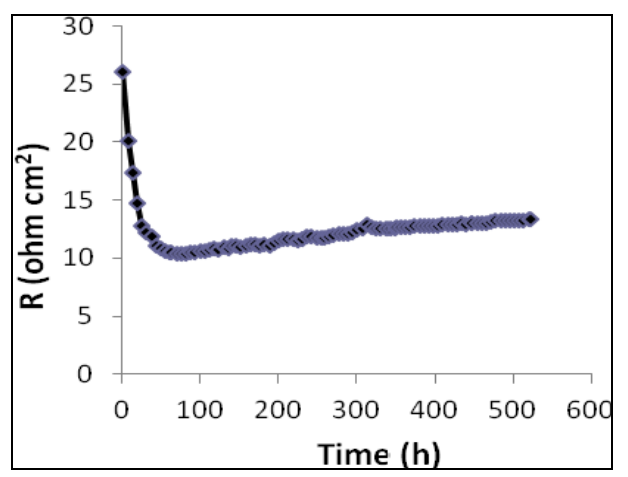

(a)

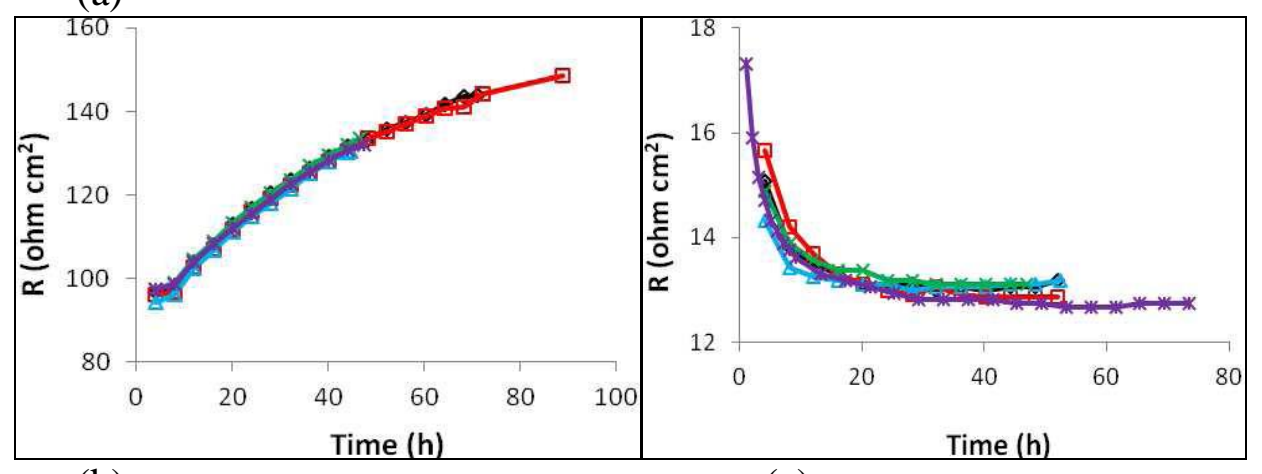

(b)

(c)

Fig. 5.9:(a) Polarization resistance of an LSM/YSZ/LSM symmetrical cell during a 522 hour soak at $800^{\circ} \mathrm{C}$. (b) Polarization resistances of the cell at $700^{\circ} \mathrm{C}$. (c) Polarization resistances of the cell at $800^{\circ} \mathrm{C}$. In (b) and (c), the temperature cycles are indicated by 1 (diamonds), 2 (squares), 3 (triangles), 4 (circles) and 5 (asterisks). 


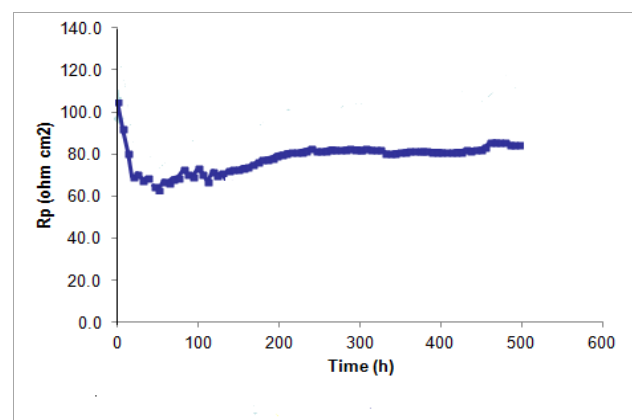

(a)

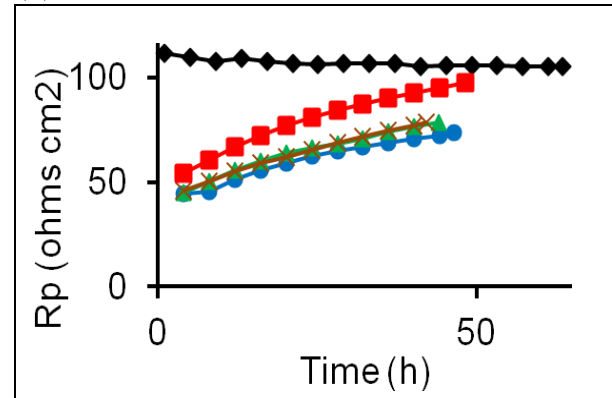

(b)

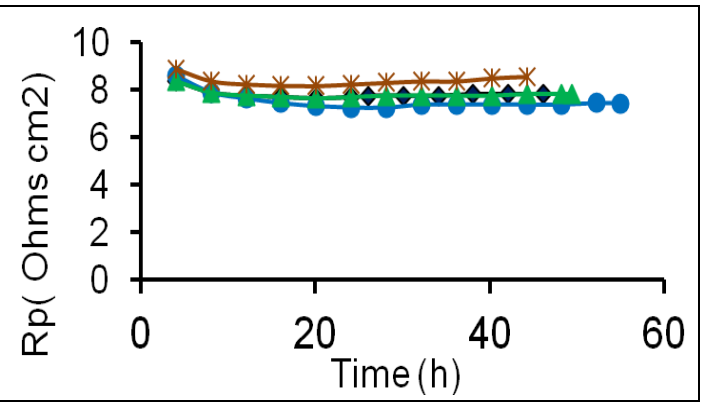

(c)

Fig 5.10(a) Polarization resistance of an LSM/YSZ/LSM symmetrical cell during a 516 hour soak at $700^{\circ} \mathrm{C}$. (b) Polarization resistances of the cell at $700^{\circ} \mathrm{C}$ after soaking at $700^{\circ} \mathrm{C}$ for 510 hour. (b) Polarization resistances of the cell at $800^{\circ} \mathrm{C}$.In (a) and (b), the temperature cycles are indicated by 1 (diamonds), 2 (circles), 3 (triangles), 4 (asterisks) and 5 (squares). In (b), the cell was shut down after four cycles.

\subsubsection{Discussion of possible causing of aging effect}

For the tested symmetrical cells, there are initially irreversible changes in the polarization resistance. With the LSM electrode, after the initial conditioning of the cell, the polarization resistance shows a reproducible rise in polarization resistance at $700^{\circ} \mathrm{C}$, and a reproducible decay in polarization resistance at $800^{\circ} \mathrm{C}$, while the LSCF electrode does not show this reversible behavior between $700^{\circ} \mathrm{C}$ and $800^{\circ} \mathrm{C}$. The possible mechanism for aging effect of the LSM electrode must explain the reversible changes in the polarization resistance behavior that occur between $700^{\circ} \mathrm{C}$ and $800^{\circ} \mathrm{C}$ and the overall irreversible decrease observed during the first few thermal cycles. Both the reversible and irreversible processes occur on the time scale of hours and mainly affect low frequency behavior. The formation of oxide ion vacancies accounts for the activation behavior of the electrode as the oxygen transport pathway is enlarged in a process with a time scale of minutes at most [10, 17-21]. However, the formation and consumption of oxide ion vacancies in the LSM lattice cannot explain the present observations with the time 
scale of several hours. Cation migration, a relatively slow process in LSM, can be a possible causing of the aging effect $[24,25]$.

Cation migration was reported to contribute mainly to microstructural changes, formation of secondary phases, and redistribution of cations within the perovskite lattice. Jiang first reported the early evidence for cation redistribution (or possibly secondary phase formation) at the LSM air interface $[5,15]$. The authors showed that the surface species/composition of the LSM electrodes significantly determine the activation process. The initial polarization resistance of fresh $\mathrm{La}_{0.72} \mathrm{Sr}_{0.18} \mathrm{MnO}_{3}$ electrodes etched with $\mathrm{HCl}$ solution prior to initial polarization measurements is much less than the same composition LSM electrode without acid etching, and the change in polarization resistance with cathodic current activation is also less than that of an unetched LSM electrode.[10, 22] The etchant solution in Jiang's experiment contained significantly higher concentrations of La and $\mathrm{Sr}$ and lower concentrations of $\mathrm{Mn}$ than predicted by the molar composition of the as-prepared LSM. This result indicates that on the surface of fresh LSM electrodes, passive species like SrO intend to enrich or segregate there, so the surface and the bulk compositions of LSM are different. The proposed mechanism of activation process on LSM electrode is the removal of passive species ( $\mathrm{SrO})$ on the LSM surface together with the simultaneous formation of oxide ion vacancies by the manganese ion reduction. [22]

Many papers also reported Sr-enrichment on the surface of LSM perovskites at high temperatures by using a variety of surface analytical techniques: Auger electron spectroscopy (AES) revealed Sr-enrichment on the surface.[23] Fisher et.al. found strontium surface segregation in $\mathrm{La}_{0.7} \mathrm{Sr}_{0.3} \mathrm{MnO}_{3}$ thin films over a wide range of temperatures and oxygen partial pressures by using total reflection $x$-ray fluorescence (TXRF). They found that the strontium surface concentration increases with decreasing $\mathrm{pO}_{2}[24,25]$. Strontium enrichment at the surface was also observed by X-ray photoelectron spectroscopy (XPS). This degree of enrichment changes with varying conditions of annealing (temperature, oxygen pressure) and polarization treatments of the samples.[3, 26, 27] Various methods of soft x-ray spectroscopy measurements support $\mathrm{Sr} / \mathrm{La}$ enrichment on the surface, enriched $\mathrm{Sr}$ formed passive species $\mathrm{Sr}_{\mathrm{x}} \mathrm{Mn}_{\mathrm{y}} \mathrm{O}_{\mathrm{z}}$ and/or $\mathrm{SrO}$ [28]. Kubicek et al., using time-of-flight secondary ion mass spectroscopy (ToF-SIMS) on an perovskite $\mathrm{La}_{0.6} \mathrm{Sr}_{0.4} \mathrm{CoO}_{3}$ (LSC) thin film, also detected similar enrichment of 
the Sr:La ratio on the surface, which is in agreement with the chemical analysis of the LSC surface etched by an acid solution[29]. Some literature reports demonstrate that the thermal history of the sample leads to a change in the degree of strontium enrichment. Fister et al.[24] and Chang et al.[25] both found that surface strontium enrichment decreases as the temperature of dense LSM films increases from $300^{\circ} \mathrm{C}$ up to $900^{\circ} \mathrm{C}$. Also, they found that the variation in the amount of Sr segregation is greater on the sample that has been subject to 72 hours of applied cathodic potential [25].

Fig. 5.4 and Fig 5.9(a) show that, when the cell was first time subject to $700^{\circ} \mathrm{C}$, there is a brief rise to a maximum and a significant decay to a minimum in the polarization resistance. These initial changes indicate that thermal aging is a complex process, including at least two process occurring during the aging experiments. Based on the above discussion, we propose that at least the two following processes maybe relative to the phenomenon we observed: (1) the initial changes in the wetting behavior of the LSM on the YSZ surface, along with (2) the segregation of cations toward and from the surfaces and/or interfaces of LSM with YSZ.

At sintering temperatures $\left(1100^{\circ} \mathrm{C}-1200^{\circ} \mathrm{C}\right), \mathrm{LSM}$ was discovered to wet the surface of YSZ, and therefore form a dense layer of LSM that inhibits oxygen ion diffusion to the TPB. [31-32] When temperatures are brought to a level well below that of sintering, cracks begin to form in the LSM film formed by the wetting process (alternatively, reverse-wetting could take place). This structure change would make the TPB length increase and the polarization resistance decrease. So the microstructural changes in the LSM material should be a cause for the observed irreversible changes in polarization resistance, particularly the decrease during the first $100 \mathrm{~h}$ of long term aging in Fig. 5.9(a).

At the same time, cations (possibly strontium) segregate from the bulk of the LSM toward the free surfaces and interfaces. The passive species could occupy the active sites and inhibit the surface dissociative adsorption and/or diffusion process for the $\mathrm{O}_{2}$ reduction reaction, and result in the increased polarization resistance. The migration of strontium within the LSM phase is proposed as the cause of the reversible changes in polarization resistance between $700^{\circ} \mathrm{C}$ and $800^{\circ} \mathrm{C}$. Based on the previous literature research, it is reasonable to propose that the strontium segregates at $700^{\circ} \mathrm{C}$, while strontium migrates into the bulk at $800^{\circ} \mathrm{C}$. Such changes of strontium 
are consistent with the appearance of the tested cell of a resistivity maximum after soaking at $700^{\circ} \mathrm{C}$, and a minimum resistivity after soaking at $800^{\circ} \mathrm{C}$. So the migration of strontium within LSM phase (leading to a secondary phase or otherwise) is proposed as the cause of the reversible changes in polarization resistance between $700^{\circ} \mathrm{C}$ and $800^{\circ} \mathrm{C}$ shown in Figs. 5.8(a)-(b), 5.9(b)-(c) and 5.10(b)-(c).

All the above discussions are the initial results from analysis of the change of cell impedance with time. Since the electrochemistry experiments alone have limited ability to confirm the cause for the reversible behavior, other surface analytic methods are required. Post-mortem surface analyses of the samples are being planned. These results are not available at the time of the writing of this dissertation.

Another possible approach for separating the processes at different frequencies is deconvolution of impedance spectra combined with complex non-linear regression fitting of the impedance spectra as discussed in chapter 2. This protocol can provide the trends in parameters for the equivalent circuit during thermal aging. We performed the extended tests with different cathode and electrolyte compositions under open circuit. The next section includes such deconvolution analysis.

\subsubsection{Deconvolution analysis of LSM/YSZ/LSM symmetrical cells and (LSM/YSZ)/YSZ/(LSM/YSZ) composite symmetrical cells}

The process for deconvolution steps and building of equivalent circuits follows the discussions in Chapter 2. The data used for fitting are obtained from experiments described in 5.3.4. The deconvolution spectrum indicates the minimum number of arc-forming elements required in the equivalent circuit. With this information, the equivalent circuit is composed of multiple elements in series and each element contributes to one of the arcs in the deconvolution spectrum. The (RQ) and Gerischer impedance elements are two common arc-generating elements we use for the aging effect. During thermal aging, certain peak frequencies in the deconvolution plot are expected to change and equivalent circuit elements strongly associated with that peak frequencies will also change. The analyses can provide the trends in parameters for the equivalent circuit with time. The same kinds of cells A and B, tested at the same time and in the same condition but ending at different temperatures, can provide additional information. 


\section{LSM/YSZ Cell A and Cell B cycle at $8^{\circ} 0^{\circ} \mathrm{C}$}

Fig. 5.11 shows the Nyquist plots and deconvolution spectra for cell A and cell B (LSM/YSZ symmetrical cells) with the first data set at $800^{\circ} \mathrm{C}$. The Nyquist plot shows the high quality of the impedance data points from $100 \mathrm{kHz}$ to $0.02 \mathrm{~Hz}$. In Fig 5.11, at least 2 arcs are visible in the Nyquist plots, and the deconvolution spectra indicate the presence of three or more arcs. For the deconvolution spectra of both cell $\mathrm{A}$ and cell $\mathrm{B}$, there is no long tail extending to the high frequency limit, which is an obvious feature for Gerischer impedance, so only RQ elements are used to fit the impedance. For cell $\mathrm{A}$, using the $\mathrm{R}(\mathrm{RQ}) 3$ model led to odd parameters and a visibly poor fit of deconvolution spectra for the data and for the simulated impedances of the equivalent circuit. The R(RQ)4 model fits the data well. However, there is a slight discrepancy below $1 \mathrm{~Hz}$ in the deconvolution spectra. Adding another RQ element (R(RQ)5) yields a noticeably better fit.

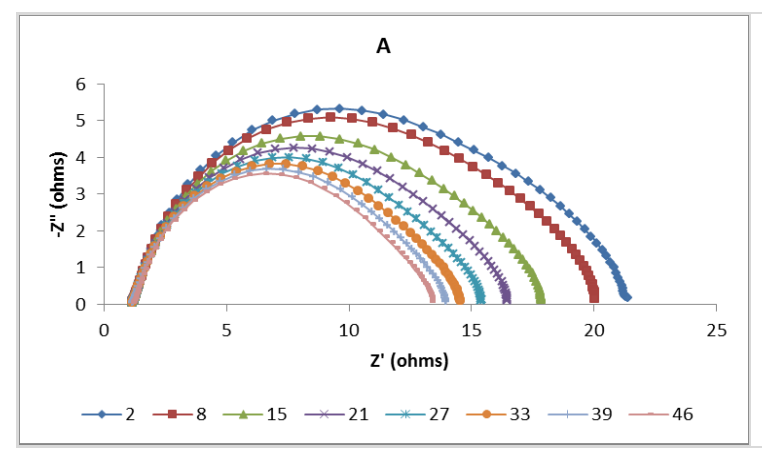

(a)

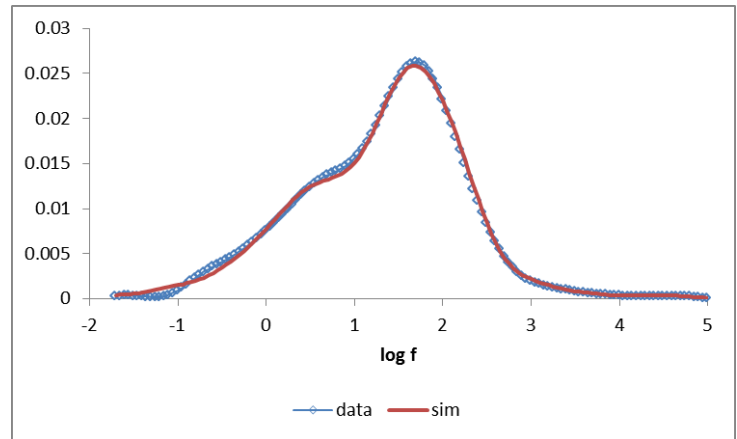

(c)

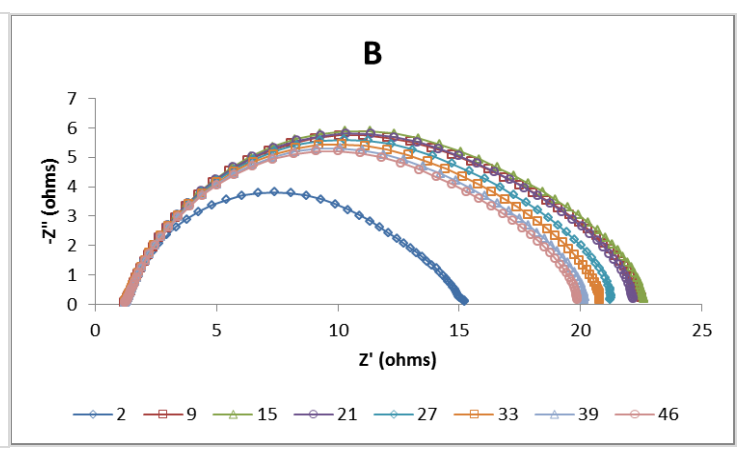

(b)

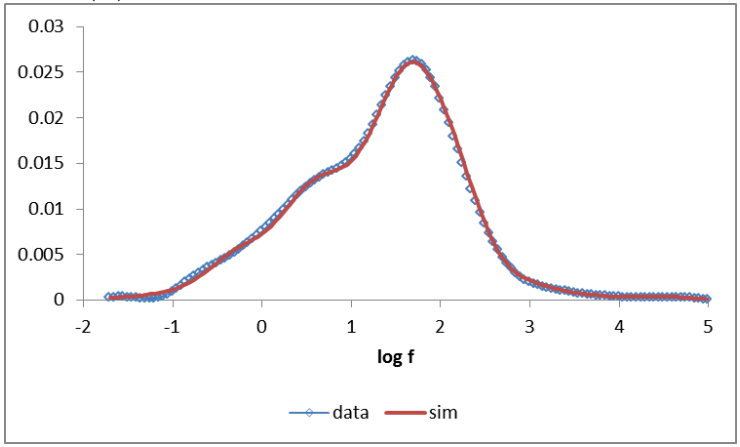

(d)

Fig. 5.11: Impedance spectra and deconvolution spectra for cell A and cell B (LSM/YSZ). (a) Nyquist plots for Sample A first 46 hours; (b) Nyquist plots for Sample B first 46 hours; (c) Deconvolution spectra for sample A first 2.2 hours; (d) Deconvolution spectra for sample B at 2.3 hour. 
Figure 5.12 illustrates the quality of the fit to the (R(RQ)5) equivalent circuit for the first 2.2 hour data collected at $800^{\circ} \mathrm{C}\left(1^{\text {st }}\right.$ cylce $)$ for cell A. All the data have been corrected for the inductance and series resistance obtained from the ZView fit. The five peaks in the deconvolution spectrum correspond to the five elements $\left(R_{1_{1}}-R_{5}\right)$. The parameters for these elements are in Table 5.1. Not only do the Nyquist plots of the data and the simulated impedances from the equivalent circuit overlay very well, but also the plots of deconvolution spectra for the data and for the simulated impedances of the equivalent circuit overlay very well. Fig 5.12(d) shows that the residuals do not exceed $0.04 \mathrm{ohm}$.

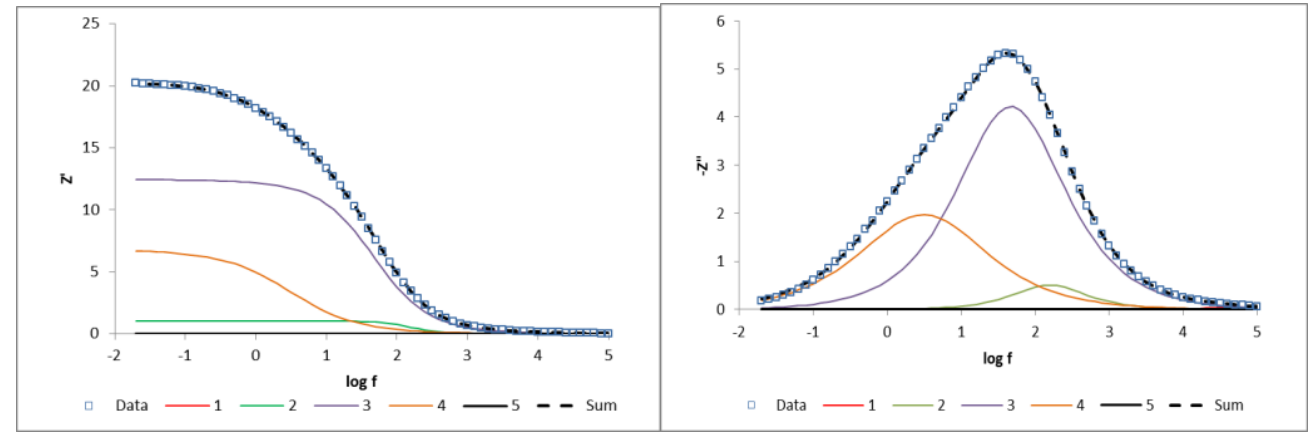

(a)

(b)
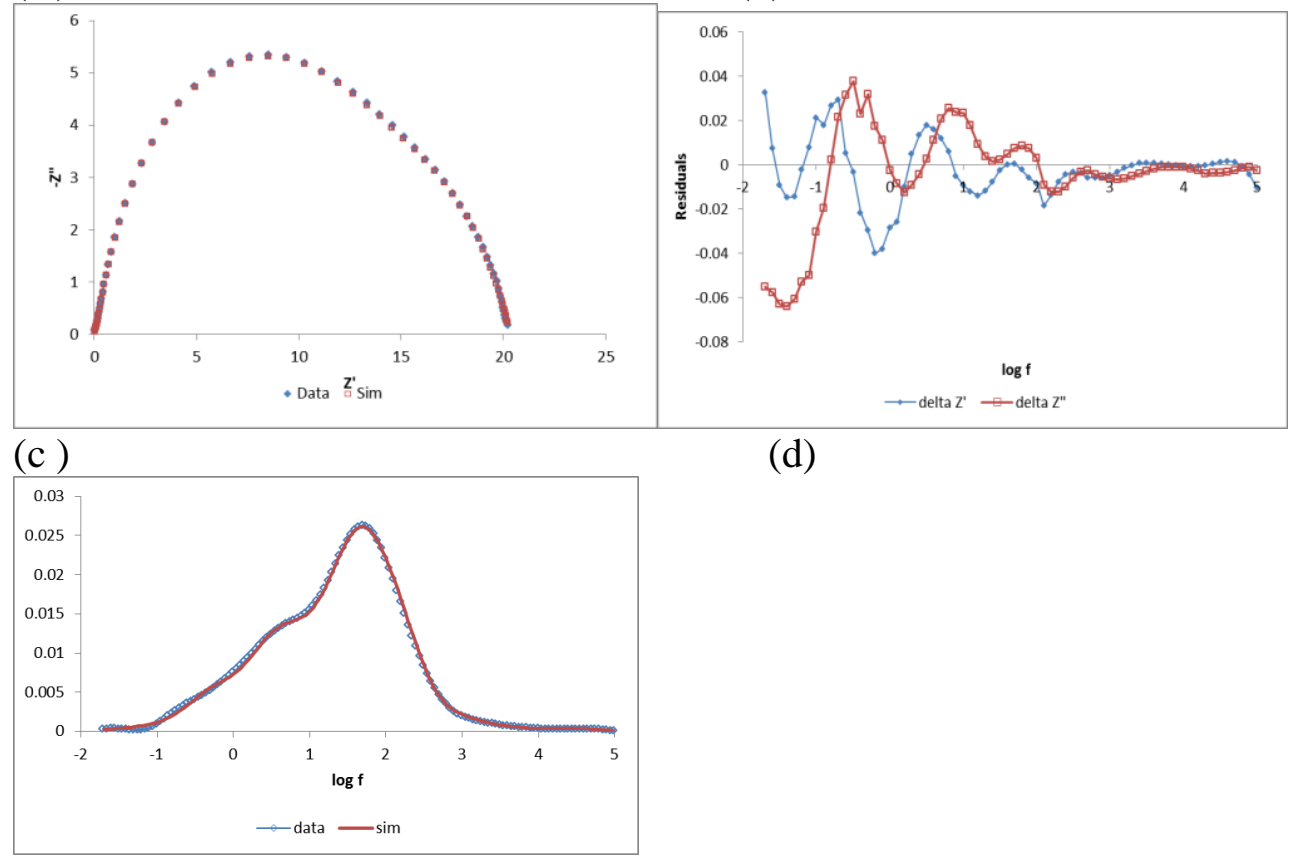

(d)

(e)

Fig. 5.12: Equivalent circuit fit for the first 2.2 hour data collected at $800^{\circ} \mathrm{C}\left(1^{\text {st }}\right.$ cycle for cell A). (a) In-phase Z' data and the contributions from each element in the equivalent circuit; (b) Out-ofphase -Z" data and the contributions from each element; (c) Nyquist plot overlaying the data and the simulated impedances from the equivalent circuit; (d) Residuals (Z'(sim) - Z'(data)) and (Z"( $\operatorname{sim})-Z$ Z'(data)); (e) Overlay plot of the deconvolution spectra for the data and for the simulated impedances of the equivalent circuit. 
Fig 5.13 shows the deconvolution plots of cell B. The overall pattern for cell B is very similar to the pattern for cell A. The impedance is dominated by a high frequency peak around $56(2.3 \mathrm{~h})$ to $40 \mathrm{~Hz}(45.7 \mathrm{~h})$, and by overlapping peaks at lower frequencies. However, fitting the first data set for Cell $\mathrm{B}$ at $800^{\circ} \mathrm{C}$ with $\mathrm{R}(\mathrm{RQ})_{5}$ proved to be difficult for all EIS data. The 5RQ model worked well for data at the end (45.7 hour),( Fig 5.14) but not for the data at the beginning (2.3 hours). The problem lies with the fit at low frequencies, below 10 Hz.(Fig 5.13) Consequently, tracking changes for the lowest frequency elements (RQ4 and RQ5) is a problem for the data at beginning. Figure 5.13 shows that, for cell $\mathrm{B}$ at $800^{\circ} \mathrm{C}$ at 2.3 hour, there is a persistent discrepancy at low frequencies caused by a very small arc visible below $0.1 \mathrm{~Hz}$, and this small arc was not fitted with this circuit. Apart from the bump below $0.1 \mathrm{~Hz}$, the overall fit is very good. This small arc disappears with time. Fig 5.14 shows that, at the end of 45.7 hours, the 5RQ model fits much better. 


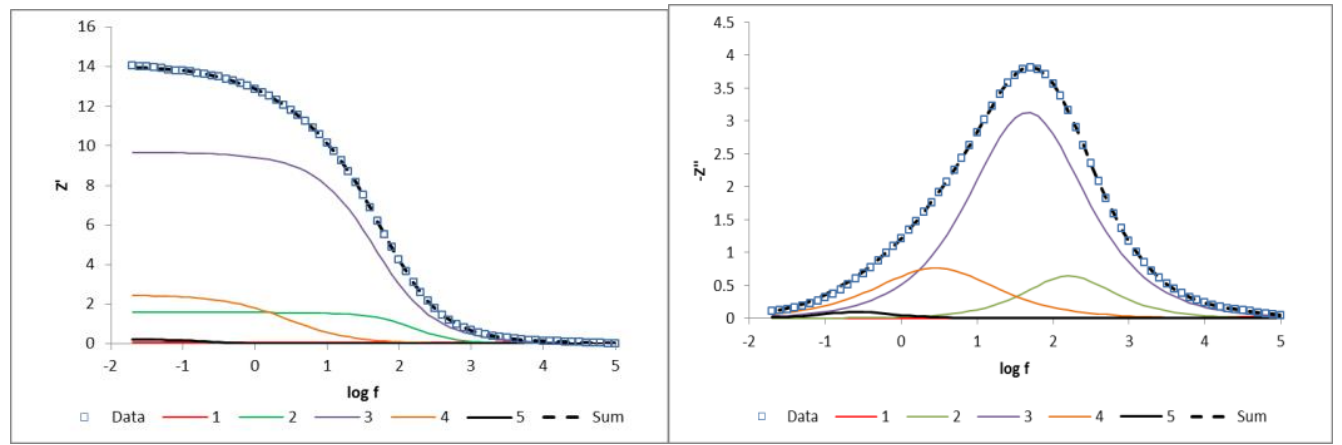

(a)

(b)
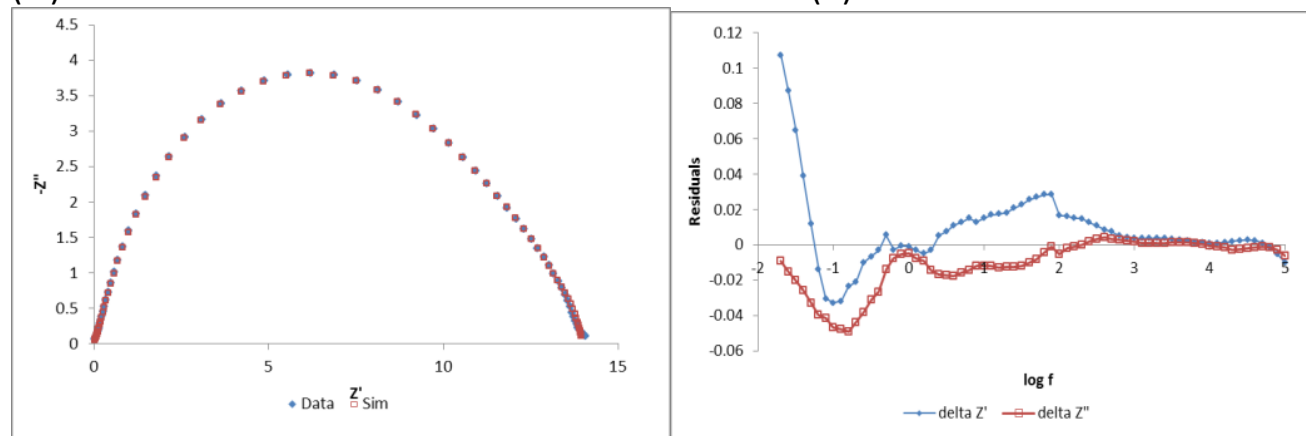

(c)

(d)

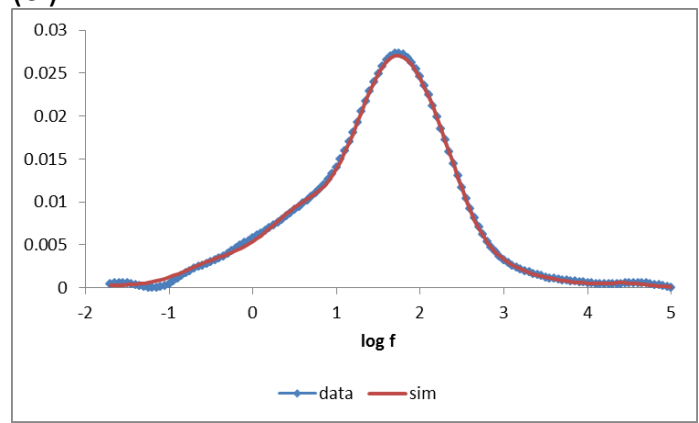

(e)

Fig. 5.13: Equivalent circuit fit for the 2.3 hour data collected at $800^{\circ} \mathrm{C}\left(1^{\text {st }}\right.$ time $)$ for cell B. (a) In-phase Z' data and the contributions from each element in the equivalent circuit; (b) Out-ofphase $-Z$ " data and the contributions from each element; (c) Nyquist plot overlaying the data and the simulated impedances from the equivalent circuit; (d) Residuals (Z'(sim) - Z'(data)) and (Z"(sim) - Z"(data)); (e) Overlay plot of the deconvolution spectra for the data and for the simulated impedances of the equivalent circuit. 


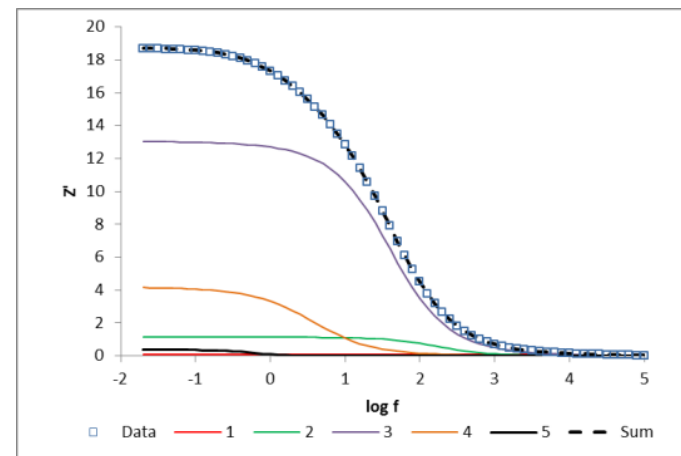

(a)

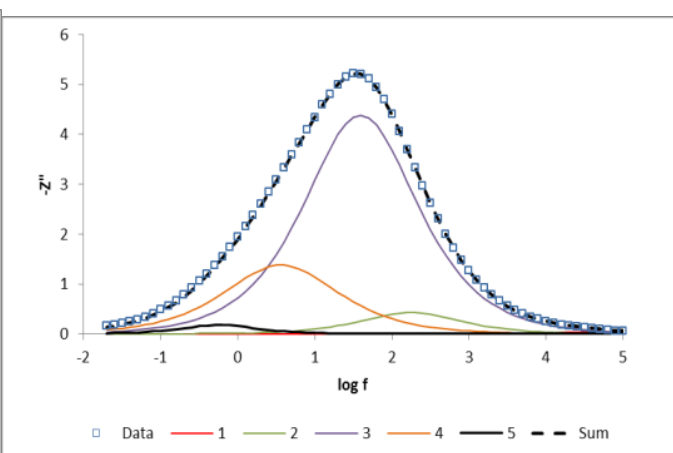

(b)

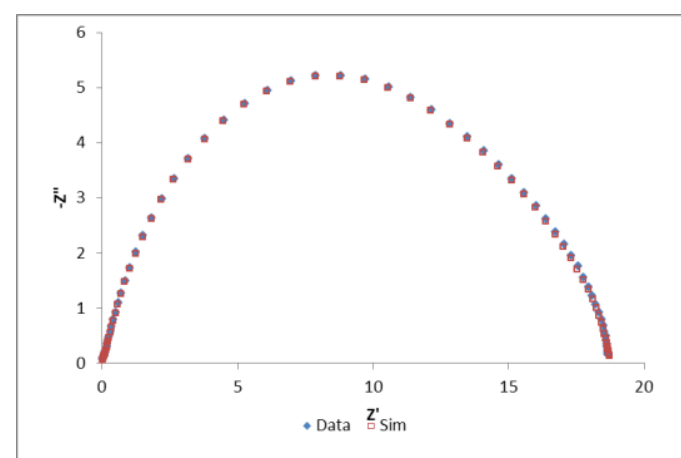

(c)

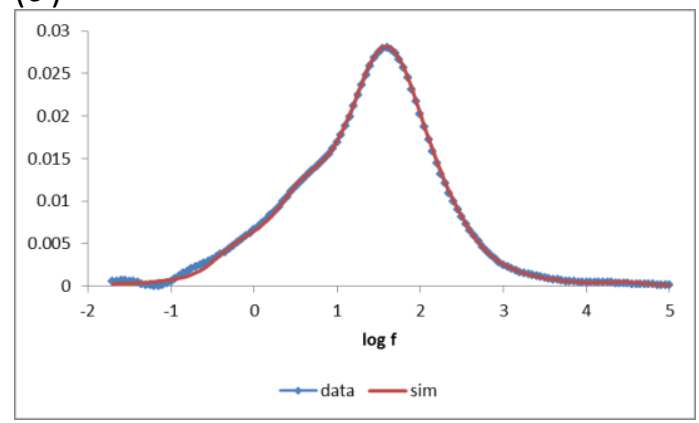

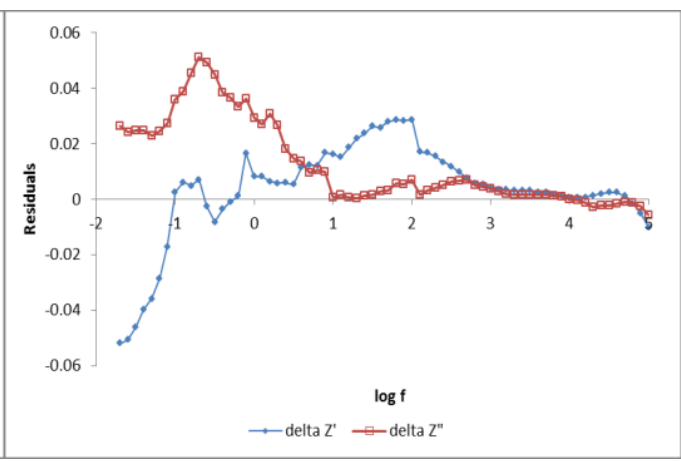

(d)

(e)

Fig. 5.14: Equivalent circuit fit for the 45.7 hour data collected at $800^{\circ} \mathrm{C}\left(1^{\text {st }}\right.$ time) for cell B. (a) In-phase Z' data and the contributions from each element in the equivalent circuit; (b) Out-ofphase $-Z$ " data and the contributions from each element; (c) Nyquist plot overlaying the data and the simulated impedances from the equivalent circuit; (d) Residuals (Z'(sim) - Z'(data)) and (Z'(sim) - Z'(data)); (e) Overlay plot of the deconvolution spectra for the data and for the simulated impedances of the equivalent circuit.

Table 5.1 contains the fitted parameters for Cell A and $\mathrm{B}$ at $800^{\circ} \mathrm{C}\left(1^{\text {st }}\right.$ data set $)$. For cell $\mathrm{B}$, because of the problem of 5RQ model fitting the data at the beginning of $800^{\circ} \mathrm{C}, \mathrm{RQ}$ values were fixed in order to force ZView to generate acceptable values for the other parameters and to obtain a very good match between the deconvolution spectra of the data and the simulation. The element RQ5 was fixed until 7.9 hour, when the low frequency deviation disappeared. Cell A has no such problem. 
Table 5.1: Fitted parameters for the $R(R Q)_{5}$ equivalent circuit to impedance data for the Cell $A$ at 2.2 hour and 45.6 hour \& Cell B at 2.3 hour and 45.7 hour $800^{\circ} \mathrm{C}\left(1^{\text {st }} \mathrm{Cycle}\right)$

\begin{tabular}{|c|c|c|c|c|c|c|}
\hline Element & Parameter & $\begin{array}{r}\text { Values at } \\
2.2 \text { hours } \\
(\text { Cell A) }\end{array}$ & $\begin{array}{l}\text { Values at } 45.6 \\
\text { hours (Cell A) }\end{array}$ & $\begin{array}{l}\text { Values at } 2.3 \\
\text { hours (Cell B) }\end{array}$ & $\begin{array}{l}\text { Values at } 45.7 \\
\text { hours (Cell B) }\end{array}$ & Units \\
\hline series $\mathrm{R}$ & R1 & 1.1 & 1.1 & 1.2 & 1.2 & ohms \\
\hline inductance & $\mathrm{L}$ & $1.0 \mathrm{E}-11$ & $1.0 \mathrm{E}-11$ & $1.0 \mathrm{E}-11$ & $1.0 \mathrm{E}-11$ & $\mathrm{H}$ \\
\hline RQ1 & $\mathrm{R} 2$ & 0.068 & 0.054 & 0.052 & 0.061 & ohms \\
\hline RQ2 & R3 & 0.81 & 0.38 & 1.6 & 1.1 & ohms \\
\hline RQ3 & R4 & 13 & 9.5 & 9.7 & 13 & ohms \\
\hline RQ4 & R5 & 6.1 & 2.1 & 2.5 & 4.2 & ohms \\
\hline RQ5 & R6 & 0.57 & 0.17 & 0.20 & 0.36 & ohms \\
\hline Rp total & & 20 & 12 & 14 & 19 & ohms \\
\hline $\mathrm{R}$ total & & 21 & 13 & 15 & 20 & ohms \\
\hline RQ1 & Q1 & $1.1 \mathrm{E}-04$ & $4.4 \mathrm{E}-05$ & $1.0 \mathrm{E}-04$ & $8.4 \mathrm{E}-05$ & \\
\hline RQ2 & Q2 & $1.2 \mathrm{E}-03$ & 1.7E-03 & $1.5 \mathrm{E}-03$ & 2.7E-03 & \\
\hline RQ3 & Q3 & $1.0 \mathrm{E}-03$ & $1.1 \mathrm{E}-03$ & $1.6 \mathrm{E}-03$ & $1.2 \mathrm{E}-03$ & \\
\hline RQ4 & Q4 & $1.7 \mathrm{E}-02$ & $4.5 \mathrm{E}-02$ & $5.3 \mathrm{E}-02$ & $2.3 \mathrm{E}-02$ & \\
\hline RQ5 & Q5 & 0.68 & 1.8 & 3.0 & 0.77 & \\
\hline RQ1 & $\mathrm{n} 1$ & 0.96 & 1.0 & 1 & 1 & \\
\hline RQ2 & $\mathrm{n} 2$ & 1 & 1 & 0.87 & 0.83 & \\
\hline RQ3 & n3 & 0.76 & 0.76 & 0.73 & 0.75 & \\
\hline RQ4 & $\mathrm{n} 4$ & 0.71 & 0.71 & 0.70 & 0.74 & \\
\hline RQ5 & n5 & 0.96 & 1 & 1 & 1 & \\
\hline RQ1 & f1 & 35000 & 35000 & 30000 & 31000 & $\mathrm{~Hz}$ \\
\hline RQ2 & $f 2$ & 165 & 245 & 162 & 175 & $\mathrm{~Hz}$ \\
\hline RQ3 & f3 & 49 & 64 & 46 & 39 & $\mathrm{~Hz}$ \\
\hline RQ4 & $f 4$ & 3.7 & 4.3 & 2.8 & 3.7 & $\mathrm{~Hz}$ \\
\hline RQ5 & f5 & 0.43 & 0.53 & 0.26 & 0.57 & $\mathrm{~Hz}$ \\
\hline
\end{tabular}

After applying deconvolution of impedance spectra combined with complex non-linear regression fitting of the impedance spectra for all the data at $800^{\circ} \mathrm{C}$ for Cells $\mathrm{A}$ and $\mathrm{B}$, the trends in parameters for the equivalent circuit as a function of time can be provided.

Figure 5.15 shows the first data set at $800^{\circ} \mathrm{C}$ of Cell A. R1 was constant at 1.12 ohms. R4 and R5 dominate the polarization resistance. $\mathrm{R} 4(\sim 40-60 \mathrm{~Hz})$ caused the rise and then decay of the 
Rp. R5 ( 4 Hz) simply decays with time. R3 and R6 contribute a small amount to the decay and become smaller fractions of the polarization resistance. Not surprisingly, there is an inverse correlation of frequency with the magnitude of each $\mathrm{R}$ value. Exponents for all 5 elements stay roughly constant. Comparing the results of cell A with cell B, R4 is dominant, but R3 and R5 contribute significantly to Rp. All three resistances contribute to the sharp rise in Rp over the first 8 hours. R3 and R5 account for most of the decay from 15 to $43 \mathrm{~h}$. This behavior is noticeably different from the pattern in Cell A.

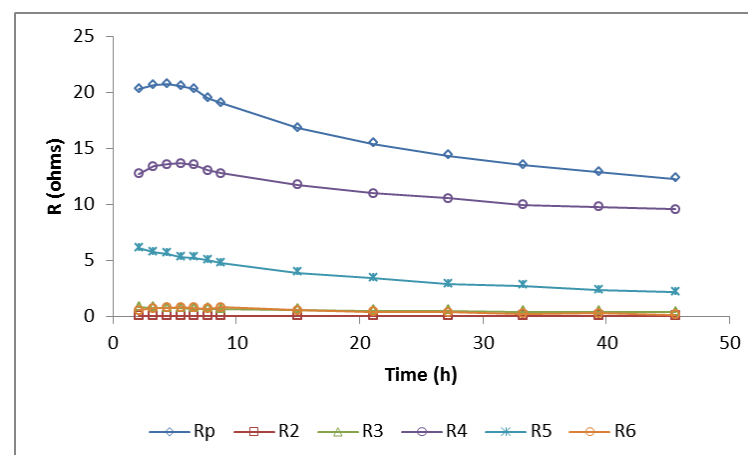

(a)

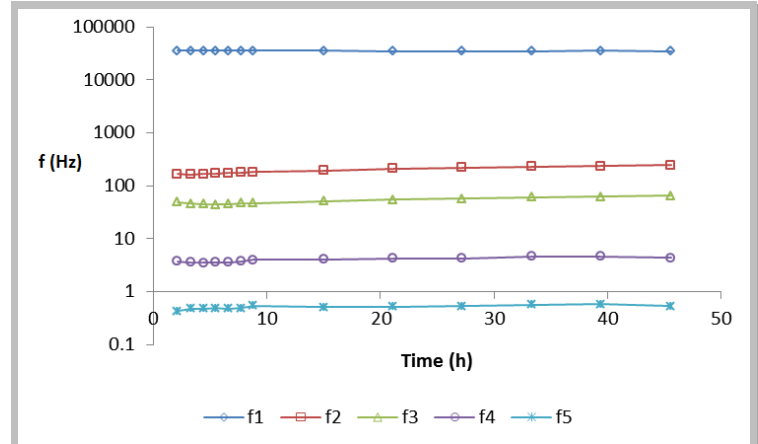

(c)

Fig. 5.15: The parameters for the equivalent circuit as a function of time for the first data set of cell A and B at $800^{\circ} \mathrm{C}$. (a) Cell A polarization resistances; (b) Cell B polarization resistances; (c) Cell A frequencies for five elements; (d) Cell B frequencies for five elements.

The second set of data of cell A and the second set of data of cell B at $800^{\circ} \mathrm{C}$ are shown in Fig 5.16. For cell A, two principle resistances R4 and R5 decay with time for both data sets and frequencies of the elements stay roughly constant. For cell B, R3 exhibits anomalous behavior, dropping suddenly from $1.5 \mathrm{ohms}$ to $0.5 \mathrm{ohms}$ (15 to 27 hours). R4 and R5 are affected by this drop, and also exhibit anomalous behavior. All three resistances contribute to the decrease in Rp. The frequencies of cell B elements also stay roughly constant. The third set of data of cell A are shown in Fig 5.17, which shows the similar trend as the second data set for cell A. 

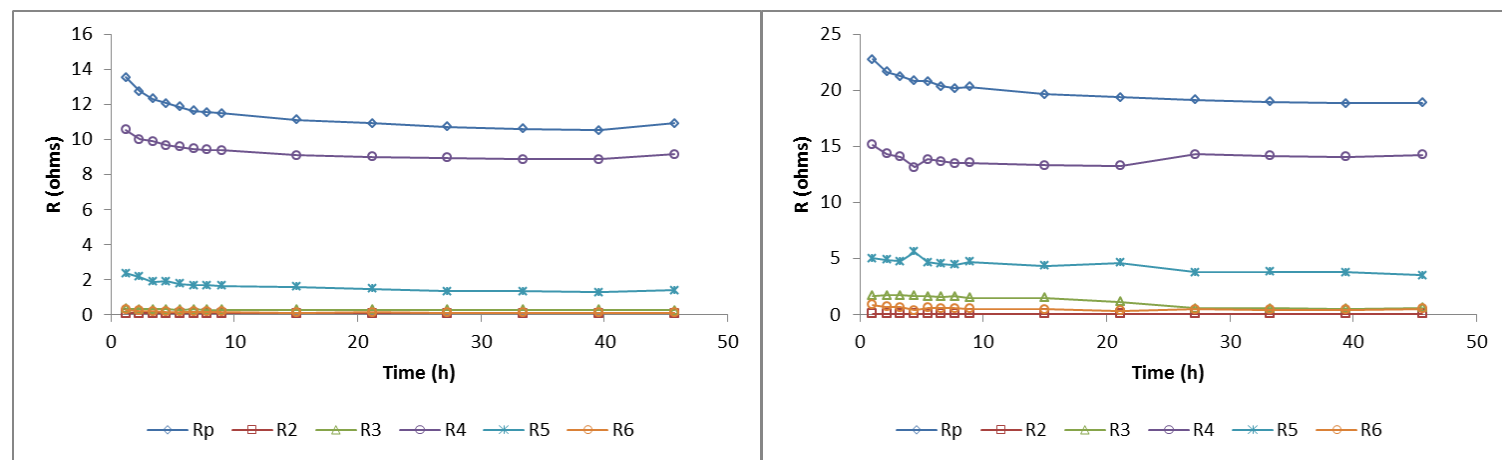

(a)

(b)
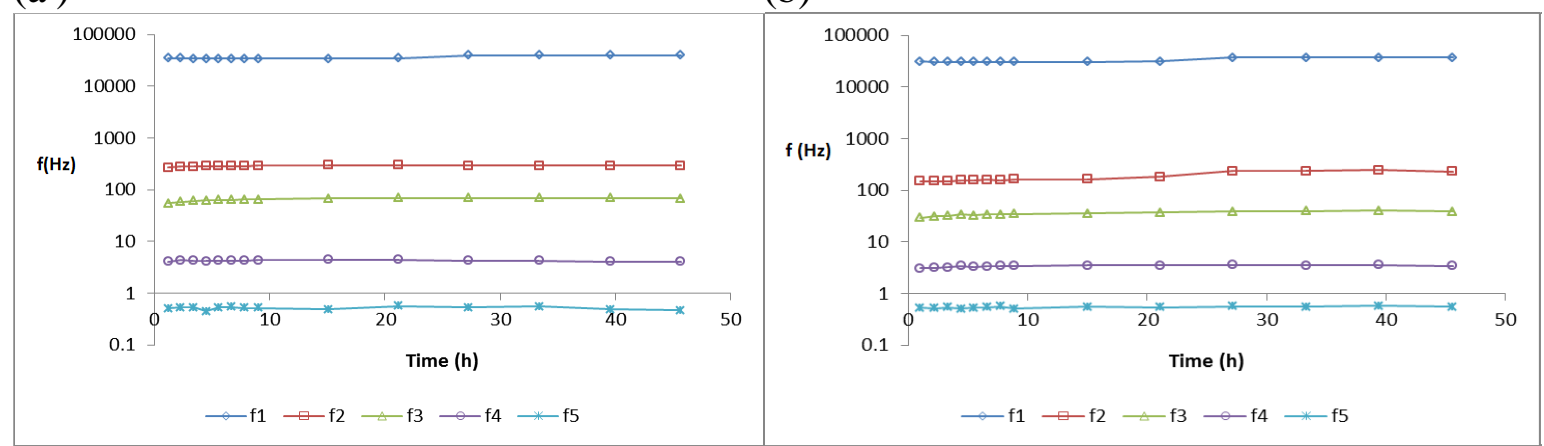

(c)

(d)

Fig. 5.16: The parameters for the equivalent circuit as a function of time for the second data set of cell $\mathrm{A}$ and $\mathrm{B}$ at $800{ }^{\circ} \mathrm{C}$. (a) Cell A polarization resistances; (b) Cell B polarization resistances; (c) Cell A frequencies for five element; (d) Cell B frequencies for five elements.

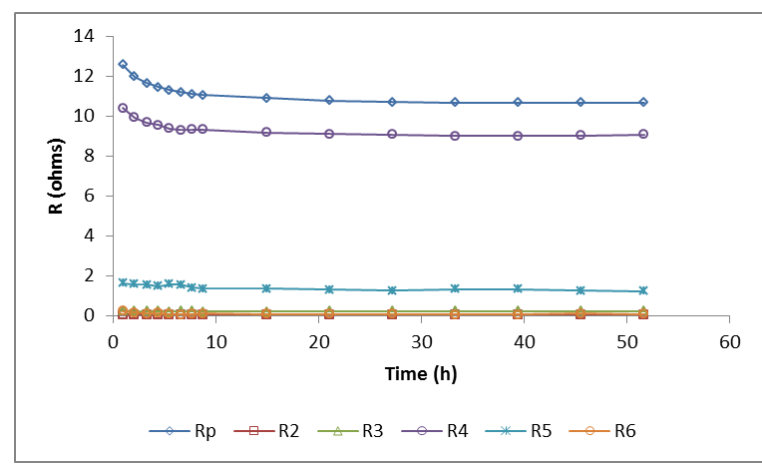

(a)

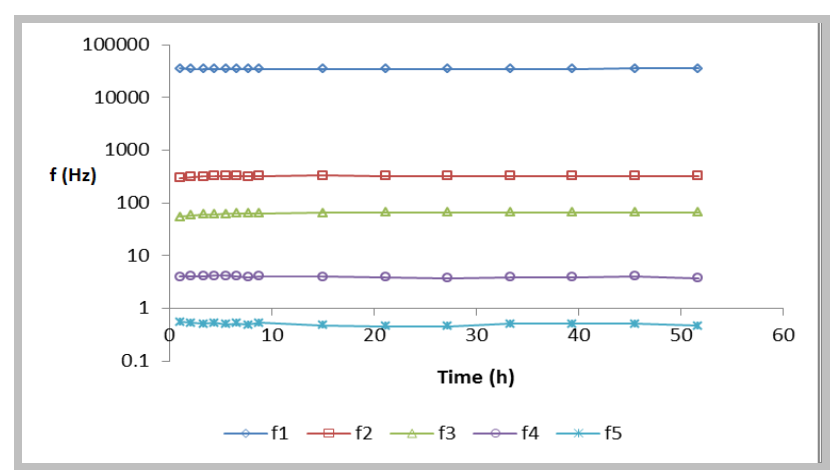

(b)

Fig. 5.17: The parameters for the equivalent circuit as a function of time for the third data set of cell A at $800{ }^{\circ} \mathrm{C}$. (a) Cell A polarization resistances; (b) Cell A frequencies for five element.

Fig 5.18 shows the overlay of corresponding polarization resistance of all the data sets for cell A and $\mathrm{B}$ at $800^{\circ} \mathrm{C}$ vs. time. All the polarization resistance values are normalized for the area and for one electrode. For cell A, the total trend in polarization resistances is due to low frequency elements R4 and R5. Both R4 and R5 show decreases relative to the previous value after aging 
at $700^{\circ} \mathrm{C}$, but the majority of the change is found in $\mathrm{R} 4$. All other elements values (R2, R3, \& R6) contribute less than $0.3 \mathrm{ohm}$ to the polarization resistance. For cell B, all three R3, R4 and R5 elements jointly account for the change of polarization resistance.

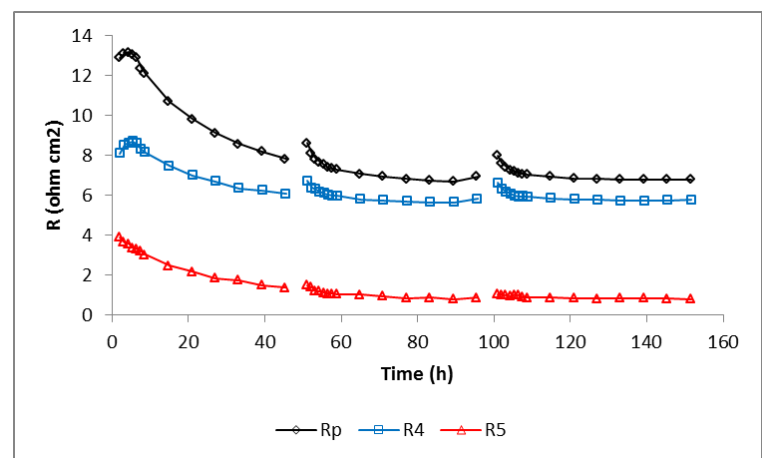

(a)

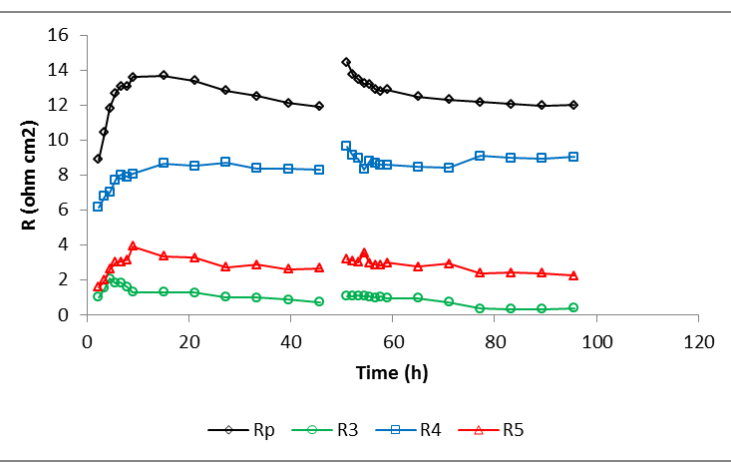

(b)

Fig 5.18: The corresponding polarization resistance of cell $\mathrm{A}$ and $\mathrm{B}$ with time at $800^{\circ} \mathrm{C}$ over two or three temperature cycles. (a) Cell A (b) Cell B. The breaks correspond to 2 days soak at $700^{\circ} \mathrm{C}$.

\section{Cell A and Cell B cycle at $700^{\circ} \mathrm{C}$}

Figure 5.19 illustrates the quality of the fit to the (R(RQ)5) equivalent circuit for the first 1.0 hour data collected at $700^{\circ} \mathrm{C}\left(1^{\text {st }}\right.$ time $)$ for cell $\mathrm{A}$. The five peaks in the deconvolution spectrum correspond to the five elements. Four elements $\left(R Q_{1-} R_{4}\right)$ contribute significantly to the impedance. Not only do the Nyquist plots of the data and the simulated impedances from the equivalent circuit overlay very well, but also the plots of deconvolution spectra for the data and for the simulated impedances of the equivalent circuit show excellent fits. The 5RQ model also fits very well for all the data of cell A for $1^{\text {st }}$ time and $2^{\text {nd }}$ time at $700^{\circ} \mathrm{C}$. For cell $\mathrm{B}$, the (R(RQ)5) equivalent circuit fits to all the data sets at $700^{\circ} \mathrm{C}$ are excellent, and the deconvolution spectra clearly show the need for 5 RQ elements (Fig 5.20) 

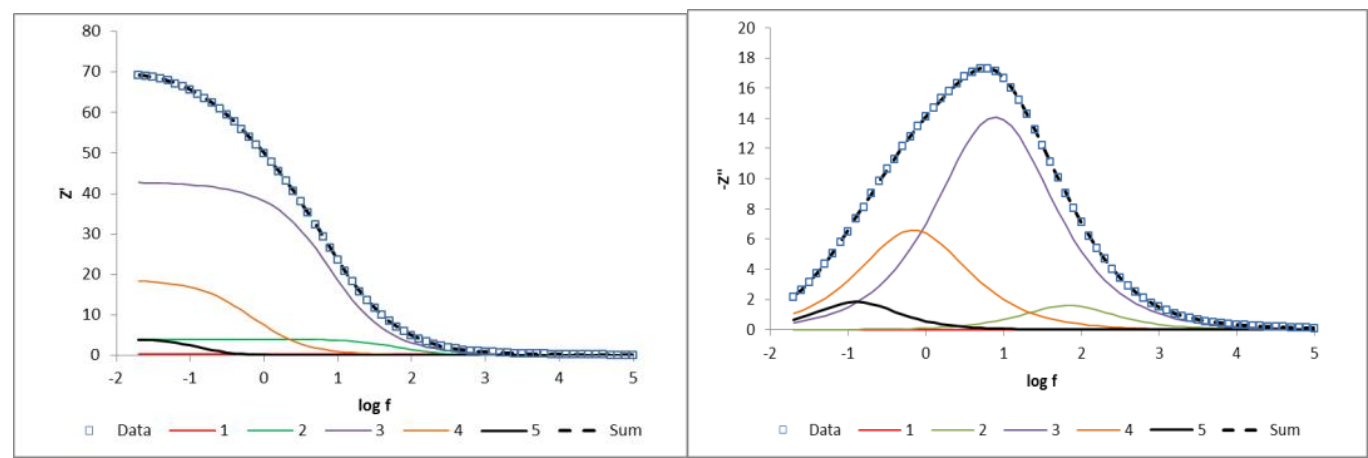

(a)

(b)

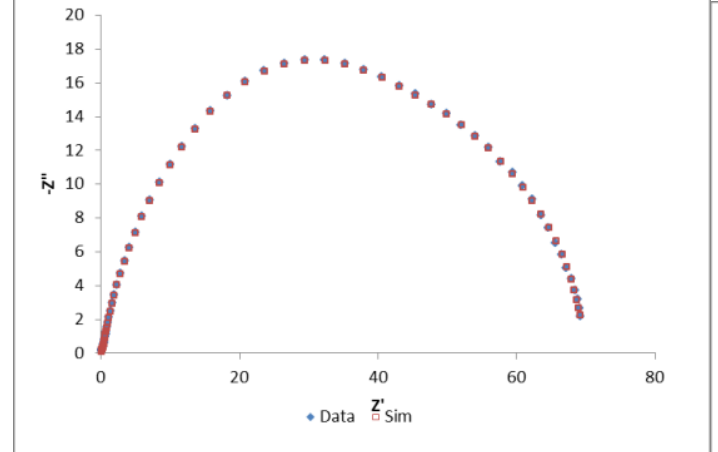

(c)

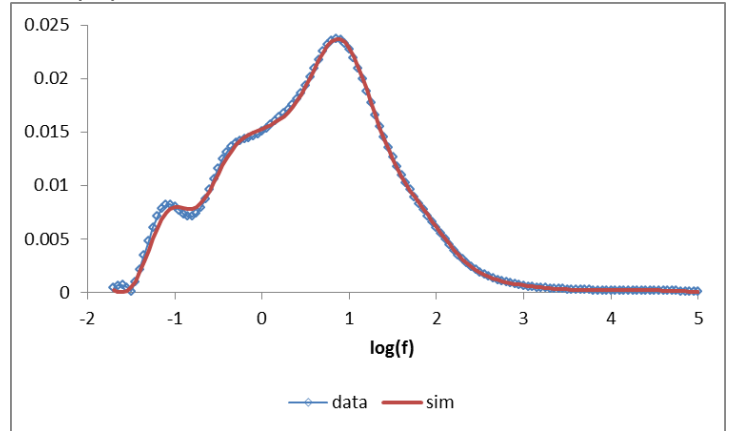

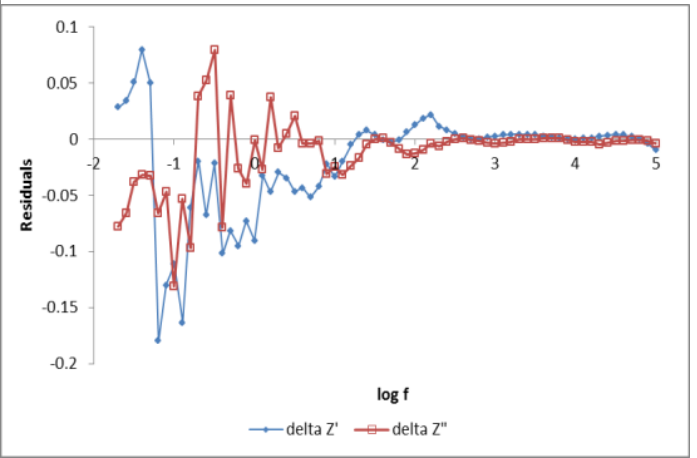

(d)

(e)

Fig. 5.19: Equivalent circuit fit for the 1.0 hour data collected at $800^{\circ} \mathrm{C}\left(1^{\text {st }}\right.$ time $)$ for cell A. (a) In-phase Z' data and the contributions from each element in the equivalent circuit; (b) Out-ofphase $-Z$ " data and the contributions from each element; (c) Nyquist plot overlaying the data and the simulated impedances from the equivalent circuit; (d) Residuals.(e) Overlay plot of the deconvolution spectra for the data and for the simulated impedances of the equivalent circuit. 


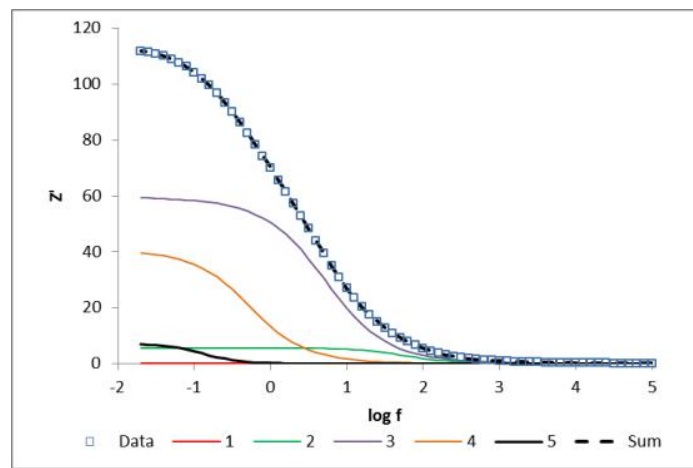

(a)

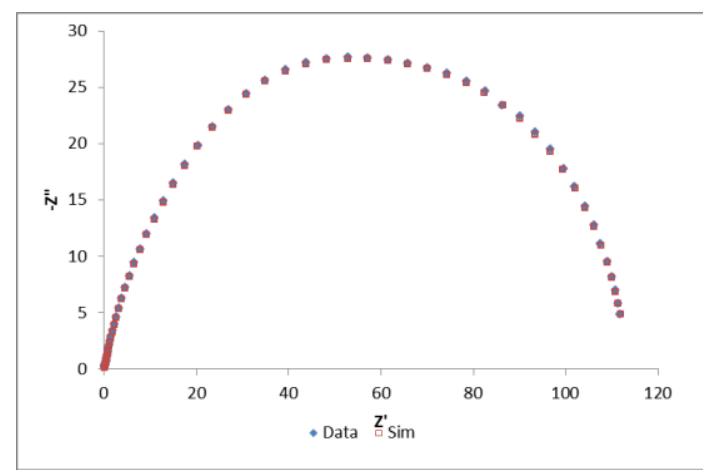

(c)

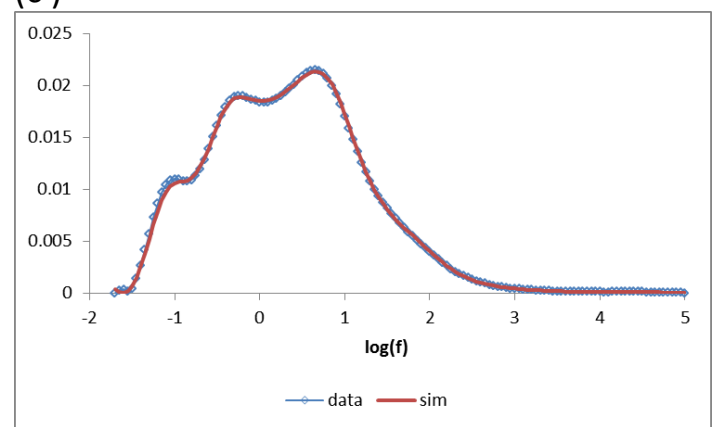

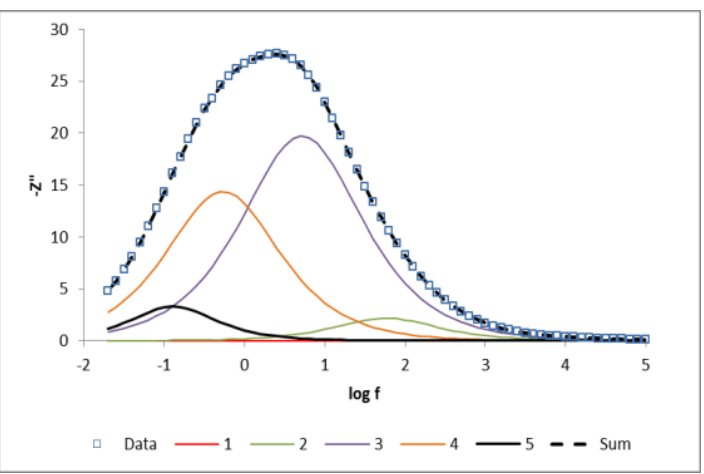

(b)

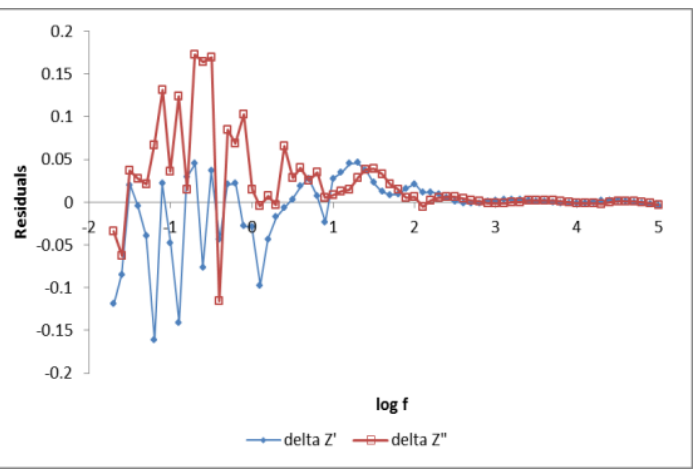

(d)

(e)

Fig. 5.20: Equivalent circuit fit for the 1.1 hour data collected at $800^{\circ} \mathrm{C}\left(1^{\text {st }}\right.$ time $)$ for cell B. (a) In-phase Z' data and the contributions from each element in the equivalent circuit; (b) Out-ofphase -Z" data and the contributions from each element; (c) Nyquist plot overlaying the data and the simulated impedances from the equivalent circuit; (d) Residuals.(e) Overlay plot of the deconvolution spectra for the data and for the simulated impedances of the equivalent circuit.

The trends in parameters for the equivalent circuit as a function of time are shown in Figures 5.21-5.23. Data for the first cycle at $700^{\circ} \mathrm{C}$ are shown in Fig. 5.21. For the first data set of cell A, series resistance R1 increased from $1.13 \mathrm{ohms}$ (at $800^{\circ} \mathrm{C}$ ) to $1.87 \mathrm{ohms}\left(700^{\circ} \mathrm{C}\right.$ ), consistent with a temperature-independent resistance of $0.77 \mathrm{ohms}$ and a temperature-dependent resistance (assumed activation energy $1.0 \mathrm{eV}$ ) of 0.36 and $1.10 \mathrm{ohms}$. Fig 5.21 shows that resistance values 
for R4 continuously increased from 43 to 54 ohms and R5 increased from 19 to $32 \mathrm{ohms}$ over 52 hours. Some noise is present in the fitted values for R5 and R6, but their sum is less noisy and shows a steady increase with time (23 to 39 ohms). R3 has minimal change from 4.0 to 4.6 ohms over 52 hours. Frequencies are nearly constant on a log scale. Four elements (RQ2 thru RQ5) contribute significantly to the polarization resistance. For Cell B ( $1^{\text {st }}$ data set), resistance values for R4 and R5 also show continuous increase over 52 hours, and they contribute to the main increase for total polarization resistance. Some noise is visible in the fitted values for R5 and R6, and apparently ZView cannot readily separate R5 and R6, since their values move in opposite directions.
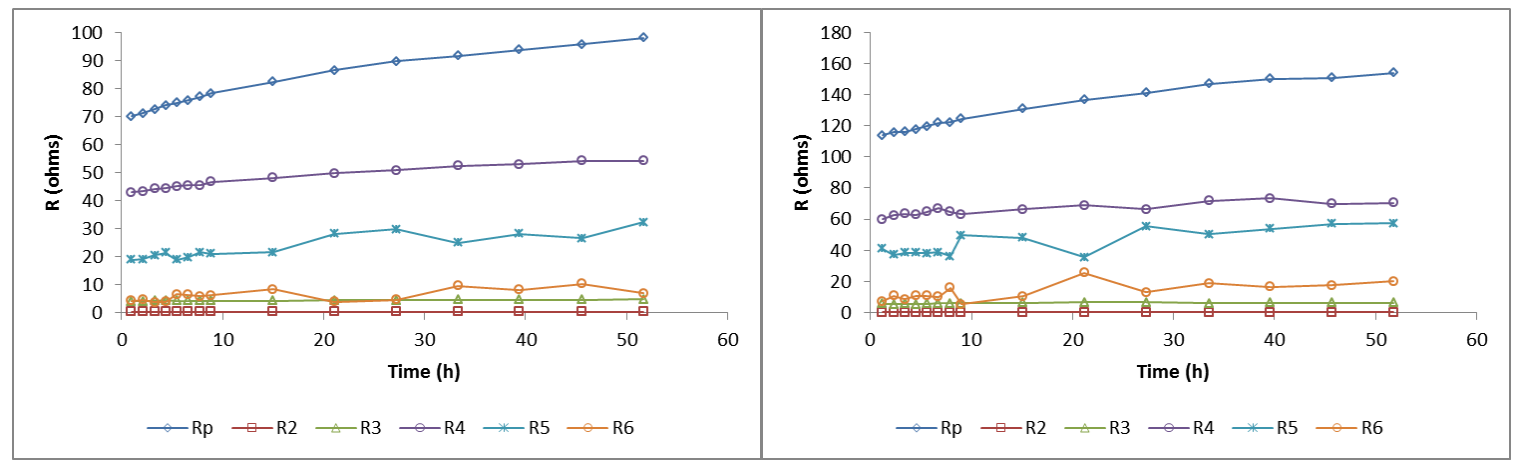

(a)

(b)
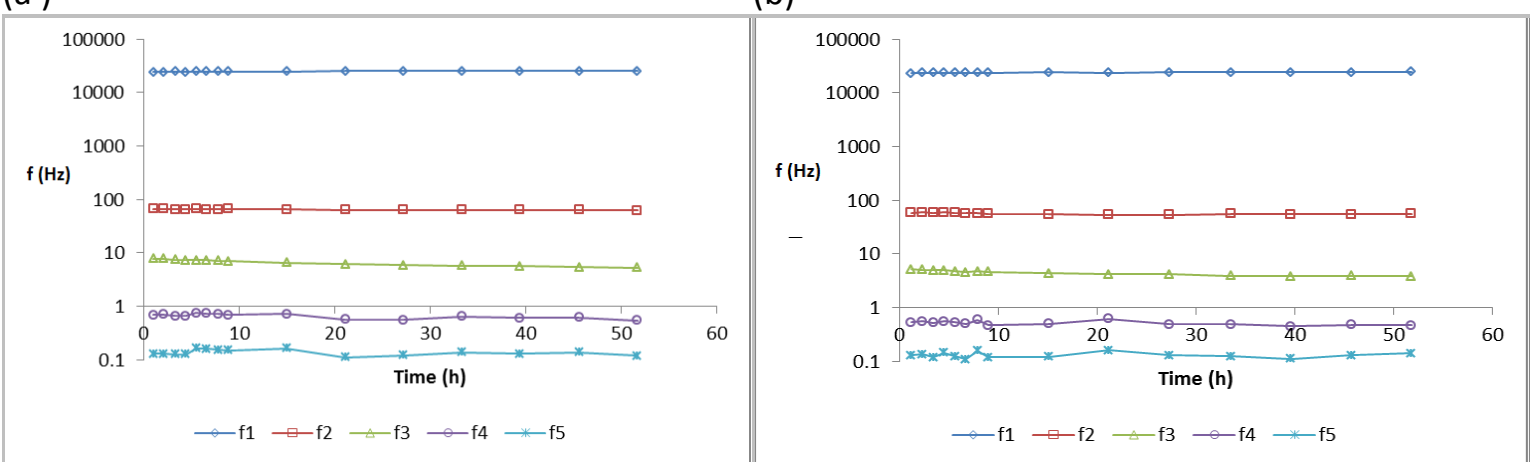

(c)

(d)

Fig. 5.21: The parameters for the equivalent circuit as a function of time for the first data set of cell A and B at $700{ }^{\circ} \mathrm{C}$. (a) Cell A polarization resistances (b) Cell B polarization resistances (c ) Cell A frequency for five elements (d) Cell B frequency for five elements.

Fig 5.22 shows the fitting parameters of cell $\mathrm{A}$ and $\mathrm{B}$ for $2^{\text {nd }}$ data set at $700^{\circ} \mathrm{C}$. For Cell A, most of the rise in polarization resistance is found in R4 and R5, while R3 and R6 are minor contributors. Variations in R4 and R5 exhibit anti-correlation with each other. All the frequencies of five elements stay approximately constant. The polarization resistances and frequencies of Cell B show the same trend as cell A. 


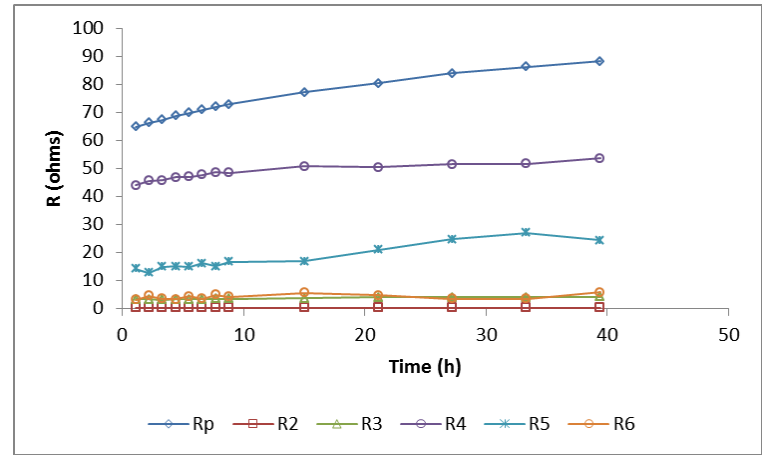

(a)

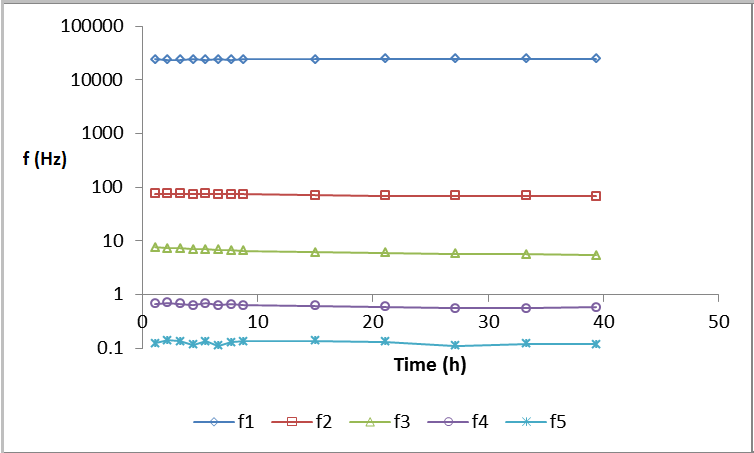

(c)

Fig. 5.22: The parameters for the equivalent circuit as a function of time for the second data set of cell A and B at $700{ }^{\circ} \mathrm{C}$; (a) Cell A polarization resistances; (b) Cell B polarization resistances; (c ) Cell A frequency for five elements; (d) Cell B frequency for five elements.

Fig 5.23 displays the overlay of Rp, R4 and R5 for the two data sets at $700^{\circ} \mathrm{C}$ for cell A. For Cell $\mathrm{B}, \mathrm{Rp}$ is overlaid with R4, R5 and R6, the three largest component resistances. For cell A, R6 was a minor component, but for cell $\mathrm{B}$ at $700^{\circ} \mathrm{C}$, it is one of the major contributors to Rp. And, for cell B, R5 and R6 are coupled in ZView; a higher value in R6 results in a lower value of R5. All three resistances appear to contribute to the rise in Rp in cell B.

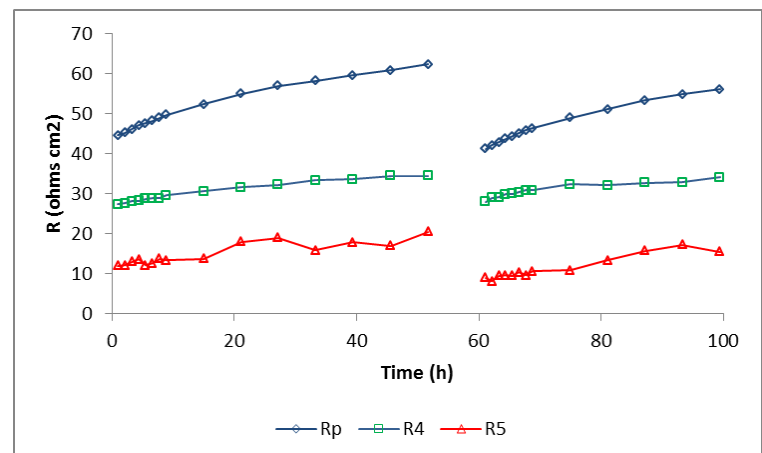

(a)

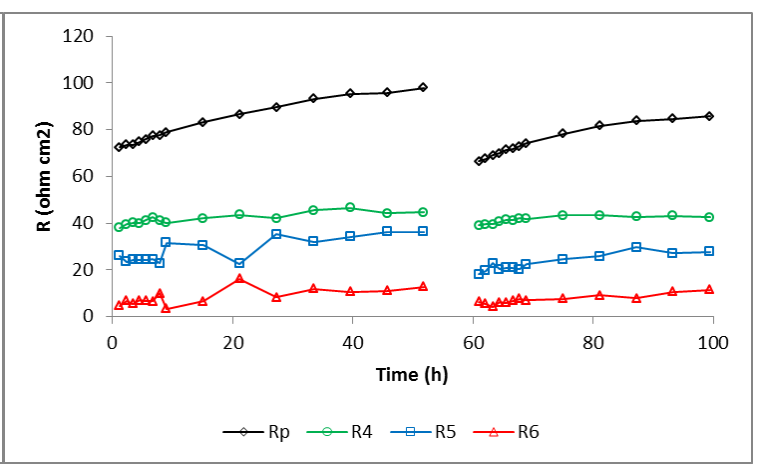

(b)

Fig 5.23: The corresponding polarization resistance of cell A and B vs. time at $700{ }^{\circ} \mathrm{C}$. (a) Cell A; (b) Cell B. 
Table 5.2: Comparison end of $800^{\circ} \mathrm{C}$ collection vs beginning of $700^{\circ} \mathrm{C}$ collection for cell A:

\begin{tabular}{|l|l|l|l|l|l|}
\hline Parameters & $\mathrm{f}(800)$ & $\mathrm{f}(700)$ & $\mathrm{R}(800)$ & $\mathrm{R}(700)$ & $\mathrm{Ea}(\mathrm{eV})$ \\
\hline R2 & $35 \mathrm{k}$ & $25 \mathrm{k}$ & 0.06 & 0.23 & 1.2 \\
\hline R3 & 245 & 62 & 0.38 & 4.6 & 2.2 \\
\hline R4 & 64 & 5.3 & 9.5 & 54 & 1.6 \\
\hline R5 & 4.3 & 0.55 & 2.1 & 32 & 2.5 \\
\hline R6 & 0.53 & 0.12 & 0.17 & 7 & 3.3 \\
\hline Rp & & & 12 & 98 & 1.9 \\
\hline
\end{tabular}

Table 5.3: Comparison end of $800^{\circ} \mathrm{C}$ collection vs beginning of $700^{\circ} \mathrm{C}$ collection for cell B:

\begin{tabular}{|l|l|l|l|l|l|}
\hline Parameters & $\mathrm{f}(800)$ & $\mathrm{f}(700)$ & $\mathrm{R}(800)$ & $\mathrm{R}(700)$ & $\mathrm{Ea}(\mathrm{eV})$ \\
\hline R2 & $31 \mathrm{k}$ & $23 \mathrm{k}$ & 0.062 & 0.27 & 1.3 \\
\hline R3 & 176 & 58 & 0.58 & 5.6 & 2.0 \\
\hline R4 & 40 & 5.2 & 14 & 60 & 1.3 \\
\hline R5 & 3.7 & 0.55 & 3.6 & 40 & 2.2 \\
\hline R6 & 0.57 & 0.13 & 0.45 & 8 & 2.6 \\
\hline Rp & & & 19 & 114 & 1.6 \\
\hline
\end{tabular}

Table 5.2 and 5.3 compare the end of $800^{\circ} \mathrm{C}$ collection with beginning of $700^{\circ} \mathrm{C}$ collection with respect to frequency for cell $\mathrm{A}$ and cell $\mathrm{B}$. For both cell A and cell B, all 5 processes increase their respective resistances and lower their respective frequencies from $800^{\circ} \mathrm{C}$ to $700^{\circ} \mathrm{C}$. All exponents decrease somewhat. The change of resistances at different temperatures leads to a wide range of apparent activation energies as shown in the Tables. The activation energy for Rp is near $2 \mathrm{eV}$ for both cells, which is typical of a pure LSM electrode. The frequencies of cell B are about the same or slightly lower than for Cell A. The resistances and the activation energies of cell B are about the same or slightly higher than Cell A. However, generally the temperature dependent parameters appear to be consistent for the two cells.

\section{Summary of the preceding observation for LSM/YSZ/LSM symmetrical cells:}

Both $800^{\circ} \mathrm{C}$ and $700^{\circ} \mathrm{C}$ EIS data were a good fit to a 5RQ model. Five RQ elements were required to fit the $700^{\circ} \mathrm{C}$ data, and were helpful in obtaining a better fit to the $800^{\circ} \mathrm{C}$ data. Cell $\mathrm{A}$ and B showed similar trends. Frequencies for Cell A and B are nearly constant at a given temperature. From $800^{\circ} \mathrm{C}$ to $700^{\circ} \mathrm{C}$, all elements appeared to decrease in frequency going and increase in the corresponding resistances. Apparent activation energies could be calculated and their values ranged from 1.3 to $3.3 \mathrm{eV}$, and apparent activation energies for cell $\mathrm{A}$ and $\mathrm{B}$ are similar, with the overall activation energy being 1.6 (cell B) to $1.9 \mathrm{eV}$ (cell A). 
However, changes in the resistance values for the lower frequency elements are difficult to separate using ZView. In general, by the deconvolution method, no single element was found to account for all of the changes in the polarization resistance with respect to time and temperature. For both cells A and B, the two largest elements (R4 \& R5) consistently changed with respect to aging or temperature. Polarization resistances for these two low frequency elements contribute to most of the total change in $\mathrm{Rp}$.

\section{Deconvolution analysis of composite (LSM/YSZ)/YSZ/(LSM/YSZ) cells}

As compared with the pure LSM/YSZ/LSM cell, the composite (LSM/YSZ)/YSZ/(LSM/YSZ) symmetrical cells (The testing for such cells is descript in 5.3.1) are also analyzed with deconvolution. Fig. 5.24 shows the Nyquist plots and deconvolution spectra for the composite cell at $800^{\circ} \mathrm{C}$. A long tail extends to the high frequency limit in deconvolution spectra. As discussed 4.4.2, an equivalent circuit including Gerischer impedance could fit deconvolution spectra with this feature. We used LR(Ge)RQ model to fit the data at $800^{\circ} \mathrm{C}$ and $\mathrm{LR}(\mathrm{Ge})(\mathrm{RQ}) 2$ model to fit the data at $700^{\circ} \mathrm{C}$, and these models appear to provide excellent fits in both impedance and deconvolution spectra (Fig 5.24).

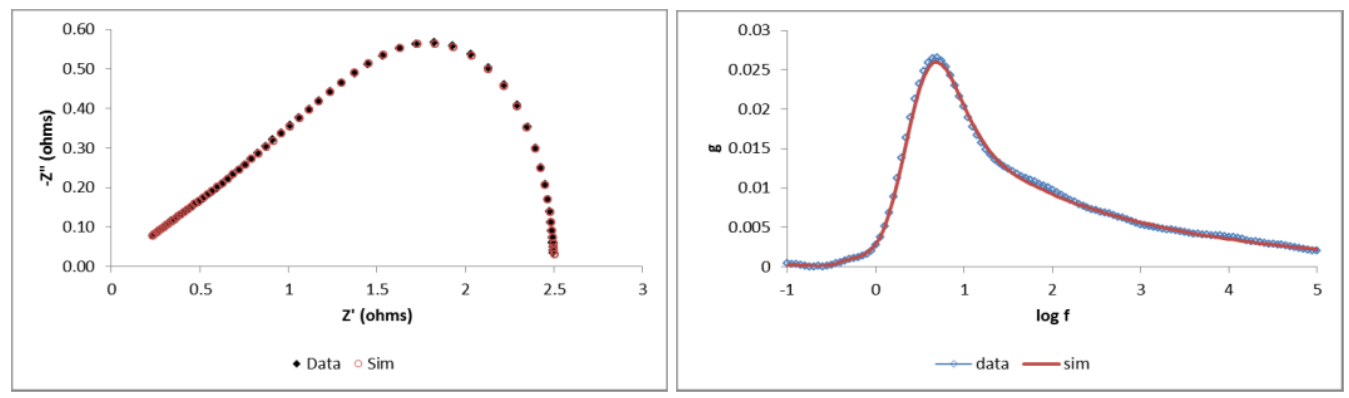

(a)

(b)

Fig 5.24: Equivalent circuit fit for the 2.0 hour data collected at $800^{\circ} \mathrm{C}$. (a) Nyquist plot overlaying the data and the simulated impedances from the equivalent circuit; (b) Overlay plot of the deconvolution spectra for the data and for the simulated impedances of the equivalent circuit

Fig 5.25 shows the contributions from each element for the out-of-phase impedance Z". At $800^{\circ} \mathrm{C}$, the Gerischer impedance contributes mostly. At $700^{\circ} \mathrm{C}$, the Gerischer impedance and one RQ element both contributes largely. 


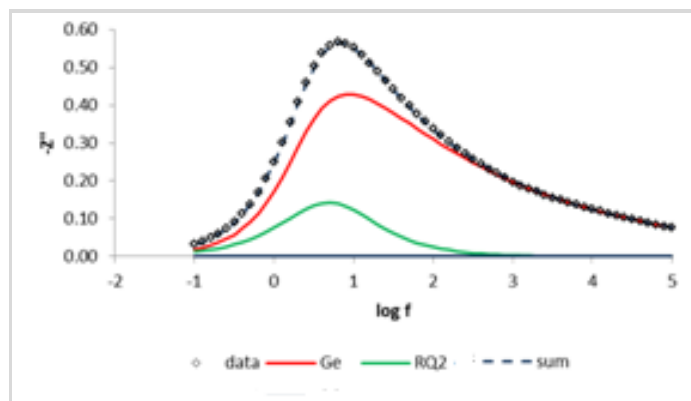

(a)

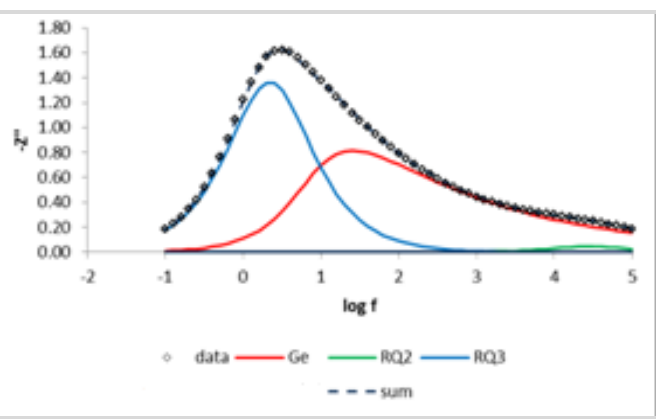

(b)

Fig. 5.25: Equivalent circuit fit for Out-of-phase $-Z$ " data and the contributions from each element (a) At $800^{\circ} \mathrm{C}$ (b) At $700^{\circ} \mathrm{C}$

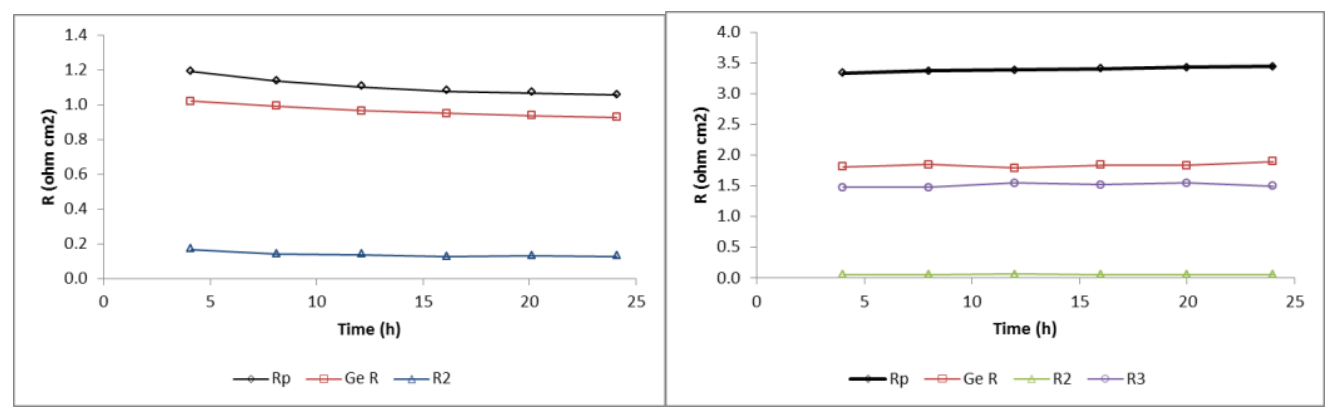

(a)

(b)

Fig. 5.26: The polarization resistances for the equivalent circuit as a function of time (a) At $800^{\circ} \mathrm{C}$ (b) At $700^{\circ} \mathrm{C}$

Fig 5.26 summarizes trends of polarization resistance at $800^{\circ} \mathrm{C}$ and $700^{\circ} \mathrm{C}$. Similar to LSM electrode, the polarization resistances of LSM/YSZ composite electrode decrease at $800^{\circ} \mathrm{C}$ and increase at $700^{\circ} \mathrm{C}$. At both $800^{\circ} \mathrm{C}$ and $700^{\circ} \mathrm{C}$, Gerischer impedance accounts for mostly in total polarization resistance change.

\subsubsection{Deconvolution analysis of LSM/GDC/LSM symmetrical cells}

Fig 5.27 shows the Nyquist plot and Bode plot at $2 \mathrm{~h}$ (first cycle) for cell $\mathrm{A}$ and $\mathrm{B}$ at $800^{\circ} \mathrm{C}$. The long tail in the Bode plot suggests that a Gerischer element should be in the equivalent circuit. However, there were abrupt changes in some of the polarization resistances using this equivalent circuit for cell A. A Gerischer element also does not fit cell B data at $800^{\circ} \mathrm{C}$. Since this symmetrical cell is composed by pure LSM on a GDC electrolyte, as we discussed 4.4.2, there is no reason to use a Gerischer impedance. We choose to use LR(RQ)5 model to fit the data at 
$800^{\circ} \mathrm{C}$ and $\mathrm{LR}(\mathrm{RQ}) 4$ model to fit the data at $700^{\circ} \mathrm{C}$, and these models appear to provide excellent fits in impedance and deconvolution spectra for both cell A and B.
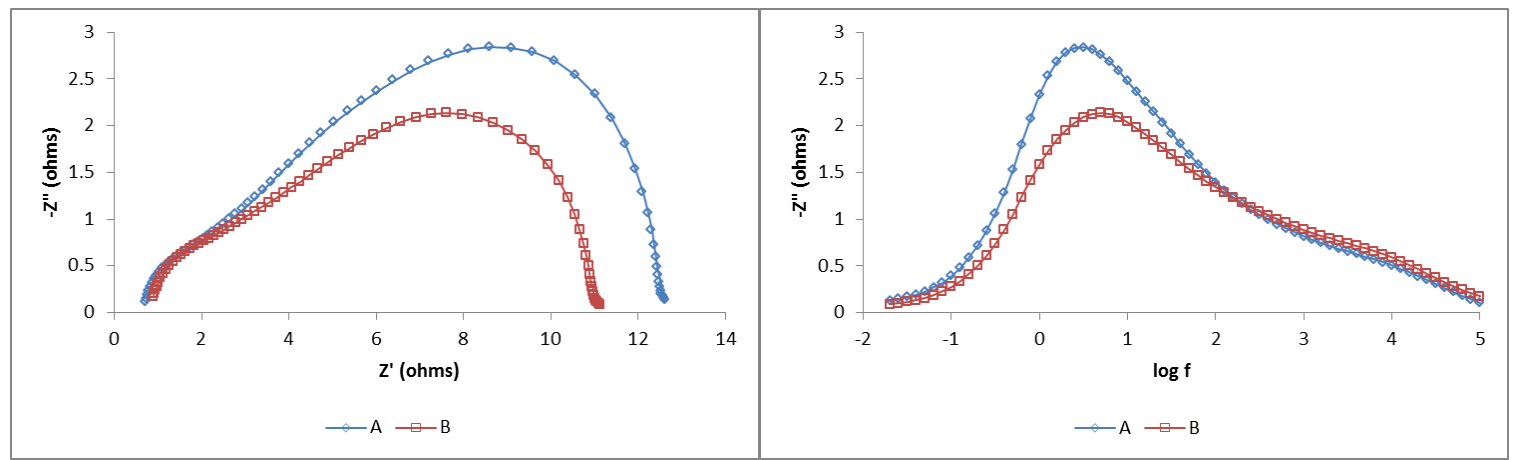

(a)

(b)

Fig. 5.27: (A) Nyquist plot and (B) Bode plot $-\mathrm{Z}$ ” vs $\log \mathrm{f}$ at first $2 \mathrm{~h}$ for cell $\mathrm{A}$ and $\mathrm{B}$ at $800{ }^{\circ} \mathrm{C}$.

\section{Cell A and Cell B at $800{ }^{\circ} \mathrm{C}$}

Fig. 5.28 shows the quality of fitting for the $\mathrm{LR}(\mathrm{RQ}) 5$ to cell A impedance at $2 \mathrm{~h}, 800^{\circ} \mathrm{C}$, first cycle. The deconvolution spectrum shows one peak and several shoulders at higher frequencies. Cell B shows a similar deconvolution spectrum.

Table 5.4 contains the fitted parameters for Cell $\mathrm{A}$ and $\mathrm{B}$ at first $2 \mathrm{~h}$ at $800^{\circ} \mathrm{C}\left(1^{\text {st }}\right.$ cycle $)$. Except for the lower inductance for cell B than for cell A, the other parameters for cell A and B are very close. 


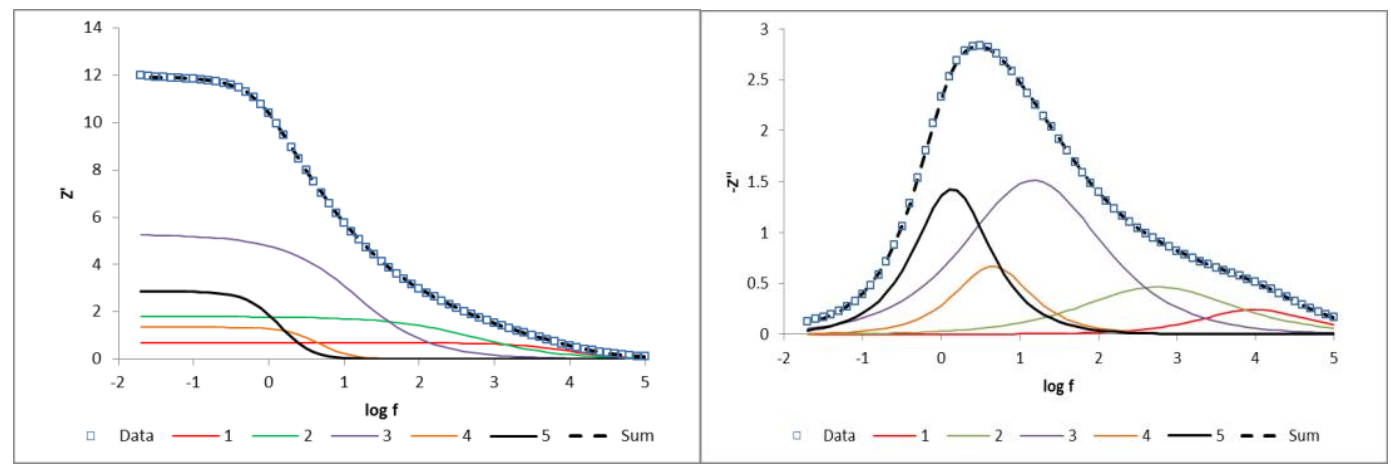

(a)

(b)

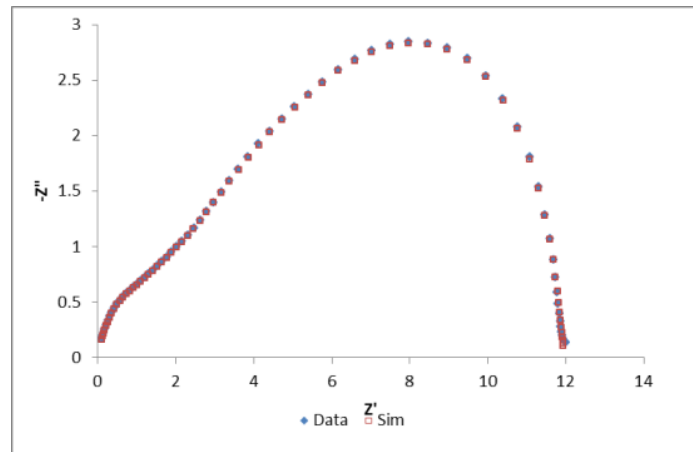

(c)

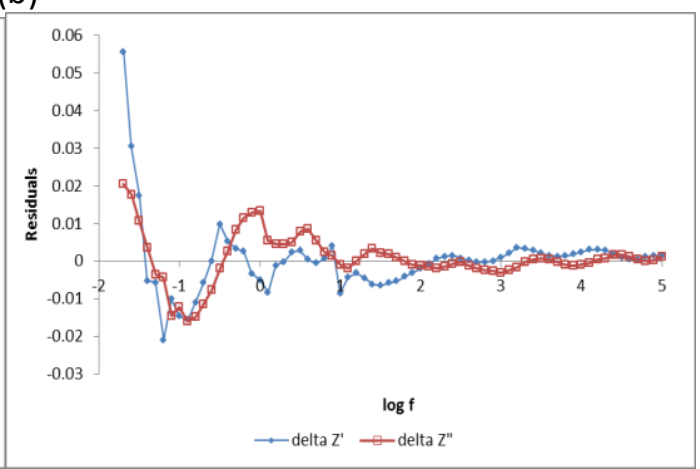

(d)

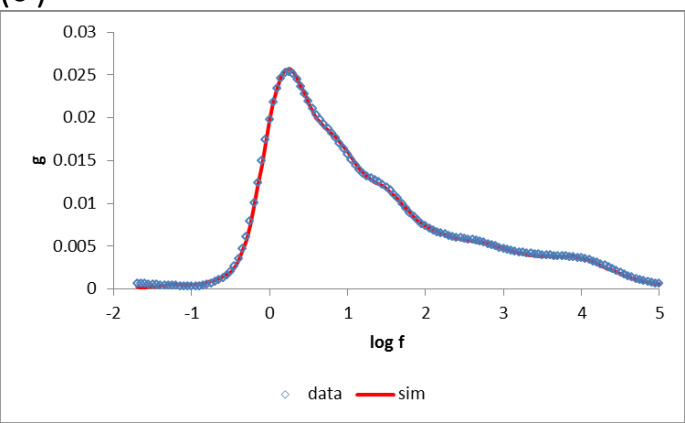

(e)

Fig. 5.28: Equivalent circuit fit for the 2.0 hour data collected at $800^{\circ} \mathrm{C}\left(1^{\text {st }}\right.$ time $)$ for cell A. (a) In-phase Z' data and the contributions from each element in the equivalent circuit; (b) Out-ofphase-Z" data and the contributions from each element; (c) Nyquist plot overlaying the data and the simulated impedances from the equivalent circuit; (d) Residuals. (e) Overlay plot of the deconvolution spectra for the data and for the simulated impedances of the equivalent circuit 
Table 5.4: Fitted parameters for the $R(R Q)_{5}$ equivalent circuit to impedance data for the Cell $A$ at 2.0 hour and Cell B at 2.1 hour at $800^{\circ} \mathrm{C}\left(1^{\text {st }} \mathrm{Cycle}\right)$

\begin{tabular}{|l|l|r|r|l|}
\hline Elements & Parameter & $\begin{array}{r}\text { Cell A } \\
\text { values }\end{array}$ & $\begin{array}{r}\text { Cell B } \\
\text { values }\end{array}$ & Units \\
\hline series R & R1 & 0.63 & 0.78 & ohms \\
\hline inductance & L & $1.0 \mathrm{E}-07$ & $2.7 \mathrm{E}-08$ & $\mathrm{H}$ \\
\hline RQ1 & $\mathrm{R} 2$ & 0.69 & 0.86 & ohms \\
\hline RQ2 & R3 & 1.8 & 1.8 & ohms \\
\hline RQ3 & R4 & 5.3 & 4.3 & ohms \\
\hline RQ4 & R5 & 1.3 & 1.8 & ohms \\
\hline RQ5 & R6 & 2.9 & 1.5 & ohms \\
\hline Rp total & & 12 & 10 & ohms \\
\hline R total & & 13 & 11 & ohms \\
\hline RQ1 & n1 & 0.78 & 0.79 & \\
\hline RQ2 & n2 & 0.61 & 0.62 & \\
\hline RQ3 & n3 & 0.66 & 0.61 & \\
\hline RQ4 & n4 & 1 & 0.92 & \\
\hline RQ5 & n5 & 1 & 1 & \\
\hline RQ1 & Q1 & $2.7 \mathrm{E}-04$ & $2.1 \mathrm{E}-04$ & \\
\hline RQ2 & Q2 & $3.8 \mathrm{E}-03$ & $3.5 \mathrm{E}-03$ & \\
\hline RQ3 & Q3 & $9.4 \mathrm{E}-03$ & $1.2 \mathrm{E}-02$ & \\
\hline RQ4 & Q4 & $2.6 \mathrm{E}-02$ & $2.3 \mathrm{E}-02$ & \\
\hline RQ5 & Q5 & 0.041 & 0.084 & \\
\hline RQ1 & $\mathrm{f1}$ & 9700 & 9200 & $\mathrm{~Hz}$ \\
\hline RQ2 & $\mathrm{f} 2$ & 573 & 584 & $\mathrm{~Hz}$ \\
\hline RQ3 & $\mathrm{f} 3$ & 15 & 20 & $\mathrm{~Hz}$ \\
\hline RQ4 & $\mathrm{f} 4$ & 4.5 & 5.1 & $\mathrm{~Hz}$ \\
\hline RQ5 & $\mathrm{f5}$ & 1.4 & 1.3 & $\mathrm{~Hz}$ \\
\hline
\end{tabular}

Fig 5.29 summarizes trends of polarization resistance and frequencies at first cycle at $800^{\circ} \mathrm{C}$ for Cell A and cell B. For cell A, low frequency elements R4 and R6 account for most of the change. The initial rise appears to be due to the lowest frequency element R6. For Cell B, most of the change in $\mathrm{Rp}$ is found in R3, R4, R5 and R6. R3 (about $400 \mathrm{~Hz}$ ) and R5 (5 Hz) show coordinated opposite movements. R3 and R6 account for the initial rise in Rp, and R4 and R5 account for most of the decay. The frequencies do not exhibit much change with aging at $800{ }^{\circ} \mathrm{C}$. 

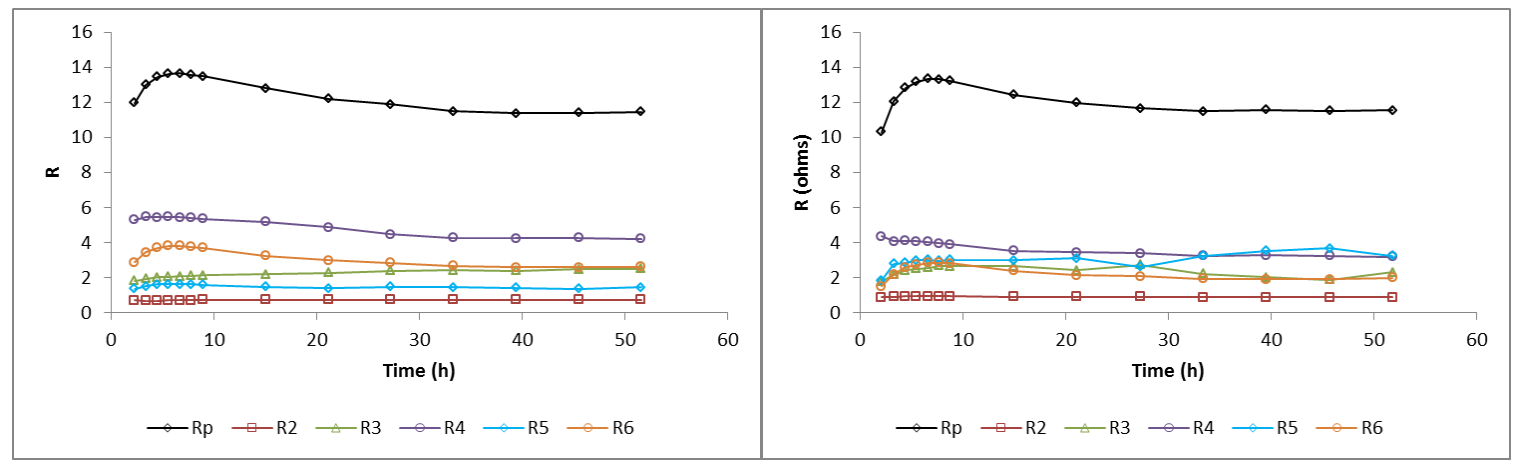

(a)

(b)
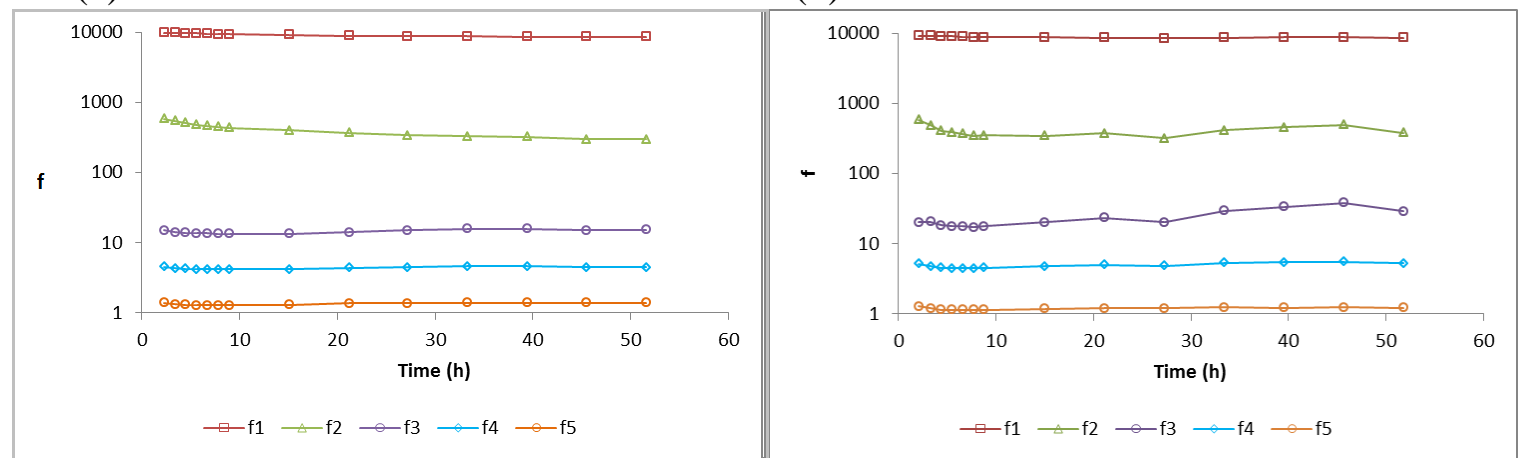

(c)

(d)

Fig. 5.29: The parameters for the equivalent circuit as a function of time for the first data set of cell A and B at $800{ }^{\circ} \mathrm{C}$. (a) Cell A polarization resistances (b) Cell B polarization resistances (c ) Cell A frequency for five elements (d) Cell B frequency for five elements

Fig 5.30 shows trends of polarization resistance and frequencies at second cycle at $800^{\circ} \mathrm{C}$ for Cell A and Cell B. For Cell A, R4 and R6 again account for most of the change in Rp. R5 changes very little. For Cell B, there is a problem with large oscillations in the parameters for RQ2, RQ3 and RQ4, which indicates a large uncertainty in the fitted values obtained from ZView.

\section{Cell A at $7^{\circ} \mathrm{C}$}

Fig 5.31 compares the data at the beginning and end of the 2-day aging for Cell $\mathrm{A}$ at $700^{\circ} \mathrm{C}$ (first cycle). Similar to Cell $\mathrm{A}$ at $800^{\circ} \mathrm{C}$, changes are mainly at frequencies below $1 \mathrm{~Hz}$. The deconvolution spectra show an increase in the lowest frequency peak. Similarly to data at $800^{\circ} \mathrm{C}$, the $700^{\circ} \mathrm{C}$ data could be fit with a LR(RQ)4 model, with $\mathrm{L}$ fixed at $1 \times 10^{-7} \mathrm{H}$. This model gives a good fit for deconvolution spectra with a slight discrepancy around 1-3 Hz (Fig 5.32(b)). Adding a $5^{\text {th }} \mathrm{RQ}$ element does not remove this slight discrepancy. We use this LR(RQ)4 model for $700^{\circ} \mathrm{C}$ data . 

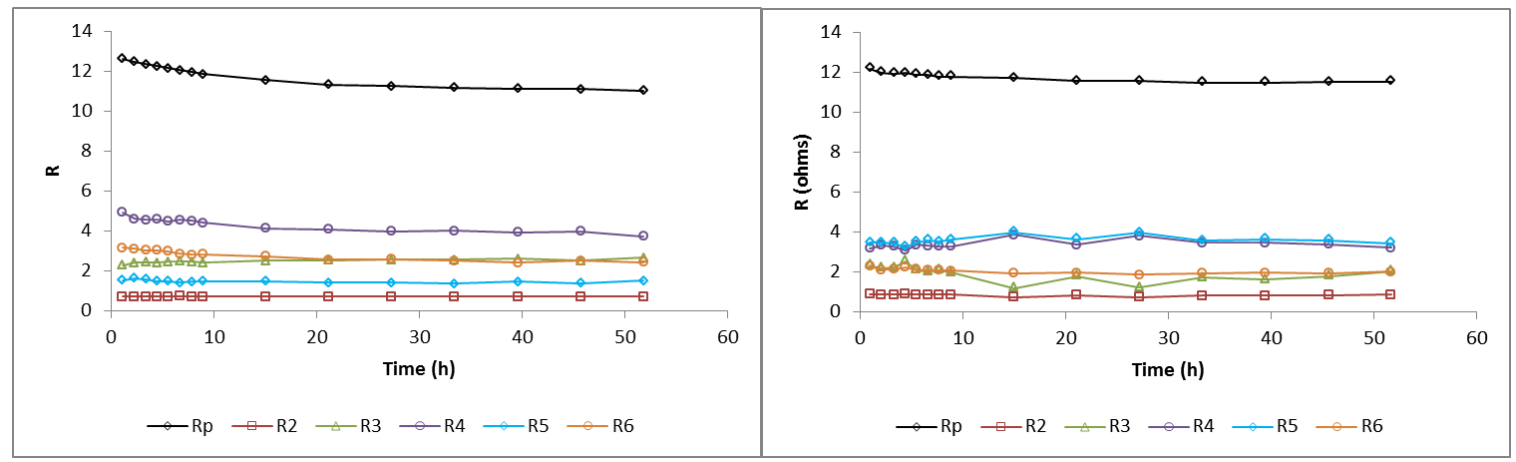

(a)

(b)

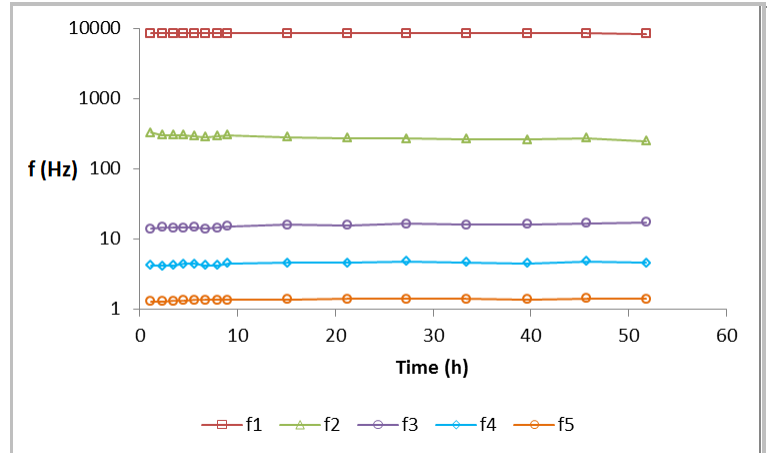

(c)

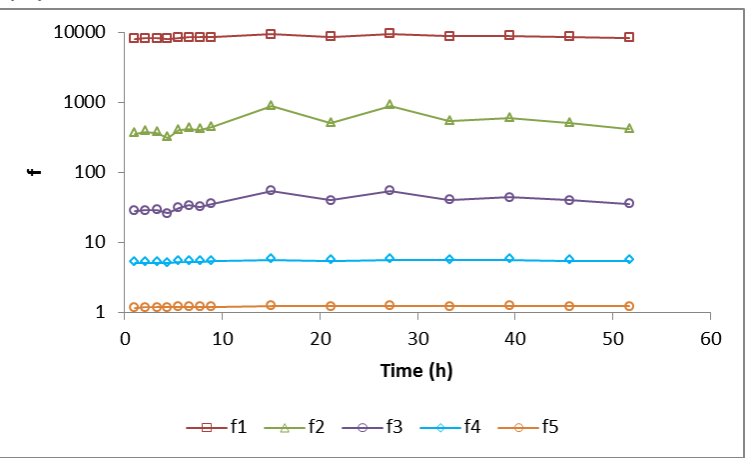

(d)

Fig. 5.30: The parameters for the equivalent circuit as a function of time for the second data set of cell A and B at $800{ }^{\circ} \mathrm{C}$. (a) Cell A polarization resistances (b) Cell B polarization resistances (c) Cell A frequency for five elements; (d) Cell B frequency for five elements. 

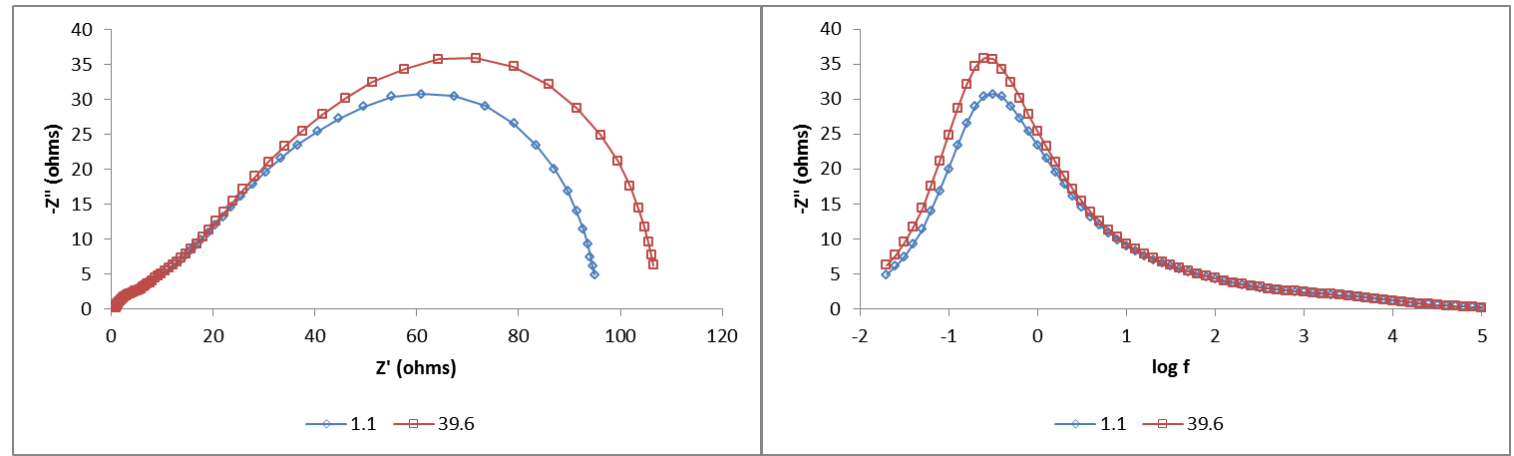

(a)

(b)

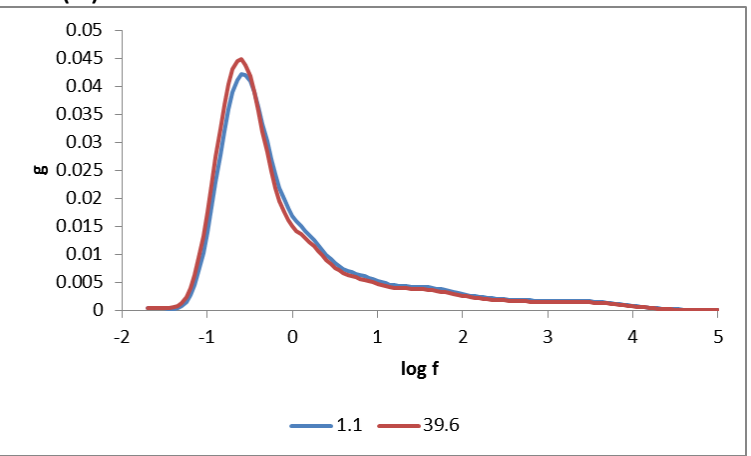

(c)

Fig 5.31: Comparison of data at the beginning and end of aging for Cell A at $700^{\circ} \mathrm{C}$ (first cycle).(a) Nyquist plot; (b) Bold plot -Z" vs log f; (c) Deconvolution spectra.

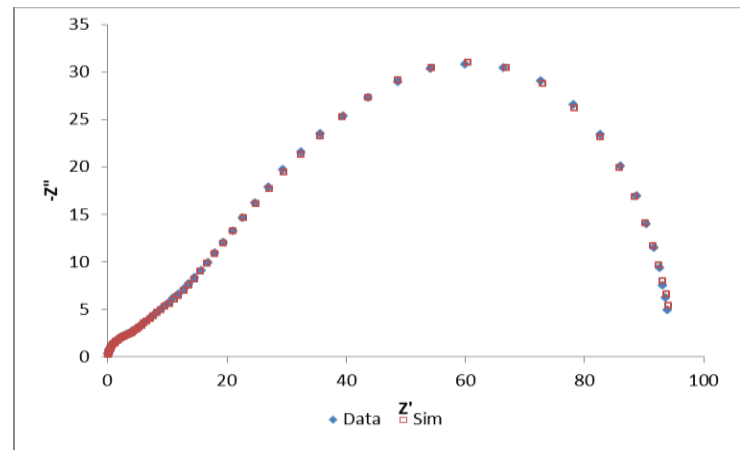

(a)

Fig. 5.32: Equivalent circuit fit for the 2.0 hour data collected at $700^{\circ} \mathrm{C}\left(1^{\text {st }}\right.$ time $)$ for cell $\mathrm{A}(\mathrm{A})$ Nyquist plot overlaying the data and the simulated impedances from the equivalent circuit;.(B) Overlay plot of the deconvolution spectra for the data and for the simulated impedances of the equivalent circuit. 


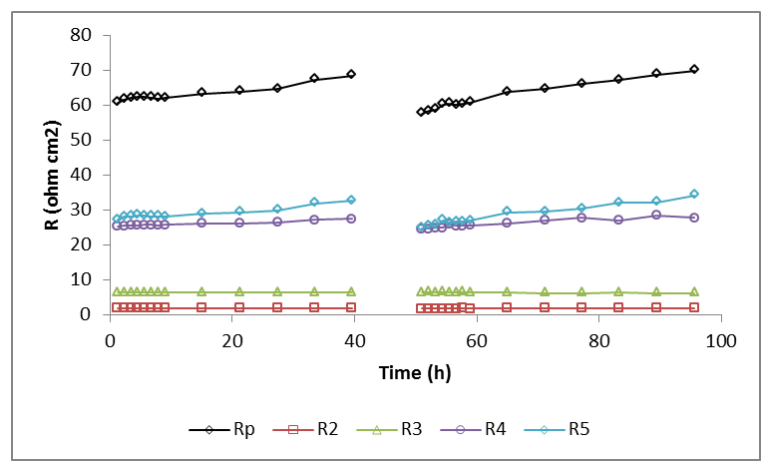

Fig 5.33: The corresponding polarization resistance of cell A vs. time at $700^{\circ} \mathrm{C}$.

Fit with a LR(RQ)4 model, Fig 5.33 shows for both cycles for cell $A$ at $700^{\circ} \mathrm{C}, \mathrm{R}_{\mathrm{p}}$ increases and slightly drop after $800^{\circ} \mathrm{C}$ aging. All changes are associated with the low frequency elements $\mathrm{R} 4$ and R5. Cell B (data not shown) exhibits similar patterns in the element values.

\section{Summary of the preceding observation for LSM/GDC/LSM symmetrical cells:}

The LSM/GDC symmetrical cells showed a similar pattern of aging compared to the LSM/YSZ symmetrical cells. The polarization resistance decreases at $800^{\circ} \mathrm{C}$ and increases at $700^{\circ} \mathrm{C}$. Most of the changes in Rp values are associated with low frequency elements.

\subsubsection{Deconvolution analysis of LSCF/GDC/LSCF symmetrical cells}

As discussed in 4.4.2, Adler/Lane/Steele model predicts an ideal Gerischer impedance (exponent $\mathrm{n}=0.5)$ for a mixed ionic/electronic conductor. The electrode material LSCF is the mixed ionic and electronic conductor, so the equivalent circuits include the Gerischer impedance. The deconvolution spectra for $800^{\circ} \mathrm{C}$ for cell A show three major peaks (Fig. 5.34), so a three elements circuit $\mathrm{LR}(\mathrm{Ge})(\mathrm{RQ})_{2}$ is used for fitting the $800^{\circ} \mathrm{C}$ data. The deconvolution spectra for $700^{\circ} \mathrm{C}$ show only one major peak (Fig 5.34), so a simple one element circuit LR(Ge) without the extra RQ element is good for fitting the $700^{\circ} \mathrm{C}$ data. The two models also exhibit high quality in fits of the $800^{\circ} \mathrm{C}$ and $700^{\circ} \mathrm{C}$ data for cell B. 

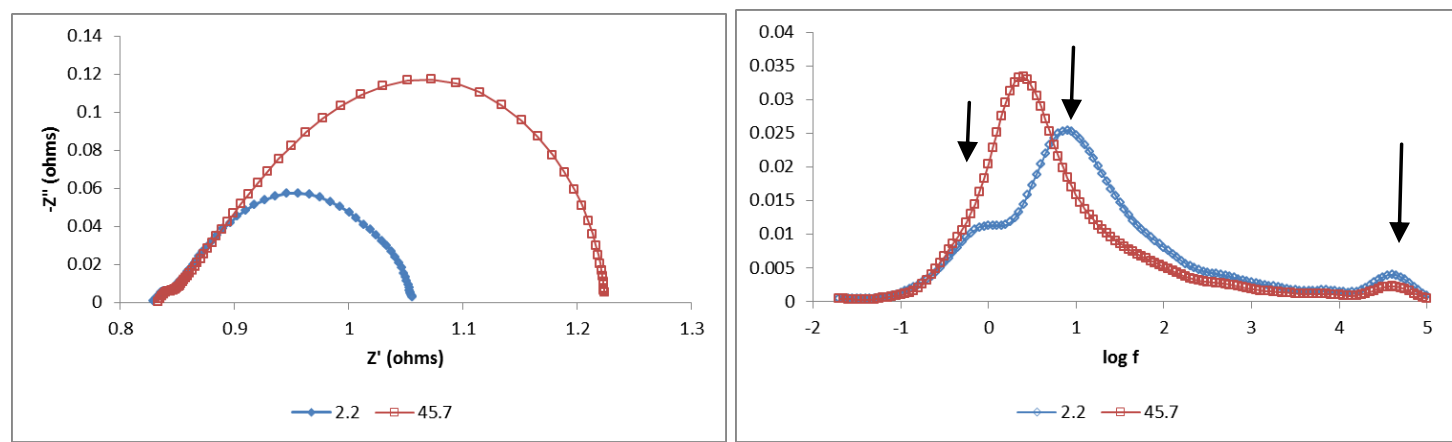

(a)

(b)
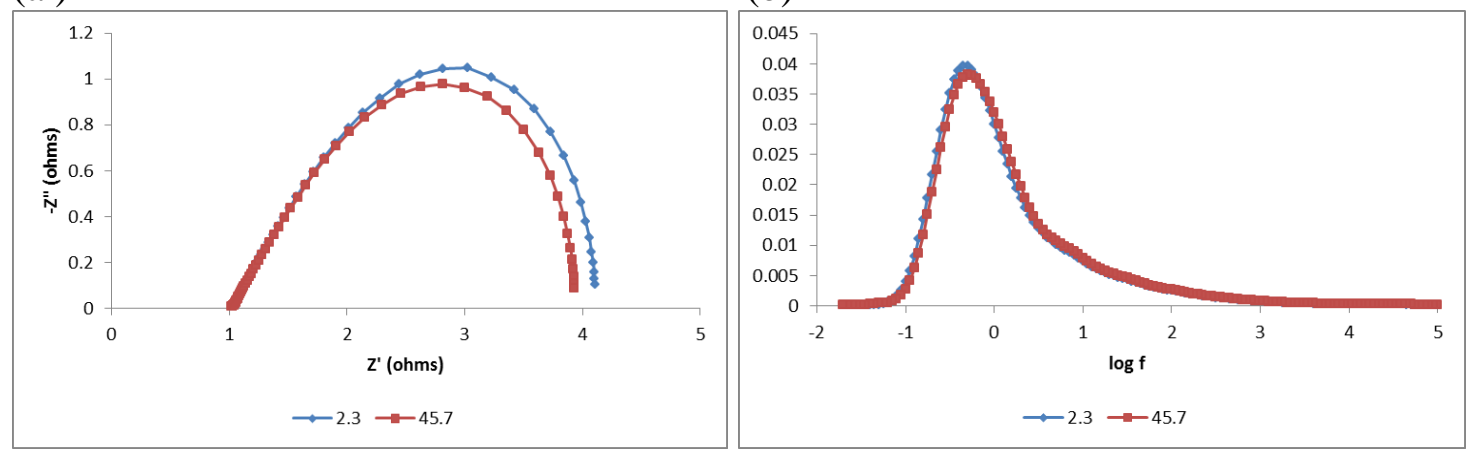

(c)

(d)

Fig. 5.34: Impedance spectra and deconvolution spectra for cell A (LSCF/GDC). (a) Nyquist plots for Sample A first 46 hours at $800^{\circ} \mathrm{C}$; (b) Deconvolution spectra for sample A first 46 hours at $800^{\circ} \mathrm{C}$; (c) Nyquist plots for sample A first 46 hours at $700^{\circ} \mathrm{C}$; (d) Deconvolution spectra sample A first 46 hours at $700^{\circ} \mathrm{C}$.

Table 5.5 shows fitted parameters with the $\mathrm{LR}(\mathrm{Ge})(\mathrm{RQ})_{2}$ equivalent circuit to impedance data for the Cell $\mathrm{A}$ at 2.2 hour and at 45.7 hour at $800^{\circ} \mathrm{C}\left(1^{\text {st }}\right.$ Cycle) and Table 5.6 shows $\mathrm{LR}(\mathrm{Ge})$ equivalent circuit for the Cell $\mathrm{A}$ at 2.3 hour at $700^{\circ} \mathrm{C}\left(1^{\text {st }} \mathrm{Cycle}\right)$. For $800{ }^{\circ} \mathrm{C}$, the inductance values are fixed to allow better fit of the high frequency peak (RQ2). 
Table 5.5: Fitted parameters for the $\mathrm{LR}(\mathrm{Ge})(\mathrm{RQ})_{2}$ equivalent circuit to impedance data for the Cell $\mathrm{A}$ at 2.2 hour and at 45.7 hour at $800^{\circ} \mathrm{C}\left(1^{\mathrm{st}} \mathrm{Cycle}\right)$

\begin{tabular}{|l|l|r|r|l|}
\hline Elements & Parameters & $2.2 \mathrm{~h}$ at $800{ }^{\circ} \mathrm{C}$ & $45.7 \mathrm{~h}$ at $800^{\circ} \mathrm{C}$ & Units \\
\hline series R & R1 & 0.83 & 0.83 & ohms \\
\hline inductance & $\mathrm{L}$ & $6.0 \mathrm{E}-09$ & $6.0 \mathrm{E}-09$ & $\mathrm{H}$ \\
\hline $\mathrm{Ge}$ & $\mathrm{T}$ & $2.6 \mathrm{E}-02$ & $7.8 \mathrm{E}-02$ & \\
\hline $\mathrm{Ge}$ & $\mathrm{P}$ & 0.40 & 0.42 & \\
\hline $\mathrm{Ge}$ & $\mathrm{Rp}$ & 0.14 & 0.28 & ohms \\
\hline $\mathrm{Ge}$ & $\mathrm{U}$ & 1 & 1 & \\
\hline $\mathrm{Ge}$ & $\mathrm{f} 1$ & 13 & 4.1 & $\mathrm{~Hz}$ \\
\hline RQ2 & $\mathrm{R} 2$ & 0.0096 & 0.0092 & ohms \\
\hline RQ2 & $\mathrm{n} 2$ & 1 & 1 & \\
\hline RQ2 & $\mathrm{Q} 2$ & $4.2 \mathrm{E}-04$ & $4.7 \mathrm{E}-04$ & \\
\hline RQ2 & $\mathrm{f} 2$ & 40000 & 37000 & $\mathrm{~Hz}$ \\
\hline RQ3 & $\mathrm{R} 3$ & 0.080 & 0.11 & ohms \\
\hline RQ3 & $\mathrm{n} 3$ & 0.76 & 0.88 & \\
\hline RQ3 & $\mathrm{Q} 3$ & 2.3 & 1.9 & \\
\hline RQ3 & $\mathrm{f} 3$ & 0.93 & $\mathrm{~Hz}$ \\
\hline
\end{tabular}

Table 5.6: $\mathrm{LR}(\mathrm{Ge})$ equivalent circuit for the Cell $\mathrm{A}$ at 2.3 hour at $700^{\circ} \mathrm{C}\left(1^{\mathrm{st}} \mathrm{Cycle}\right)$

\begin{tabular}{|l|l|r|l|}
\hline Elements & Parameters & $2.3 \mathrm{~h}$ at $700^{\circ} \mathrm{C}$ & Units \\
\hline series R & $\mathrm{R} 1$ & 1.0 & ohms \\
\hline inductance & $\mathrm{L}$ & $1.0 \mathrm{E}-10$ & $\mathrm{H}$ \\
\hline $\mathrm{Ge}$ & $\mathrm{T}$ & 0.52 & \\
\hline $\mathrm{Ge}$ & $\mathrm{P}$ & 0.47 & \\
\hline $\mathrm{Ge}$ & $\mathrm{Rp}$ & 2.0 & ohms \\
\hline $\mathrm{Ge}$ & $\mathrm{U}$ & 1 & \\
\hline $\mathrm{Ge}$ & $\mathrm{f} 1$ & 0.56 & $\mathrm{~Hz}$ \\
\hline
\end{tabular}

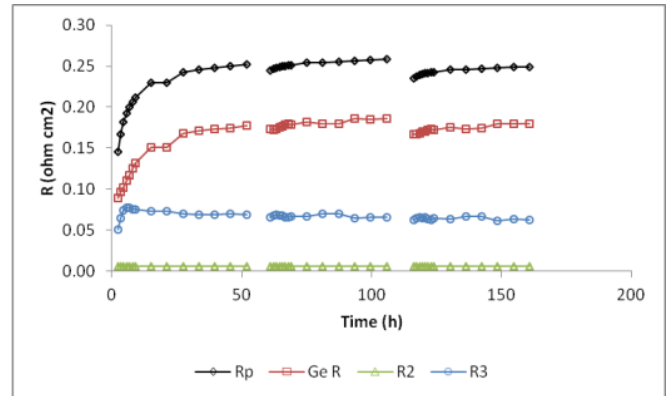

(a)

Fig 5.35: The corresponding polarization resistance of cell A vs. time (a) At $800^{\circ} \mathrm{C}$;

(b) At $700^{\circ} \mathrm{C}$.

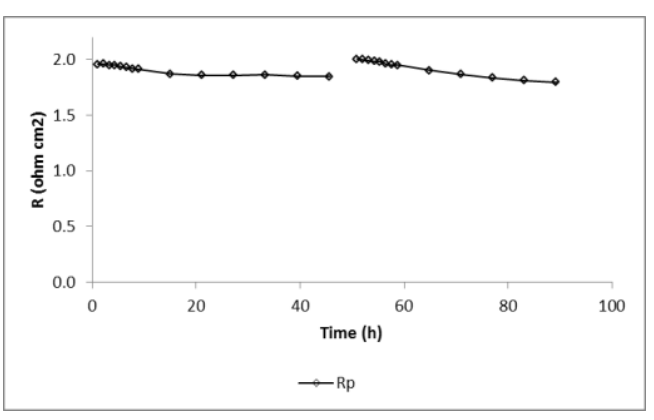

(b) 
Fig 5.35 shows the polarization resistance of cell A aging at $800^{\circ} \mathrm{C}$ and $700^{\circ} \mathrm{C}$. The Rp total resistances show an increase at $800^{\circ} \mathrm{C}$ and decrease at $700^{\circ} \mathrm{C}$. This aging pattern is totally different from the aging pattern of LSM electrodes, and agrees with our observation in 5.4.1. Both low frequency elements Ge and RQ2 contribute most of the total polarization change at $800^{\circ} \mathrm{C}$. The RQ2 element is associated with the initial increase and the remaining aging change is only associated with the Ge element. This observation is evidence for possible two processes associated with the aging. Cell B (data not shown) exhibits similar patterns in the element values.

\section{Summary of the preceding observation for LSCF/GDC/LSCF symmetrical cells:}

The Gerischer impedance and the low frequency RQ2 element are associated with most of the change in the polarization resistance at $800 \mathrm{deg}$ C. These two elements show different aging patterns, with the Gerischer resistance increasing steadily and the RQ resistance decreasing steadily. A single Gerischer element fits the impedance data at $700^{\circ} \mathrm{C}$. LSCF electrodes shows an increase in $\mathrm{Rp}$ values at $800^{\circ} \mathrm{C}$ and a decrease in $\mathrm{Rp}$ values at $700^{\circ} \mathrm{C}$. This pattern is the opposite of the polarization resistance changes for the LSM electrodes.

\subsubsection{Discussion for the trends and hypotheses for the deconvolution results}

The aging patterns for LSM/YSZ/LSM, (LSM/YSZ)/YSZ/(LSM/YSZ) and LSM/GDC/LSM symmetrical cells are similar. The polarization resistances show initial rise and then repeatable drop during cycling at $800^{\circ} \mathrm{C}$. The polarization resistances also slightly rise each time after aging at $700^{\circ} \mathrm{C}$. The polarization resistance repeatly rise during cycling at $700^{\circ} \mathrm{C}$. After each time aging at $800^{\circ} \mathrm{C}$, the initial polarization resistances show a slight drop. The LSCF/GDC/LSCF symmetrical cells exhibit opposite trends. Polarization resistances of LSCF/GDC electrodes show an initial sharp rise and then a repeatable slow rise during cycling at $800^{\circ} \mathrm{C}$, with a slight drop in initial $R_{p}$ after each time aging at $700^{\circ} \mathrm{C}$. Rp for LSCF/GDC electrodes repeatly decrease slowly during cycling at $700^{\circ} \mathrm{C}$, with a slight rise in initial $\mathrm{R}_{\mathrm{p}}$ after each time aging at $800^{\circ} \mathrm{C}$.

For the LSM/YSZ/LSM, (LSM/YSZ)/YSZ/(LSM/YSZ) and LSM/GDC/LSM symmetrical cells, deconvolution spectra suggest that multiple processes occurr in LSM electrodes over the tested range of frequencies (4-5 orders of magnitude). So, multiple equivalent circuit elements including RQ elements are needed to match the impedance and deconvolution spectra. 
LSCF/GDC/LSCF symmetrical cells only need simple equivalent circuit elements including one Gerischer impedance element to match the impedance and deconvolution spectra. A Gerischertype element works well for impedance of the (LSM/YSZ) composite electrode and LSCF electrodes, but does not work for the LSM/YSZ/LSM and LSM/GDC/LSM symmetrical cells. Comparing YSZ with GDC electrolytes, the major frequencies contributing to the LSM impedance are at higher frequencies for YSZ $(40-60 \mathrm{~Hz})$ and are at lower frequencies for GDC electrolyte $(4-6 \mathrm{~Hz})$. For all types of symmetrical cells, the deconvolution spectra show that frequencies associated with aging occurs at low frequencies, with peak changes around 1-10 Hz, and almost no change above $100 \mathrm{~Hz}$. The changes in equivalent circuit element parameters such as the polarization resistance and peak frequency reflect the aging trend. Deconvolution and equivalent circuit analyses of symmetrical cells also demonstrate the complexity of the impedance, and provide accurate values for series resistance and inductance. However, the equivalent circuit parameters alone do not provide insights into the real processes in the electrodes. A model is needed to confirm the mechanism of oxygen reduction with the aging phenomenon.

The observed aging of these LSM and LSCF electrodes affects the lower frequencies in the impedance data while higher frequency data is essentially constant with time. These observations suggest that there are two mechanisms for oxygen reduction. The proposed hypotheses suggest that the lower frequencies are associated with oxygen reduction at or very near the triple Phase boundary(3PB) and higher frequencies are associated with oxygen reduction at the double phase boundary (2PB) of LSM (LSCF) and YSZ. There are two pathways for oxygen reduction in electrode[33,34]:

(1) Absorbed oxygen moves via surface diffusion on the LSM electrode, and then it is reduced at the Triple Phase Boundary (3PB, the junction of LSM, YSZ and gas phases) (Surface pathway).

(2) Oxygen is adsorbed and reduced on the LSM surface. Oxide ions diffuse through LSM bulk and they are transferred at the double phase boundary (2PB) at the LSM and YSZ interface.( Bulk pathway).

The surface pathway via the TPB is generally believed to dominate in a real LSM electrode at open circuit condition $[35,36]$. The bulk pathway via the $2 \mathrm{~PB}$ has been demonstrated for very 
thin LSM dots. [37] Our hypothesis proposes that both 3PB and 2PB mechanisms contribute to the impedance in pure LSM cathodes. The 3PB mechanism exhibits aging and dominates the lower frequencies. The $2 \mathrm{~PB}$ mechanism is not associated with aging and contributes to the higher frequencies. This hypothesis is in agreement with the mechanism that we proposed previously. The aging effect is associated with the migration of segregated cations on the surface. The altered surface composition would affect the 3PB pathway (change in charge transfer kinetics) but not the $2 \mathrm{~PB}$ pathway since the $2 \mathrm{~PB}$ mechanism is controlled by mass transfer of oxygen species through the bulk. Fleig proposed using an equivalent circuit of Warburg impedance in parallel with the double layer capacitance for 2PB mechanism [37], and changes in surface composition would not affect the impedance.

At this stage, the mechanisms associated with aging effect are not well understood. The future works includes testing the $2 \mathrm{~PB} / 3 \mathrm{~PB}$ hypothesis. For confirming the hypothesis for aging effect, it required to confirm that the aging behavior directly correlates with changes of surface composition of LSM. The proposed surface analysis technical is transmission electron microscope (TEM). TEM analysis is able to identify surface structure and surface composition. If the TEM can detect surface composition and bulk composition ratio changes with respect to thermal aging, the hypothesis can be confirmed. The aged samples have been sent to Dr. Song's lab (WVU MAE) for TEM analysis. A proper model for the simulation of aging effects may also help to address the hypothesis. 


\subsection{References}

[1] Ormerod, R.M. Chem. Soc. Rev. 2003, 32, 17-28.

[2] Adler, S.B. Chem. Rev. 2004, 104, 55-69.

[3] Backhaus-Ricoult, M.; Adib, K.; Clair, T.S.; Luerssen, B.; Gregoratti, L.; Barinov, A. Solid State Ionics 2008, 179, 891-895.

[4] Wang, S.Z.; Jiang, Y.; Zhang, Y.H.; Yan, J.W.; Li, W.Z. J. Electrochem. Soc. 1998, 145, 1932-1939.

[5] Jiang, S.P.; Love, J.G. Solid State Ionics 2001, 138, 183-190.

[6] Jiang, S.P. J. Power Sources 2003, 124, 390-402.

[7] Leng, Y.J.; Chan, S.H.; Khor, K.A.; Jiang, S.P. J. Appl. Electrochem. 2004, 34, 409-415.

[8] Jiang, S.P.; Wang, W. Electrochem. Solid-State Lett. 2005, 8, A115-A118.

[9] Wang, W.; Jiang, S.P. Solid State Ionics 2006, 177, 1361-1369.

[10] Jiang, S.P. J. Solid State Electrochem. 2007, 11, 93-102.

[11] Nielsen, J.; Jacobsen, T. Solid State Ionics 2008, 179, 1314-1319.

[12] Woo, L.Y.; Glass, R.S.; Gorte, R.J.; Orme, C.A.; Nelson, A.J. J. Electrochem. Soc. 2009, 156, B602-B608.

[13] McIntosh, S.; Adler, S.B.; Vohs, J.M.; Gorte, R.J. Electrochem. Solid-State Lett. 2004, 7, A111-A114.

[14] McEvoy, A. J. Solid State Ionics 2000, 135, 331-336.

[15] Jiang, S.P. J. Mater. Sci. 2008, 43, 6799-6833.

[16] Lee, Y.K.; Kim, J.Y.; Kim, I.; Moon, H.S.; Park, J.W.; Jacobson, C.P.; Visco, S.J. J. Mater. Sci. 2003; 115, 219-228.

[17] Hammouche, A.; Siebert, E.; Hammou, A.; Kleitz, M.; Caneiro, A. J. Electrochem. Soc. 1991, 138, 1212-1214.

[18] Jiang, Y.; Wang, S.; Zhang, Y.; Yan, J.; Li, W. J. Electrochem. Soc. 1991, 145, 373-375.

[19] Lee, H.Y.; Cho, W.S.; Oh, S.M.; Wiemhöfer, H.D.; Göpel, W. J. Electrochem. Soc. 1995, $142,2659-2661$. 
[20] Odgaard, M.; Skou, E. Solid State Ionics 1995, 86, 1217-1219.

[21] Siebert, E.; Hammouche, A.; Kleitz, M. Electrochim. Acta 1995, 40, 1741-1744.

[22]. Jiang, S.P.; Love, J.G. Solid State Ionics 2001, 138, 183-186.

[23] Katsiev, K.; Yildiz, B.; Balasubramaniam, K.; Salvador, P.A. Appl. Phys. Lett. 2009, 95, 104-107.

[24] Fister, T.T.; Fong, D.D.; Eastman, J.A.; Baldo, P.M.; Highland, M.J.; Fuoss, P.H.; Balasubramaniam, K.R.; Meador, J.C.; Salvador, P.A. Appl. Phys. Lett. 2008, 93, 122-125.

[25] Chang, K.C.; Ingram, B.; Balasubramaniam, K.; Yildiz, B.; Hennessy, D.; Salvador, P.; Leyarovska, N.; You, H. Mater. Res. Soc. Sym. Proc. 2009, pp. 1126.

[26] Caillol, N.; Pijolat, M.; Siebert, E. Appl. Surf. Sci. 2007, 253, 4641-4648.

[27] Wu, Q.H.; Liu, M.L.; Jaegermann, W. Mater. Lett. 2005, 59, 1980-1983.

[28] Piper, L.F.J.; Preston, A.R.H.; Cho, S.W.; DeMasi, A.; Chen, B.; Laverock, J.; Smith, K.E.; Miara, L.J.; Davis, J.N.; Basu, S.N.; Pal, U.; Gopalan, S.; Saraf, L.; Kaspar, T.; Matsuura, A.Y.; Glans, P.A.; Guo, J.H. J. Electrochem. Soc. 2011, 158, B99-B105.

[29] Kubicek, M.; Limbeck, A.; Fromling, T.; Hutter, H.; Fleig, J. J. Electrochem. Soc. 2011, 158, B727-B734.

[30] La O, G.J.; Savinell, R.F.; Shao-Horn, Y. J. Electrochem. Soc. 2009, 156, B771-B781.

[31] Huang, Y.; Vohs, J.M.; Gorte, R.J. J. Electrochem. Soc. 2005, 152, A1347-A1353.

[32] Huang, Y.; Vohs, J.M.; Gorte, R. J. Electrochem. Solid-State Lett. 2006, 9, A237-A240.

[33] Yamajia, T.H.; Sakaia, N.; Yokokawaa, H.; Kawada, T.; Kato, T. Solid State Ionics 2000, $127,55-65$.

[34] Horita, T.; Yamaji, K.; Sakai, N.; Yokokawa, H.; Kato, T. J. Electrochem. Soc. 2001, 148, J25-J30.

[35] Pakalapati, S.R.; Celik, I.; Finklea, H.O.; Gong, M.; Liu, X. ECS Tran 2011, 35, 963-976.

[36] Li, Y.; Gemmen, R.; Liu. X. J. Power Sources 2010, 195, 3345-3358.

[37] Brichzin, V.; Fleig, J.; Habermeier, H.U.; Cristiani, G. J. Electrochem. Solid-State Lett. 2002, 152, 499-507. 


\section{Chapter 6: Conclusions}

The body of the dissertation is composed of three chapters, including the experimental approaches to investigate the ring reference electrode and micro-reference electrode to separate the anode performance from cathode for different geometries SOFC cells (Chapter 3), the deconvolution combined with non-linear regression fitting of equivalent circuit approach for the two-electrode impedance data to identify the contributions associated with anode and cathode on SOFC performance (Chapter 4), and aging effect of LSM electrode and deconvolution analysis for addressing the aging effect (Chapter 5). The first two chapters aim to separate the anode and cathode performances and assign the processes appearing in deconvolution plots to one electrode or both electrodes. The last chapter aims to not only investigate the trends of total polarization resistances and parameters for equivalent circuit with aging but also the mechanisms associated with aging behaviors. In this chapter, the results, significances and contributions for all these researches are briefly summarized. Recommendations for future work are given based on the findings.

\subsection{Significances and Contributions}

Electrode polarization losses are a significant obstacle to commercialization of solid oxide fuel cells, particularly for SOFCs operating at intermediate temperatures $\left(600-800^{\circ} \mathrm{C}\right)$. The long term degradation of cell performance is also a big issue for commercializing SOFCs. There are many studies aiming to clarify electrode polarization mechanisms and degradation mechanisms. However, the impedance data for a single electrode reported by different groups on similar systems often have considerable discrepancies, which makes people doubt that such impedance data does not really reflect the mechanisms in one electrode but depend on experimental artifacts by using the reference electrode. A number of studies using simulations had shown the problems of accurately obtain a single electrode impedance from three-electrode measurements. However, not many papers have validated the single electrode impedance data obtained using the reference electrode by experimental approaches. We used an experimental approach to test the cells with reference electrode at three flow conditions (normal, low air and low fuel conditions) and our experimental results confirmed the simulation results. The placement of the reference electrode is the reason for inaccurately obtaining one electrode performance for cells with conventional 
geometries (thin electrolyte layer). Our experimental results showed that a ring reference electrode directly put far from the cathode cannot accurately separate single electrode performance and a micro-reference electrode delicately placed within one electrolyte distance away from the cathode also cannot accurately obtain single electrode performance. So a reference electrode cannot provide information about a single electrode for a conventional designed fuel cell.

To identify the contribution associated with the cathode and anode, we need an independent method without using the reference electrode. We used deconvolution analysis with non-linear regression fitting of equivalent circuit approach for our two-electrode impedance data, which were obtained from the cells with a reference electrode. This method protocol we used was developed by Ivers-Tiffee and co-workers. They used the Fourier transformation technique for the experimental impedance spectra to obtain the distribution function of time constants in the time domain. This mathematical technique increases the resolution of frequency in impedance spectra, and so assists in identifying electrochemical processes in impedance spectra. These electrochemical processes are not visible or they overlap in the impedance spectra, but show up as obvious peaks in deconvolution plots. With the same deconvolution protocol, we investigated solid oxide fuel cells based on differences in impedance spectra with respect to a change of operating parameters (gas flow conditions and temperatures) and the result are presented as a distribution of relaxation times with respect to $\log (f)$. We are able to use this method to separate the anode and cathode contributions and to identify various types of processes. Compared to Ivers-Tiffee et al. deconvolution analysis for SOFCs in wide range of gas compositions, the primary benefit for our deconvolution analysis is that the cells providing impedance data for deconvolution are the same cells tested with reference electrodes. Therefore, we are able to compare the assignment of polarization resistances from the two methods, the assignment from deconvolution analysis and the apparent assignments provided by using the reference electrode. Ivers-Tiffee et al. used cells with a pure LSCF cathode or LSM cathodes, while we analyzed cells with LSM/YSZ composite cathodes, which is a more common cathode composition. And, we used different equivalent circuits from theirs for our cells, so our research broadens the picture of cell behavior for different compositions, which could also provide a benefit for other researchers. We presented all the deconvolution analyses with a widely used Excel® spreadsheet 
without using any special mathematical software, which also improved the practicality of the deconvolution method.

We systematically investigated the aging effect for cathodes by using the symmetrical cells with cathode material electrodes, tested them at open air conditions. The observed aging behavior is reversible at $700{ }^{\circ} \mathrm{C}$ and $800{ }^{\circ} \mathrm{C}$. The deconvolution analyses were applied for the obtained impedance data, which provide information like changes of equivalent circuit parameters (polarization resistances, peak frequencies) with respect to aging. We generated two hypotheses to explain the aging effect. They are: (1) the low frequency range impedance associated with 3PB oxygen reduction mechanism is responding to aging; and (2) the high frequency range impedance associated with $2 \mathrm{~PB}$ oxygen reduction mechanism is almostly constant with aging. We aimed to correlate the observed performance changes to real physical changes in the cathode microstructure or composition. At present, the most likely physical changes in the cathode are migration of segregated cations on the surface. This aging effect investigation has never been reported by others. Since there are already research about cathode degradation, our research may provide a unique aspect for investigating cathode degradation for cells without passing current. This research is also useful in connecting discrete observations made by multiple approaches like modeling, material microstructure and composition analysis to generate a unified picture of cathode degradation that is relevant to commercial SOFC systems.

\subsection{Future work and recommendations}

When applying the deconvolution method to commercially relevant cells, peaks in the middle frequencies from the cathode and anode are not clearly separated. Using wider range of gas flow conditions is possible to get these processes separated. As discussed in chapter 4, by varying the $\mathrm{H}_{2} / \mathrm{H}_{2} \mathrm{O}$ ratio or replacing $\mathrm{H}_{2} / \mathrm{H}_{2} \mathrm{O}$ with $\mathrm{CO} / \mathrm{CO}_{2}$ or $\mathrm{D}_{2} / \mathrm{D}_{2} \mathrm{O}$, the cell kinetics will change and peak frequency for the anode element will move to lower frequency and become separated from the cathode element peak frequencies in higher frequency ranges. So, the overlapped processes associated with anode and cathode can be easily identified.

In order to understand clearly the mechanisms associated with the aging effect, future work should seek the evidence of the aging behavior directly correlated with changes of surface composition of LSM. Although there are lots of surface analysis techniques, the proper surface 
analysis techniques for our samples are total reflection $\mathrm{x}$-ray fluorescence (TXRF) and transmission electron microscopy (TEM). Both analysis techniques are able to identify surface structure and surface composition. However, both techniques require sample preparation and can only be applied at room temperature. Since many changes may happen during sample preparation and sample cooling down, it is a challenge to detect surface composition and bulk composition ratio changes with respect to thermal aging. A proper model for simulation aging effect may also help to address the aging behavior. 